Marcelo Gómez Álvarez

Nuevas ideas sobre la función del complejo olivar superior basadas en sus conexiones

TESiS DOCTORAL

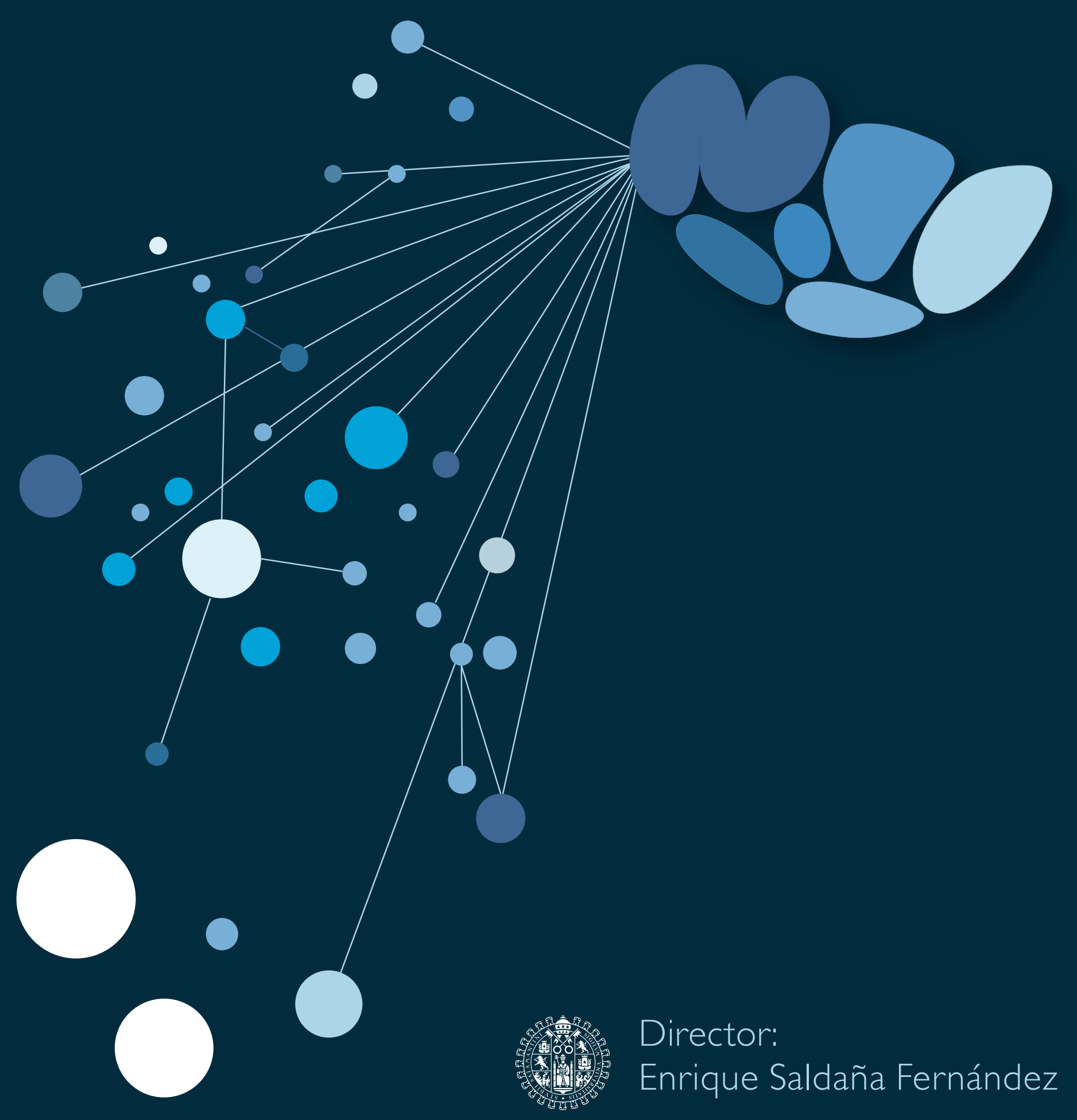




\section{NUEVAS IDEAS SOBRE LA FUNCIÓN DEL COMPLEJO OLIVAR SUPERIOR BASADAS EN SUS CONEXIONES}

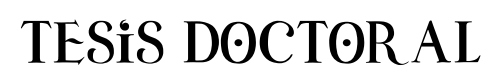

Salamanca, 2014

\section{Marcelo Gómez Álvarez}

Director:

Enrique Saldaña Fernández

Instituto de Neurociencias de Castilla y León

Universidad de Salamanca

España 
(2014) Los autores permiten copiar, reproducir, distribuir y comunicar públicamente esta tesis, siempre y cuando se cite y se reconozca a los autores e instituciones originales. No se permite generar obra derivada ni utilizar el manuscrito con finalidades comerciales. 
D. Enrique Saldaña Fernández, Profesor Titular del Departamento de Biología Celular y Patología de la Universidad de Salamanca e investigador del Instituto de Neurociencias de Castilla y León (INCyL),

\section{CERTIFICA}

Que la Tesis Doctoral titulada "Nuevas ideas sobre la función del complejo olivar superior basadas en sus conexiones" ha sido realizada por el Ldo. D. Marcelo Gómez Álvarez bajo mi dirección. Este Trabajo es fruto de años de esfuerzos y la consecuencia lógica de la ilusión, la dedicación, la constancia y el buen hacer del Ldo. Gómez Álvarez. Se trata de una obra sumamente original que reúne con creces las dosis de calidad y rigor científicos necesarias para que se proceda a su mantenimiento y defensa con el fin de optar al Grado de Doctor.

Lo que firmo en Salamanca a 2 de septiembre de dos mil catorce.

Fdo.: Enrique Saldaña Fernández 
Este trabajo ha sido posible gracias a una subvención del Ministerio de Ciencia y Tecnología (proyecto BFU2004-05909), una del Ministerio de Ciencia e Innovación (proyecto BFU2008-04197/BFI), una del Instituto de Salud Carlos III (PI10/01803), una de la Consejería de Educación y Cultura de la Junta de Castilla y León (proyecto SA007C05), y una de la Consejería de Sanidad de la Junta de Castilla y León, así como a una beca del Programa de Formación de Profesorado Universitario del Ministerio de Educación, Cultura y Deporte (AP2008-03406). 


\section{AGRADECIMIENTOS}

Son muchas las personas que con su ayuda hicieron posible este trabajo. A todas ellas quisiera expresar mi más humilde y sincera gratitud.

En primer lugar, quisiera agradecer a mi director de tesis Enrique Saldaña Fernández la orientación, el seguimiento y la continua supervisión, pero sobre todo la motivación y la ilusión que me ha transmitido a lo largo de este proceso. Gracias por brindarme todos estos valiosos detalles que me han llevado a culminar este gran trabajo.

Mi gratitud a mis compañeros de laboratorio: Ma Auxiliadora Aparicio (“Jefecita”), Emmanuel Márquez, Joseba Miranda, María González, Eva Perretta y Estefanía Tristán por brindarme su amistad y su ayuda incondicional durante la realización de esta investigación. Este es el esfuerzo de un gran equipo de trabajo.

Una mención especial a Margarita Heredia, Adelaida Sánchez, Miguel Merchán, Ignacio Plaza ("Nacho"), Albert Berrebi, Manuel Malmierca, Enrique López Poveda y David Díaz ("Primo"), y a los docentes y miembros de la comunidad científica, quienes han aportado grandes beneficios a mi formación en el campo de la investigación y en la realización de este trabajo. Gracias por compartir sus valiosos conocimientos y facilitarme material y equipo de laboratorio.

Finalmente, deseo expresar mi más sincero y afectuoso agradecimiento a mi señora madre, a mi familia, a la Srta. Calvini y a todos aquellos amigos que me han brindado su ayuda y me han animado en este largo proceso que culmina con esta tesis doctoral.

A cada uno de ellos, gracias...TOTALES!!! 
A mí madre

y a la memoria de mi abuela Consuelo (1916-2010) 
"Es preciso sacudir enérgicamente el bosque de las neuronas cerebrales adormecidas; es menester hacerlas vibrar con la emoción de lo nuevo e infundirles nobles y elevadas inquietudes."

(Santiago Ramón y Cajal, 1901)

"The tonotopic organization established in the cochlea is sustained throughout the mammalian auditory system, and, in fact, provides its only consistent organizationalfeature."

(Douglas W. Webster, 1992) 


\section{ÍNDICE}

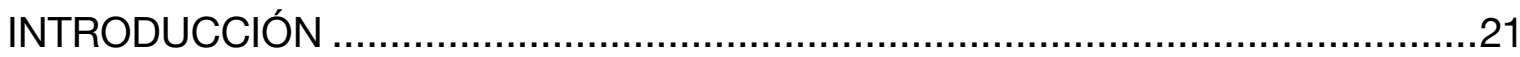

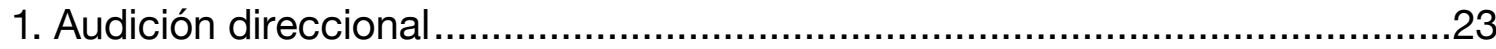

2. Localización del sonido en el plano vertical (elevación).................................25

3. Localización de la distancia a la que se encuentra la fuente sonora...............26

4. Localización del sonido en el plano horizontal (azimut).................................28

5. La audición direccional y el sistema auditivo central.....................................33

6. Bases morfofuncionales de la detección de las DII: la oliva superior lateral ..36

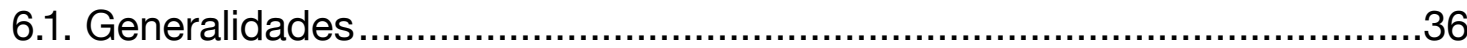

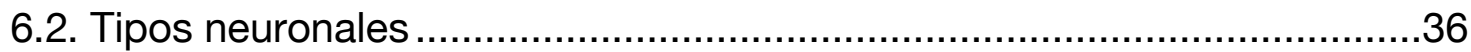

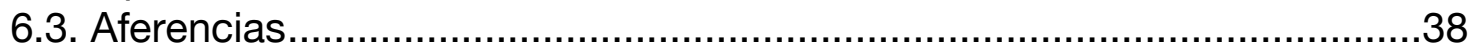

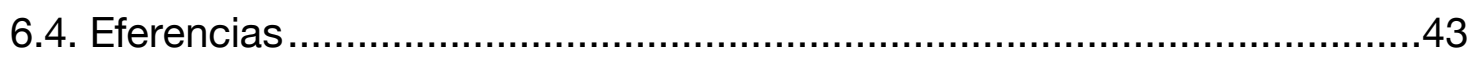

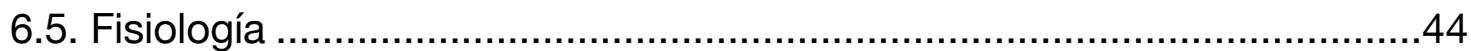

7. Bases morfofuncionales de la detección de las DIT: la oliva superior medial.45

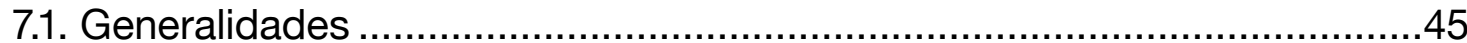

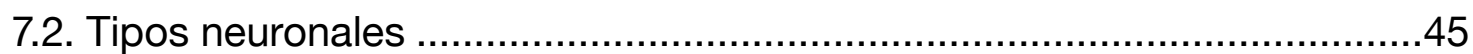

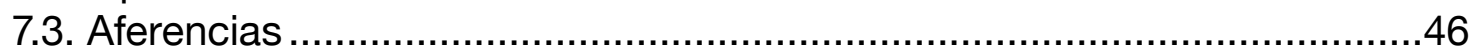

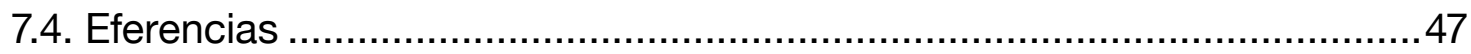

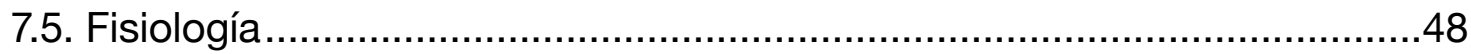

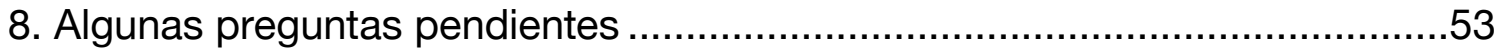

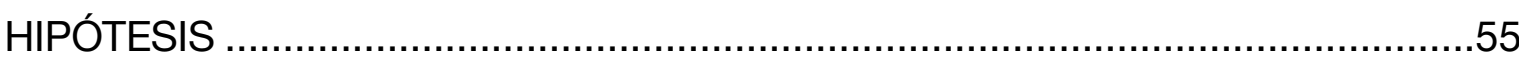

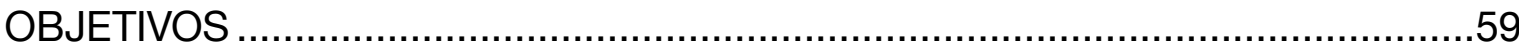

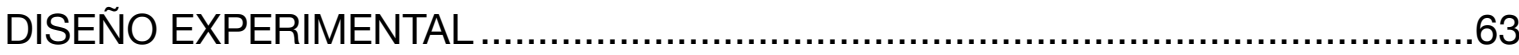

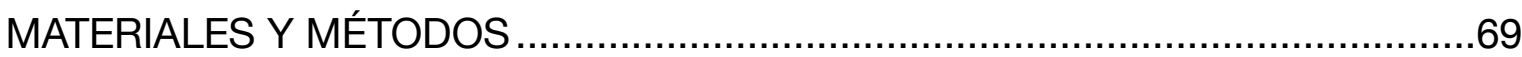

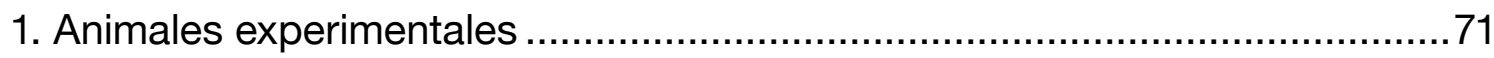

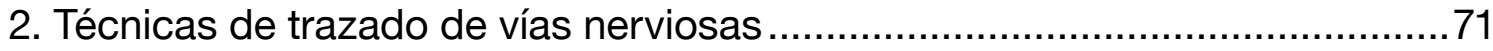

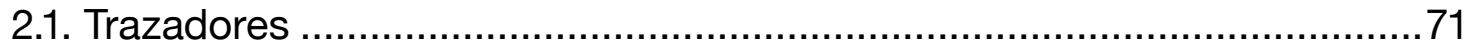

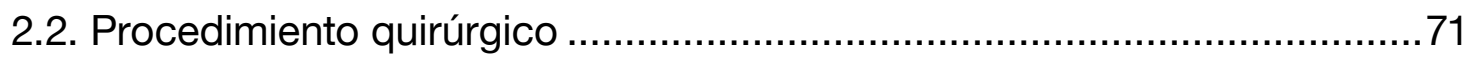

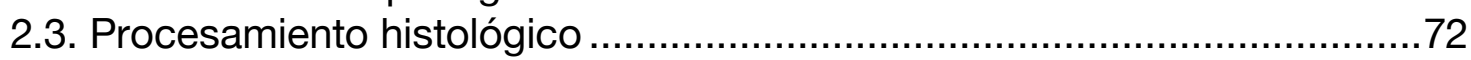

2.3.1. Fijación ......................................................................................

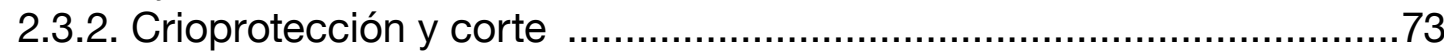

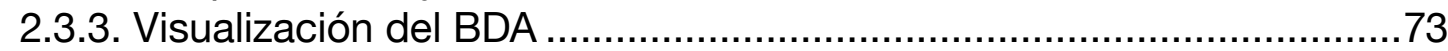

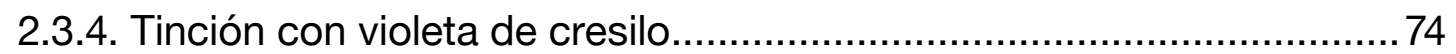

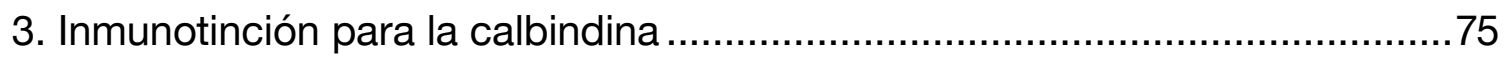

4. Detección inmunofluorescente de MAP2 y GlyT2 ......................................75

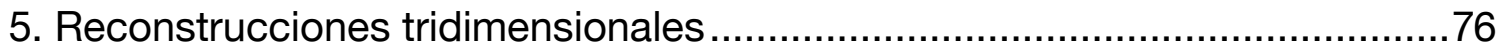

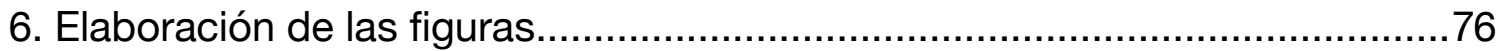

6.1. Pseudodibujos de cámara clara ("Illustrator Drawings")..........................77

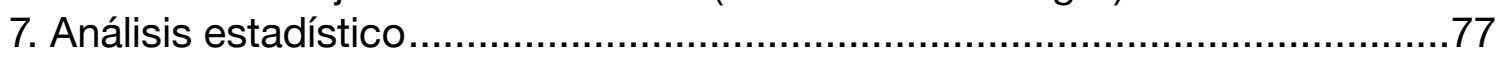




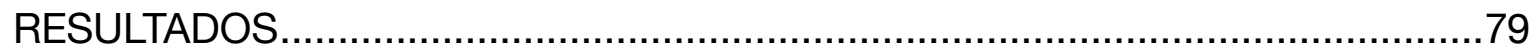

1. Casos con inyección de bda en la OSL de la rata ........................................

1.1. Organización anisótropa y tonotópica de la OSL de la rata.........................81

1.2. Zonas de inyección de BDA en la OSL.................................................82

1.3. Calidad del marcado retrógrado y del marcado anterógrado ....................84

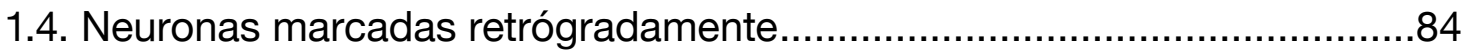

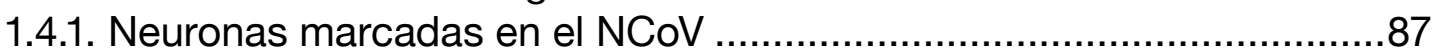

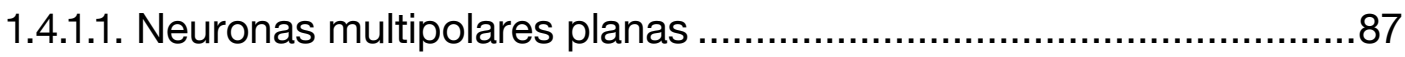

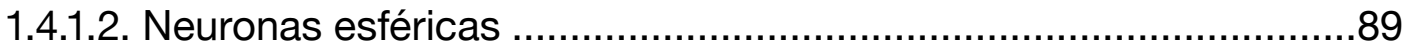

1.4.1.3. Neuronas marcadas en el NCoVc ................................................91

1.4.2. Neuronas marcadas en el NMCT ...................................................91

1.4.3. Neuronas marcadas en el NVCT ..................................................93

1.4.4. Distribución de las neuronas marcadas............................................94

1.4.5. Número de neuronas marcadas.....................................................98

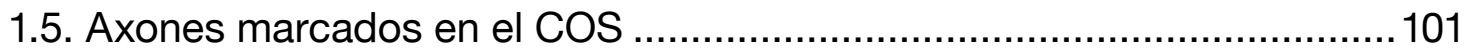

1.5.1. Organización general del COS ......................................................102

1.5.2. Campos terminales marcados en el COS: Patrón general ................104

1.5.3. Topografía (tonotopía) de los campos terminales marcados en el COS...109

1.5.3.1. Campos terminales marcados en el NPS ..................................109

1.5.3.2. Campos terminales marcados en la OSMi ................................. 112

2. Casos con inyección de BDA en la osl del jerbo .........................................115

2.1. Zonas de inyección de BDA en la OSL..............................................116

2.2. Neuronas marcadas retrógradamente .................................................116

2.3. Axones marcados en el COS............................................................ 116

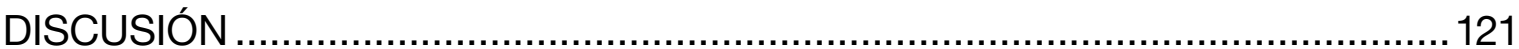

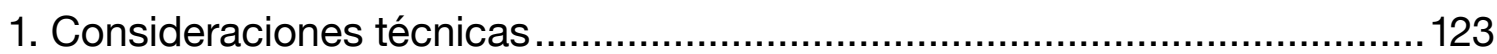

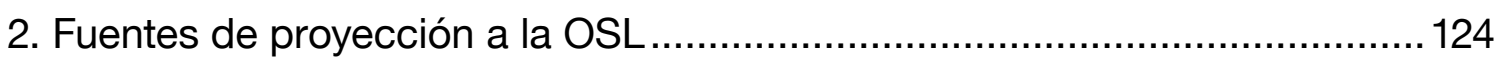

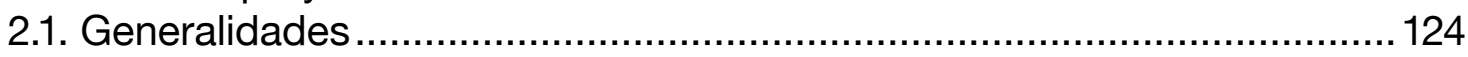

2.2. Tipos neuronales que inervan a la OSL.......................................... 125

2.2.1. Neuronas esféricas del NCoAV .....................................................125

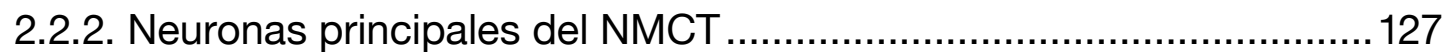

2.2.3. Neuronas multipolares planas del NCoV .......................................129

2.2.4. Neuronas multipolares pequeñas del NVCTc ..................................130

2.2.5. Las neuronas globulares no inervan a la OSL ................................132

2.3. Destino de las proyecciones troncoencefálicas que inervan a la OSL ...135

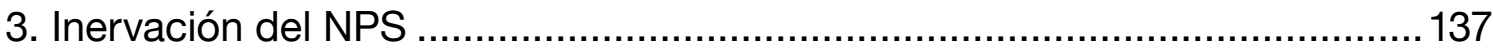

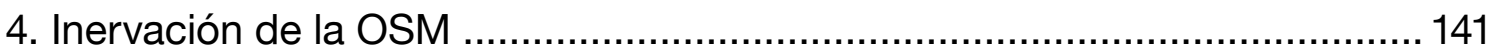

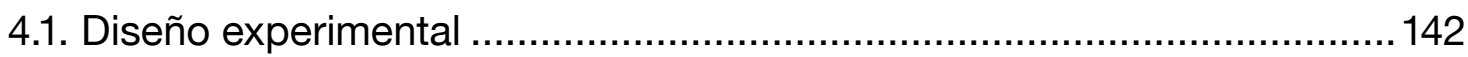

4.2. La OSM contiene una representación incompleta de frecuencias .........143

4.3. Segregación de impulsos excitadores e inhibidores en las neuronas de la OSM...144 
CONCLUSIONES.

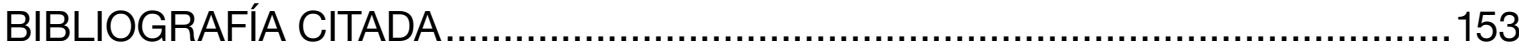

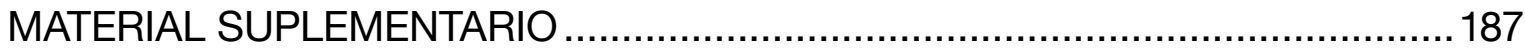




\section{ABREVIATURAS}

\begin{tabular}{|c|c|}
\hline 8 & Nervio coclear \\
\hline BDA & Dextrano biotinado \\
\hline CB & Calbindina \\
\hline $\mathbf{C l}$ & Colículo inferior \\
\hline $\cos$ & Complejo olivar superior \\
\hline DAB & Diaminobencidina \\
\hline DIF & Diferencia interauricular de fase \\
\hline DII & Diferencia interauricular de intensidad \\
\hline DIT & Diferencia interauricular de tiempo \\
\hline GlyT2 & Transportador de glicina de tipo 2 \\
\hline MAP2 & Proteínas asociadas a microtúbulos de tipo 2 \\
\hline NCo & Núcleos cocleares \\
\hline NCoD & Núcleo coclear dorsal \\
\hline NCoAV & Núcleo coclear anteroventral \\
\hline NCoPV & Núcleo coclear posteroventral \\
\hline NCoV & Núcleo coclear ventral \\
\hline NLCT & Núcleo lateral del cuerpo trapezoide \\
\hline NLL & Núcleos del lemnisco lateral \\
\hline NMCT & Núcleo medial del cuerpo trapezoide \\
\hline NVCT & Núcleo ventral del cuerpo trapezoide \\
\hline NPD & Núcleo periolivar dorsal \\
\hline NPS & Núcleo parolivar superior \\
\hline OSL & Oliva superior lateral \\
\hline OSM & Oliva superior medial \\
\hline PB & Tampón de fosfato sódico \\
\hline RC & Retraso coclear \\
\hline tz & Cuerpo trapezoide \\
\hline VLL & Núcleo ventral del lemnisco lateral \\
\hline
\end{tabular}

Nota: A lo largo del texto, para especificar que un núcleo o célula es ipsolateral o contralateral a la zona de inyección (o a cualquier otra manipulación experimental), hemos utilizado la abreviatura correspondiente seguida de la letra "i" o "c". 


\section{AUDICIÓN DIRECCIONAL}

Determinar la posición de la fuente sonora es crucial para la supervivencia de los animales. Saber de dónde procede un sonido puede suponer la diferencia entre comer y no comer, o entre ser comido y sobrevivir. La audición espacial se utiliza para encontrar pareja, ubicar presas potenciales o evitar depredadores (Fay y Popper, 2005; Yost, 2008; Schnupp y cols., 2011). Aunque estas aplicaciones parezcan poco relevantes para los seres humanos actuales, la capacidad de localizar sonidos en el espacio puede resultar crucial para evitar, por ejemplo, un vehículo que se nos vienen encima (Yin, 2002). Además, la localización de las fuentes de sonido desempeña un papel esencial para la atención selectiva y, en particular, para interpretar los sonidos en entornos ruidosos. Gracias a nuestra capacidad para separar o aislar unos sonidos de otros en función de su procedencia, podemos prestar atención a un instrumento determinado de la orquesta o entender lo que dice una voz que se mezcla con otras muchas. En otras palabras, el conocer el origen espacial de los sonidos nos permite percibir estímulos acústicos que de otro modo serían incomprensibles, cuando no prácticamente inaudibles (Bronkhorst, 2000; Haykin y Chen, 2005; Darwin, 2008; Culling y Akeroyd, 2010).

Para el sistema auditivo, deducir la procedencia espacial de los sonidos representa un desafío colosal porque, a diferencia de lo que sucede con otros sistemas sensoriales, como el visual o el somatosensorial, en el receptor auditivo no se codifica un mapa del espacio acústico, sino únicamente un mapa de frecuencias sonoras. Por lo tanto, para deducir el origen de los sonidos, el sistema auditivo debe analizar la ingente cantidad de información acústica que recibe cada oído (información monoauricular), compararla con la que recibe el otro oído (información

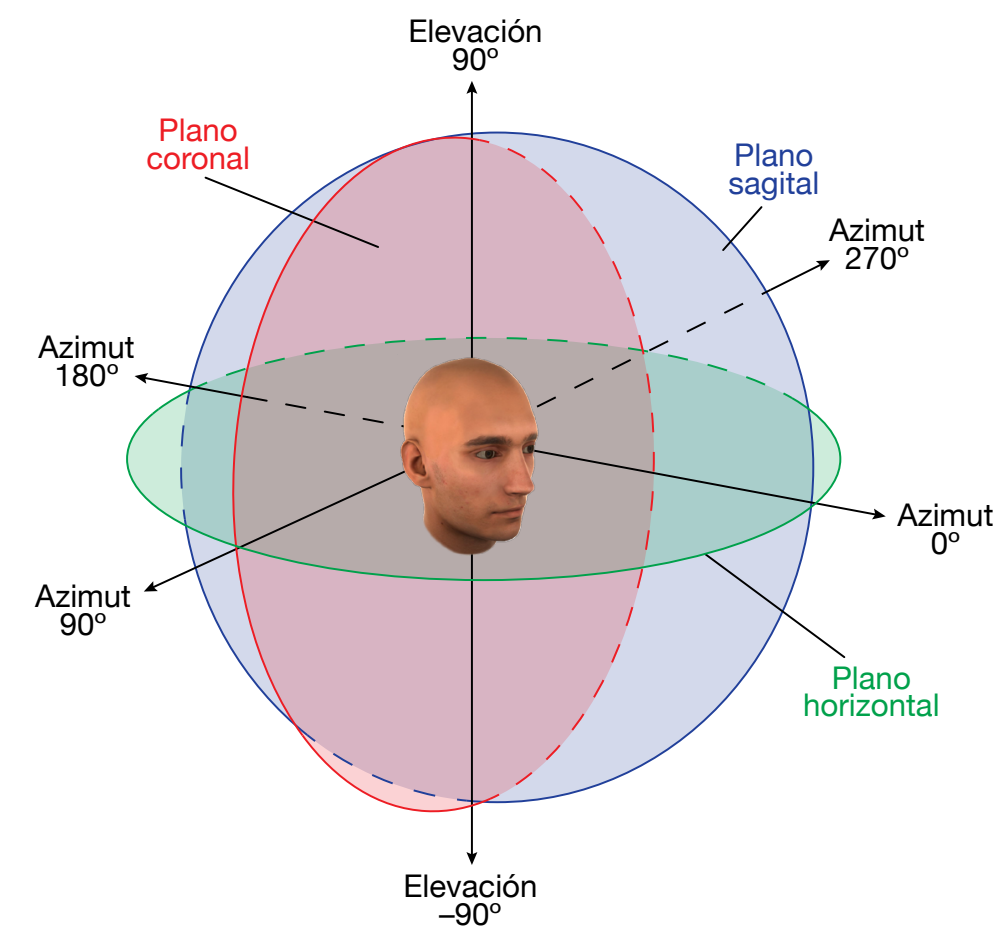

Figura 1. Ilustración del sistema de coordenadas (azimut y elevación) utilizado para definir la posición de las fuentes de sonido con respecto a la cabeza. 
biauricular), y notar cómo se modifica toda esta información cuando cambia la orientación de la cabeza [y las orejas] del oyente, o varía la posición relativa entre éste y la fuente sonora (información dinámica).

Con respecto al oyente, la fuente de sonido se encuentra en un punto del espacio que puede definirse por sus tres coordenadas esféricas: azimut, elevación y distancia (Gourévitch y Brette, 2012). El azimut es la desviación horizontal con respecto al plano sagital del oyente, y se expresa en grados. Un punto situado justo enfrente del oyente posee un azimut de $0^{\circ}$; los puntos que se encuentran exactamente a su derecha, justo detrás, o exactamente a la izquierda del oyente, poseen valores de azimut de $90^{\circ}, 180^{\circ}$ y $270^{\circ}$, respectivamente (Fig. 1).

La elevación es la desviación vertical con respecto a un plano horizontal que pase por los oídos y también se mide en grados. Los puntos situados por encima de los oídos poseen una elevación positiva, y los situados debajo de los oídos, elevación negativa. La elevación de una fuente de sonido ubicada justo encima de la cabeza es de $90^{\circ}$, de $180^{\circ}$ si se encuentra exactamente detrás, y de $-90^{\circ}$ si se halla debajo del oyente (Fig. 1). Por último, la distancia es la longitud que separa al oyente de la fuente de sonido y se expresa en metros.

La audición direccional es la rama de la acústica que analiza los mecanismos por los que los oyentes son capaces de averiguar las coordenadas de cada fuente sonora. Se trata de una ciencia amplia, cuyo estudio detallado excedería claramente los límites de esta Introducción. Por ello, aquí vamos a limitarnos a resumir las pistas y los mecanismos principales a través de los cuales el sistema auditivo calcula la elevación, la distancia y el azimut de las fuentes sonoras. El lector interesado puede encontrar información adicional en alguna de las excelentes publicaciones recientes dedicadas a este tema (Blauert, 2005; Popper y Fay, 2005; Warren, 2008; Yost y cols., 2008; Howard y Angus, 2009; Culling y Akeroyd, 2010; Gelfand, 2010; Strumillo, 2011; Letowski y Letowski, 2012).

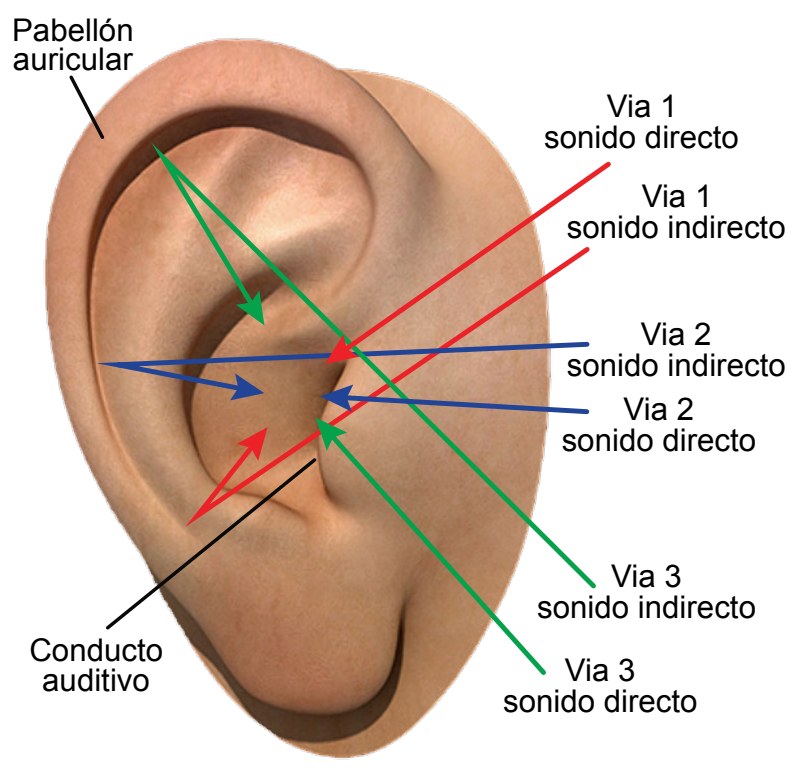

Figura 2. Esquema que ilustra las diferencias entre los sonidos que alcanzan el conducto auditivo externo directamente y los que lo hacen después de haber sido reflejados en los diferente pliegues del pabellón auricular. Ilustración basada en la figura 11.26 de Bear y cols. (2007). 


\section{LOCALIZACIÓN DEL SONIDO EN EL PLANO VERTICAL (ELEVACIÓN)}

La capacidad para localizar una fuente de sonido en el plano vertical radica en la mezcla de frecuencias que lo integran (es decir, en su composición espectral) y en el hecho de que antes de llegar a la membrana timpánica, los sonidos se reflejan en el torso, los hombros y, sobre todo, las orejas y el conducto auditivo externo del oyente (Batteau, 1967; Musicant y Butler, 1984) (Fig. 2). La reflexión de cada sonido depende de su frecuencia y su ángulo de incidencia (LópezPoveda y Meddis, 1996; Hofman y cols., 1998; Tollin y cols., 2013). Así, cada fuente de sonido genera un patrón de reflexión único según su posición espacial, que hace que los sonidos de determinadas frecuencias se intensifiquen, y los de otras frecuencias se atenúen. A este patrón de reflexión se le denomina "función de transferencia relativa a la cabeza", y es único para cada persona o animal. En la figura 3 se muestra el espectro de frecuencias registrado en el oído derecho de un oyente estimulado por un mismo sonido procedente de tres elevaciones distintas. Como puede comprobarse, las frecuencias que son reforzadas o amortiguadas dependen del ángulo de incidencia del sonido. Es particularmente llamativa la atenuación de los sonidos de ciertas frecuencias (Fig. 3).

En los seres humanos, son especialmente informativas las muescas que se producen para ciertas frecuencias agudas, superiores a los 5-6 kHz (Musicant y Butler, 1984; Ferguson y Cabrera, 2005; ver también la figura 3). Por esta razón, resulta más ambiguo deducir la procedencia vertical de los sonidos graves, que la de los sonidos agudos.

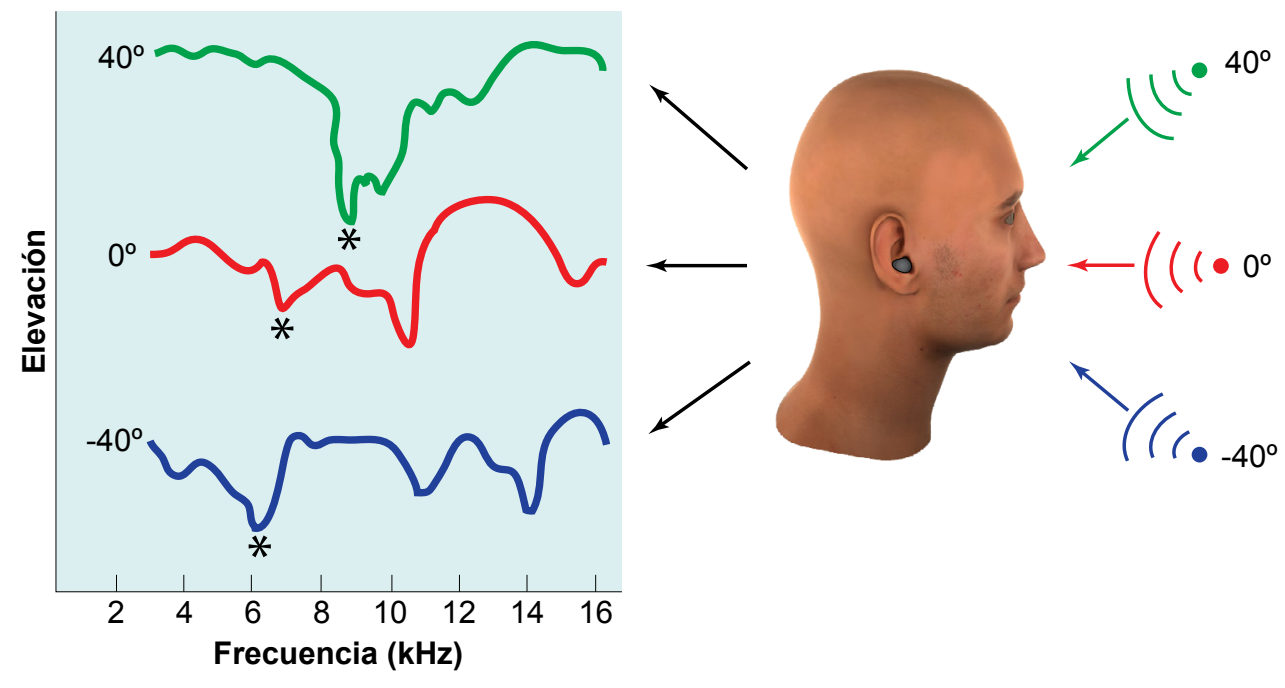

Figura 3. Esquema que muestra el espectro de frecuencias registrado en el oído derecho de un oyente estimulado por un mismo sonido procedente de tres elevaciones distintas. Los asteriscos indican las muescas correspondientes a las frecuencias que son especialmente atenuadas y que dependen de la elevación de la fuente sonora. Ilustración basada en una figura de Goldstein (2007). 


\section{LOCALIZACIÓN DE LA DISTANCIA A LA QUE SE ENCUENTRA LA FUENTE SONORA}

Los factores de los que depende la percepción de la distancia a la que se encuentra la fuente de sonido han sido menos estudiados que los mecanismos en los que se basa la percepción de la elevación o del azimut. Esto puede haberse debido en parte a que la precisión con la que los seres humanos calculamos la distancia es muy inferior a nuestra apreciación del azimut o la elevación. En general, tendemos a infravalorar a qué distancia se encuentran las fuentes de sonido lejanas (situadas a más de $2 \mathrm{~m}$ del oyente, aproximadamente), mientras que, por el contrario, solemos pensar que las fuentes cercanas (situadas a menos de $2 \mathrm{~m}$ ) se hallan más lejos de lo que en realidad están (Zahorik y cols., 2005).

La apreciación de la distancia se debe sobre todo a una combinación de pistas monoauriculares, de modo que las pistas biauriculares desempeñan un papel muy secundario. Son tres las pistas monoauriculares más útiles:

A. La intensidad del sonido. El sentido común sugiere que la intensidad del sonido es una información muy valiosa para saber si un sonido procede de una fuente cercana o de una lejana. De hecho, por propia experiencia, todos sabemos que un mismo sonido suena más intenso cuando se genera cerca del oyente, que cuando procede de un punto distante. Desde el punto de vista físico, es bien conocido que para sonidos generados en un punto concreto del espacio y que se transmiten en campo abierto (es decir, sin obstáculos, ni reflexiones), la onda sonora es una perturbación esférica cuya intensidad decrece de modo inversamente proporcional al cuadrado de la distancia con respecto a la fuente sonora. En la práctica, teniendo en cuenta la naturaleza logarítmica de la escala de los decibelios, los sonidos se atenúan aproximadamente $6 \mathrm{~dB}$ cada vez que se dobla la distancia (Coleman, 1963) (Fig. 4). Aunque esta es la teoría, en el mundo real la disminución progresiva de la intensidad es menos útil de lo que cabría esperar. Si una persona con los ojos cerrados oye un determinado sonido, y luego oye el mismo sonido pero $6 \mathrm{~dB}$ más flojo, en teoría debería percibir que la fuente sonora se ha alejado el doble, y sin embargo no es así; en condiciones normales, el oyente no siente que se haya movido la

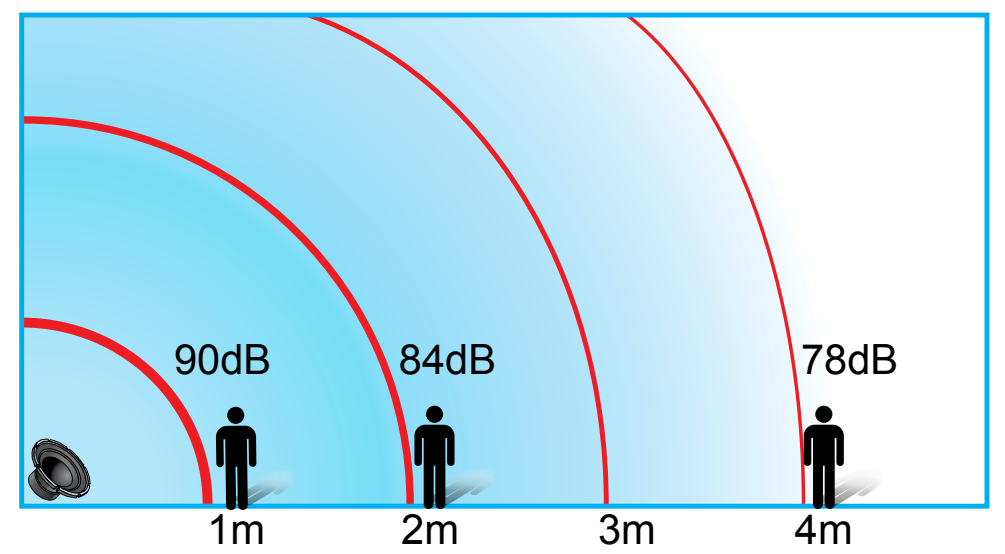

Figura 4. La intensidad de los sonidos que se propagan en campo abierto disminuye siguiendo la ley del inverso del cuadrado de la distancia. Cada vez que se dobla la distancia, la intensidad disminuye aproximadamente $6 \mathrm{~dB}$. 
fuente sonora, sino más bien que se ha bajado el volumen del estímulo. Se ha comprobado experimentalmente que cuando se utiliza como única pista el cambio en la intensidad del sonido, las personas perciben sistemáticamente que las fuentes de sonido se encuentran más cerca de lo que están en realidad (Békésy, 1938; Cochran y cols., 1968; Gardner, 1969; Petersen, 1990; Begault, 1991; Blauert, 1997). Es más, para que una persona perciba que la distancia que la separa de la fuente de sonido se ha doblado, es necesario disminuir la intensidad del estímulo en unos 20 dB (Blauert, 1997), mucho más, por tanto, que los 6 dB teóricos.

B. La reverberación. En el mundo real, los sonidos llegan a los oyentes tanto directamente, como después de haberse reflejado en todo tipo de objetos (Mershon y Bowers, 1979; Richards y Wiley, 1980; Gourévitch y Brette, 2012). Esto es especialmente cierto en el interior de los edificios, donde los sonidos se reflejan en las paredes, el techo y el suelo de la estancia, y en los objetos contenidos en ella (Nielsen, 1993; Bronkhorst y Houtgast, 1999). Si los sonidos directos y los sonidos reflejados se atenúan con la distancia en la misma medida, una pista muy útil para calcular la distancia es la proporción entre la energía del sonido directo y la energía del sonido reflejado (Sheeline, 1983). Imaginemos que un oyente está frente a una fuente sonora situada a $2 \mathrm{~m}$, y que $1 \mathrm{~m}$ detrás de él hay una pared (Fig. 5A). El sonido directo alcanza al oyente después de haber recorrido $2 \mathrm{~m}$, pero cuando le llega el sonido reflejado, éste ha recorrido $4 \mathrm{~m}$ (los $3 \mathrm{~m}$ que van de la fuente sonora a la pared, y $1 \mathrm{~m}$ que hay entre la pared y el oyente), es decir, se ha doblado la distancia, por lo que el sonido reflejado debería ser al menos 6 dB más débil. Si la fuente de sonido se aleja del oyente y de la pared, el sonido directo y el sonido reflejado llegan al

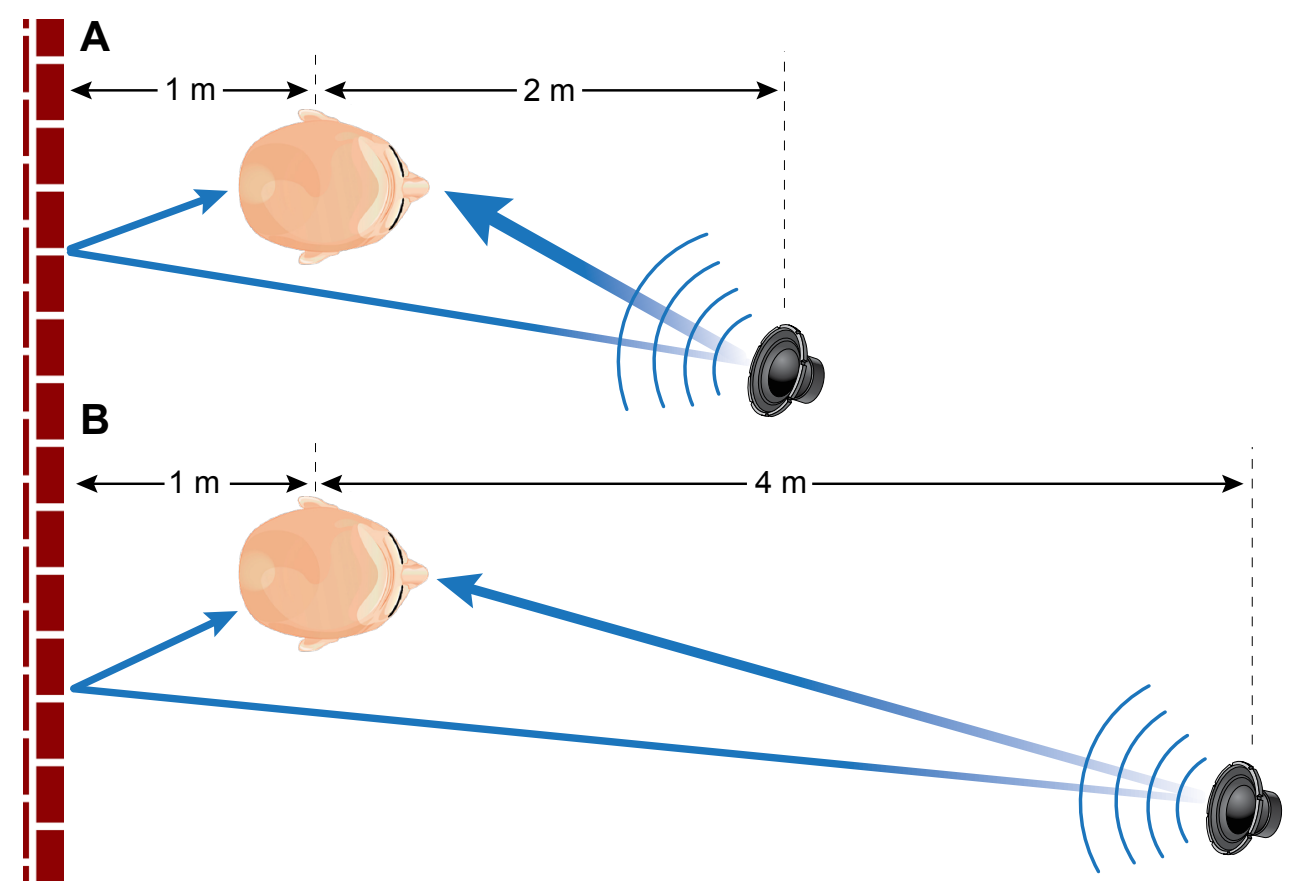

Figura 5. Papel de la reverberación en la percepción de la distancia a la que se encuentran las fuentes de sonido. (A) Cuando la fuente sonora está próxima al oyente, la intensidad del sonido que le llega directamente es sensiblemente mayor que la del sonido reflejado. (B) Cuanto más lejos está la fuente sonora, menor es la diferencia entre la intensidad del sonido directo y la intensidad del sonido reflejado. 
oyente después de haber recorrido distancias más similares y, por lo tanto, su intensidad es muy parecida (Fig. 5B). Así pues, para fuentes sonoras cercanas, la diferencia entre la intensidad del sonido directo y la del sonido reflejado es muy apreciable, mientras que a medida que aumenta la distancia, disminuye la diferencia de intensidad.

C. La composición espectral del sonido. La composición espectral de los sonidos, es decir, la energía relativa de las ondas sonoras de las diversas frecuencias, cambia con la distancia. Esto se debe fundamentalmente a que cuando se propagan por el aire, los sonidos agudos se atenúan más que los sonidos graves. Esta es la razón por la que un trueno que se produce cerca del oyente posee un sonido rico y brillante, con frecuencias muy variadas, mientras que un trueno oído en la distancia suena como un estímulo sordo en el que predominan los tonos graves. De modo similar, cuando una persona habla a lo lejos, se perciben mejor las vocales que las consonantes, porque éstas poseen más energía de frecuencias altas. No obstante, la absorción de la energía sonora por el aire es un fenómeno relativamente débil, pues representa unos 3 ó 4 dB por cada 100 m de distancia (Ingård, 1953), por lo que el cambio en la composición espectral de los sonidos sólo resulta una pista útil para calcular distancias muy largas.

\section{LOCALIZACIÓN DEL SONIDO EN EL PLANO HORIZONTAL (AZIMUT)}

A diferencia de la percepción de la elevación y la percepción de la distancia, que se basan en pistas monoauriculares, la localización de las fuentes de sonido en el plano horizontal depende de la información biauricular. La clave radica en que tenemos dos oídos y la información que reciben es ligeramente distinta (Fig. 6). Así, si un sonido procede del lado izquierdo, llega antes al oído izquierdo, que está más cerca, que al oído derecho, y este factor se conoce como diferencia interauricular de tiempo (DIT). Además, si el sonido proviene del lado izquierdo,

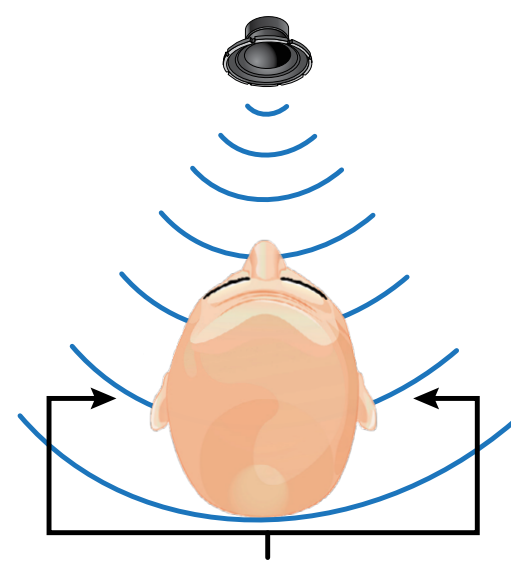

Las ondas sonoras llegan a la vez y con la misma intensidad.

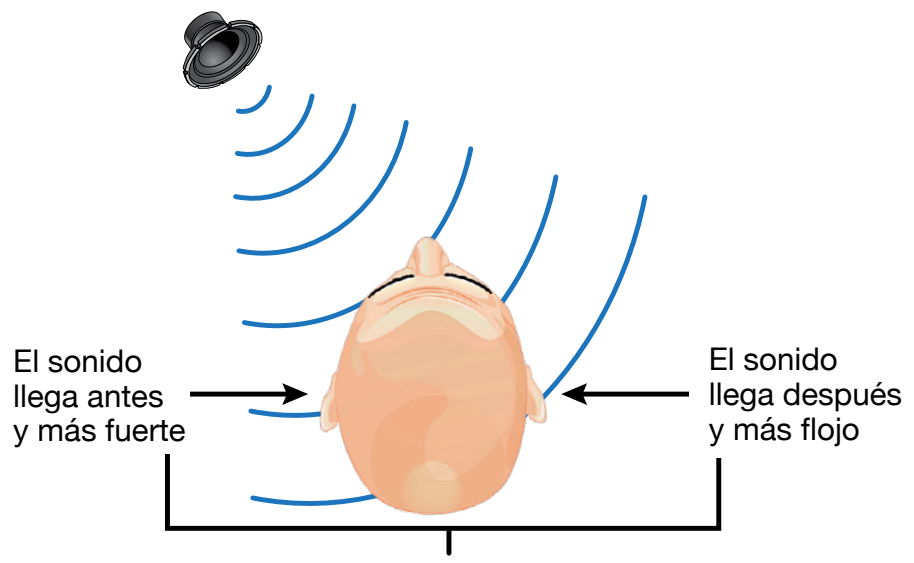

El sistema nervioso central compara las sutiles diferencias entre los sonidos que llegan a un oído y los que llegan al otro.

Figura 6. Representación esquemática de cómo se generan las dos principales pistas biauriculares para la detección de azimut de las fuentes sonoras: la diferencia interauricular de tiempo y la diferencia interauricular de intensidad. 
alcanza con menor intensidad al oído derecho, no sólo porque está más lejos de la fuente sonora, sino sobre todo porque la cabeza actúa como una pantalla acústica que amortigua el estímulo; a esta discrepancia se la denomina diferencia interauricular de intensidad (DII). Estos dos factores, la DIT y la DII, son las principales pistas que utiliza el cerebro para determinar el azimut de la fuente sonora (Fig. 6), y fueron propuestos hace más de 100 años por Lord Rayleigh (Wightman y Kistler, 1993). La DIT y la DII le sirvieron de base a Lord Rayleigh para formular lo que se conoce como la "teoría doble de la localización espacial del sonido".

La utilidad relativa de la DIT y la DIl depende de la relación entre la distancia que separa a los dos oídos y la longitud de la onda sonora (Kuhn, 1977). En la especie humana, los sonidos de más de 2 ó $3 \mathrm{kHz}$ poseen longitudes de onda más cortas que el diámetro de la cabeza y son incapaces de bordearla, de manera que el oído más alejado de la fuente sonora queda dentro de una zona de sombra acústica (Fig. 7). En consecuencia, los sonidos agudos generan una

A

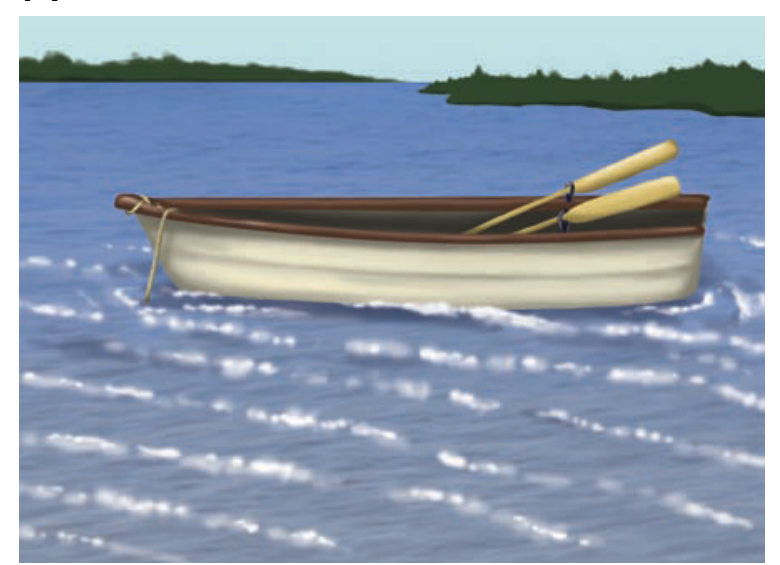

C

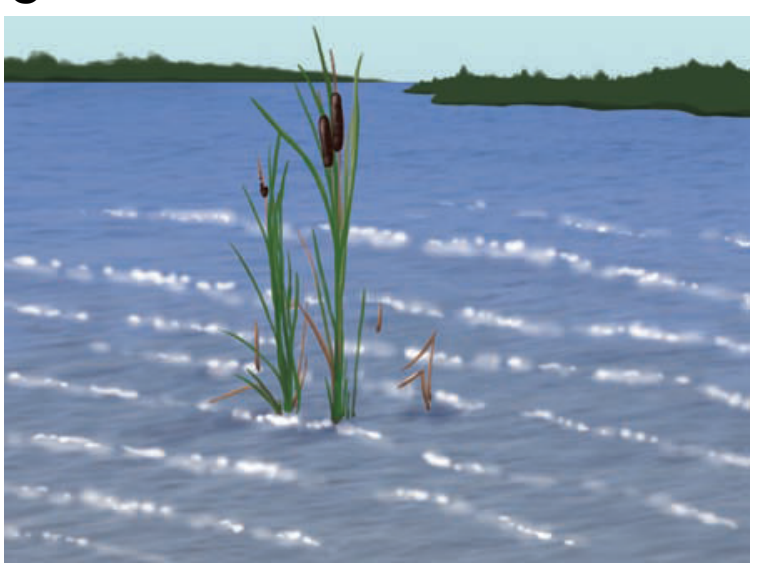

B

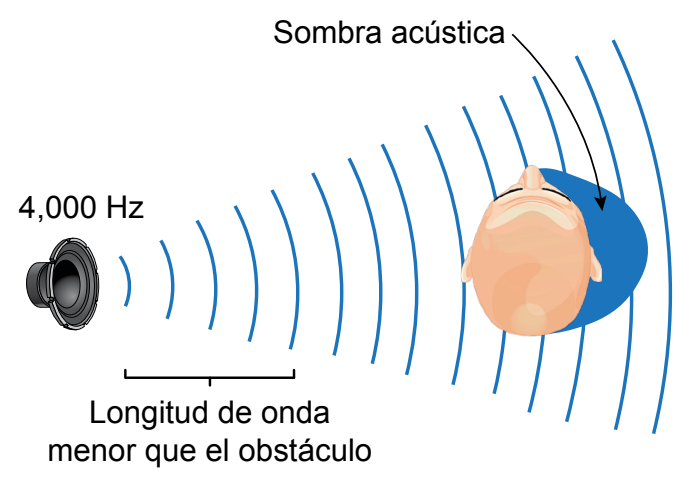

D

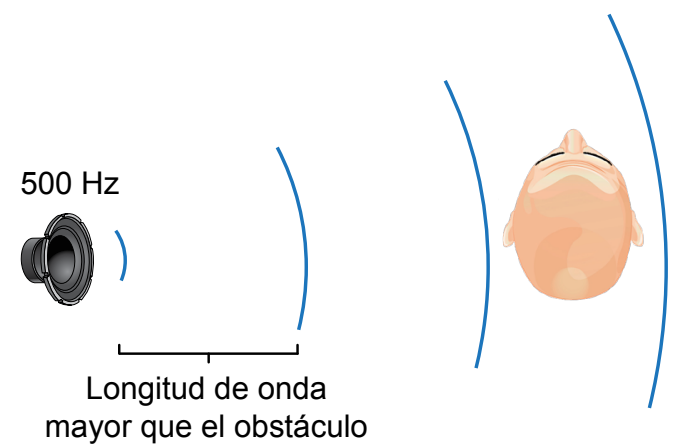

Figura 7. Relación entre la longitud de onda y la DII. Cuando una onda encuentra un obstáculo mayor que su longitud de onda, es incapaz de bordearlo (A). Por eso los sonidos de frecuencia alta, cuya longitud de onda es menor que el diámetro de la cabeza, generan una sombra acústica que da a lugar a diferencias interauriculares de intensidad apreciables (B). Cuando el obstáculo es menor que la longitud de onda, las ondas se difractan y lo bordean sin dificultad (C). Por ello los sonidos graves, cuya longitud de onda es mayor que la cabeza, no generan sombras acústicas y las ondas alcanzan los dos oídos prácticamente con la misma intensidad (D). Ilustración basada en la figura 12.5 de Goldstein (2010). 
DIl apreciable. Por el contrario, los sonidos graves, al tener una longitud de onda mayor que la cabeza, se difractan fácilmente y son capaces de bordear la cabeza y alcanzar los dos oídos prácticamente con la misma intensidad, por lo que generan DII insignificantes. Por ello, la DII es una pista especialmente útil para los sonidos agudos.

La DIT varía con el ángulo de incidencia del sonido (Fig. 8). Asumiendo que el sonido viaja a unos $340 \mathrm{~m} / \mathrm{s}$, la máxima DIT (que se produce cuando el sonido posee un azimut de $90^{\circ}$ ó $270^{\circ}$ ) es de unos $660 \mu \mathrm{s}$ en los seres humanos (Fig. 9), de unos $400 \mu \mathrm{s}$ en el gato, y de unos $135 \mu \mathrm{s}$ en el jerbo (Feddersen y cols., 1957; Calford y cols., 1986; Heffner y Heffner, 1988; Yin y Chan, 1990; Grothe $y$ cols., 2010). A medida que la fuente de sonido se acerca a la línea media, disminuye la DIT; de hecho, los seres humanos somos capaces de distinguir desviaciones de apenas 1 ó 2 grados, que corresponden a una DIT asombrosamente pequeña, de tan solo $10 \mu \mathrm{s}$ (Klemm, 1920; Klumpp y Eady, 1956; Blauert, 1997). En teoría, esta formidable capacidad para detectar las DIT debería funcionar para cualquier sonido, con independencia de su frecuencia, pero en la práctica no es así. Esto se debe a que los sonidos naturales poseen siempre una duración prolongada y el sistema auditivo no detecta sólo el retraso absoluto con el que los sonidos alcanzan los dos oídos, sino que sigue extrayendo información sobre la posición de la fuente sonora mientras dura el sonido. Para ello, el cerebro compara la fase de la onda sonora que llega a cada oído, de manera que más que utilizar DIT absolutas, el sistema auditivo trabaja con diferencias interauriculares de fase (DIF) (Fig. 10). Si la fuente de sonido posee un azimut de $0^{\circ}$ (o de $180^{\circ}$ ), la onda sonora alcanza los dos oídos exactamente en la misma fase; a medida que la fuente sonora se desvía, se produce un desfase que crece con el azimut (Fig. 10A, B). Esta DIF es inequívoca para los sonidos cuya longitud de onda es mayor que la distancia entre los dos oídos (los sonidos graves), porque a cada azimut le corresponde una DIF única. Sin embargo, para los sonidos agudos se trata de una pista ambigua, pues una determinada DIF puede ser

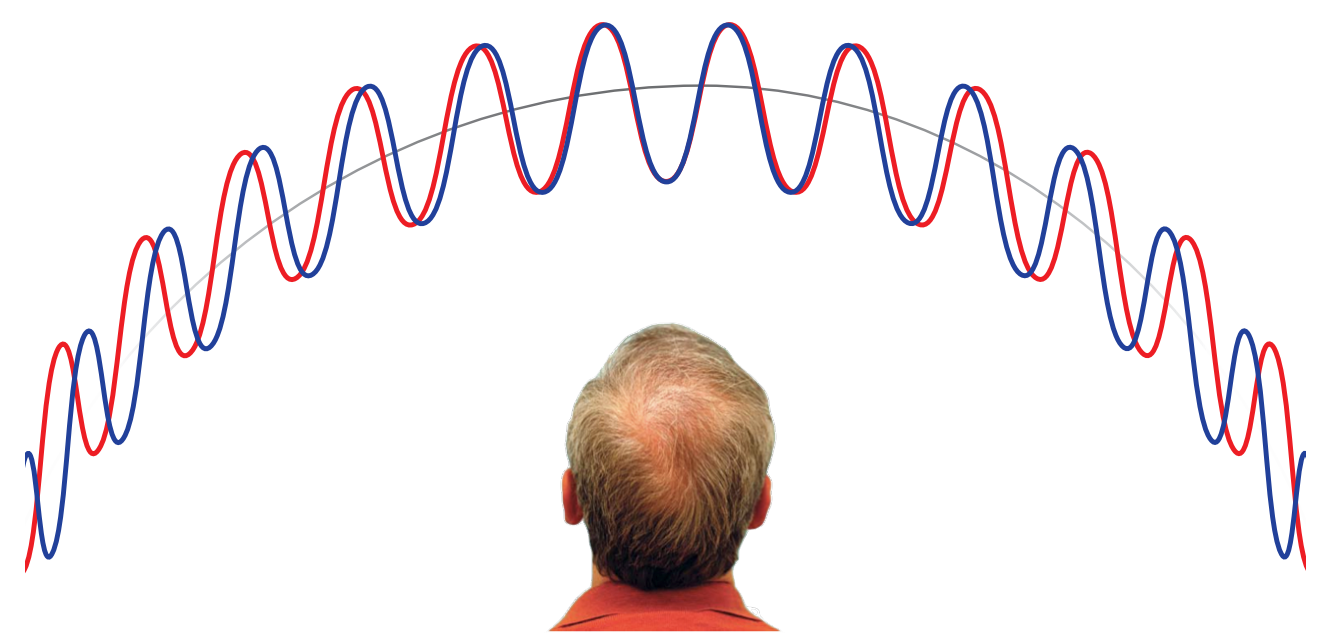

Figura 8. Relación entre el azimut de la fuente sonora y la DIT. Cuando el sonido procede de un punto situado frente al oyente, las ondas alcanzan los dos oídos a la vez. A medida que la fuente sonora se desvía de la línea media, aumenta el retraso con el que el sonido llega al oído más alejado. Cada color representa un oído. Ilustración elaborada a partir de una idea reflejada en la figura 5.5 de Schnupp y cols. (2011). 


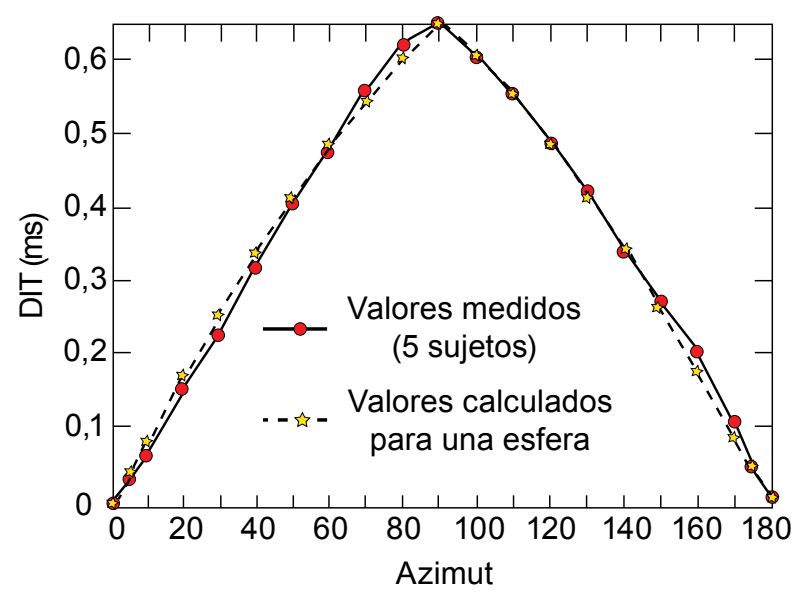

Figura 9. Representación de cómo cambian en la especie humana las diferencias interauriculares de tiempo (DIT) generadas por clicks en función del azimut de la fuente sonora. Los puntos rojos corresponden a valores reales medidos en los oídos de 5 personas. Los puntos amarillos muestran las diferencias teóricas que cabría esperar si la cabeza fuera una esfera perfecta. Figura basada en datos de Feddersen y cols. (1957).

generada por un mismo sonido procedente de dos puntos distintos del espacio y que por lo tanto generan retrasos diferentes (Fig. 10C, D). Por todos estos motivos, la DIT y la DIF alcanzan su máxima utilidad para localizar las fuentes de sonidos graves.

La teoría doble de la localización espacial del sonido ha encontrado apoyo en experimentos conductuales. Con los ojos tapados, las personas identifican mucho mejor la procedencia de los sonidos graves (de menos de $2 \mathrm{kHz}$ ) o agudos (de más de $5 \mathrm{kHz}$ ), que la de los sonidos intermedios, porque en cada extremo del espectro acústico resulta más eficaz una de las dos pistas biauriculares, mientras que en el centro ninguna de las dos funciona tan bien y su mezcla conlleva una cierta ambigüedad (Stevens y Newman, 1934; Mills, 1958; Casseday y Neff, 1973; Brughera y cols., 2013). No obstante, sería inexacto pretender que la DIT no desempeña ningún papel en la localización de los sonidos agudos, ya que se ha demostrado psicoacústicamente que puede detectarse eficazmente la DIT en el envoltorio de los sonidos agudos complejos (Klumpp y Eady, 1956; David y cols., 1959; Yost y cols., 1971; Henning, 1974; McFadden y Pasanen, 1976; Bernstein, 2001). Del mismo modo, no debería asumirse que la DIl resulta totalmente inútil para los sonidos graves, pues éstos generan DIl apreciables cuando la fuente de sonido se halla próxima al oyente (Brungart y Rabinowitz, 1999; Shinn-Cunningham y cols., 2000). Por todo ello, parece aconsejable considerar la teoría doble de Rayleigh como una interesante noción de hasta qué punto las pistas biauriculares dependen de la frecuencia del sonido, más que como una asunción de que la detección de los sonidos en el plano horizontal se basa en la segregación absoluta de dos canales funcionales entre los que no existe intersección.

"El azimut de las fuentes de sonido se deduce gracias a pistas biauriculares. La DIT es especialmente útil para los sonidos graves, mientras que la DII es más eficaz para los sonidos agudos". 
A

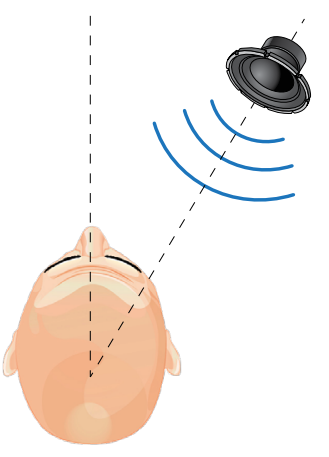

B

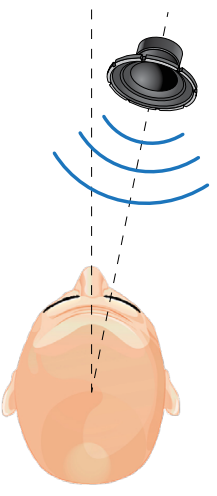

C

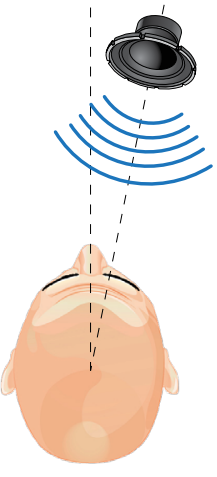

D

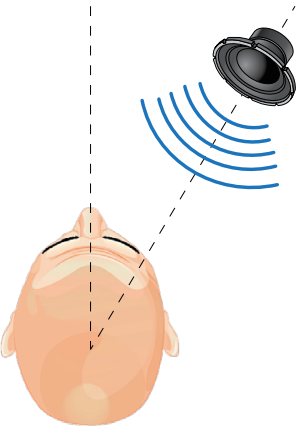

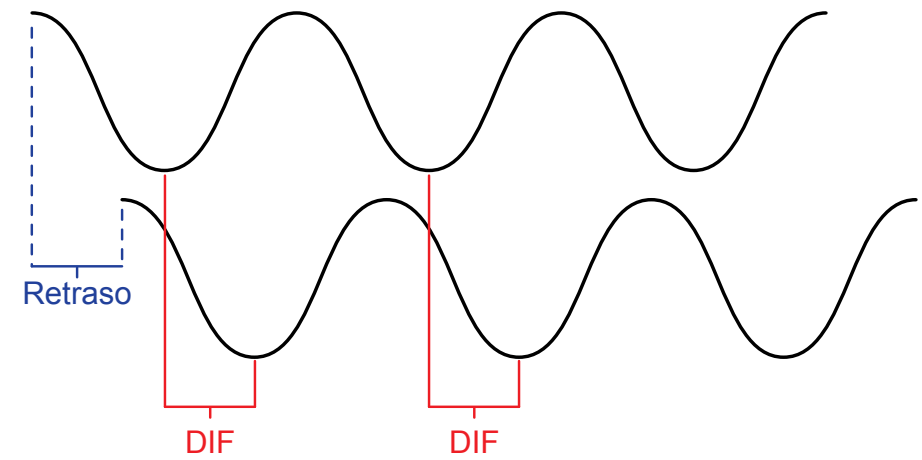
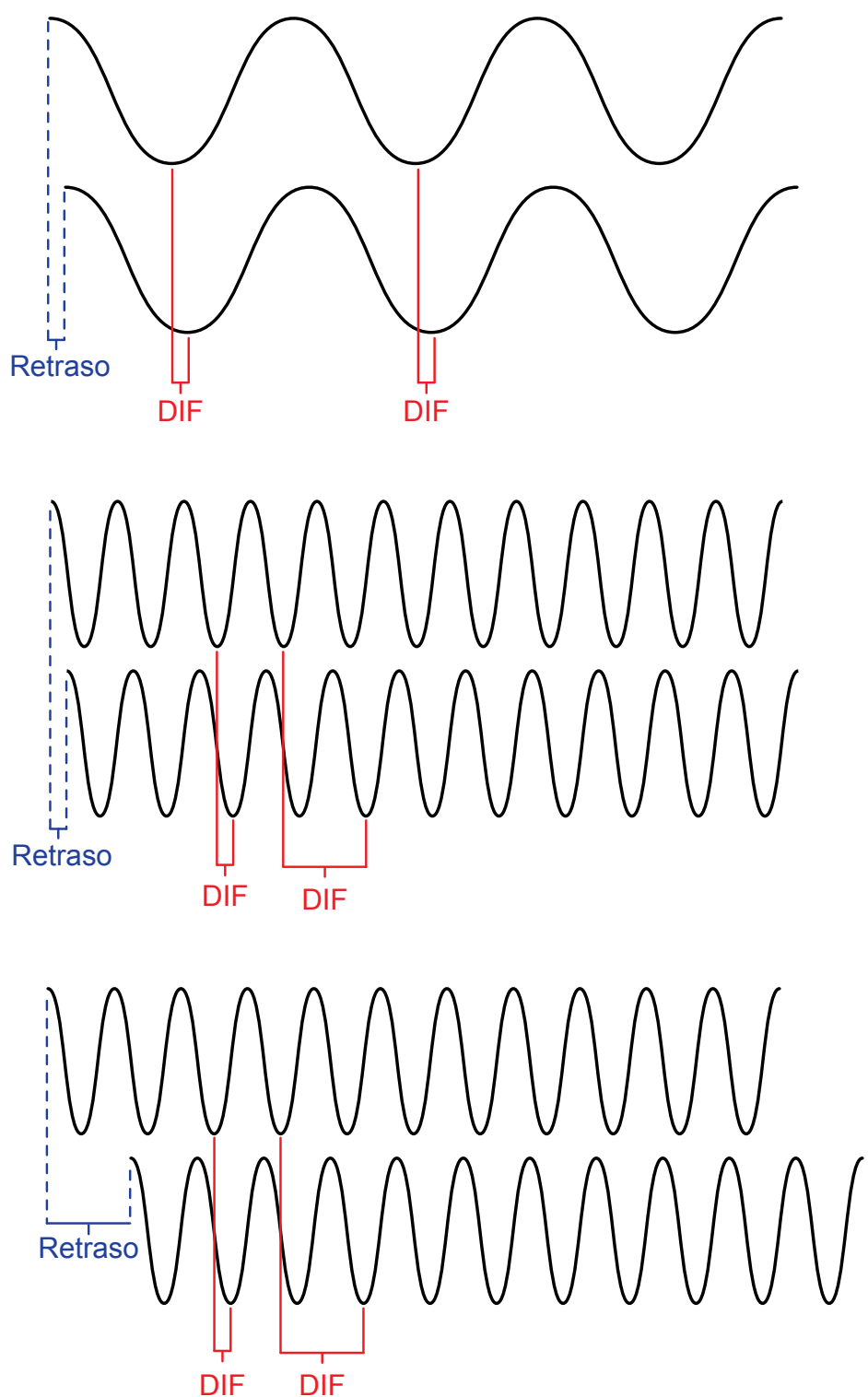

Figura 10. Detección de la diferencia interauricular de fase (DIF). Los sonidos de frecuencia baja generan DIF inequívocas. (A) y (B) muestran dos tonos graves de la misma frecuencia procedentes de puntos con diferente azimut; al aumentar el azimut, aumenta el retraso (DIT) y también la DIF. Los sonidos agudos generan DIF ambiguas. La imagen $\mathbf{C}$ muestra un sonido agudo procedente del mismo punto que el sonido $\mathbf{B}$ y que por lo tanto produce el mismo retraso. Sin embargo, en el sonido agudo ese retraso da lugar a dos DIF distintas. Los sonidos agudos $\mathbf{C}$ y $\mathbf{D}$ poseen la misma frecuencia pero distinto azimut por lo que producen un retraso distinto. A pesar de ello, ambos dan lugar a las mismas DIF. 


\section{LA AUDICIÓN DIRECCIONAL Y EL SISTEMA AUDITIVO CENTRAL}

La información acústica que llega a la cóclea se transmite a través del nervio coclear al sistema nervioso central, donde la procesan distintos núcleos. La información va pasando de modo más o menos secuencial por los núcleos cocleares (NCo), el complejo olivar superior (COS), los núcleos del lemnisco lateral (NLL), el colículo inferior $(\mathrm{Cl})$ y el cuerpo geniculado medial del tálamo antes de ganar la corteza cerebral (Fig 11). Los NCo, el COS, los NLL y el Cl son estructuras troncoencefálicas, mientras que cuerpo geniculado medial del tálamo se encuentra en el diencéfalo, y las áreas auditivas de la corteza cerebral son lógicamente telencefálicas.

La mayoría de los científicos aceptan que el procesamiento inicial de la información biauricular ocurre en el COS, un conjunto de núcleos situado en la región ventral de la calota protuberancial o puente y que constituye el primer lugar de convergencia masiva de las vías nerviosas que parten de los oídos derecho e izquierdo. Dos destacados núcleos del COS, la oliva superior lateral (OSL) y la oliva superior medial (OSM), desempeñan un papel primordial en esta función: en la OSL empiezan a codificarse las DII, mientras que en la OSM reside la capacidad de detectar las DIT (Masterton y cols., 1967, 1975; Masterton, 1992; Tollin, 2003). La existencia de vías paralelas más o menos especializadas para procesar las DIT o las DIl se confirma por el hecho de que en determinados pacientes con esclerosis múltiple se deteriora la capacidad de detectar las DIT, pero que conserva intacta la capacidad para percibir las DII (Levine y cols., 1993; Furst y cols., 2000). Además, se ha comprobado electroencefalográficamente que las áreas corticales que se activan cuando se detectan las DIT no coinciden del todo con las que se activan ante las DIl (Edmonds y Krumbholz, 2014).

Dada la estrecha relación entre la frecuencia de los sonidos y la capacidad para detectar de dónde proceden, conviene tener en cuenta cómo se distribuye la información espectral de los estímulos acústicos a lo largo de la vía auditiva. La denominada organización tonotópica del sistema auditivo tiene su origen en las propiedades mecánicas de la membrana basilar de la cóclea, por las cuales los sonidos graves excitan de forma máxima a las células ciliadas de la región apical de la cóclea, y los sonidos agudos, a las células ciliadas de la región basal (von Békésy, 1960; Russell y Sellick, 1977). Esta selectividad se transmite a través de las fibras del nervio coclear hasta el núcleo coclear ventral (NCoV): las neuronas ventrales reciben la información coclear apical (de frecuencias graves), y las neuronas dorsales, la información basal (de frecuencias agudas). Así, dentro de cada núcleo auditivo las neuronas que procesan sonidos de una determinada frecuencia se encuentran agrupadas, y separadas de las que procesan sonidos de otra frecuencia. En conjunto, la distribución de frecuencias dentro de cada núcleo forma un gradiente, de manera que en un extremo del núcleo se procesan los sonidos graves y en el otro, los agudos. Las vías ascendentes, que parten de los NCo, conservan esta organización tonotópica, que es transmitida de unos núcleos a otros a lo largo de toda la vía auditiva. En cada eslabón, las neuronas de un núcleo que procesan sonidos de una frecuencia dada inervan selectivamente a las neuronas del núcleo siguiente encargadas de procesar sonidos de la misma frecuencia, y sólo a esas. De este modo, todas las conexiones entre núcleos auditivos centrales son estrictamente topográficas y tonotópicas, y conociendo la organización tonotópica del núcleo de partida y la del núcleo de llegada de una proyección dada, puede deducirse su topografía. 


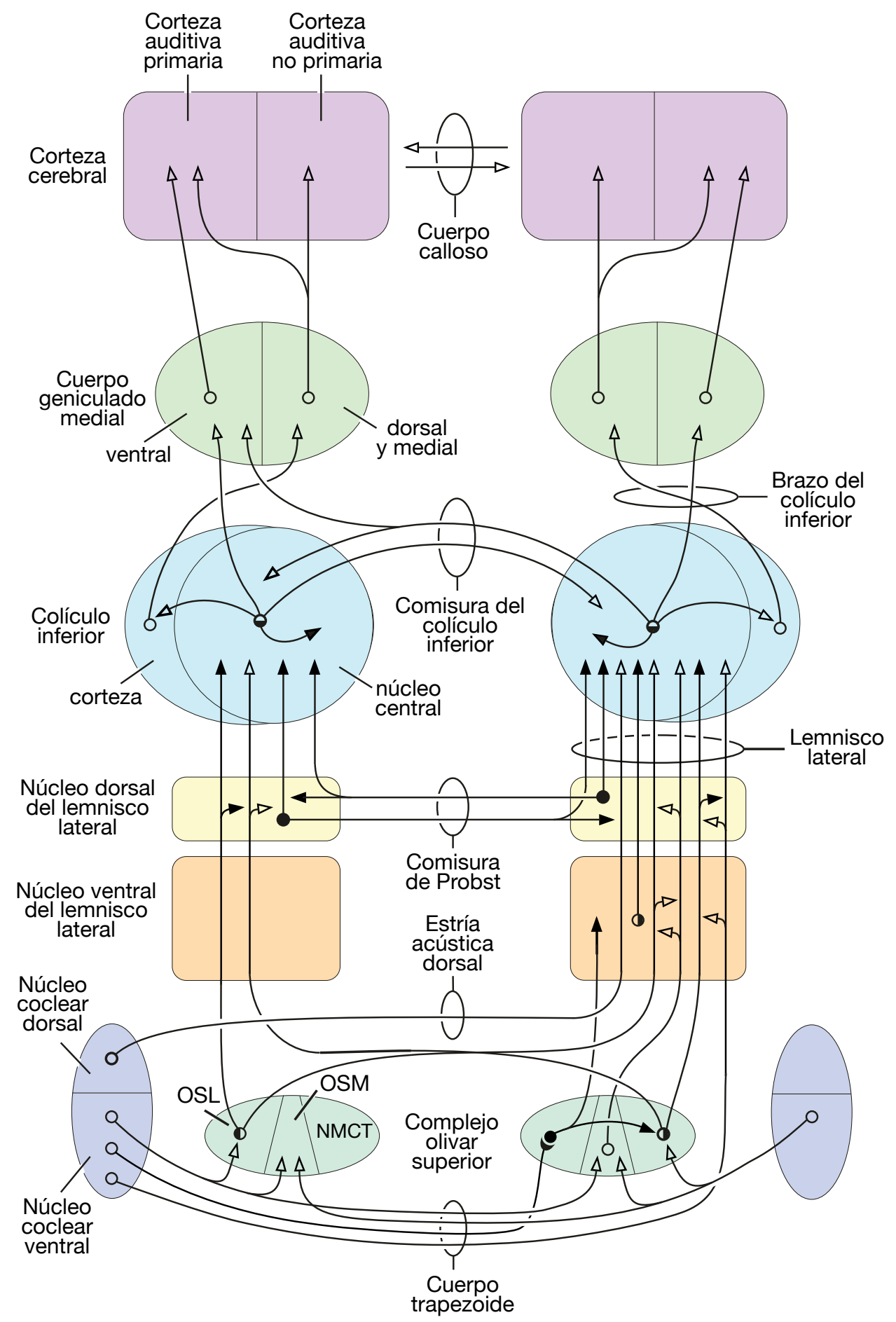

Figura 11. Esquema de la organización de la vía auditiva ascendente del cerebro de los mamíferos. El esquema incluye únicamente los principales núcleos auditivos e ilustra el camino seguido por la información auditiva que llega al oído izquierdo. A fin de reflejar la convergencia de la información biauricular que tiene lugar en la oliva superior medial (OSM), se ha incluido también la proyección del núcleo coclear ventral derecho al COS de ambos lados. Cada proyección se ha representado con un círculo en el núcleo de origen y una flecha en el núcleo de llegada (con la excepción de los cálices del Held del núcleo medial del cuerpo trapezoide [NMCT], que abrazan al soma de la neurona postsináptica). Los círculos huecos indican proyecciones excitadoras y los círculos negros, proyecciones inhibidoras (glicinérgicas o GABAérgicas). En el caso de proyecciones mixtas, el círculo aparece dividido en dos mitades, una hueca y la otra negra. Esquema elaborado por Enrique Saldaña. 
En los siguientes párrafos describimos sucintamente la organización tonotópica de los núcleos auditivos del cerebro de los mamíferos más relevantes para nuestro propósito. Para cada uno de ellos, se citan únicamente las investigaciones funcionales pioneras que desvelaron su tonotopía y aquellos artículos que se consideran de especial utilidad. Para los fines de nuestro estudio, resultan particularmente interesantes los trabajos generales de la organización tonotópica de los núcleos auditivos de la rata o del jerbo llevados a cabo por Ryan y cols. (1982), Müller (1990) y Friauf (1992).

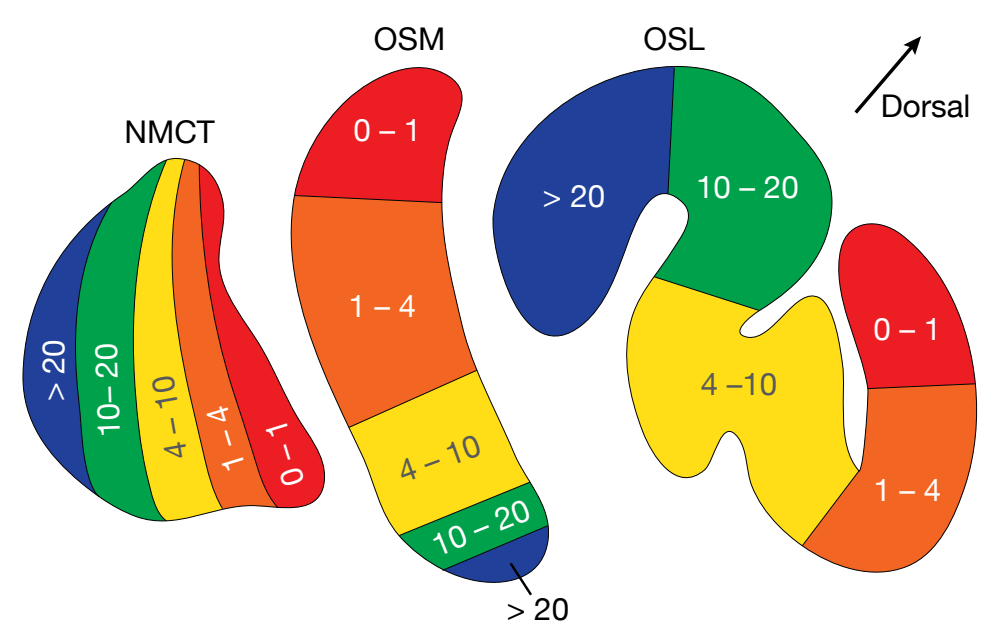

Figura 12. Representación esquemática de la organización tonotópica de la OSL, la OSM y el NMCT del lado derecho del gato, elaborada a partir de registros electrofisiológicos de la actividad de neuronas en respuesta a la estimulación con tonos puros. Cada núcleo se ha dividido en una serie de regiones cuyas neuronas son sensibles al rango de frecuencias indicado en la figura. El código de colores permite comparar qué regiones de los distintos núcleos son sensibles a cada rango de frecuencias. Ilustración elaborada a partir de la figura 21 de Guinan y cols. (1972).

En cada una de las divisiones de los NCo (anteroventral [NCoAV], posteroventral [NCoPV] y dorsal [NCoD]), las neuronas sensibles a los sonidos graves y las sensibles a los sonidos agudos se sitúan, respectivamente, en las regiones ventral y dorsal (Rose y cols., 1959; Evans y Nelson, 1973; Goldberg y Brownell, 1973; Woolfy Ryan, 1985 [jerbo]; Yajima y Hayashi, 1989 [rata]; Kaltenbach y Lazor, 1991). Dentro de la OSM, se observa un claro gradiente dorsoventral de frecuencias crecientes (Fig. 12; ver también Goldberg y Brown, 1968, 1969; Guinan y cols., 1972; Inbody y Feng, 1981 [rata]; Müller, 1990 [jerbo]; Yin y Chan, 1990). En la OSL, las neuronas que procesan los sonidos más graves se encuentran en el extremo lateral del núcleo, y las neuronas sensibles a sonidos cada vez más agudos ocupan posiciones progresivamente más mediales (Fig. 12; ver también Tsuchitani y Boudreau, 1966; Guinan y cols., 1972; Sanes y cols., 1989 [jerbo]; Sommer y cols., 1993 [rata]). Este mismo orden lateromedial de frecuencias progresivamente más altas es compartido por otros núcleos del COS, como el núcleo medial de cuerpo trapezoide (NMCT) (Fig. 18; Guinan y cols., 1972; Sommer y cols., 1993 [rata]; Kopp-Scheinpflug y cols., 2002 [jerbo]), el núcleo parolivar superior (NPS) (Dehmel y cols., 2002 [jerbo]; Kulesza y cols., 2003 [rata]) y el núcleo ventral del cuerpo trapezoide (NVCT) (Friauf, 1992 [rata]). Por último, en el núcleo central del $\mathrm{Cl}(\mathrm{NCCl})$, las neuronas que responden a los sonidos más graves y a los más agudos 
se disponen, respectivamente, en las láminas fibrodendríticas más dorsolaterales y las más ventromediales (Rose y cols., 1966; Clopton y Winfield, 1973 [rata]; Kitzes, 1984 [jerbo]; Kelly y cols., 1991 [rata]; Malmierca y cols., 2008 [rata]).

\section{BASES MORFOFUNCIONALES DE LA DETECCIÓN DE LAS DII: LA OLIVA SUPERIOR LATERAL}

\subsection{Generalidades}

La OSL es un núcleo de estructura singular. En la mayoría de las especies posee forma de lámina dispuesta rostrocaudalmente, con su eje mayor aproximadamente horizontal, pero con diversos pliegues, a los que debe su característico aspecto plisado o fruncido (Fig. 13A). Su contorno en las secciones coronales (perpendiculares a su eje rostrocaudal) varía considerablemente de unas especies a otras: presenta una forma semejante a una " $U$ " en el ratón (Ollo y Schwartz, 1979; Darrow y cols., 2006; Hirtz y cols., 2011; 2012), el jerbo (Nordeen y cols., 1983; Helfert y Schwartz, 1987; Sanes y cols., 1990, 1992; Sanes y Siverls, 1991; Kil y cols., 1995; Schwartz y Eager, 1999; Kaiser y cols., 2011), el hámster (Sánchez-Gónzalez y cols., 2003; Jenkins y Simmons, 2006) y el cobaya (Altschuler y cols., 1983; Robertson y cols., 1987; Kumoi y cols., 1993); se parece a una "S" tumbada en la rata (Harrison e Irving, 1966; White y Warr, 1983; Osen y cols., 1984; Vetter y Mugnaini, 1992; Kreinest y cols., 2009), la chinchilla (Saint Marie y Baker, 1990; Kelley y cols., 1992; Kim y cols., 1997; Morest y cols., 1997) y el gato (Fig. 13B; ver también Cajal, 1904; Osen y cols., 1984; Glendenning y cols., 1991); y ofrece contornos aún más complejos en el hurón (Henkel y Brunso-Bechtold, 1991, 1998) y en diversos murciélagos (Kuwabara y Zook, 1992; Vater, 1995; Winer y cols., 1995). La Fig. 13 ilustra la organización tridimensional y la citoarquitectura básica de la OSL del gato.

\subsection{Tipos neuronales}

En la OSL se han descrito diversos tipos neuronales morfológicamente distintos, cuyo número varía de unas especias a otras, e incluso de unos estudios a otros (p. ej., Helfert y Schwartz, 1986 [gato], 1987 [jerbo]; Majorossy y Kiss, 1990 [gato]; Sanes y cols., 1990 [jerbo]; Henkel y BrunsoBechtold, 1991 [hurón]; Rietzel y Friauf, 1998 [rata]). No obstante, el tipo más abundante, que puede representar al menos el $75 \%$ de las neuronas, son las denominadas neuronas principales de la OSL. Se trata de neuronas bipolares o fusiformes que poseen campos dendríticos aplanados y orientados rostrocaudalmente y perpendicularmente con respecto al contorno del núcleo (Fig. 13; ver también Cant, 1984; Sanes y cols., 1990; Rietzel y Friauf, 1998).

Las neuronas principales de la OSL se reparten entre las que inervan al Cl ipsolateral (Cli), y las que inervan al Cl contralateral (Clc) (Henkel y Brunso-Bechtold, 1993, 1998; Brunso-Bechtold y cols., 1994; Moore y cols., 1995; Kelly y cols., 1998; Loftus y cols., 2004; Cant y Benson, 2006; Kelly y cols., 2009; para referencias anteriores, ver Henkel y Brunso-Bechtold, 1993). Aunque las neuronas de la OSL de proyección directa y las de proyección cruzada son muy similares morfológicamente, difieren en algunos aspectos fundamentales. Por una parte, las neuronas que inervan al Clc son 
A

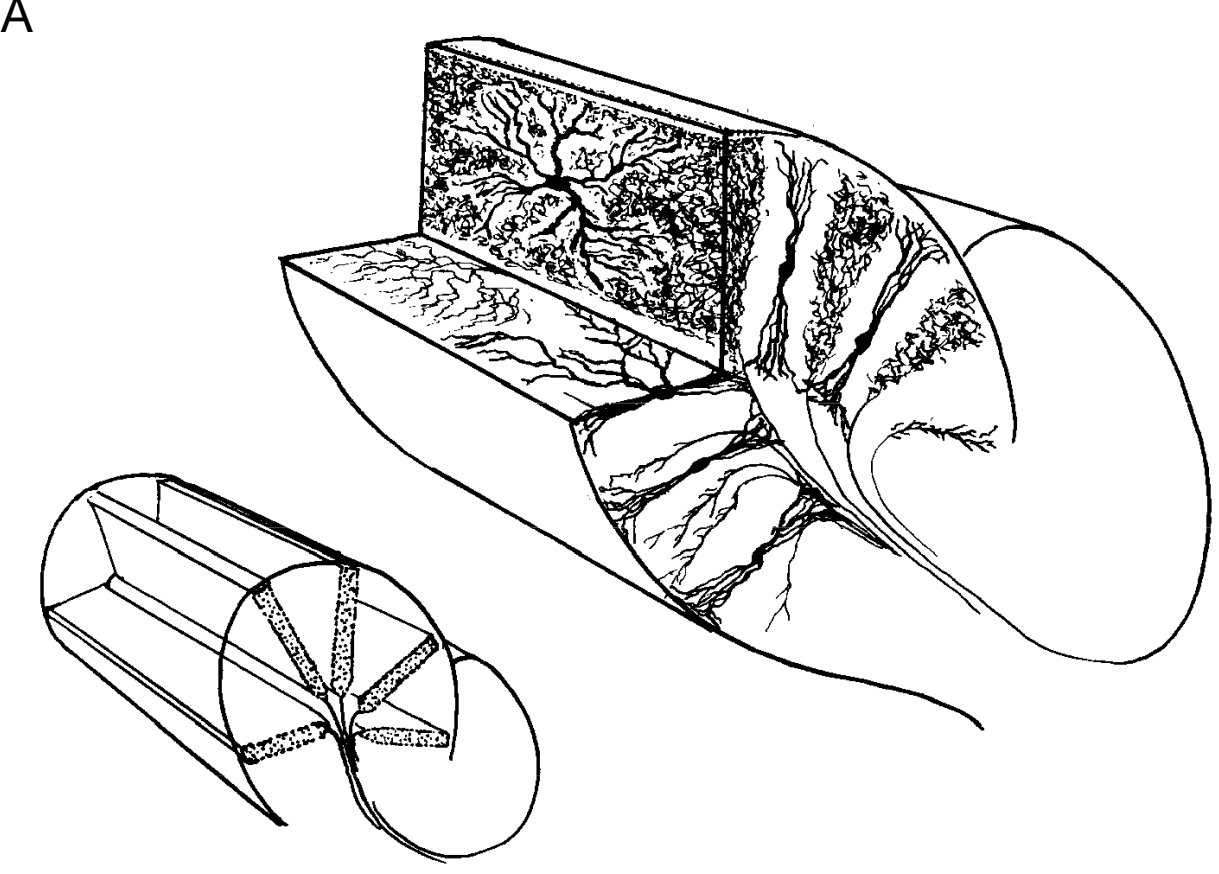

B

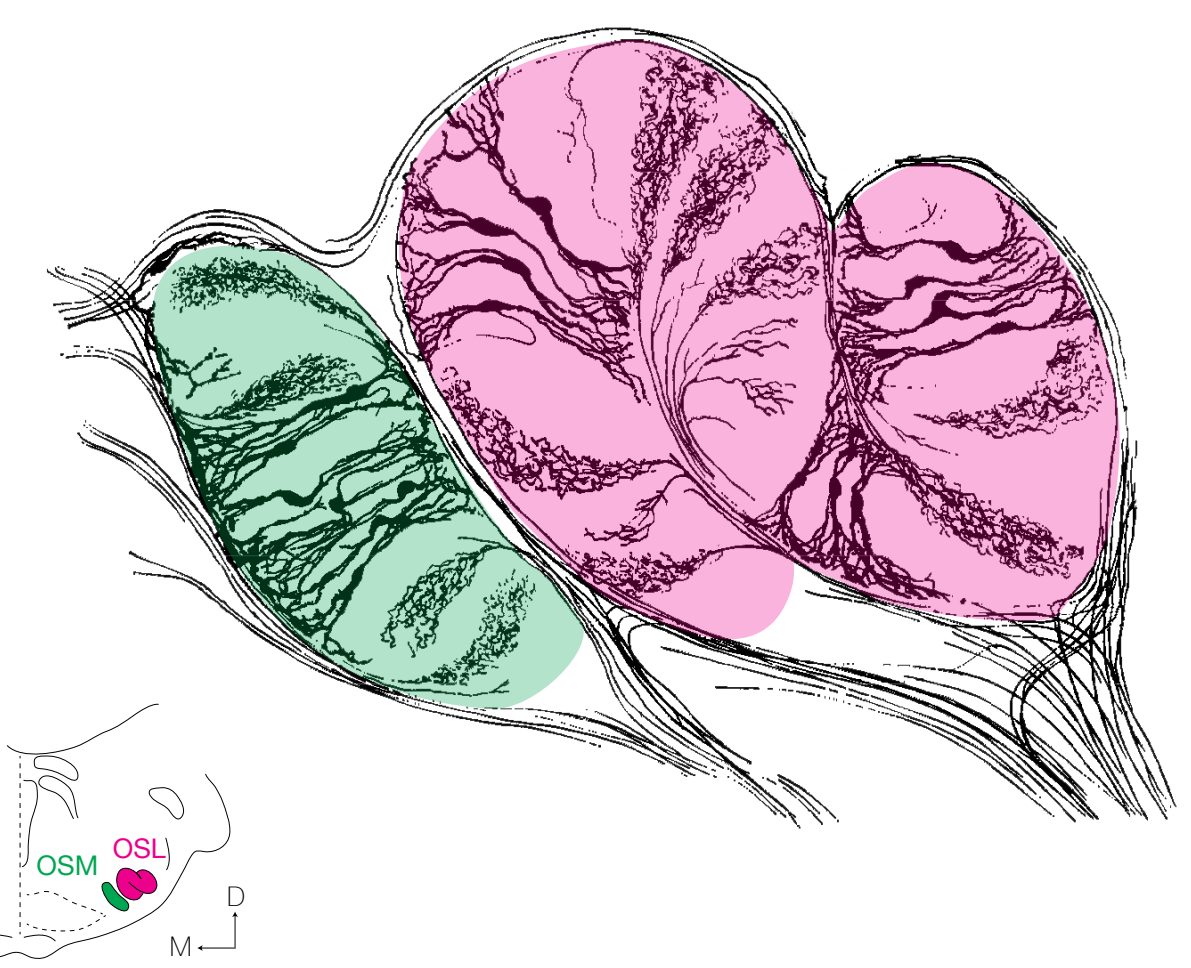

Figura 13. (A) Representación esquemática de la organización tridimensional de la OSL del gato. Tanto las neuronas del núcleo como los campos terminales de los axones aferentes son aplanados y se disponen perpendicularmente al contorno del núcleo para formar láminas que recorren toda la extensión rostrocaudal de la OSL. Ilustración basada en la figura 4 de Scheibel y Scheibel (1974). (B) Dibujo de una sección coronal ideal del COS del gato en la que se ha resaltado la OSL en rosa y la OSM en verde. En ambos núcleos se han dibujado tanto ejemplos representativos del tipo neuronal característico, como ejemplos de axones terminales que inervan al núcleo, tal como se ven en secciones impregnadas con el método de Golgi. En este plano de corte, las neuronas de la OSL y las de la OSM tienen aspecto fusiforme con dos troncos dendríticos opositopolares. El esquema del ángulo inferior izquierdo muestra la posición de la OSM y OSL en una sección coronal. Ilustración basada en la figura 1 de Scheibel y Scheibel (1974). 
excitadoras, mientras que las que inervan al Cli son en su mayoría glicinérgicas y, por lo tanto, inhibidoras (Saint Marie y cols., 1989; Saint Marie y Baker, 1990; Glendenning y cols., 1992; Oliver $y$ cols., 1995; Fredrich y cols., 2009). Por otra, durante el desarrollo embrionario las neuronas de proyección cruzada nacen antes que las de proyección directa (Kudo y cols., 1996).

En los roedores, pero no en los carnívoros, se encuentran dentro de la OSL las neuronas olivococleares laterales, que forman parte del sistema eferente a través del cual el sistema nervioso central modula la función de la cóclea (White y Warr, 1983 [rata]; Aschoff y Ostwald, 1988 [rata, cobaya]; Vetter y Mugnaini, 1992 [rata]; Cantos y cols., 2000 [rata]; Horvath y cols., 2000 [rata]; Sánchez-Gánzalez y cols., 2003 [hámster]). Su forma y orientación son similares a las de las neuronas principales (Vetter y Mugnaini, 1992), pero constituyen una población neuroquímicamente heterogénea (Vetter y cols., 1991 [rata]).

\subsection{Aferencias}

La clave de la detección de las DII radica en que las neuronas principales de la OSL son excitadas por los sonidos que llegan al oído ipsolateral, e inhibidas por los que alcanzan el oído contralateral. La estimulación ipsolateral procede del NCoAV ipsolateral (NCoAVi), y la inhibición llega del NMCT ipsolateral (NMCTi), que a su vez es excitado por el NCoV contralateral (NCoVc) (Fig. 14).

La proyección del NCoAV a la OSL fue descrita inicialmente con técnicas de degeneración (Stotler, 1953 [gato]; Powell y Cowan, 1962 [gato]; Harrison e Irving, 1966 [rata]; Warr, 1966 [gato]; Goldberg y Brown, 1968 [perro]; Harrison y Feldman, 1970 [rata]; Strominger y Strominger, 1971 [mono Rhesus]) y posteriormente confirmada con métodos de trazado fisiológico (Glendenning y

\section{Diferencia interauricular de intensidad}

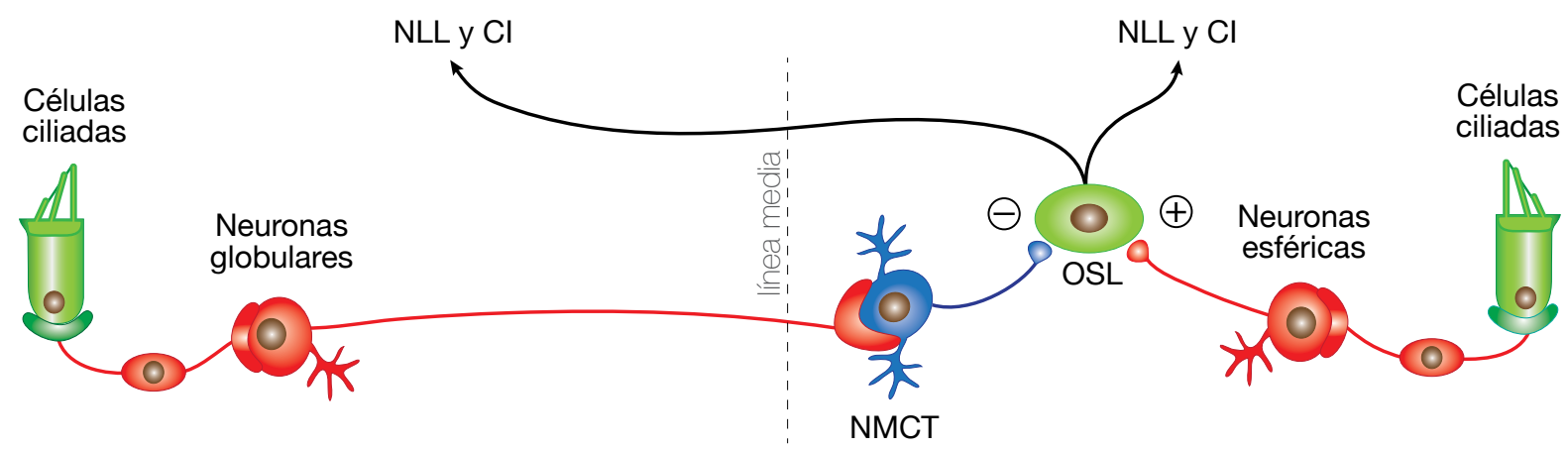

Figura 14. Esquema del circuito nervioso básico para la detección de las DII en la OSL. La información acústica transducida por las células ciliadas internas es transmitida por las neuronas del ganglio espiral a los diversos tipos neuronales de los $\mathrm{NCo}$, incluidas las neuronas globulares y las neuronas esféricas del NCoV. Cada neurona de la OSL es excitada directamente por neuronas esféricas de su mismo lado, y es inhibida por neuronas del NMCT, que a su vez son excitadas por neuronas globulares contralaterales. De esta manera en la OSL a la actividad procedente del oído ipsolateral se le resta la actividad que llega del oído contralateral. Por su parte las neuronas de la OSL envían la información procesada a los NLL y al CI de ambos lados. Ilustración basada en la figura 5 de Brugge (2013). 
cols., 1985 [gato]; Shneiderman y Henkel, 1985 [gato]; Zook y Casseday, 1985 [murciélago bigotudo]; Cant y Casseday, 1986 [gato]; Casseday y cols., 1988 [murciélago de herradura]; Friauf y Ostwald, 1988 [rata]; Robertson y Winter, 1988 [cobaya]; Müller, 1990 [jerbo]; Vater y Feng, 1990 [murciélago de herradura]; Cant, 1991 [gato]; Smith y cols., 1993 [gato]; Grothe y cols., 1994 [murciélago mejicano Tadarida brasiliensis]). Esta proyección está formada fundamentalmente por el axón de neuronas esféricas.

Las neuronas esféricas del NCoAV se denominan así por la forma de su soma (Osen, 1969a, b). Suelen poseer una o dos dendritas relativamente gruesas y lisas que a corta distancia del soma explotan en un ramillete de ramas cortas y sin espinas, que les proporcionan un típico aspecto de arbusto (Brawer y cols., 1974; Cant y Morest, 1979a; Tolbert y cols., 1982; Rouiller y Ryugo, 1984; Saldaña y cols., 1987; Gómez-Nieto y Rubio, 2009). Cada neurona esférica es inervada por uno o dos bulbos de Held, grandes especializaciones caliciformes de las fibras del nervio coclear que abrazan el soma, con el que establecen múltiples contactos sinápticos (Brawer y Morest, 1975; Cant y Morest, 1979b; Sento y Ryugo, 1989; Ryugo y Sento, 1991). Esto garantiza que la actividad de las fibras del nervio coclear, con toda su información temporal, se transmite fielmente a las neuronas esféricas (Blackburn y Sachs, 1989; Joris y Smith, 2008; Englitz y cols., 2009; Dehmel y cols., 2010; Kuenzel y cols., 2011). Por eso, en los histogramas de respuesta en función del tiempo, las neuronas esféricas muestran un "patrón pseudoprimario", muy parecido al de las fibras del nervio coclear (Rhode y Smith, 1986; Blackburn y Sachs, 1990; Smith y cols., 1993; Young y Sachs, 2008; Roos y May, 2012). Las neuronas esféricas se encuentran repartidas exclusivamente por

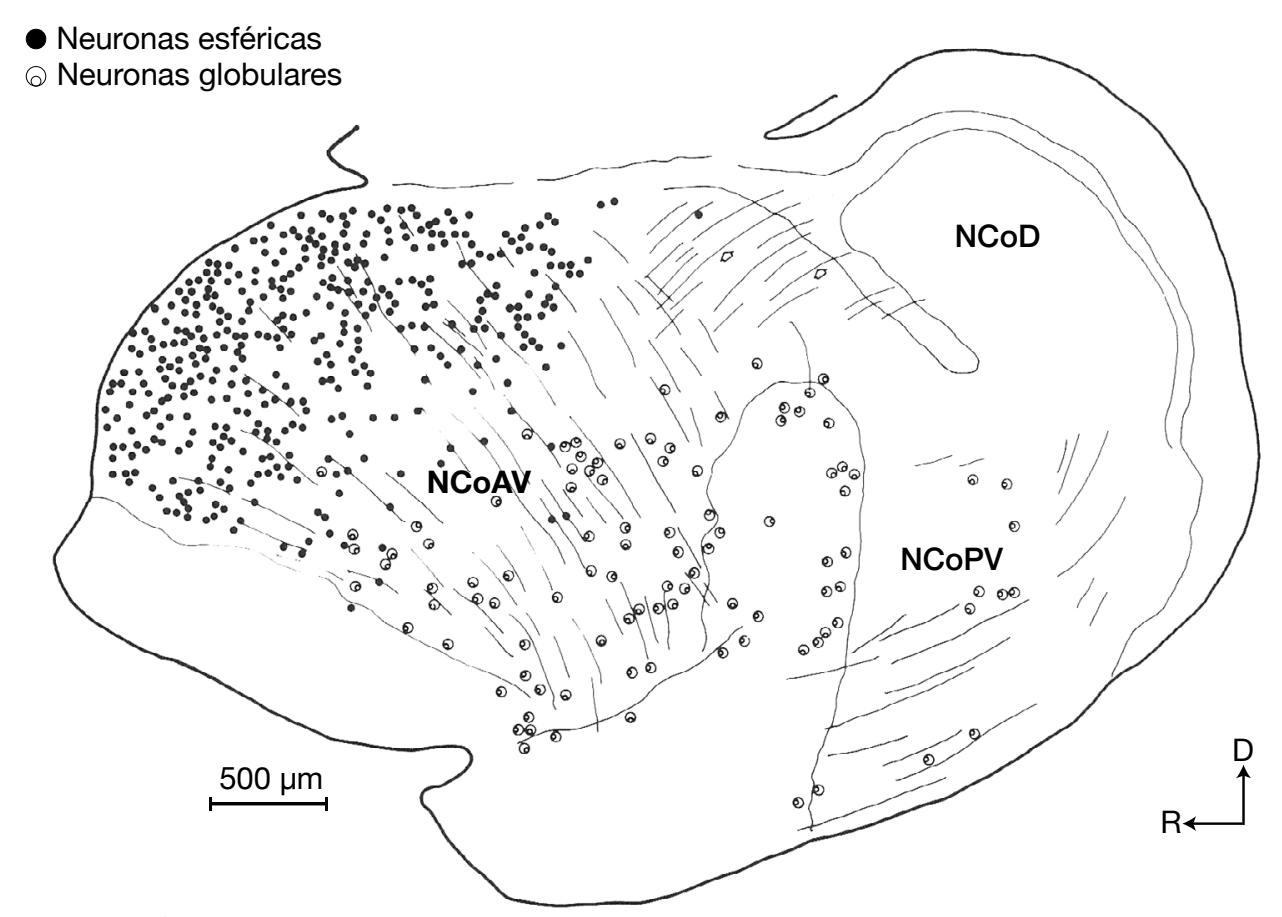

Figura 15. Dibujo de una sección parasagital de los NCo del gato teñida con el método de Nissl. Cada punto negro indica la posición de una neurona esférica, y cada circunferencia con un pequeño círculo excéntrico señala la posición de una neurona globular. Mientras que las neuronas esféricas ocupan la mitad rostral del NCoAV, las globulares se reparten por la mitad caudal del NCoAV y la mitad rostral del NCoPV. Ilustración basada en la figura 2 de Cant (1991). 
el NCoAV (Fig. 15; ver también Glendenning y cols., 1985; Shneiderman y Henkel, 1985; Cant y Casseday, 1986; Casseday y cols., 1988). Son células glutamatérgicas (Glendenning y cols., 1991) y sus botones sinápticos terminan sobre todo en las dendritas distales de las neuronas de la OSL (Cant, 1984; Zook y DiCaprio, 1988; Helfert y cols., 1992).

También la proyección del NMCT a la OSL de su mismo lado se describió inicialmente en estudios de degeneración anterógrada (van Noort, 1969 [gato]; Browner y Webster, 1975 [rata canguro]) y se confirmó después ampliamente con trazadores neuroanatómicos (Glendenning y cols., 1985; Shneiderman y Henkel, 1985 [gato]; Spangler y cols., 1985 [gato]; Henkel y Gabriele, 1999 [hurón]). Además, la proximidad entre el NMCT y la OSL ha posibilitado el estudio de sus relaciones mediante la inyección intracelular de trazadores en el NMCT, bien in vitro (Zook

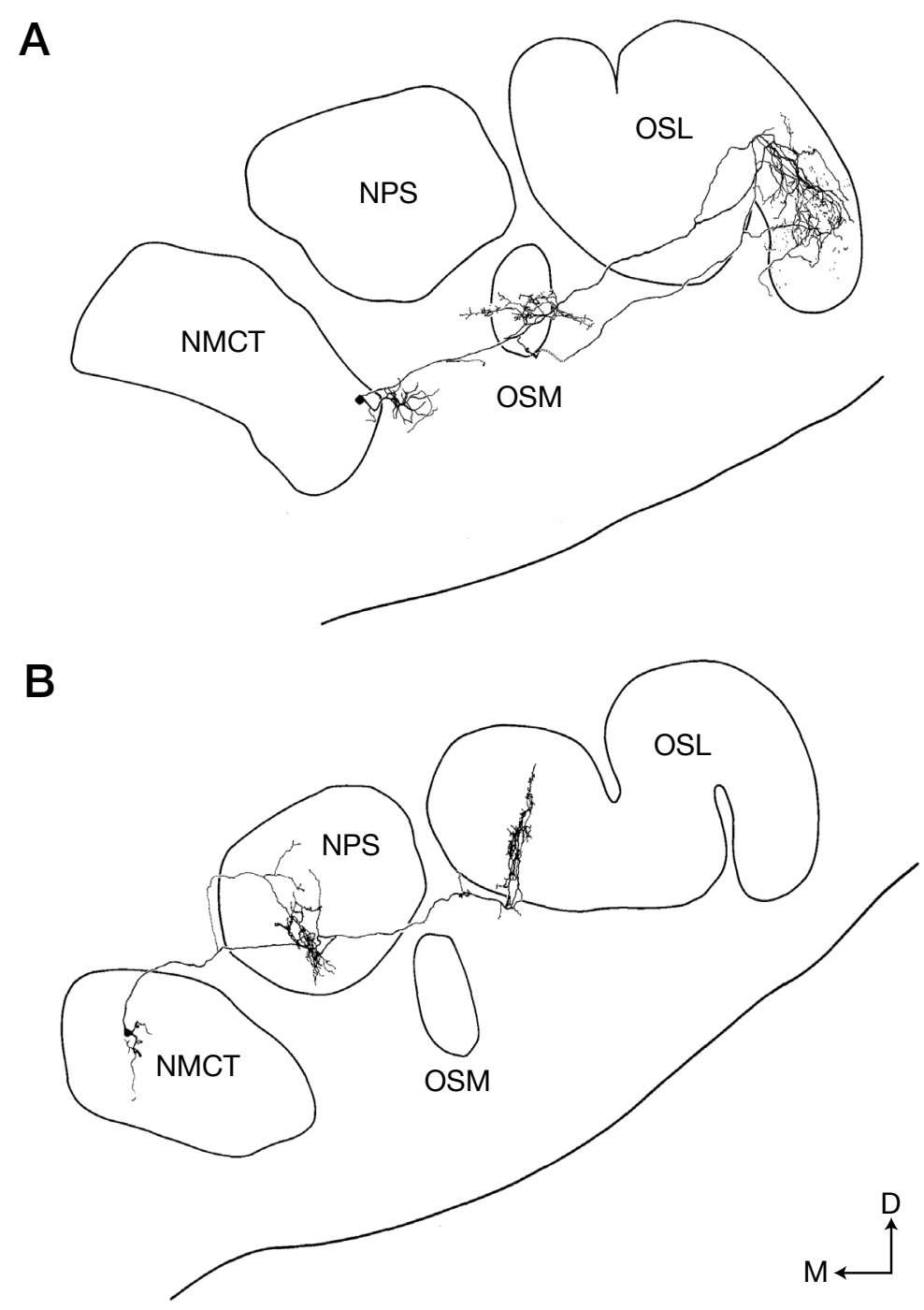

Figura 16. Dibujos de cámara clara de sendas neuronas del NMCT de la rata que fueron estudiadas electrofisiológicamente en rodajas coronales y posteriormente marcadas con neurobiotina inyectada intracelularmente, lo que permitió observar sus árboles dendríticos y buena parte de su axón. (A) La neurona se encuentra en la porción ventrolateral del NMCT inerva a la OSM y a la mitad ventral del limbo lateral de la OSL. (B) La neurona cuyo soma reside en la mitad medial del NMCT inerva a la mitad medial NPS y a la limbo medial de la OSL. El campo terminal de la OSL es muy estrecho y perpendicular al contorno del núcleo. Ilustración basada en las figuras $2 \mathrm{~A}$ y $3 \mathrm{~A}$ de Banks y Smith (1992). 
y DiCaprio, 1988 [murciélago moreno]; Kuwabara y Zook, 1991, 1992 [ratón, jerbo, murciélago bigotudo y murciélago moreno]; Sanes y Siverls, 1991 [jerbo]; Banks y Smith, 1992[rata]), o bien in vivo (Sommer y cols., 1993) [rata]; Smith y cols., 1998 [gato]).

Las neuronas principales del NMCT, que son el tipo celular característico de este núcleo, suelen poseer soma esférico y entre una y cuatro dendritas relativamente gruesas y lisas, que a cierta distancia del soma se dividen en varias ramas distales de disposición variable, por lo común delgadas y desprovistas de espinas (Morest, 1968b; Ollo y Schwartz, 1979; Kuwabara y Zook, 1991; Schofield y Cant, 1991; Banks y Smith, 1992; Sommer y cols., 1993; Smith y cols., 1998). La inyección intracelular de trazadores ha demostrado que todas las neuronas principales del NMCT inervan a la OSL de su mismo lado, y que sus axones forman campos terminales estrechos y perpendiculares al contorno del núcleo (Fig. 16; ver también Zook y DiCaprio, 1988; Kuwabara y cols., 1991; Sanes y Siverls, 1991; Banks y Smith, 1992; Kuwabara y Zook, 1992; Sommer y cols., 1993; Smith y cols., 1998; Hirtz y cols., 2012; Clause y cols., 2014). Estos mismos estudios han revelado que, además de a la OSL, las neuronas principales del NMCT pueden inervar, entre otros blancos, a la OSM (Fig. 16A), al NPS (Fig. 16B) y al núcleo ventral del lemnisco lateral. Las neuronas principales del NMCT son glicinérgicas (Wenthold y cols., 1987; Helfert $y$ cols., 1989; Adams y Mugnaini, 1990; Bledsoe y cols., 1990; Henkel y Brunso-Bechtold, 1995) y sus botones sinápticos actúan preferentemente sobre el soma y las dendritas proximales de las neuronas de la OSL (Cant, 1984; Brunso-Bechtold y cols., 1994; Smith y cols., 1998), inhibiéndolas poderosamente (Moore y Caspary, 1983; Wu y Kelly, 1992).

La proyección del NCoV al NMCT contralateral (NMCTc) está formada por los axones de neuronas globulares. Estas deben su nombre a la forma del soma (Osen, 1969a, b) y sus árboles dendríticos arbustiformes son muy similares a los de las neuronas esféricas (Smith y Rhode, 1987; Friaufy Ostwald, 1988; Lauer y cols., 2013). Las neuronas globulares se encuentran en las porciones más caudales del NCoAV y en las porciones más rostrales del NCoPV, de modo que su territorio de distribución se solapa muy poco con el de las neuronas esféricas (Fig. 15). Cada neurona globular es inervada por varias fibras del nervio coclear (Rhode y Smith, 1986; Spirou y cols., 2005), que con frecuencia forman bulbos de Held modificados que establecen múltiples contactos sinápticos con el soma de la neurona globular (Smith y Rhode, 1987; Reddy cols., 2000; Ryugo y cols., 2006). Por este motivo, igual que sucedía con las neuronas esféricas, las neuronas globulares reciben una copia bastante fiel de la actividad de las fibras del nervio coclear (Carney, 1990; Guinan y Li, 1990; Smith y cols., 1998; Paolini y cols., 2001; Trussell, 2002) y en los histogramas de respuesta en función del tiempo muestran un "patrón pseudoprimario con muesca" (Rhode y Smith, 1986; Smith y Rhode, 1987; Spirou y cols., 1990; Smith y cols., 1991; Paolini y cols., 2001; Rhode, 2008; Kopp-Scheinpflug y cols., 2011). El axón de las neuronas globulares es relativamente grueso y cruza la línea media por la porción ventral del cuerpo trapezoide. En el NMCT de lado opuesto cada axón da lugar a un cáliz de Held que rodea al soma de una neurona principal (Fig. 17A) y que constituye la especialización sináptica más grande de todo el sistema nervioso central (Cajal, 1904; Morest, 1968a; Kuwabara y cols., 1991; Smith y cols., 1991; Sätzler y cols., 2002; Schneggenburger y Forsythe, 2006; Grande y Wang, 2011). Cada cáliz establece numerosas uniones sinápticas glutamatérgicas con el soma de la neurona principal (Fig. 17B; ver 
también Barnes-Davies y Forsythe, 1995; Sätzler y cols., 2002; Lauer y cols., 2013), lo que garantiza que cada potencial de acción de la neurona globular se transmita con precisión a la neurona principal postsináptica (Paolini y cols., 2001; Rhode, 2008; Kopp-Scheinpflug y cols., 2008, 2011).

De los datos anteriores se desprende que cada neurona de la OSL recibe información temporalmente muy precisa de los dos oídos: es excitada por los impulsos procedentes del oído ipsolateral (gracias a la proyección directa de la neuronas esféricas del NCoAVi) e inhibida por los impulsos procedentes del oído contralateral (gracias a la inhibición glicinérgica ejercida por las neuronas principales del NMCT, que a su vez son excitadas por neuronas globulares del $\mathrm{NCoV})$.

Además de las proyecciones de las neuronas esféricas del NCoAV y de las neuronas principales del NMCT, la OSL puede recibir otras proyecciones de menor importancia. Con técnicas de trazado se ha puesto de manifiesto una proyección del NCoPV ipsolateral (NCoPVi) (Friaufy Ostwald, 1988 [rata]; Thompson y Thompson, 1987, 1991 [cobaya]; Thompson, 1998 [gato]; Grothe y cols., 1994 [murciélago mejicano Tadarida brasiliensis]; Doucet y Ryugo, 2003 [rata]; Darrow y cols., 2012 [ratón]; Gómez-Nieto y cols., 2014 [rata]). En los roedores, esta proyección parte de neuronas multipolares planas, cuyo axón envía una colateral al NCoD (Figura 18; Doucet y Ryugo, 1997, 2003, 2006 [rata]; Darrow y cols., 2012 [ratón]). También con trazadores anterógrados se ha

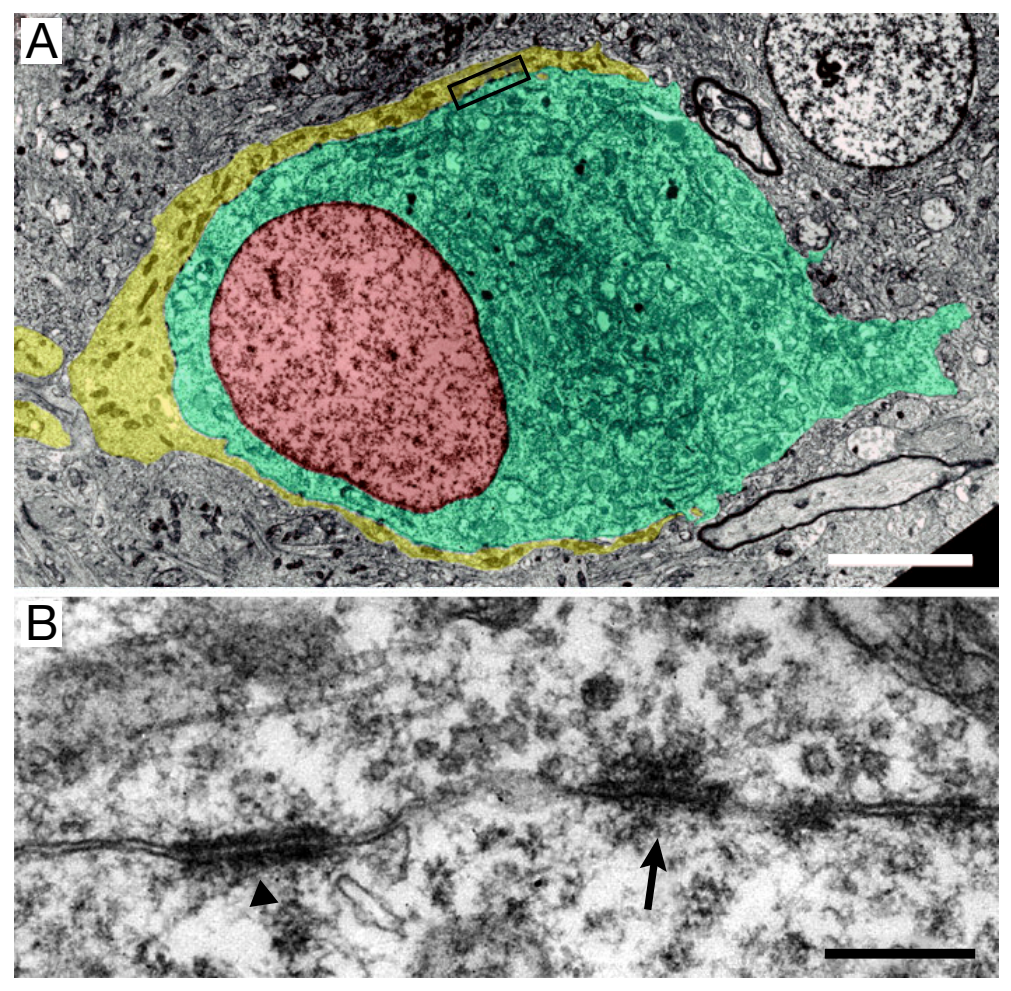

Figura 17. (A) Microfotografía electrónica del soma de una neurona principal del NMCT de la rata y del cáliz de Held que lo abraza. El soma se ha resaltado en verde, el cáliz en amarillo, y el núcleo de la neurona en rojo. La barra de aumento equivale a $5 \mu \mathrm{m}$. (B) Detalle del área enmarcada en la parte superior de A, que ilustra la relación entre el cáliz de Held y su neurona postsináptica. La flecha señala una zona activa, y la punta de flecha indica una unión adherente o de anclaje. La barra de aumento equivale a 0,3 $\mu \mathrm{m}$. Imágenes tomadas de la figura 2 de Sätzler y cols. (2002). 
descubierto una proyección del NVCT contralateral (NVCTc) a la OSL (Warr y Beck, 1996; GómezNieto y cols., 2008), aunque se desconoce qué tipo neuronal la origina. Además, algunos autores han descrito que la OSL es inervada directamente por neuronas globulares del NCoV ipsolateral (NCoVi) (Friauf y Ostwald, 1988; Kuwabara y Zook, 1991; Smith y cols., 1991), si bien este punto es objeto de debate (Cant y Benson, 2003). También es motivo de discrepancia la lateralidad de la proyección del NCoV a la OSL: mientras que en la mayoría de los estudios esta proyección se describe como estrictamente ipsolateral (Friaufy Ostwald, 1988; Kuwabara y cols., 1991; Doucet y Ryugo, 2003; Darrow $y$ cols., 2012), algunos autores han descrito un cierto componente bilateral (Goldberg y Brown, 1969; Warr, 1972; Glendenning y cols., 1985; Zook y Leake, 1989), que parece ser especialmente denso en el jerbo (Müller, 1990; Kil y cols., 1995; Russell y Moore, 1995).

\subsection{Eferencias}

Como dijimos más arriba, la mayoría de las neuronas de la OSL inervan al Cli o al Clc. Son muy pocas las neuronas con proyecciones bilaterales. Dentro del $\mathrm{Cl}$ sus axones forman campos terminales laminares en la mitad ventral del núcleo central que se disponen paralelos a las conocidas láminas fibrodendríticas del núcleo (Shneiderman y Henkel, 1987 [gato]; Oliver y cols., 1997 [gato]; Oliver, 2000 [gato]; Loftus y cols., 2004 [gato]; Cant, 2013 [jerbo]). En el gato se ha descrito que las proyecciones ascendente de la OSL son ligeramente asimétricas: en ambos $\mathrm{Cl}$ los axones forman plexos laminares estrechos separados por franjas de anchura similar a la de los plexos; sin embargo, la posición de los plexos marcados en el Cli parece corresponder a la de los huecos que quedan entre los plexos del lado contralateral y viceversa (Shneiderman y Henkel, 1987). Este patrón no se ha confirmado en otras especies.

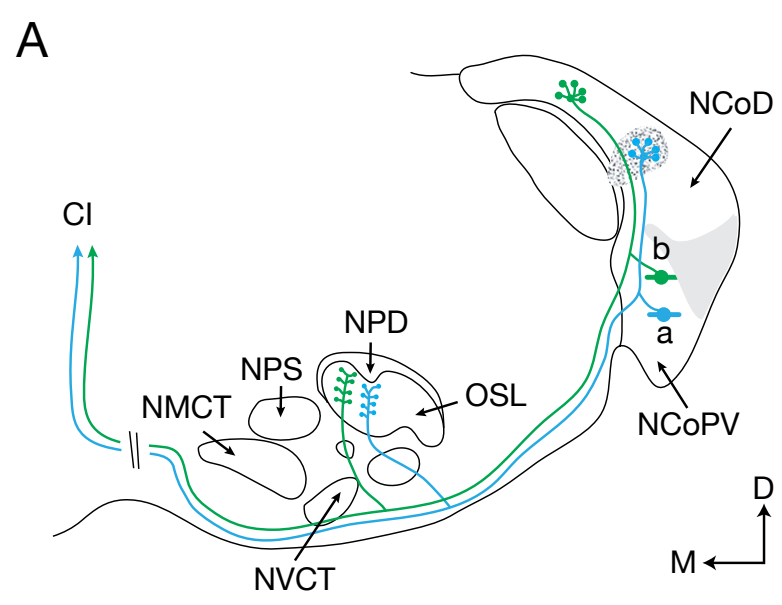

B

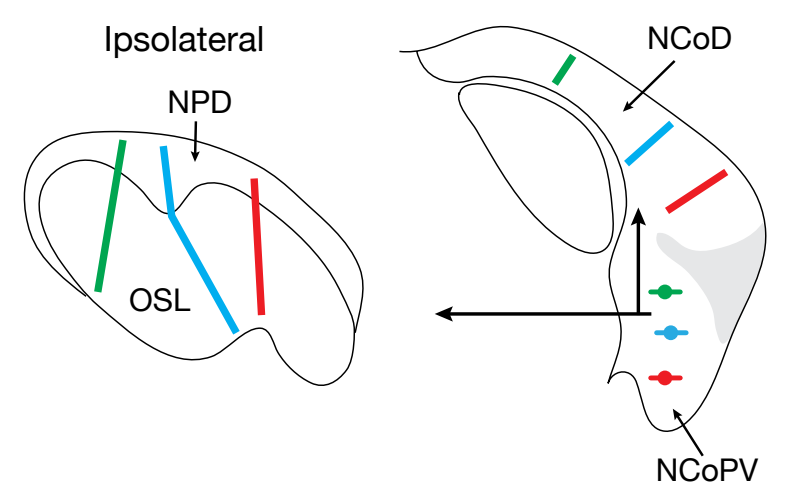

Figura 18. (A) Representación esquemática de las proyecciones de la neuronas multipolares planas del NCoPV de la rata. Cada una de estas neuronas envía una rama colateral para el $\mathrm{NCoD}$ y otra para la OSL ipsolateral (OSLi) antes de continuar su camino hacia el CIc. Una buena forma de marcar selectivamente la proyección de las multipolares planas a la OSL es inyectar en el NCoD un trazador bidireccional como el dextrano biotinado (BDA). Ilustración basada en la figura 7D de Doucet y Ryugo (2003). (B) Relación entre la organización tonotópica de las neuronas multipolares planas del NCoPV y la de los núcleos inervados por ella (el NCoD y la OSL). Cada color representa una neurona multipolar plana y el territorio del $\mathrm{NCoD}$ y la OSL inervado por ella. Ilustración basada en la figura 8 de Doucet y Ryugo (2003). 


\subsection{Fisiología}

Antes de que se hubieran identificado las principales aferencias que recibe la OSL, los registros extracelulares de la actividad de neuronas del núcleo permitieron relacionarlo con la detección de las DII (Galambos y cols., 1959; Boudreau y Tsuchitani, 1968). Esta hipótesis se basó en el hecho de que las neuronas de la OSL responden vivamente a la estimulación del oído ipsolateral, pero esta actividad se reduce progresivamente a medida que se aumenta la intensidad de los estímulos acústicos aplicados al oído contralateral (Caird y Klinke, 1983; Sanes y Rubel, 1988; Joris y Yin, 1995; Park y cols., 1997; Tollin y Yin, 2002). Con registros intracelulares in vivo o in vitro se ha comprobado que la estimulación ipsolateral y la estimulación contralateral generan, respectivamente, potenciales postsinápticos excitadores y potenciales postsinápticos inhibidores (Caspary y Faingold, 1989; Finlayson y Caspary, 1989; Sanes, 1990; Wu y Kelly, 1992). Se dice, por ello, que las neuronas de la OSL poseen un patrón de respuesta biauricular "IE" (inhibición contralateral y excitación ipsolateral). La figura 19 muestra cómo la actividad de una neurona de la OSL cambia en función de la DII.

Para que las neuronas de la OSL puedan codificar eficazmente las DII, es necesario que el impulso excitador ipsolateral y el impulso inhibidor contralateral les lleguen simultáneamente. Esto plantea una dificultad geométrica, porque obviamente el oído y los NCoVi están más cerca

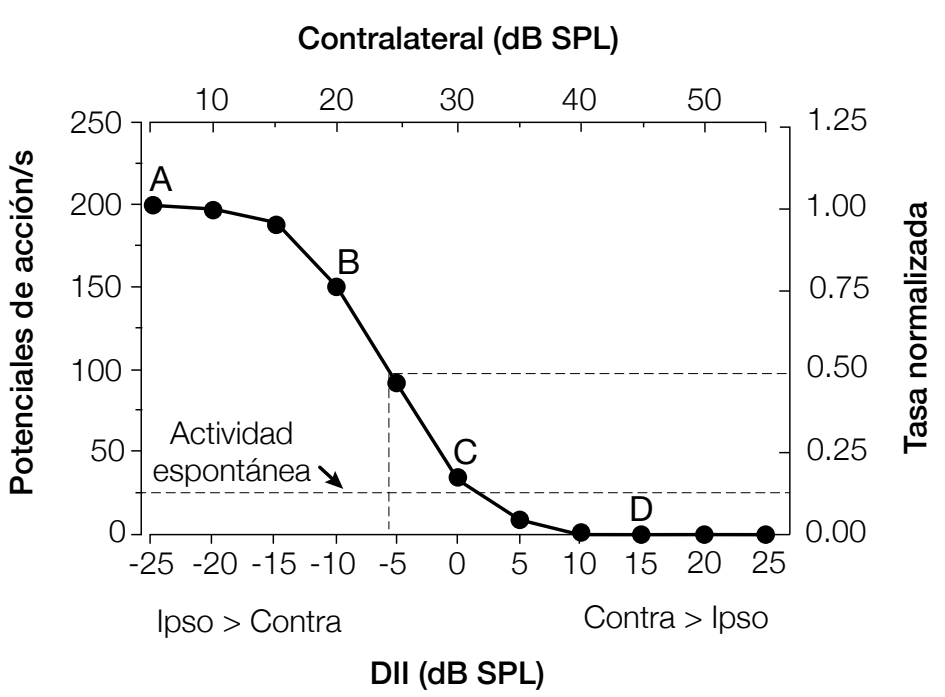

Figura 19. Patrón de respuesta de una neurona de la OSL del gato en función de la DII. Para obtener la curva, se estimuló el oído ipsolateral a la OSL con un sonido de intensidad constante (30 dB SPL) y se fue cambiando la intensidad del estímulo aplicado al oído contralateral. La abscisa superior indica la intensidad del sonido contralateral y la abscisa inferior refleja la diferencia entre la intensidad del sonido contralateral y la del ipsolateral, de modo que los valores negativos denotan que el sonido ipsolateral fue más intenso. En el eje de ordenadas izquierdo se representa la actividad en potenciales de acción por segundo, y en el eje derecho, la tasa normalizada de actividad. Las neuronas de la OSL muestran su actividad máxima cuando el estímulo ipsolateral es más intenso que el contralateral (es decir, cuando hay una DII a favor del oído ipsolateral). A medida que se iguala la intensidad de los dos estímulos, disminuye la actividad de la neurona y cuando la intensidad contralateral es mayor que la ipsolateral, la actividad neuronal disminuye hasta niveles menores incluso que la actividad espontánea (que aparece representada por la línea horizontal discontinua próxima al eje de abscisas inferior). Ilustración basada en la figura 1E de Tollin y Yin (2002). 
de la OSL que los contralaterales. Sin embargo, la diferencia en la distancia se ve compensada por el distinto calibre de los axones que intervienen en el circuito, ya que el axón de las neuronas esféricas es aproximadamente tres veces más delgado que el de las globulares, y dos veces más delgado que el de las neuronas principales del NMCT (Joris y Yin, 1998). Además, mientras que las sinapsis excitadoras se encuentran sobre todo en las dendritas distales de las neuronas de la OSL, las sinapsis inhibidoras suelen ser axosomáticas o axodendríticas muy proximales (Cant, 1984; Helfert y cols., 1992; Smith y cols., 1998). Estas diferencias en la velocidad de conducción y en el lugar de la neurona de la OSL en el que terminan las vías ipsolaterales y las contralaterales hacen que habitualmente los impulsos inhibidores lleguen sólo unos $200 \mu$ s después que los excitadores.

\section{BASES MORFOFUNCIONALES DE LA DETECCIÓN DE LAS DIT: LA OLIVA SUPERIOR MEDIAL}

\subsection{Generalidades}

En la mayor parte de los mamíferos, la OSM es un núcleo con forma de lámina vertical que recorre rostrocaudalmente el COS. En las secciones coronales aparece como una estrecha columna más o menos vertical de neuronas dispuestas a modo de empalizada, y que se encuentra entre la OSL, que queda por fuera, y el NMCT y NPS, más mediales. La OSM está especialmente bien desarrollada en las especies sensibles a los sonidos graves, como el gato (Scheibel y Scheibel, 1974; Kiss y Majorossy, 1983; Yin y Chan, 1990), el jerbo (Russell y Moore, 1999; Rautenberg y cols., 2009; Mylius y cols., 2013) y el hombre (Moore, 1987; Nara y cols., 1994; Kulesza, 2007, 2014), y es proporcionalmente más pequeña en las especies que oyen sobre todo sonidos de frecuencia muy alta (Ollo y Schwartz, 1979 [ratón]; Rogowski y Feng, 1981 [rata]; Schofield y Cant, 1991 [cobaya]).

\subsection{Tipos neuronales}

Igual que en la OSL, en la OSM se han descrito diversos tipos neuronales, que difieren en su forma, posición y orientación. No obstante, el tipo característico, directamente implicado en la codificación de las DIT, son las neuronas que constituyen la columna central del núcleo (Cajal, 1904; Schwartz, 1977 [gato]; Feng y Rogowski, 1980; Rogowski y Feng, 1981 [rata]; Kiss y Majorossy, 1983 [gato]; Henkel y Brunso-Bechtold, 1990 [hurón]; Smith, 1995 [cobaya]; Russell y Moore, 1999 [jerbo]; Kapfer y cols., 2002 [jerbo, rata y zarigüeya]; Chirila y cols., 2007 [jerbo]; Kulesza, 2007 [hombre]; Rautenberg y cols., 2009 [jerbo]). Se trata de neuronas que en secciones coronales aparecen fusiformes o bipolares, con campos dendríticos aplanados y de disposición aproximadamente horizontal (Fig. 20). De los extremos del soma parten sendas dendritas primarias, una dirigida medialmente y la otra, lateralmente. Las dendritas son relativamente gruesas y muy poco ramificadas salvo en su porción más distal. El axón puede nacer del soma o de una dendrita proximal. 


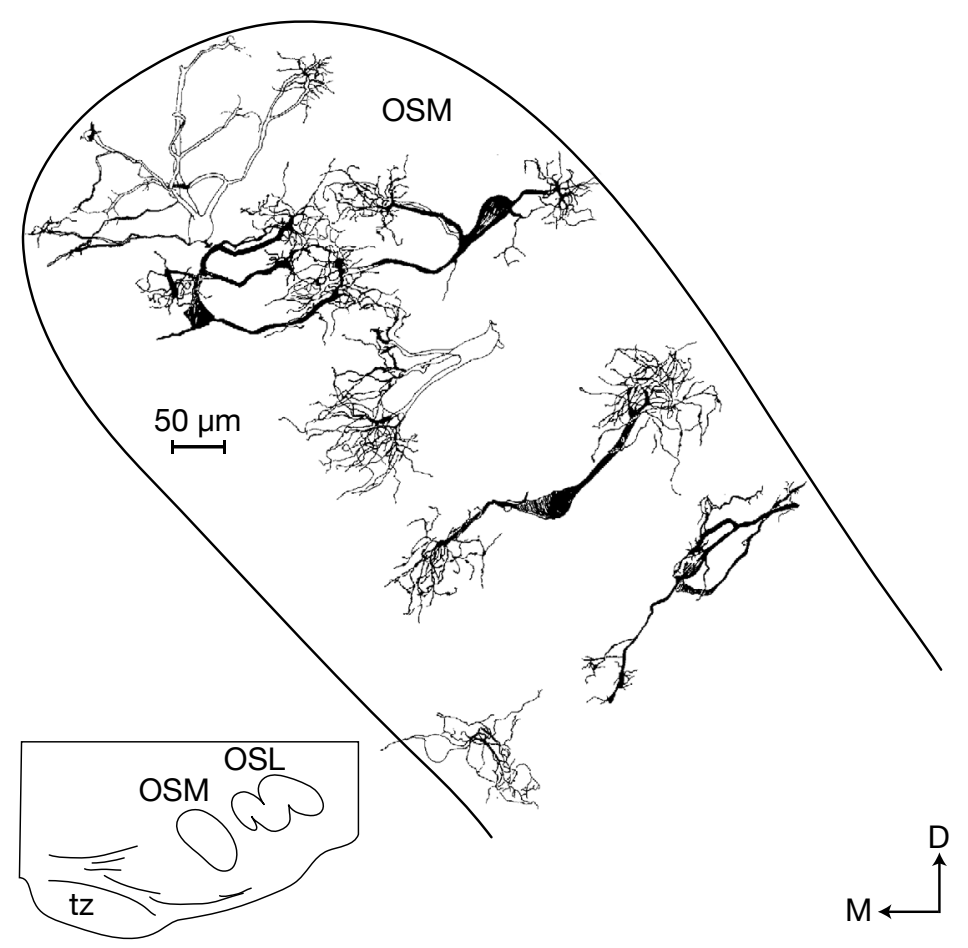

Figura 20. Dibujos de cámara clara de neuronas de la OSM derecha del hurón impregnadas con el método de Golgi. Aunque su forma varía, las neuronas más típicas poseen soma fusiforme y sendas dendritas medial y lateral que presentan un tupido ramillete distal de ramas delgadas o filiformes. Ilustración basada en la figura 2 de Henkel y Brunso-Bechtold (1990).

\subsection{Aferencias}

Las neuronas de la OSM reciben proyecciones excitadoras y proyecciones inhibidoras (Fig. 21). La excitación procede de las neuronas esféricas del NCoAV de ambos lados, que son las mismas que inervan a la OSL (Glendenning y cols., 1985; Shneiderman y Henkel, 1985), y su efecto excitador se ha comprobado con registros intracelulares (Smith, 1995; Scott y cols., 2005; Chirila $y$ cols., 2007). Las dendritas laterales son inervadas por las neuronas esféricas ipsolaterales, y las dendritas mediales reciben sinapsis del axón de las neuronas esféricas contralaterales (Stotler, 1953; Harrison e Irving, 1966; Warr, 1966; Perkins, 1973; Lindsey, 1975; Russell y Moore, 1999, 2002). Mediante la reconstrucción de axones individuales se ha comprobado que una misma neurona esférica inerva tanto a la OSM ipsolateral (OSMi), como a la OSM contraletaral (OSMc) (Smith y cols., 1993; Beckius y cols., 1999; Karino y cols., 2011). Como cabía esperar, los botones sinápticos que inervan a las dendritas mediales de la OSMc poseen las características morfológicas habitualmente asociadas con las sinapsis excitadoras (Lindsey, 1975; Smith y cols., 1993; Kil y cols., 1995).

La principal fuente de inhibición de la OSM son las neuronas principales del NMCT (Smith y cols., 2000; Lohrke y cols., 2005; Magnusson y cols., 2005; Kandler y cols., 2009), que, como dijimos más arriba, inervan también a la OSL y son claramente glicinérgicas. En el jerbo la mayoría de los botones sinápticos glicinérgicos inervan al soma y la porción más proximal de las dendritas de la OSM (Kapfer y cols., 2002; Werthat y cols., 2008; Couchman y cols., 2010; Hassfurth y cols., 
2010), mientras que en la rata los botones glicinérgicos aparecen más repartidos por el soma y las dendritas (Kapfer y cols., 2002).

En la mayoría de los estudios de las dos últimas décadas, se menciona una segunda proyección que inhibe a la OSM y que procede del núcleo lateral del cuerpo trapezoide ipsolateral (NLCTi) (Cant y Hyson, 1992; Kuwabara y Zook, 1992; Brand y cols., 2002; Couchman y cols., 2010; Roberts y cols., 2014). Sin embargo, seguramente debido a la pequeñez del NLCT, esta proyección ha sido mucho menos explorada que la del NMCT y no se han caracterizado apenas ni las neuronas que participan en ella, ni sus propiedades funcionales (Fig 21).

\subsection{Eferencias}

La inmensa mayoría, si no todas las neuronas de la OSM inervan al Cli (Adams, 1979; BrunsoBechtold y cols., 1981; Henkel y Spangler, 1983; Aitkin y Schuck, 1985; Saint Marie y Baker, 1990; Kelly y cols., 1998). Sus axones ascienden por el lemnisco lateral y emiten ramas colaterales para el núcleo dorsal del lemnisco lateral (Henkel, 1997). Dentro del Cl los axones de la OSM forman un denso campo terminal que ocupa la porción dorsolateral del núcleo central, donde se procesan los sonidos más graves (Henkel y Spangler, 1983; Oliver y cols., 2003; Cant, 2013). Por lo tanto, la distribución de los axones de la OSM dentro del $\mathrm{Cl}$ es mucho más restringida que la de los axones de la OSL. Las neuronas de la OSM son glutamatérgicas y sus axones poseen botones con vesículas redondeadas claras y que establecen sinapsis asimétricas con las neuronas del Cl (Oliver y cols., 1995; Oliver, 2000).

\section{Diferencia interauricular de tiempo}

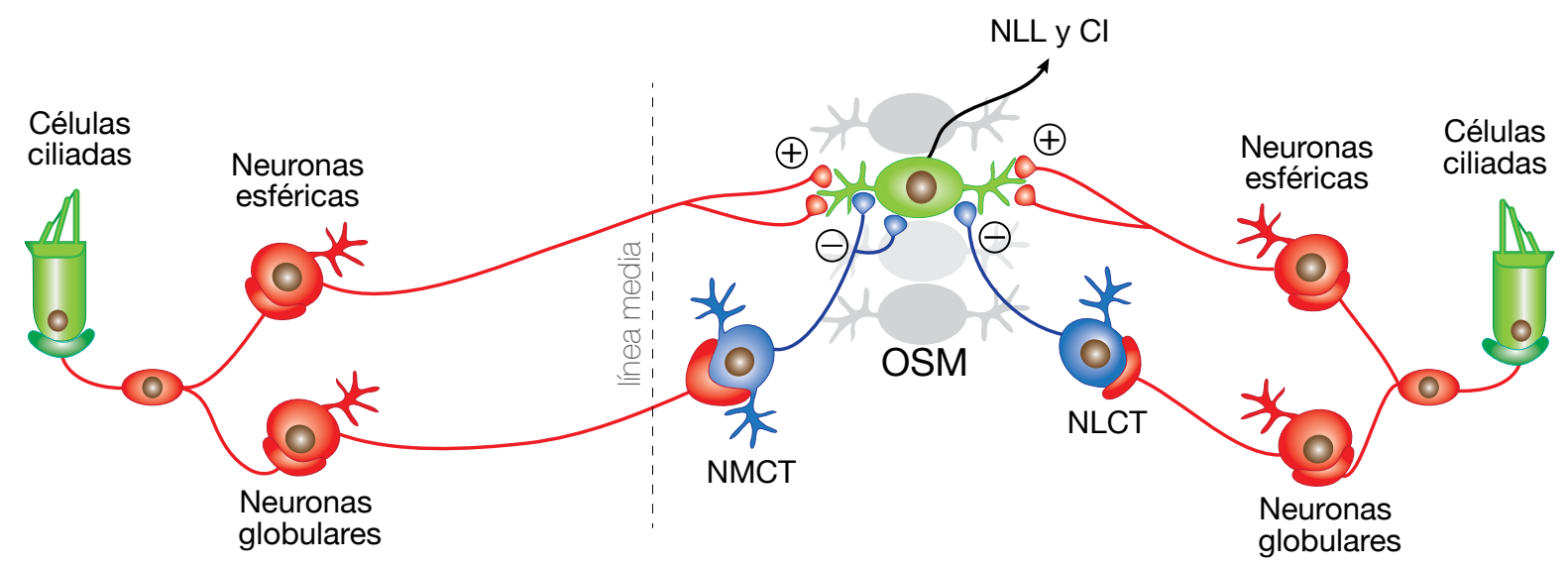

Figura 21. Esquema del circuito nervioso básico para la detección de las DIT en la OSM. La información acústica transducida por las células ciliadas internas es transmitida por las neuronas del ganglio espiral a los diversos tipos neuronales de los NCo, incluidas las neuronas globulares y las neuronas esféricas del NCoV. Cada neurona de la OSM es excitada directamente por neuronas esféricas de ambos lados: las dendritas lateral y medial de la neurona de la OSM son inervadas, respectivamente, por neuronas esféricas ipsolaterales y por neuronas esféricas contralaterales. Además, cada neurona de la OSM es inhibida por neuronas del NMCT ipsolateral, que a su vez son excitadas por neuronas globulares contralaterales, y por neuronas del NLCTi, presumiblemente excitadas por neuronas globulares ipsolaterales. Por su parte las neuronas de la OSM envían la información procesada a los NLL y al CI de su mismo lado. Ilustración basada en la figura 5 de Brugge (2013). 


\subsection{Fisiología}

Detectar las DIT requiere tal grado de finura, que bien podría tratarse de la función temporalmente más precisa de cuantas se llevan a cabo en el sistema nervioso central de los vertebrados (Skottun, 1998; Carr y MacLeod, 2010; Grothe y cols., 2010). Las neuronas de la OSM son sensibles a la excitación procedente de cada uno de los dos oídos, pero se excitan de forma máxima con la estimulación biauricular adecuada (Yin y Chan, 1990), por lo que se dice que poseen un patrón de respuesta biauricular "EE" (excitación contralateral y excitación ipsolateral). Si se estimula un animal experimental con un estímulo biauricular en el que se cambia sistemáticamente la DIT, se comprueba que cada neurona de la OSM responde de manera máxima cuando los estímulos llegan con una determinada DIT o, más correctamente, con una determinada DIF. A este valor se le suele denominar "retraso característico" de la neurona. Si la neurona responde de manera máxima ante ese retraso característico, es porque con ese estímulo concreto los impulsos de las neuronas esféricas ipsolaterales y contralaterales que la inervan, que transmiten una información temporalmente precisa, llegan a la vez, es decir, en fase. De esto se desprende que cada neurona de la OSM actúa como un "detector de coincidencia", pues se activa cuando los impulsos ipsolaterales y los impulsos contralaterales coinciden en el tiempo.
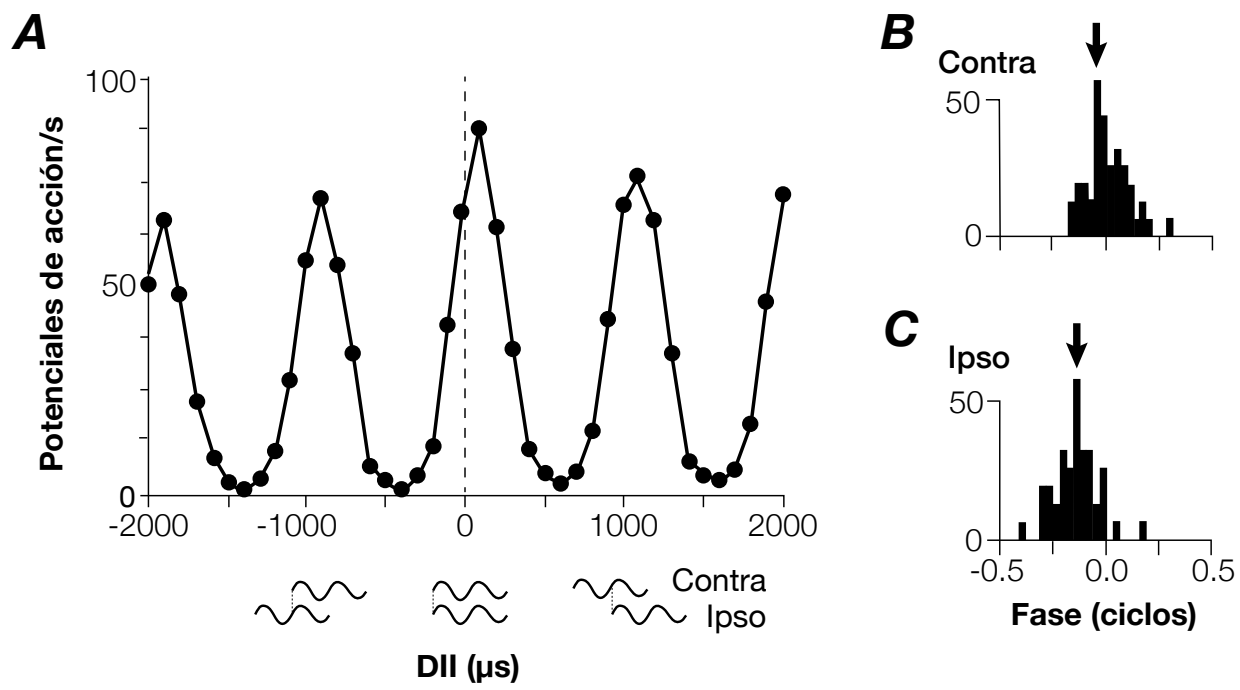

Figura 22. (A) Sensibilidad de una neurona de la OSM del gato a las DIT. En el eje de ordenadas se ha representado la actividad neuronal en potenciales de acción por segundo. El eje de abscisas indica la DIT: los valores negativos (situados a la izquierda del 0), señalan que el sonido ipsolateral precedió al contralateral, y los valores positivos, lo contrario. El estímulo utilizado poseía una frecuencia de $1000 \mathrm{~Hz}$, a la que le corresponde un período de $1 \mathrm{~ms}$; por esta razón, el patrón de respuesta parece repetirse cada vez que la DIT aumenta o disminuye $1 \mathrm{~ms}$, lo que demuestra que la neurona es sensible a la DIF. Los histogramas de la derecha muestran cómo la misma neurona responde de forma máxima en determinada fase del ciclo sonoro cuando se estimula al animal sólo a través del oído contralateral (B) o sólo a través del ipsolateral (C). El desfase entre la respuesta ipsolateral y la contralateral es de 0,14 ciclos, que equivalen a unos $140 \mu \mathrm{s}$. Por ello, la respuesta de la neurona es máxima cuando la DIT es de $140 \mu \mathrm{s}$, ó $1140 \mu \mathrm{s}$, o $2140 \mu \mathrm{s}$, (o para DIT negativas, de $-860 \mu$ s ó $-1860 \mu$ s). Ilustración basada en la figura 4.5 de Yin (2002), elaborada a partir de datos de Yin y Chan (1990). 
El papel de las neuronas de la OSM como detectores de coincidencia plantea un interesante problema biológico: ¿Cómo se las arregla el sistema auditivo para que, siendo estimulado antes un oído que el otro, los impulsos procedentes del oído ipsolateral y los del oído contralateral lleguen a la neurona a la vez? Pongamos un ejemplo: La neurona cuya respuesta se muestra en la figura 22 se encuentra en la OSM derecha de un gato y su retraso característico es de $140 \mu \mathrm{m}$, lo que quiere decir que esta neurona se activa de manera máxima cuando el animal oye un sonido procedente del hemiespacio izquierdo y que llega con un ángulo que genera una DIT de 140 us (por convención, al retraso o DIT le asignamos un valor positivo cuando el sonido llega antes al oído contralateral, y un valor negativo cuando llega antes al ipsolateral). El camino que siguen los impulsos de uno y otro lado es similar, porque intervienen los mismos tipos neuronales, pero hay una diferencia fundamental: la distancia que separa a la OSM derecha del NCoAV izquierdo es considerablemente mayor que la que la separa del NCoAV derecho. Para que la neurona de la OSM se active, basta con que el tiempo de conducción del impulso izquierdo sea $140 \mu$ s mayor que el del oído izquierdo, pues con eso se compensaría la DIT y ambos impulsos llegarían a la neurona a la vez. Dicho en otras palabras, en nuestro ejemplo la circuitería de la OSM genera un "retraso interno (RI)" equivalente a la DIT, de manera que ambos valores se anulan. Podríamos representarlo como una ecuación simple, que debe cumplir el siguiente requisito:

$$
D I T-R I=0
$$

Aunque el ejemplo que acabamos de utilizar puede parecer sencillo, el problema es de una complejidad formidable porque las neuronas de la OSM en su conjunto tiene que ser capaces de codificar todas las DIT posibles para el animal, de manera que el sistema auditivo debe contener circuitos suficientes como para compensarlas todas. Además, en la OSM hay neuronas que poseen retrasos característicos negativos, es decir, que responden de manera máxima cuando el estímulo ipsolateral precede al contralateral, lo que hace que el retraso interno debido a la mayor longitud de los circuitos contralaterales se sume a la DIT.

Para explicar cómo el cerebro codifica las DIT, Lloyd A. Jeffress propuso en 1948 un modelo integrado por neuronas que actúan como detectores de coincidencia (hoy sabemos que se trata de las neuronas de la OSM, algo desconocido en 1948) y que son inervadas por axones procedentes de ambos lados cuya longitud cambia de manera sistemática (Fig. 23). Según Jeffress, es la diferente longitud de los axones ipsolaterales y contralaterales la que permite compensar las DIT, y para esta disposición acuñó el término de "líneas de retraso". El modelo de Jeffress predice que cada neurona detecta una DIT única y que dentro del núcleo las neuronas están dispuestas en orden creciente o decreciente de DIT, de manera que crean un mapa topográfico de DIT. Por lo tanto, lo que Jeffress ideó fue el sustrato ideal que permitiría convertir un código estrictamente temporal en un código espacial, basado en la posición que ocupan dentro del núcleo las neuronas responsable de codificar cada DIT.

Debido a su incuestionable elegancia, el modelo de Jeffress (1948) ha servido de estímulo para décadas de intensa investigación dedicada a comprobarlo experimentalmente. Los frutos más relevantes se han obtenido con aves, cuyo sistema auditivo se ajusta notablemente al modelo 
(Carr y Konishi, 1988, 1990; Overholt y cols., 1992; Kopply Carr, 2008; para referencias adicionales, ver las revisiones de Konishi, 2003; Ashida y Carr, 2011). En el sistema auditivo de las aves, los detectores de coincidencia son las neuronas del núcleo laminar, que poseen estructura bipolar, con unas dendritas dirigidas dorsalmente y otras, ventralmente. Estas neuronas son inervadas por las neuronas del núcleo magnocelular, cuyos axones de longitud variable crean las líneas de retraso. Más específicamente, las neuronas del núcleo magnocelular inervan a las dendritas dorsales de las neuronas el núcleo laminar de su mismo lado, y a las dendritas ventrales de las neuronas del lado opuesto. Se ha demostrado una organización similar en el sistema auditivo de ciertos reptiles (Carr y cols., 2009).

A diferencia de las aves y los reptiles, la situación en los mamíferos no es en absoluto tan clara (Joris y cols., 1998; Joris y Yin, 2007; Ashida y Carr, 2011). Los estudios electrofisiológicos no han encontrado el esperable mapa de DIT dentro de la OSM. Yin y Chan (1990) hallaron una cierta tendencia en la OSM del gato, según la cual el retraso característico de las neuronas rostrales suele ser menor que el de las neuronas caudales, pero no lo suficientemente sólida como para confirmar el modelo. Tampoco han tenido éxito los intentos de caracterizar las líneas de retraso. Mediante la reconstrucción de axones individuales de neuronas esféricas del gato, se ha visto que algunos de los axones que inervan la OSMc recorren el núcleo en sentido rostrocaudal, dejando colaterales a su paso (Smith y cols., 1993; Beckius y cols., 1999; Karino y cols., 2011), lo que parece ajustarse a la predicción original. Sin embargo, otros axones cruzados siguen trayectorias muy diferentes, y el patrón de distribución de los axones dentro de la OSMi

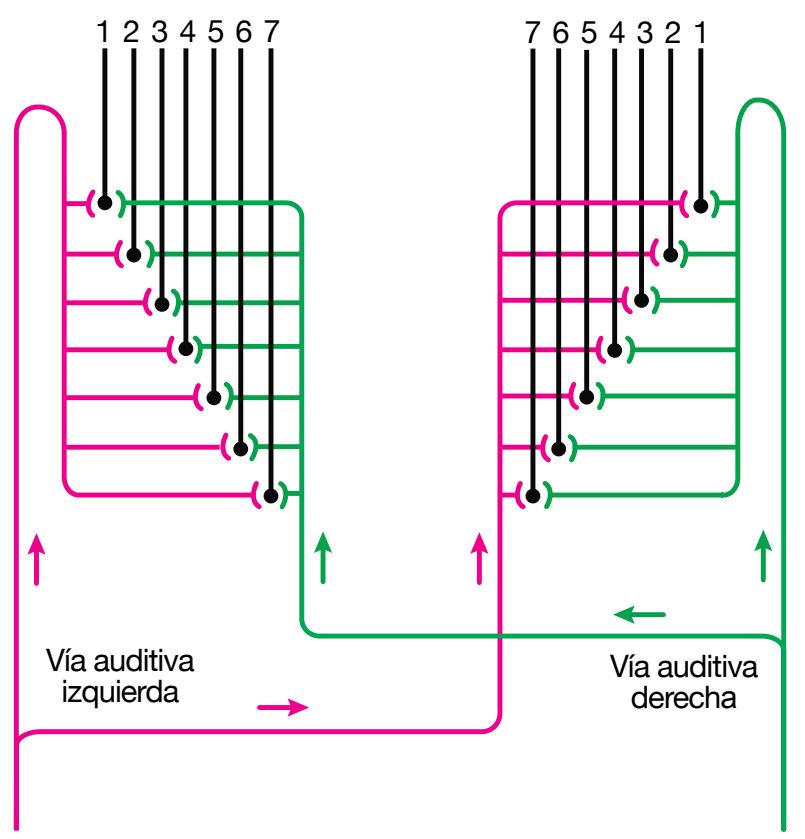

Figura 23. Esquema del modelo de Jeffress para explicar cómo la DIT puede traducirse en un mapa topográfico dentro del cerebro. La información procedente del oído izquierdo (representada en rosa) y la procedente del oído derecho (en verde) convergen en cada lado del cerebro en las neuronas que actúan como detectores de coincidencia, representadas en negro y que transmiten la información biauricular a centros superiores. Ilustración basada en la figura 1 de Jeffress (1948). Pulsando en este enlace Vídeo suplementario 1, puede verse un vídeo realizado por el grupo de Tom Yin en el que muestran cómo funciona el modelo de Jeffress. 
es aún más variado, de manera que tampoco los datos anatómicos demuestran firmemente el modelo en los mamíferos. En un estudio reciente con rodajas frescas in vitro, se comprobó que los estímulos contralaterales tardan en llegar a la OSM del jerbo aproximadamente 500 us más que los ipsolaterales (Jercog y cols., 2010), una diferencia muy superior al rango fisiológico de DIT que puede percibir esta especie y claramente incompatible con la existencia de líneas de retraso eficaces.

Dado que las líneas de retraso por sí solas no resultan satisfactorias para explicar la función de las neuronas de la OSM, se han propuesto otros mecanismos. El primero de ellos, que podría ser complementario de las líneas de retraso, tiene en cuenta que el tiempo de conducción depende no sólo de la longitud del axón, sino también de factores como el calibre del axón y la distancia entre los nódulos de Ranvier. En el pollo, las ramas del axón de las neuronas del núcleo magnocelular que inervan al núcleo laminar contralateral son más gruesas y poseen distancias internodales más largas que las ramas que inervan al ipsolateral, lo que proporciona una mayor velocidad de conducción a la proyección contralateral (Seidl y cols., 2010). Sin embargo, en el gato las ramas del axón de las neuronas esféricas que inervan a la OSMi poseen el mismo grosor que las que inervan a la OSMc (Karino y cols., 2011) y no se ha investigado si su distancia intermodal es o no igual.

Otro mecanismo propuesto para compensar las DIT tiene que ver con el hecho de que cada estímulo sonoro no excita a todas las células ciliadas de la cóclea simultáneamente, sino que genera una onda de presión que se transmite por el interior de la cóclea desde la base hasta el ápex. Por ello, las células ciliadas basales, que procesan sonidos agudos, se activan antes que las apicales, y a esta diferencia en el tiempo de activación se la denomina "retraso coclear $(R C)$ ). Se ha calculado que esta onda avanza a razón de unos $3 \mathrm{~mm} / \mathrm{ms}$, por lo que, teniendo en cuenta la longitud de la cóclea, el máximo $\mathrm{RC}$ es de unos $8 \mathrm{~ms}$ en la especie humana, de algo más de 2,5 ms en la rata, y de 1,6 ms en el ratón. Para que el RC pudiera contribuir a compensar la DIT, sería necesario que el detector de coincidencia recibiera del oído ipsolateral información de una frecuencia mayor (más basal) que la que le llega del oído contralateral, de tal manera que se cumpla que:

$$
D I T-R I-R C=0
$$

En el caso de la OSM, la hipótesis del retraso coclear implicaría un desfase tonotópico, es decir, que una misma neurona tendría que ser inervada por neuronas del NCoAVi más dorsales que las neuronas esféricas del NCoAVc que la inervan. Aunque la idea del retraso coclear ha recibido notable apoyo teórico y de modelos computacionales (Schroeder, 1977; Shamma y cols., 1989; Bonham y Lewis, 1999; Joris y cols., 2006; Day y Semple, 2011), no se ha demostrado experimentalmente, pues no hay datos fisiológicos que indiquen que una misma neurona posee distinta frecuencia característica para los estímulos ipsolaterales que para los contralaterales, ni resultados anatómicos que demuestren que la inervación de la OSM es asimétrica.

También puede contribuir a compensar las DIT la inervación glicinérgica que las neuronas de la OSM reciben del NMCT. Mediante registros extracelulares in vivo de neuronas de la OSM del jerbo, se ha demostrado que cuando se bloquea la inhibición glicinérgica microinyectando 
estricnina, aumenta el ritmo de descarga de la neurona y, mucho más interesante, su retraso característico disminuye hasta aproximarse a 0 (Figura 24; Brand y cols., 2002; Grothe, 2003; Pecka y cols., 2008). El que en ausencia de inhibición glicinérgica el retraso de las neuronas se acerque a 0 sugiere dos conclusiones importantes: por una parte indica que, por sí sola, la excitación bilateral transmite una información espacial bastante limitada; por otra, sugiere que en condiciones fisiológicas, en el caso de neuronas con retraso coclear $(\mathrm{RC})$ positivo, la inhibición contralateral (mediada por el NMCT) debe preceder a la excitación contralateral directa (Brand y cols., 2002; Grothe, 2003; Pecka y cols., 2008).

Un último mecanismo tiene en cuenta la peculiar geometría de las neuronas de la OSM y el hecho de que las sinapsis excitadoras sobre las dendritas mediales no son funcionalmente idénticas a las sinapsis excitadoras sobre las dendritas laterales. En rodajas de la OSM del jerbo estudiadas in vitro, la rampa ascendente de los potenciales postsinápticos excitadores provocados por la estimulación excitadora ipsolateral es más rápida que la de los potenciales desencadenados por los estímulos contralaterales (Jercog y cols., 2010).

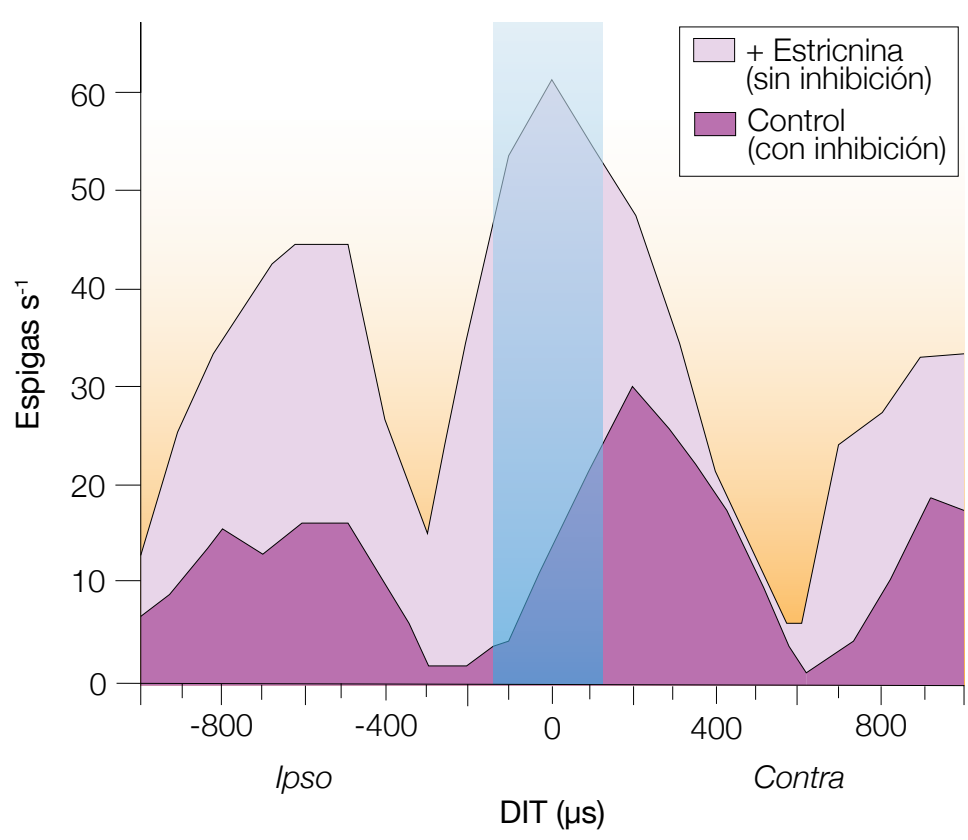

Figura 24. Papel de la inhibición glicinérgica en la detección de la DIT. Se trata de una gráfica similar a la de la figura 22A que muestra la sensibilidad de una neurona de la OSM del jerbo a las DIT. El área morada muestra la respuesta de la neurona en condiciones normales. Esta posee un retraso característico de unos $200 \mu$ s, mayor que el rango fisiológico de las DIT del jerbo (indicado por la franja azul vertical). Cuando se bloquea la inhibición glicinérgica mediante la microinyección de estricnina (área rosa), aumenta el ritmo de descarga de la neurona y su retraso característico se desplaza hacia la izquierda, hasta aproximarse a $0 \mu \mathrm{s}$. Ilustración basada en la figura 5 de Grothe (2003). 


\section{ALGUNAS PREGUNTAS PENDIENTES}

La ingente cantidad de datos expuestos hasta aquí prueba hasta qué punto la cuestión de la audición direccional ha atraído y sigue atrayendo la atención de numerosos laboratorios de todo el mundo, que se enfrentan a ella desde variadísimos puntos de vista. A pesar de ello, todavía es mucho lo que se desconoce y algunas preguntas relativamente básicas sobre el sustrato neural del procesamiento biauricular carecen de respuesta:

- Si las DIT (especialmente eficaces para los sonidos graves) se codifican en la OSM, y las DII (más útiles para los sonidos agudos) se procesan en la OSM, ¿no deberían la OSM y la OSL contener una representación de frecuencias distinta, acorde con su papel? Y si alguno de estos dos núcleos procesa todo el espectro de frecuencias audibles, ¿no podría estar integrado por regiones hodológica y funcionalmente distintas?

- Hasta ahora, las proyecciones que inervan a la OSM se han investigado sobre todo analizando axones de neuronas individuales. Sin embargo, para comprender el significado biológico de un núcleo cerebral, lo que interesa conocer es cómo se comportan las poblaciones de neuronas que intervienen en su función. ¿Cómo se distribuyen colectivamente las proyecciones que inervan a la OSM? ¿Son las proyecciones excitadoras ipsolateral y contralateral realmente simétricas? ¿Qué relación guardan las proyecciones inhibidoras con respecto a las excitadoras? ¿En qué parte de las neuronas de la OSM terminan todas estas aferencias?

- La OSM y la OSL comparten algunas aferencias con otros núcleos del COS, como el NPS, cuya función no parece estar relacionada con el procesamiento de información espacial. ¿En qué medida el mejorar el conocimiento sobre las conexiones de las dos olivas puede aportar información sobre la función del NPS?

- ¿Existen diferencias notables en la organización y las conexiones de la OSL y la OSM entre los mamíferos que, como la rata, basan su audición en las frecuencias altas, y los que, como el jerbo, oyen sobre todo frecuencias graves? 


\section{HIPÓTESIS}




\section{HIPÓTESIS:}

1. Los mecanismos que permiten detectar las diferencias interauriculares de tiempo (o de fase) y las diferencias interauriculares de intensidad podrían comprenderse mejor si se conocieran con precisión las conexiones nerviosas de los núcleos en los que se codifica la información sobre la posición de las fuentes de sonido en el plano horizontal: la oliva superior lateral (OSL) y la oliva superior medial (OSM).

2. La inyección del trazador bidireccional dextrano biotinado (BDA) en la OSL de los mamíferos debe permitir analizar los tipos neuronales que la inervan y todas las proyecciones de éstos.

3. Dado que la OSL y la OSM comparten sus principales aferencias, la inyección de BDA en la OSL debe marcar en el mismo experimento las tres principales poblaciones de axones que inervan a la OSM: axones de neuronas esféricas del núcleo coclear anteroventral ipsolateral, axones de neuronas esféricas del núcleo coclear anteroventral contralateral, y axones de neuronas del núcleo medial del cuerpo trapezoide ipsolateral.

4. Teniendo en cuenta la peculiar organización citoarquitectónica y tonotópica de la OSL, inyectando BDA en ella podremos analizar la tonotopía de los núcleos en los que residen los tipos neuronales que la inervan, así como la tonotopía de otros núcleos inervados por estos mismos tipos neuronales.

5. Los aspectos fundamentales de las conexiones del complejo olivar superior son compartidos por distintas especies de mamíferos, con independencia de su rango auditivo. 
El objetivo general de esta tesis es ampliar el conocimiento sobre la función y el significado biológico del complejo olivar superior (COS) de los mamíferos a través del análisis histológico de las principales conexiones nerviosas de los núcleos que lo integran. Este objetivo general puede desglosarse en los siguientes objetivos específicos:

1. Identificar y cuantificar los tipos neuronales que inervan a la oliva superior lateral (OSL) de la rata y analizar su morfología y distribución.

2. Analizar en un mismo experimento la distribución de las tres principales aferencias que recibe la oliva superior medial (OSM) de la rata: axones de neuronas esféricas del núcleo coclear anteroventral ipsolateral, axones de neuronas esféricas del núcleo coclear anteroventral contralateral, y axones de neuronas principales del núcleo medial del cuerpo trapezoide ipsolateral.

3. Obtener información sobre el núcleo parolivar superior de la rata, que también es inervado por neuronas que inervan a la OSL.

4. Deducir la organización tonotópica de los núcleos del COS de la rata.

5. Comprobar si las conexiones nerviosas de la OSL y la OSM del jerbo siguen los mismos principios de organización que las de la rata. 


\section{DISEÑO EXPERIMENTAL}


Esta tesis se basa en una serie de experimentos morfológicos. Para alcanzar nuestros cuatro primeros objetivos, hemos inyectado el trazador neuroanatómico bidireccional dextrano biotinado (BDA) en la oliva superior lateral (OSL) de la rata (Rattus norvegicus), una especie cuyo sistema auditivo ha sido ampliamente estudiado desde múltiples puntos de vista y en cuyo manejo nuestro grupo de investigación posee abundante experiencia. El trazador BDA reúne varias propiedades singulares:

1. Aunque frecuentemente se le ha considerado un trazador predominantemente anterógrado, el BDA suele proporcionar un excelente relleno del soma y las dendritas de las neuronas marcadas retrógradamente (Fig 25A). En cada uno de nuestros experimentos estudiamos las neuronas marcadas en el núcleo coclear anteroventral (NCoAV), el núcleo medial del cuerpo trapezoide (NMCT) y otros núcleos para clasificarlas atendiendo a sus características morfológicas, las cuantificamos y analizamos su distribución. En casos seleccionados, elaboramos reconstrucciones tridimensionales de su distribución espacial.

2. Como el BDA es un magnífico trazador anterógrado, en todos los casos hallamos abundantes axones marcados mediante el transporte genuinamente anterógrado (Fig. 25B). A esta categoría probablemente pertenecen la mayor parte de los axones marcados en los núcleos del lemnisco lateral (NLL), el colículo inferior (Cl) y el cuerpo geniculado medial de nuestros experimentos, que no han sido objeto de estudio en esta Tesis.

3. El BDA da lugar al denominado transporte colateral, a veces llamado también "falso transporte anterógrado": el trazador captado por las porciones distales de un axón es transportado en sentido retrógrado hasta que llega a una bifurcación; en ese punto, parte del trazador continúa retrógradamente hacia el soma, mientras que el resto se introduce en la colateral, por la que viaja anterógradamente hasta las porciones más distales (Fig. 25C). Por ello, en los experimentos de BDA, muchos de los axones marcados no pertenecen a neuronas de la zona de inyección, sino a neuronas que inervan a la zona de inyección, y se han marcado mediante el transporte colateral. Como es bien conocido que las neuronas esféricas del NCoAV inervan tanto a la OSL como a la oliva superior medial (OSM) de ambos lados, en nuestros experimentos aprovechamos el transporte colateral para marcar selectivamente los axones de las neuronas esféricas que inervan a la OSM ipsolateral (OSMi) y a la OSM contralateral (OSMc) (Fig. 25C). De modo similar, como las neuronas principales del NMCT inervan tanto a la OSL como a la OSM, en nuestros experimentos también se marcaron selectivamente los axones del NMCT que inervan a la OSMi (Fig. 25C). Por lo tanto, la inyección de BDA en la OSL proporcionó la oportunidad única de marcar en la misma preparación las tres aferencias principales de la OSM: Ios axones de neuronas esféricas del NCoAV ipsolateral (NCoAVi), los axones de neuronas esféricas del NCoAV contralateral (NCoAVc) y los axones de neuronas principales del NMCT ipsolateral. Dado que las neuronas del NMCT inervan también al núcleo parolivar superior (NPS), los mismos experimentos nos permitieron analizar los axones del NMCT que inervan al NPS. 
4. El BDA genera zonas de inyección de pequeño tamaño, especialmente cuando se inyecta en un núcleo que, como la OSL, posee una organización anisótropa que limita la difusión del trazador. Debido a que las conexiones entre núcleos auditivos son tonotópicas, el obtener zonas de inyección de pequeño tamaño nos permitió analizar con enorme finura la topografía de las neuronas que inervan a la OSL y la topografía de los axones que inervan a la OSM. A modo de ejemplo, en cada uno de nuestros casos pudimos analizar si las regiones de la OSM inervadas por los axones procedentes del NCoAVi, del NCoAVc y del NMCT son las mismas o distintas.

A

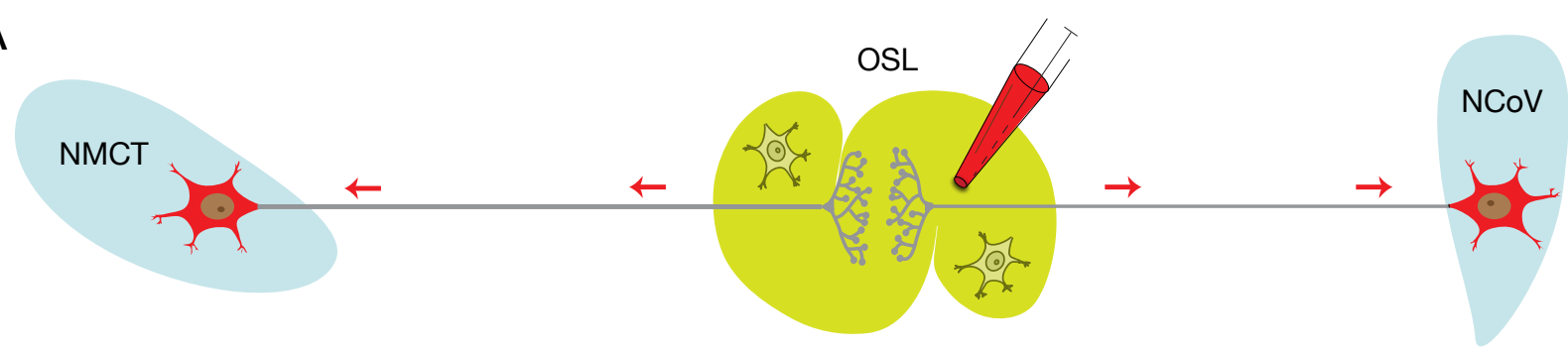

B
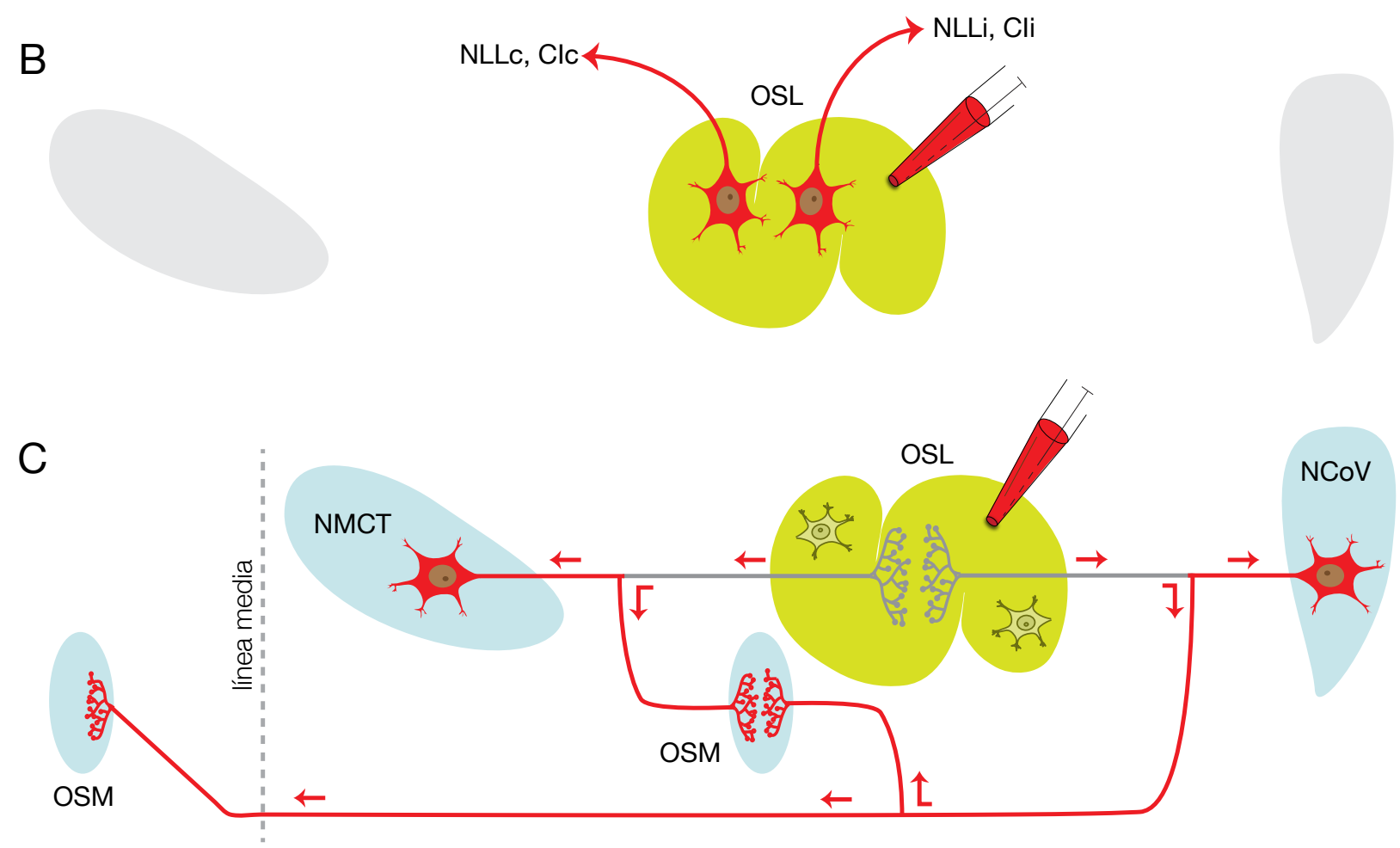

Figura 25. Tipos de transporte que se obtienen con la inyección extracelular de BDA. Debido a su carácter bidireccional, la inyección de BDA en la OSL (micropipetas de vidrio) da lugar a tres tipos de marcado: (A) Marcado retrógrado de las neuronas que inervan a la OSL. En la figura se han ilustrado sendas neuronas del NMCT y el NCoV. (B) Marcado anterógrado de los axones de las neuronas de la OSL, entre cuyos destinos se incluyen los núcleos del lemnisco lateral (NLL) y el colículo inferior (CI) de ambos lados. (C) Transporte de colaterales de los axones que inervan a la OSL. En la figura se han representado una colateral del axón de una neurona del NMCT (que inerva a la OSMi), y dos colaterales del axón de una neurona del $\mathrm{NCoV}$ (una para la OSMi y la otra para la OSMc). 
Debido a que la audición de la rata se basa sobre todo en frecuencias agudas, que transmiten información limitada sobre las diferencias interauriculares de tiempo, hemos realizado con fines de confirmación algunos experimentos similares (inyección de BDA en la OSL) con jerbos, roedores cuyo rango auditivo es más parecido al humano que el de las ratas. Con estos experimentos dimos cumplimiento a nuestro quinto objetivo específico.

A lo largo de la Tesis, en diversas ocasiones nos vimos en la necesidad de realizar experimentos complementarios para responder preguntas concretas. Tales experimentos consistieron en inyectar BDA en núcleos auditivos de la rata distintos de la OSL, como el NPS, la OSM o el Cl, o en visualizar inmunocitoquímicamente ciertas proteínas endógenas, como la calbindina, el transportador de glicina de tipo 2 ó la proteína asociada a microtúbulos de tipo 2. Los motivos para realizar cada uno de estos ensayos y el tipo de información que proporcionaron se describen en las secciones pertinentes de esta Memoria. 


\section{ANIMALES EXPERIMENTALES}

Para esta investigación hemos utilizado ratas albinas (Rattus norvegicus) hembra de la cepa Wistar de 190-210 g de peso corporal $(n=57)$, y jerbos mongoles (Meriones unguiculatus) hembra de 50-65 g $(\mathrm{n}=8)$ adquiridos en el laboratorio de Charles River de Francia e Italia, respectivamente (Fig. 26). Todos los procedimientos aplicados habían sido aprobados previamente por el Comité de Bioética de la Universidad de Salamanca y se ajustan a lo dispuesto en el Real Decreto $1201 / 2005$ y a la Directiva Europea 63/2010. En todo momento, extremamos el cuidado en el diseño y en la ejecución de los experimentos para disminuir el sufrimiento y el número de animales usados.
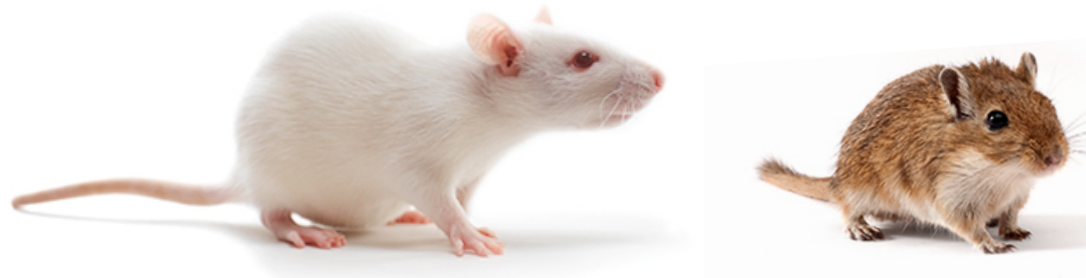

Figura 26. Rata albina (Rattus norvegicus) y jerbo mongol (Meriones unguiculatus).

\section{TÉCNICAS DE TRAZADO DE VÍAS NERVIOSAS}

\subsection{Trazadores}

Como trazadores neuroanatómicos bidireccionales, hemos utilizado dos dextranos biotinados (BDA) de distinto peso molecular: el BDA de 10.000 Da (producto D-1956 de Invitrogen -antes Molecular Probes-, Eugene, Oregón, EE.UU.), y el BDA de 3.000 Da (producto D-7135 de Invitrogen). Ambos fueron inyectados al 10\% en tampón de fosfato sódico (PB) 0,1 M, a pH 7,3. También realizamos un pequeño número de experimentos en los que inyectamos una mezcla de BDA de 10.000 Da al 5\% y BDA de 3.000 Da al $5 \%$.

\subsection{Procedimiento quirúrgico}

Anestesiamos a los animales con una mezcla de ketamina (Imalgene $100 \AA$, Merial, Toulouse, Francia; $80 \mathrm{mg} / \mathrm{kg}$ ) y xilacina (Rompun ${ }^{\circledR}$, Bayer, Leverkusen, Alemania; $6 \mathrm{mg} / \mathrm{kg}$ ) inyectada intramuscularmente y repartida la dosis $(1 \mathrm{ml} / \mathrm{kg})$ entre los dos muslos. En algunos casos, por la duración de la operación, se utilizó una dosis adicional de la misma mezcla. Tras comprobar la abolición de los reflejos motores de retirada, colocamos a los animales en un aparato estereotáctico (Kopf 900, David Kopf Instruments, Tujunga, California, EEUU) de modo que la superficie del cráneo quedó horizontal (Fig. 27). Con un bisturí practicamos una incisión sagital en la piel para exponer y perforar el cráneo con una fresa de dentista. Tras la craneotomía, abrimos la duramadre, salvo en los casos en los que se encontraba cerca de algún seno venoso. Mediante técnicas estereotácticas y utilizando como referencia las coordenadas calculadas a partir de sendos atlas del cerebro de la rata (Paxinos y Watson, 2005) y del jerbo (Loskota y cols., 
1974) (ver Tabla 1), insertamos en el cerebro una micropipeta de borosilicato (World Precision Instruments, Inc., Sarasota, Florida, EE.UU.) cargada con el trazador y con un diámetro interno en su punta de entre 10 y $25 \mu \mathrm{m}$. Cuando la pipeta alcanzó la posición deseada, liberamos el trazador iontoforéticamente aplicando una corriente de $5 \mu \mathrm{A}$ en ciclos de $7 \mathrm{~s}$ cada $14 \mathrm{~s}$ durante 10-20 min aportada por un generador de corriente Midgard ${ }^{\mathrm{TM}}$ Precision Current Source (Stoelting, Wood Dale, Illinois, EE.UU.). Para esquivar el seno venoso sagital, en la mayoría de los casos la pipeta se introdujo utilizando un ángulo de $20^{\circ}$ con el plano coronal, de manera que la pipeta siguió una trayectoria de dorsocaudal a ventrorrostral. Para evitar el reflujo del trazador a lo largo del trayecto de penetración, esperamos 10-20 min antes de retirar la micropipeta. Por último, suturamos la herida y dejamos al animal en condiciones adecuadas de estabulación.

\subsection{Procesamiento histológico}

\subsubsection{Fijación}

Luego de una supervivencia de 7-10 días, anestesiamos los animales con una sobredosis de pentobarbital sódico (Dolethal, Vetoquinol, Madrid; $60 \mathrm{mg} / \mathrm{kg}$ ) administrada intraperitonealmente. Tras comprobar que los reflejos motores se habían abolido y que el animal estaba profundamente dormido, comenzamos la perfusión transcardíaca (Fig. 28). Primero se hizo un lavado del árbol vascular con solución salina ( $\mathrm{NaCl}$ al 0,9\%) y luego se perfundió con una solución de formaldehído al $4 \%$ en $\mathrm{PB} 0,1 \mathrm{M}$, a pH 7,3, preparado a partir de formalina comercial.

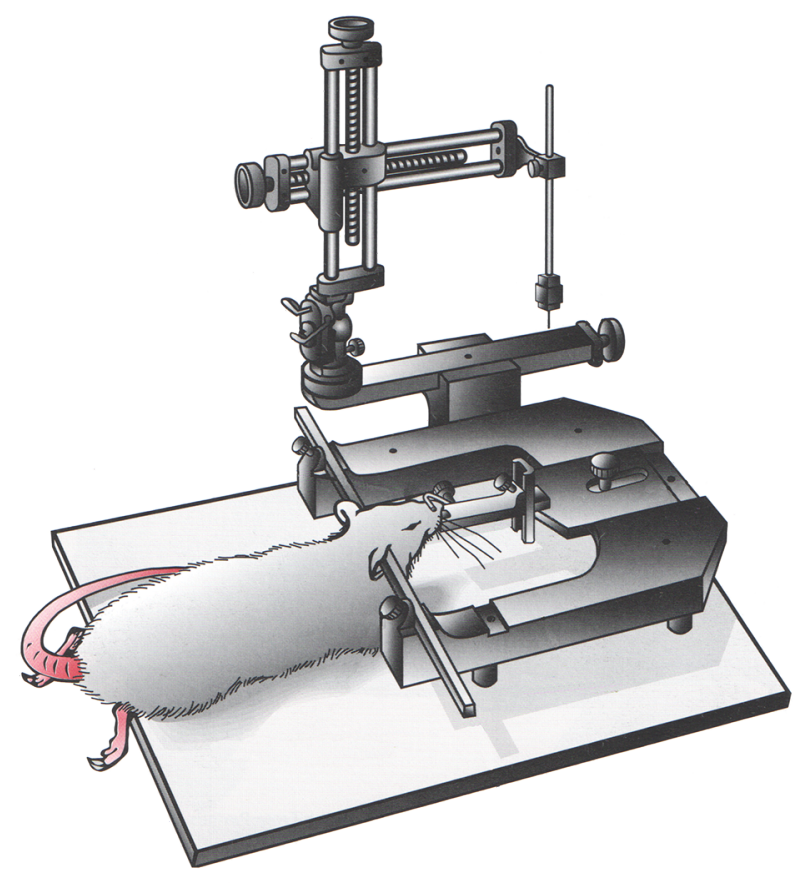

Figura 27. Aparato estereotáctico.

Tabla 1. Ejemplos de coordenadas estereotácticas con las que obtuvimos resultados satisfactorios. La coordenada rostrocaudal expresa la distancia con respecto al plano coronal interauricular; la lateral, la distancia con respecto al plano mediosagital; y la dorsoventral, la distancia con respecto al plano horizontal interauricular. Los valores negativos indican que un punto es caudal o ventral con respecto al plano interauricular correspondiente.

\begin{tabular}{cccccc}
\hline & & \multicolumn{4}{c}{ Coordenadas estereotácticas } \\
\cline { 3 - 6 } Especie & Núcleo & Rostrocaudal & Lateral & Dorsoventral & Ángulo \\
\hline Rata & Cl & $-0,4$ & $-2,6$ & 5,2 & 0 \\
Rata & NMCT & $-1,1$ & $-1,3$ & $-0,8$ & $20^{\circ}$ \\
Rata & NPS & $-1,5$ & $-1,9$ & $-0,1$ & $20^{\circ}$ \\
Rata & OSL & $-1,5$ & $-2,2$ & $-0,1$ & $20^{\circ}$ \\
Rata & OSM & $-0,8$ & $-1,9$ & $-0,3$ & $20^{\circ}$ \\
Jerbo & OSL & $-0,5$ & $-1,4$ & $-0,4$ & $15^{\circ}$ \\
\hline
\end{tabular}




\subsubsection{Crioprotección y corte}

Tras la perfusión extrajimos cuidadosamente el encéfalo y lo tallamos en planos coronales, utilizando un molde adecuado (modelo 400c de Activational Systems, Inc., en la actualidad ASI Instruments, Inc., Miami, Florida, EE.UU). Con el fin de poder distinguir los dos lados del encéfalo a la hora de montar las secciones, a los encéfalos les clavamos longitudinalmente una aguja en el lado izquierdo e hicimos una muesca sobre la corteza cerebral con un bisturí.

Crioprotegimos los encéfalos en una solución de sacarosa al $30 \%$ en PB 0,1 M a $\mathrm{pH} 7,3$ a $4{ }^{\circ} \mathrm{C}$ en agitación suave durante 72 horas. Posteriormente los cortamos con un microtomo de congelación (modelo HM 430

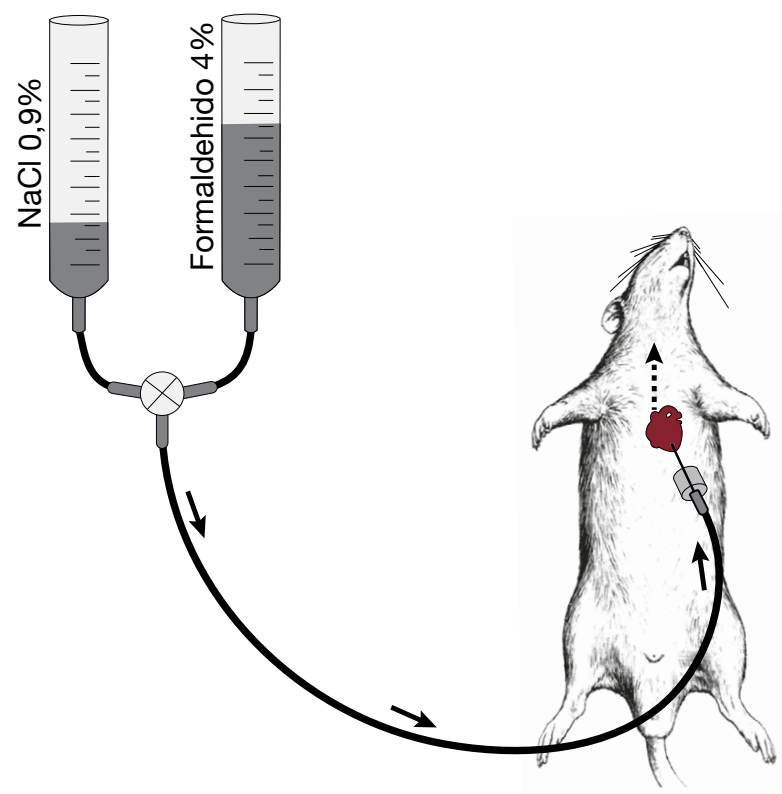

Figura 28. Perfusión transcardíaca. de Microm, Heidelberg, Alemania) para obtener secciones coronales de $40 \mu \mathrm{m}$ de grosor. Las secciones se recolectaron de forma alterna en 8 pocillos en tampón Tris 0,05 M, a pH 7,6.

\subsubsection{Visualización del BDA}

Para visualizar el BDA, permeabilizamos el tejido lavando las secciones con tampón Tris 0,05 M con un 0,5 \% de detergente Tritón X-100 (Merck, Darmstadt, Alemania), a pH 7,6 (Tris$\mathrm{Tx}$ ). Después, incubamos las secciones a $4^{\circ} \mathrm{C}$, en agitación suave y durante un mínimo de 12 horas en un complejo de avidina, biotina y peroxidasa (ABC; Vectastain, Vector, Burlingame, California, EE.UU.), diluido en Tris-Tx.

Tras lavar las secciones con tampón Tris $0,05 \mathrm{M}$, a pH 7,6, las revelamos utilizando como cromógeno diaminobencidina (DAB) y sulfato de níquel y amonio en tampón Tris 0,05 M, a $\mathrm{pH} 8,0$. Esta reacción genera un producto de color negro que contrasta fuertemente sobre el fondo incoloro de las secciones no contrastadas y sobre la tinción morada de las secciones contrastadas con el método de Nissl. Finalmente interrumpimos la reacción con varios lavados de tampón. Para adherir las secciones a los portaobjetos utilizamos una solución de gelatina al 0,2 \% en tampón Tris $0,05 \mathrm{M}$ a pH 8 y las dispusimos en portaobjetos de cristal siguiendo un orden rostrocaudal y respetando la orientación de derecha e izquierda. Posteriormente las pusimos a desecar en una placa caliente (Stuart Hotplate SB300, Fisher Scientific, Leicestershire, Inglaterra), a una temperatura de $36^{\circ} \mathrm{C}$ durante 48 horas. Luego las deshidratamos en un gradiente de etanoles de concentración creciente, las aclaramos con xileno, y las protegimos con cubreobjetos utilizando como pegamento Entellan ${ }^{\circledR}$ (Merck). De cada caso, contrastamos con violeta de cresilo una de cada cuatro secciones como referencia citoarquitectónica. 


\subsubsection{Tinción con violeta de cresilo}

Nuestro protocolo para contrastar las secciones está inspirado en el protocolo descrito en el atlas del cerebro de la rata de Paxinos y Watson (2005). La receta para preparar la solución del colorante al $0,25 \%$ fue la siguiente $(300 \mathrm{ml})$ :

\begin{tabular}{|c|c|}
\hline Acetato de violeta de cresilo (producto C1791-5G, Sigma, San Luis, EE.UU.) & $0,6 \mathrm{~g}$ \\
\hline Acetato de sodio $1 \mathrm{M}\left(1,64 \mathrm{~g}\right.$ de $\mathrm{NaC}_{2} \mathrm{H}_{3} \mathrm{O}_{2} \cdot 2 \mathrm{H}_{2} \mathrm{O}$ en $\left.20 \mathrm{ml} \mathrm{H} \mathrm{H}_{2} \mathrm{O}\right)$ & $18 \mathrm{ml}$ \\
\hline Ácido acético $1 \mathrm{M}$ (6 ml de ácido acético glacial en 96 ml Hz2O) & $102 \mathrm{ml}$ \\
\hline $\mathrm{H}_{2} \mathrm{O}(\mathrm{d})$ & $180 \mathrm{ml}$ \\
\hline
\end{tabular}

Tras preparar la solución, la agitamos continuamente durante al menos 7 días y antes de usarla, la filtramos con filtros de acetato de celulosa de 0,2 $\mu$ m de diámetro de poro (con el papel de filtro queda retenida una cantidad excesiva de colorante). Para lograr una coloración uniforme de las secciones, la tinción con violeta de cresilo se realizó bajo agitación continua y a $37^{\circ} \mathrm{C}$ en una cubeta con un volumen elevado de colorante (como mínimo $200 \mathrm{ml}$ ). El resto de los pasos se llevaron a cabo a temperatura ambiente siguiendo el siguiente protocolo:

\begin{tabular}{lc}
\hline Xileno & $2 \times 5 \mathrm{~min}$ \\
\hline Etanol al $100 \%$ & $2 \times 5 \mathrm{~min}$ \\
\hline Etanol al $90 \%$ & $5 \mathrm{~min}$ \\
\hline Etanol al $70 \%$ & $5 \mathrm{~min}$ \\
\hline $\mathrm{H}_{2} \mathrm{O}(\mathrm{d})$ & $30 \mathrm{~s}$ \\
\hline Violeta de cresilo $(0,25 \%)$ a $37^{\circ} \mathrm{C}$ y en agitación suave & $15 \mathrm{~min}$ \\
\hline $\mathrm{H}_{2} \mathrm{O}(\mathrm{d})$ & $3 \mathrm{~min}$ \\
\hline Etanol al $70 \%$ & $3 \mathrm{~min}$ \\
\hline Etanol al $90 \%$ con un $1 \%$ de ácido acético glacial & $3 \mathrm{~min}$ \\
\hline Etanol al $90 \%$ & $3 \mathrm{~min}$ \\
\hline Etanol al $100 \%$ & $3 \mathrm{~min}$ \\
\hline Triclorometano (cloroformo) & $3 \mathrm{~min}$ \\
\hline Etanol al $100 \%$ & $3 \mathrm{~min}$ \\
\hline Xileno & $3 \times 3 \mathrm{~min}$ \\
\hline Entellan & \\
\hline
\end{tabular}

En ocasiones, repetimos el ciclo de diferenciación pasando las secciones del último etanol absoluto al etanol al $90 \%$ con ácido acético. 


\section{INMUNOTINCIÓN PARA LA CALBINDINA}

Tras haber perfundido y crioprotegido el cerebro como se ha explicado más arriba, obtuvimos por congelación secciones de $40 \mu \mathrm{m}$, que lavamos abundantemente en tampón TrisTx. A continuación las incubamos durante 24 horas en un antisuero policlonal de ratón contra calbindina (CB; Sigma, San Luis, Missouri, EE.UU.; dilución 1:500 en Tris-Tx), y después durante 4 horas en un antisuero biotinado de cabra contra IgG de ratón (Sigma; dilución 1:200 en TrisTx). Seguidamente, las incubamos durante un mínimo de 12 horas en el complejo ABC (Vector) preparado en Tris-Tx a $4{ }^{\circ} \mathrm{C}$ y con agitación suave. Posteriormente lavamos las secciones en Tris-Tx y luego en tampón Tris 0,05 M (sin detergente), y revelamos la peroxidasa asociada a la $\mathrm{CB}$ mediante una sencilla reacción histoquímica incubando las secciones durante 10-15 min en una solución de DAB al 0,05 \% y $\mathrm{H}_{2} \mathrm{O}_{2}$ al 0,0005 \% en Tris 0,05 $\mathrm{M}$, a pH 7,6. Este método genera un producto de reacción de color marrón. Por último, montamos, aclaramos y cubrimos las secciones. De cada caso, procesamos una de cada dos secciones para visualizar la CB y la otra mitad las contrastamos con violeta de cresilo como referencia citoarquitectónica.

\section{DETECCIÓN INMUNOFLUORESCENTE DE MAP2 Y GLYT2}

Tras la perfusión y crioprotección del cerebro, obtuvimos por congelación secciones de 40 $\mu \mathrm{m}$ de espesor. Las lavamos con PB al 0,1 M a pH 7,3 a temperatura ambiente y, a continuación, las preincubamos durante 1 hora con un medio de bloqueo compuesto por suero de cabra al 1 \% en tampón PB 0,1 M con un 0,5 \% de detergente Tritón X-100 (PB-Tx). Al cabo de ese tiempo, se incubaron las secciones en este mismo medio al que se le añadieron los anticuerpos primarios contra proteínas asociadas a microtúbulos de tipo 2 (MAP2) y contra el transportador de glicina de tipo 2 (GlyT2) descritos en la tabla 2. Esta incubación se llevó a cabo a $4{ }^{\circ} \mathrm{C}$ y en agitación suave durante 48 horas. El GlyT2 es un eficaz marcador de botones sinápticos glicinérgicos, y MAP2 un buen marcador de los microtúbulos de dendritas y somas, por lo que permite ver selectivamente las neuronas.

Tras la incubación simultánea con los dos anticuerpos primarios (GlyT2 y MAP2), las secciones fueron lavadas con PB-Tx (sin suero) y posteriormente incubadas durante 2 horas a temperatura ambiente y en oscuridad con los anticuerpos secundarios fluorescentes en una dilución 1:500 en PB-Tx. Tras una serie de lavados con PB, las secciones se montaron en portaobjetos de cristal y se protegieron con cubreobjetos utilizando Vectashield (Vector).

En la tabla 2 se especifican los distintos anticuerpos primarios y secundarios empleados en los experimentos con fluorescencia, con sus respectivas diluciones y se detalla la especie en la que han sido obtenido. 
Tabla 2. Diluciones de anticuerpos primarios y secundarios, y la especie en la que ha sido obtenido.

\begin{tabular}{rccc}
\hline Anticuerpo primario & Dilución & Anticuerpo secundario & Dilución \\
\hline Anti-MAP2 (hecho en ratón) & $1: 2000$ & Alexa Fluor 488 anti-lgG de ratón & $1: 500$ \\
Anti-GlyT2 (hecho en cobaya) & $1: 5000$ & Alexa Fluor 568 anti-lgG de cobaya & $1: 500$ \\
\hline
\end{tabular}

\section{RECONSTRUCCIONES TRIDIMENSIONALES}

Elaboramos reconstrucciones tridimensionales del tronco del encéfalo de 4 ratas utilizando secciones coronales de $40 \mu \mathrm{m}$ de espesor. Dibujamos las secciones con la ayuda del programa Neurolucida (Versión 10; MBF Bioscience, Williston, Vermont, EE.UU.) que controla el desplazamiento de la platina del microscopio Leica DMRB, y acotamos los NCo, la OSL y el NMCT del lado de la zona de inyección, y el NVCT contralateral. Además, en cada sección marcamos con un punto el soma de cada neurona marcada retrógradamente y dibujamos la línea media, el agujero producido por la aguja y cualesquiera otras referencias útiles para alinear las secciones. Una vez completados los dibujos de la serie, creamos con el programa Neurolucida una primera versión del conjunto de secciones alineadas. A continuación, pulimos esta versión con el programa NeuroExplorer (Versión 10; MBF Bioscience). Con esta última aplicación informática mejoramos la alineación de las secciones, suavizamos sus contornos, asignamos colores a las diferentes estructuras y rotamos interactivamente las imágenes para realizar fotografías y vídeos. Para interactuar con los enlaces y visualizar los vídeos que contiene esta Tesis, es necesario utilizar la aplicación informática Adobe Acrobat Reader.

\section{ELABORACIÓN DE LAS FIGURAS}

Las secciones las estudiamos, dibujamos y fotografiamos con un microscopio Zeiss Axioskop 40 (Oberkochen, Alemania) equipado con lentes objetivo plan semiapocromáticas de 2,5x (A.N. $=0,075), 5 x($ A.N. = 0,15), 10x (A.N. =0,30), 20x (A.N. =0,50), $40 x($ A.N. = 0,75), y 100x de inmersión en aceite (A.N. = 1,40). Las microfotografías las tomamos con una cámara digital Zeiss AxioCam MRc 5 acoplada al microscopio.

Las secciones procesadas para fluorescencia fueron estudiadas y fotografiadas con un microscopio confocal espectral, Leica TCS SP2 (Leica Instruments GmbH, Mannheim, Alemania), acoplado a un microscopio invertido Leica DMIRE2 con objetivos PL Apo de 20x (A.N. = 0,70), 40x de inmersión en aceite (A.N. = 1.25-0.75), y 63x de inmersión en aceite (A.N. = 1.32-0.6).

A fin de ajustar exclusivamente el brillo, el contraste y el equilibrio de color de las microfotografías, tratamos posteriormente cada documento digital con el programa Adobe Photoshop 13.0 para Macintosh. Por último, nos servimos del programa Adobe Illustrator 16.0 también para Machintosh para componer las planchas de ilustraciones y elaborar los esquemas. 
Con el objeto de proporcionar a la Tesis una uniformidad estilística e idiomática, hemos rehecho y traducido muchas de las ilustraciones, identificando siempre en el texto su procedencia. Las figuras en las que no se menciona un origen son de elaboración propia.

\subsection{Pseudodibujos de cámara clara ("Illustrator drawings")}

Para comparar los axones marcados en el Cli de sendos casos con inyección de BDA en el NPS y la OSM, nos hemos inspirado en la técnica informática "Photoshop Drawing" utilizada por Cant (2013). Para ello, y valiéndonos de la aplicación Adobe lllustrator, pasamos las fotografías digitales de cada caso a una escala de grises. Posteriormente a las imágenes en blanco y negro les aplicamos el filtro "tampón" ("stamp"). El valor de "suavizar" siempre se estableció en 1, pero el ajuste de "equilibrio de luz y sombra" varió en cada imagen, dependiendo de la exposición y la tinción de fondo de cada sección. El filtro "tampón" permite convertir una imagen monocromática de mapa de bits en un gráfico vectorial. Finalmente a los axones de cada caso (convertidos en vectores), les otorgamos un color diferente, y con la herramienta "pincel" dibujamos el contorno de la superficie del cerebro. Por último, combinamos digitalmente en la misma imagen los axones marcados en el $\mathrm{Cl}$ de los dos experimentos estudiados.

\section{ANÁLISIS ESTADÍSTICO}

Para comparar la proporción de neuronas marcadas en distintos casos con inyección de BDA en la OSL, aplicamos la prueba de Chi-cuadrado. El análisis estadístico se realizó con el programa Microsoft Excel y la aplicación informática GraphPad Prism versión 5 para Machintosh (GraphPad Software Inc., San Diego, California, EE.UU.). Para calcular la significación estadística, consideramos intervalos de confianza del $95 \%$. 



\section{CASOS CON INYECCIÓN DE BDA EN LA OSL DE LA RATA}

\subsection{Organización anisótropa y tonotópica de la OSL de la rata}

Igual que en otros mamíferos, la oliva superior lateral (OSL) de la rata está integrada por láminas fibrodendríticas rostrocaudales compuestas por neuronas con campos dendríticos aplanados y más o menos paralelos a los de las neuronas vecinas y que se entremezclan con plexos de axones terminales paralelos a las dendritas. Para ilustrar la orientación de las láminas fibrodendríticas de la OSL de la rata, nos hemos basado tanto en la colección de casos impregnados con el método de Golgi de la histoteca del Laboratorio de Neurobiología de la Audición del Instituto de Neurociencias de Castilla y León (INCyL), como en nuestra amplia colección de experimentos de trazado en los que se marcaron neuronas o axones dentro de la OSL. A modo de ejemplo, la figura 29A muestra abundantes elementos macados en la OSL con una clara distribución laminar. Nuestros datos sobre la orientación de las láminas son totalmente coincidentes con los de otros autores que mostraron la orientación de neuronas de la OSL de la rata (Harrison y Feldman, 1970 [ver su Fig. 18]; Lu y cols., 1987 [su Fig. 1B]; Vetter y cols., 1991 [sus Figs. 1, 2, 4A]; Vetter y Mugnaini, 1992 [sus Figs. 2, 5D-E]; Friauf, 1993 [sus Figs. 2-4]; Lohmann y Friauf, 1996 [sus Figs. 6A, 7F, 8E]; Kungel y cols., 1997 [sus Figs. 1, 2]; Rietzel y Friauf, 1998 [sus Figs. 2, 3, 6, 8]; Wu y Fu, 1998 [su Fig. 1]; Adam y cols., 1999 [su Fig. 5]; Bittencourt y cols., 1999 [su Fig. 4]; Kim y Kandler, 2003 [su Fig. 1]; Kelly y cols., 2009 [su Fig. 3E-F]) o la orientación de los axones terminales que la inervan (Friaufy Ostwald, 1988 [su Fig. 4]; Banks y Smith, 1992 [sus Figs. 2, 3]; Friauf, 1993 [su Fig. 7]; Sommer y cols., 1993 [sus Figs. 6, 7, 9, 10]; Warr y cols., 1997 [su Fig. 4B]; Doucet y Ryugo, 2003 [sus Figs. 3, 4, 6]; Kim y Kandler, 2003 [su Fig. 1]; Kraus e Illing, 2004 [su Fig. 2D]; Rosskothen-Kuhl e Illing, 2014 [su Fig. 4]).

La figura 29B ilustra de modo esquemático la orientación de las láminas fibrodendríticas tal como aparecen en secciones coronales del nivel rostrocaudal central del núcleo. En el limbo lateral de la OSL las láminas son más o menos horizontales y perpendiculares al contorno del núcleo, mientras que las de los limbos central y medial son más verticales y oblicuas con respecto al contorno. Los puntos amarillos indican el centro de cada lámina. La línea roja que pasa por estos puntos ilustra el eje tonotópico de la OSL, que posee una longitud de 1,3 mm. Obsérvese que el eje tonotópico es relativamente vertical en los limbos lateral y central, pero más horizontal en el limbo medial.

Los números situados por fuera del núcleo en la figura 29B dan una idea aproximada de la organización tonotópica de la OSL de la rata basada en estudios anteriores (ver el pie de foto). El eje tonotópico del núcleo se extiende desde el extremo ventral del limbo lateral, donde se procesan los sonidos más graves, hasta el extremo medial del limbo medial, en el que se procesan los más agudos. La figura 29B sugiere que el limbo lateral comprende aproximadamente el 40 $\%$ del eje tonotópico y procesa las frecuencias $<10 \mathrm{kHz}$, el limbo central abarca un $30 \%$ del eje tonotópico y se encarga de las frecuencias comprendidas entre 10 y $15 \mathrm{kHz}$, y el limbo medial incluye otro $30 \%$ del eje tonotópico y se ocupa de las frecuencias $>15 \mathrm{kHz}$. Estos datos apuntan a que la OSL de la rata posee una representación completa del rango espectral audible de esta especie (Kelly y Masterton, 1977; Heffner y cols., 1994). 


\subsection{Zonas de inyección de BDA en la OSL}

Estos resultados se basan en 18 casos exitosos con una única inyección de dextrano biotinado (BDA) centrada en la OSL de ratas adultas y en los que el trazador se transportó eficazmente tanto en sentido anterógrado, como en sentido retrógrado. La forma de las zonas de inyección estuvo claramente condicionada por la organización anisótropa del núcleo (Fig. 29A, B). Debido a que las propias láminas fibrodendríticas actúan como una barrera para la difusión del trazador, nuestras zonas de inyección fueron típicamente aplanadas y se extendieron a lo largo de la mayor parte de la extensión rostrocaudal del núcleo.
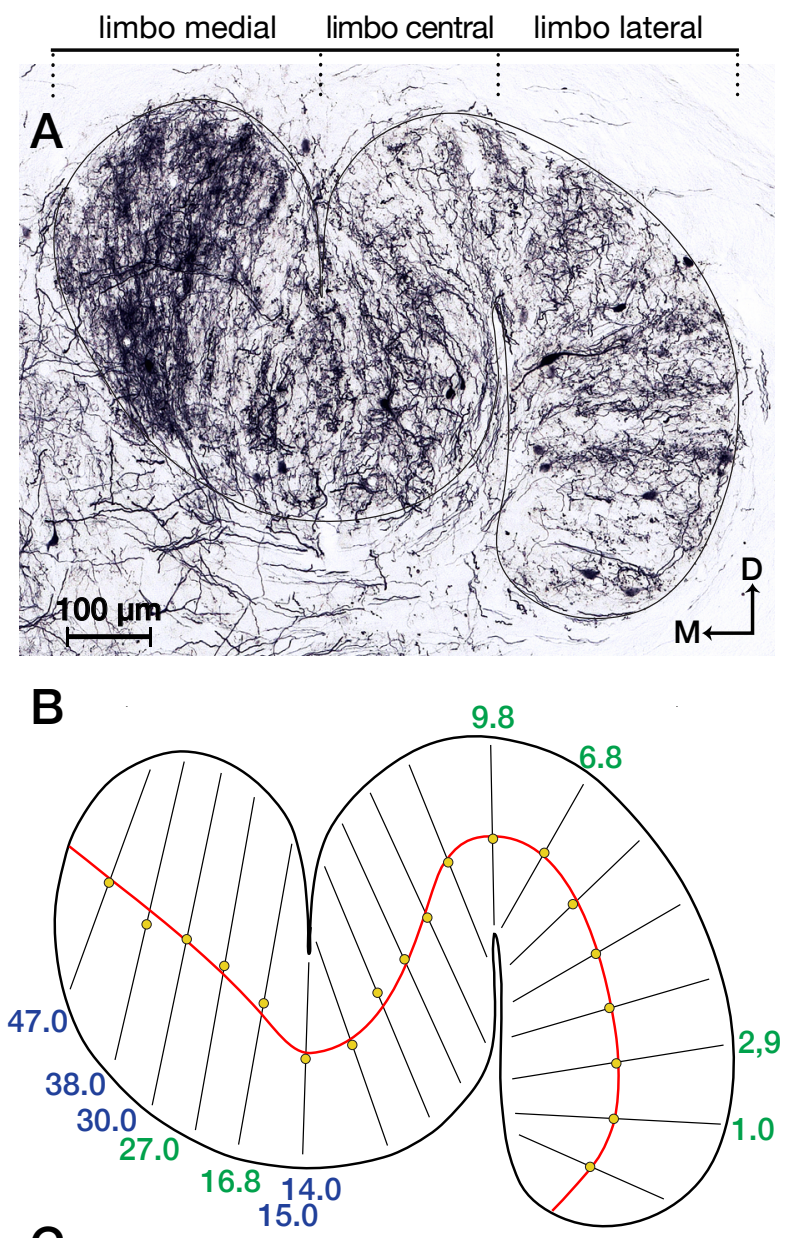

C

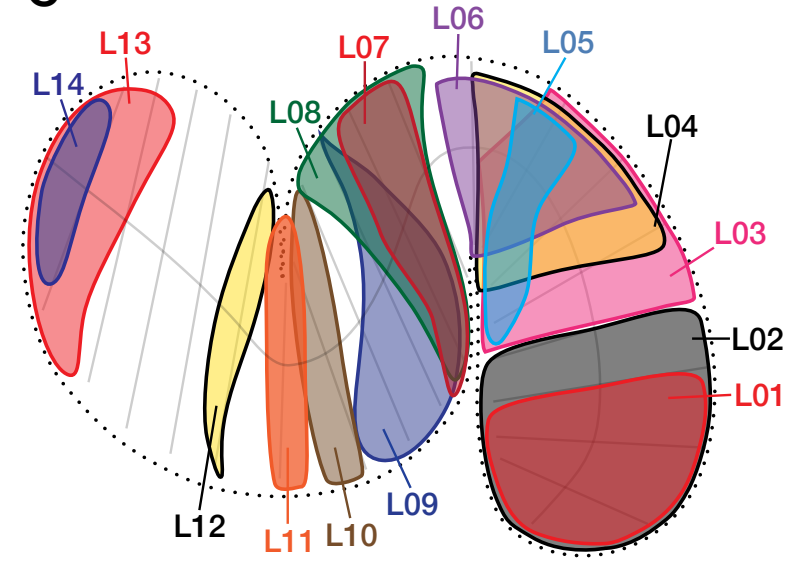

Figura 29. Organización laminar de la OSL de la rata. (A) Sección coronal de la OSL de un caso con una zona de inyección de BDA centrada en la porción más rostral y lateral del cuerpo trapezoide y no visible en la imagen. Obsérvese la distribución anisótropa de todos los elementos marcados dentro del núcleo y cómo las dendritas de las neuronas marcadas retrógradamente se disponen alineadas con los plexos de axones terminales. Aunque el origen de los axones marcados en este experimento es incierto, la figura sirve para ilustrar la orientación de las láminas fibrodendríticas de la OSL. (B) Representación esquemática de las láminas fibrodendríticas de la OSL. En una sección coronal ideal de la porción central de la OSL, se han representado con líneas negras delgadas diversas láminas fibrodendríticas. Los puntos amarillos indican el centro de cada lámina. La línea roja que pasa por estos puntos ilustra el eje tonotópico de la OSL. Los puntos amarillos dividen el eje tonotópico en 20 porciones de igual longitud, de manera que la distancia entre dos puntos adyacentes representa el 5\% del eje tonotópico. Los números situados por fuera del núcleo indican la posición aproximada de los axones terminales marcados en estudios previos en los que se inyectó intracelularmente peroxidasa en neuronas de frecuencia característica identificada electrofisiológicamente in vivo. Los números verdes indican la posición del axón de neuronas de los NCo (Friauf y Ostwald, 1988), y los números azules la posición del axón de neuronas del NMCT (Sommer y cols., 1993). (C) Representación esquemática de la posición y el tamaño de la zona de inyección de 14 casos de nuestro estudio, identificados con números correlativos derivados de su posición a lo largo del eje tonotópico del núcleo. En conjunto, abarcan todo el rango tonotópico de la OSL, desde el extremo ventral del limbo lateral (caso L01), hasta el extremo medial del limbo medial (caso L14). El trazador inyectado fue el BDA de 10.000 Da en todos los casos salvo en los casos L12 y L14, en los que se inyectó BDA de $3.000 \mathrm{Da}$, y el caso L03, en el que se inyectó una mezcla de los dos trazadores a partes iguales. 
La figura 29C ilustra el tamaño y la posición de la zona de inyección de 14 casos representativos. La zona de inyección y los resultados de los otros 4 casos fueron prácticamente idénticos a los de alguno de los casos representados y por simplicidad no los hemos incluido en la figura. A fin de facilitar la comprensión de los resultados y la comparación entre casos, los 14 casos ilustrados los hemos numerado correlativamente por su posición a lo largo del eje tonotópico de la OSL, de modo que el caso L01 corresponde a una inyección en el extremo ventral del limbo lateral, y el caso L14 a una inyección en el extremo dorsal del limbo medial. De este modo, siempre que se mencionen dos o más casos, los números inferiores se refieren a casos que afectaron a regiones de la OSL que procesan sonidos más graves, y los números superiores a casos que afectaron a regiones del núcleo que procesan sonidos más agudos.

La figura 30 muestra fotografías de la zona de inyección de cuatro casos. En la mayoría de nuestros experimentos seleccionados, la zona de inyección quedó totalmente limitada al neuropilo de la OSL (p. ej., Fig. 30A, B). En otros, aunque el trazador aparentemente difundió más allá de los límites del núcleo (p. ej., Fig. 30C, D), los resultados obtenidos fueron cualitativamente similares a los de los casos con zonas de inyección restringidas a la OSL, por lo que concluimos que la zona eficaz de captación del trazador quedó dentro de la OSL. El diámetro de las zonas de inyección con respecto al eje tonotópico osciló entre $50 \mu \mathrm{m}$ y $260 \mu \mathrm{m}$, lo que representa entre el 4 \% y el $20 \%$ del eje tonotópico de la OSL.

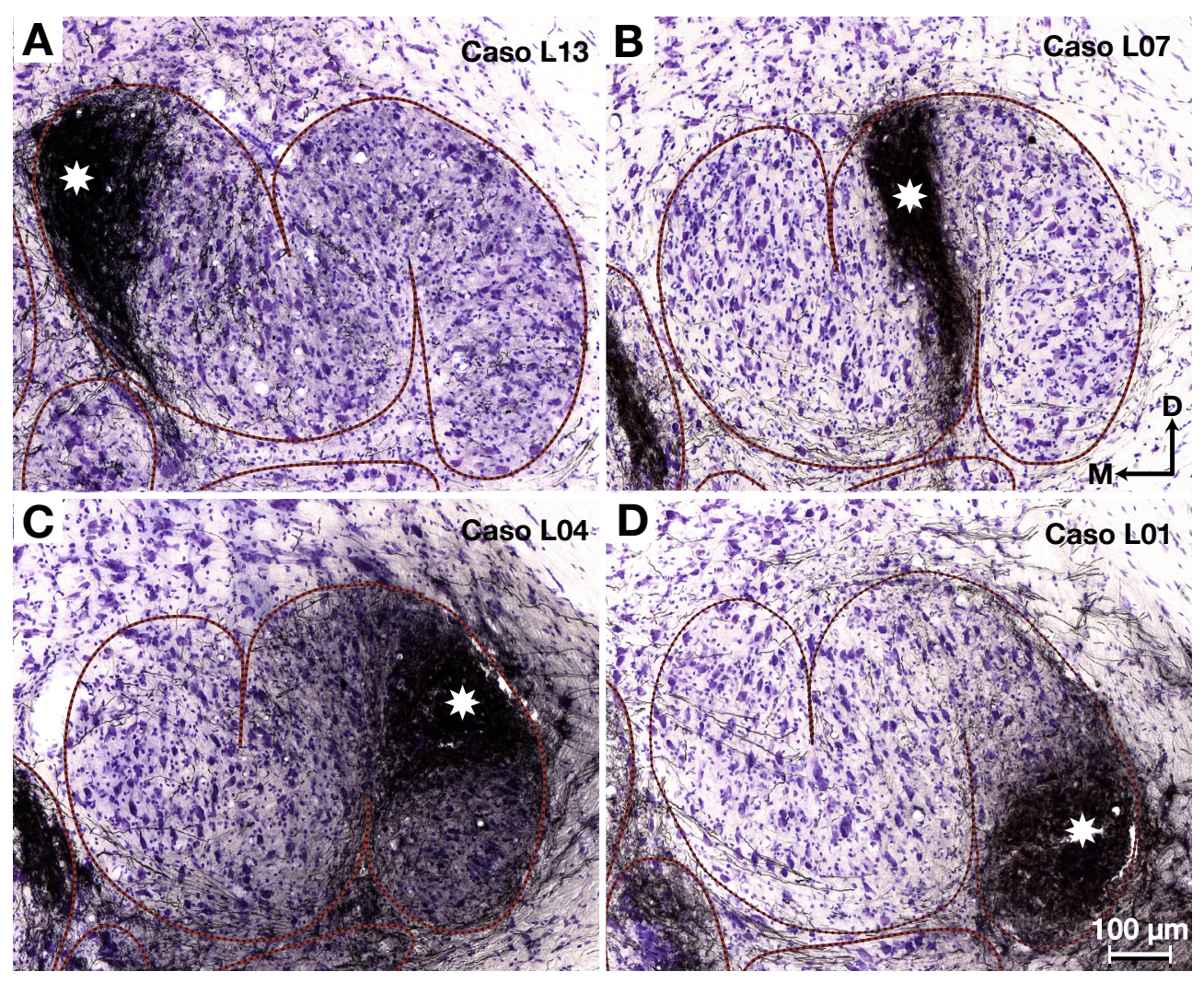

Figura 30. Zonas de inyección de BDA en la OSL de la rata. Microfotografías de la porción central de la zona de inyección de BDA en la OSL de cuatro casos representativos. Cada zona de inyección, intensamente teñida en color negro, afecta a una región tonotópica distinta. El asterisco indica el centro de la zona de inyección. Estas mismas zonas de inyección aparecen representadas esquemáticamente en la Fig. 29C. Secciones contrastadas con violeta de cresilo. La barra de aumento de $\mathbf{D}$ sirve para las cuatro fotografías. 


\subsection{Calidad del marcado retrógrado y del marcado anterógrado}

En todos nuestros casos encontramos abundantes neuronas y axones marcados. Para comparar la eficacia de los dos trazadores empleados (BDA de 10.000 Da y BDA de 3.000, inyectados solos o mezclados a partes iguales), llevamos a cabo un análisis ciego de secciones representativas de casos con zonas inyección similares en la OSL de la rata, sin que el observador supiera qué trazador se había inyectado. La evaluación de las secciones tuvo en cuenta factores como el número de neuronas marcadas retrógradamente, la textura de su relleno (difuso o puntiforme), la longitud y nitidez de los segmentos dendríticos marcados, y la densidad y nitidez de los axones marcados, tanto de paso como terminales. Este análisis reveló diferencias entre casos, pero que no parecen depender del trazador empleado. Así, observamos casos con inyección del BDA de 10.000 Da en los que la calidad del transporte anterógrado fue superior a la del transporte retrógrado, y otros realizados con el mismo trazador en los que ocurrió lo contrario; lo mismo sucedió con el trazador de 3.000 Da. Los casos en los que inyectamos los dos trazadores mezclados proporcionaron resultados similares a los de los otros casos. Por lo tanto, nuestros resultados sugieren que en nuestro modelo experimental ninguno de los dos trazadores fue más eficaz para marcar somas, dendritas o axones. En consecuencia, a partir de ahora no tendremos en cuenta el trazador inyectado en cada caso.

\subsection{Neuronas marcadas retrógradamente}

En todos los casos con inyección de BDA en la OSL, hallamos abundantes neuronas marcadas retrógradamente en cuatro núcleos auditivos troncoencefálicos: el núcleo coclear posteroventral ipsolateral (NCoPVi), el núcleo coclear anteroventral ipsolateral (NCoAVi), el núcleo medial del cuerpo trapezoide ipsolateral (NMCTi) y el núcleo ventral del cuerpo trapezoide contralateral (NVCTc) (Fig. 31). En cada uno de estos núcleos, todas o casi todas las neuronas marcadas pertenecieron a tipos neuronales bien definidos (ver más abajo). Además, en cada experimento, las neuronas marcadas en cada uno de los núcleos formaron un grupo compacto, nítido y alargado longitudinalmente (Fig. 31). Pulsando en este enlace Vídeo suplementario 2, puede verse un vídeo que muestra la distribución de las neuronas marcadas. Como veremos más adelante, la posición de estos grupos de neuronas dentro de cada núcleo varió en función de la posición de la zona de inyección a lo largo del eje tonotópico de la OSL.

En la mayoría de los experimentos, apenas encontramos neuronas marcadas fuera de los cuatro núcleos mencionados. En los casos con zona de inyección en la región de frecuencias más altas de la OSL (limbo medial), hallamos un número apreciable de neuronas marcadas en el NCoVc, aunque siempre muy inferior al de las neuronas marcadas ipsolateralmente (ver más abajo). Aunque se ha descrito que la OSL de la rata es inervada directamente por la corteza cerebral auditiva (Feliciano y cols., 1995), encontramos poquísimas neuronas corticales marcadas, y sólo en algunos casos, y se trató siempre de neuronas piramidales de la capa V. Probablemente, debido a la pequeñez de las zonas de inyección y a la lejanía entre éstas y la corteza cerebral, las neuronas piramidales que inervan a la OSL no captaron suficiente trazador como para que se transportara hasta el neocórtex. 

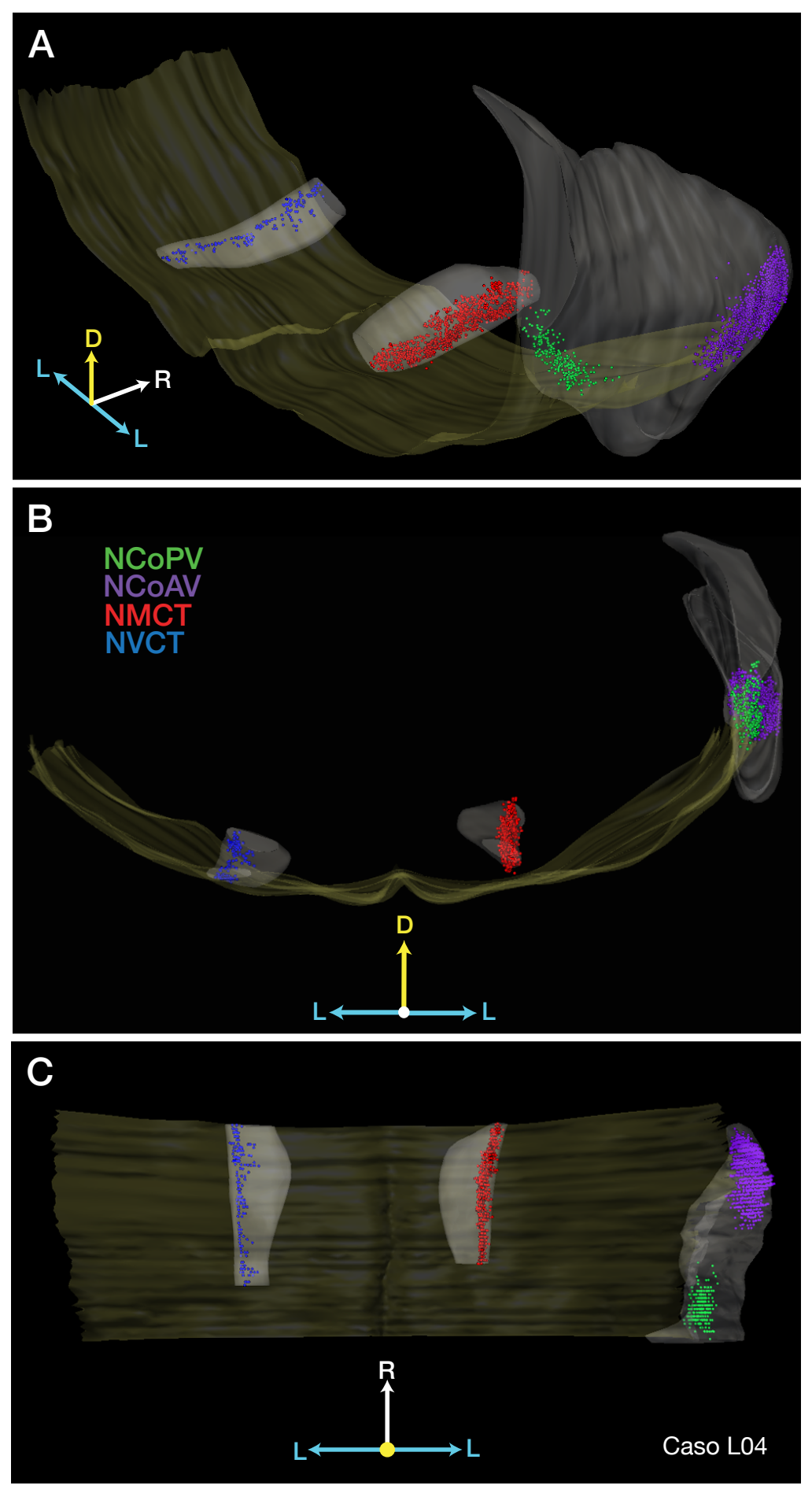

Figura 31. Distribución de las neuronas marcadas retrógradamente. Reconstrucción tridimensional de la distribución de las neuronas marcadas retrógradamente en el caso L04, cuya zona de inyección de BDA en la OSL del lado derecho se muestra en las figuras 29C y 30C. Cada punto corresponde a una neurona marcada. Se ha utilizado un mismo color para todas las neuronas marcadas en un núcleo determinado, sin distinguir entre tipos neuronales: NCoPV, en verde; NCoAV, en morado; NMCT, en rojo; y NVCT, en azul. Obsérvese que en cada núcleo las neuronas marcadas forman un grupo bien definido que abarca toda la extensión rostrocaudal del núcleo. Las imágenes muestran visiones tomadas con tres perspectivas distintas: desde un punto situado por detrás, por encima y por fuera de los núcleos cocleares derechos (A), desde un punto caudal (B), y desde un punto dorsal (C). Pulsando en este enlace Vídeo suplementario 2, puede verse un vídeo de la distribución de las neuronas marcadas en este caso. 

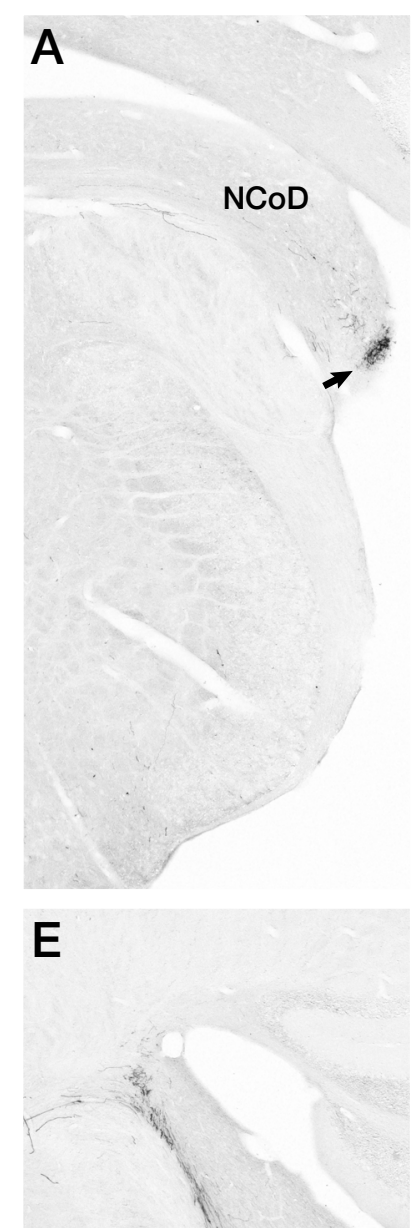

NCoAV

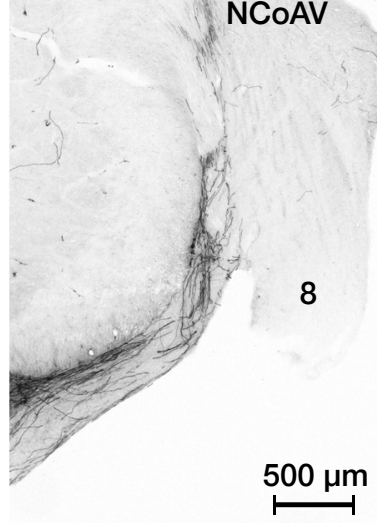

\section{B}

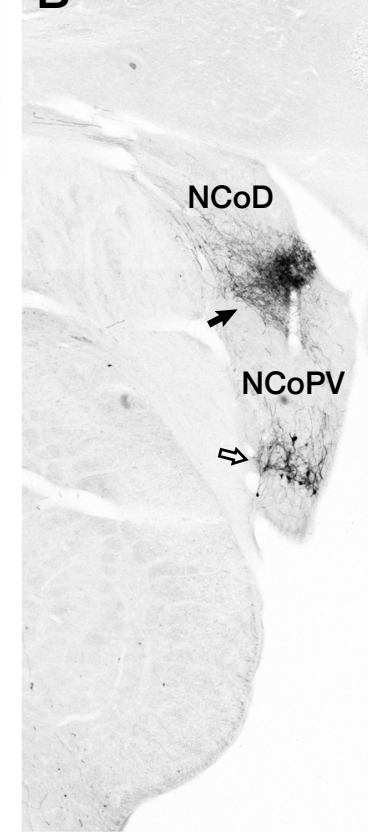

$\mathbf{F}$
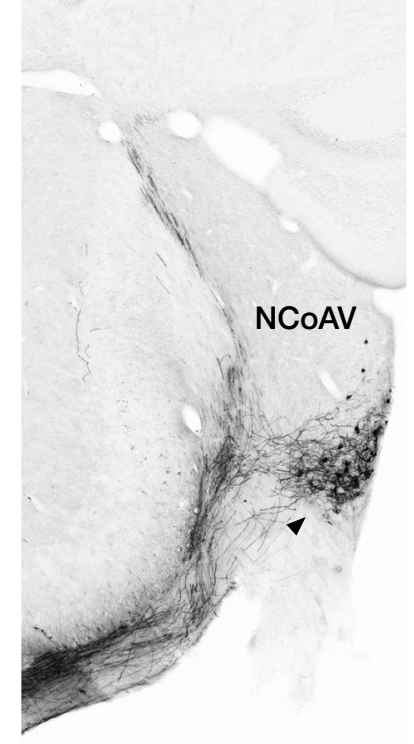

C

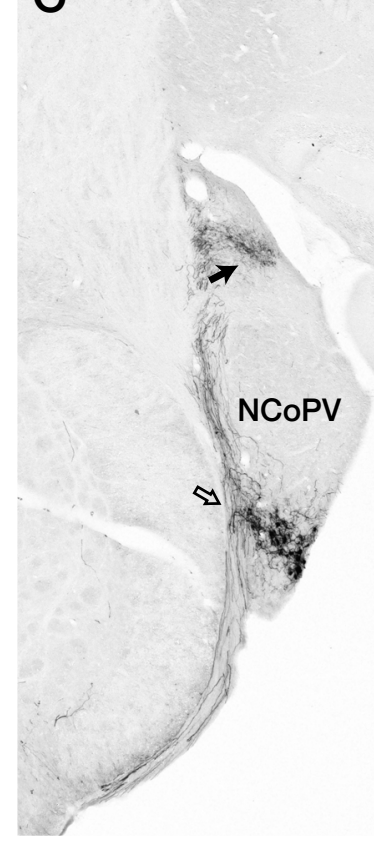

G

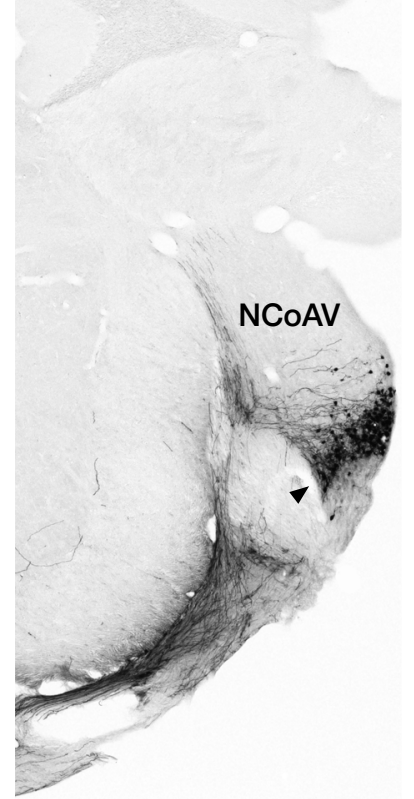

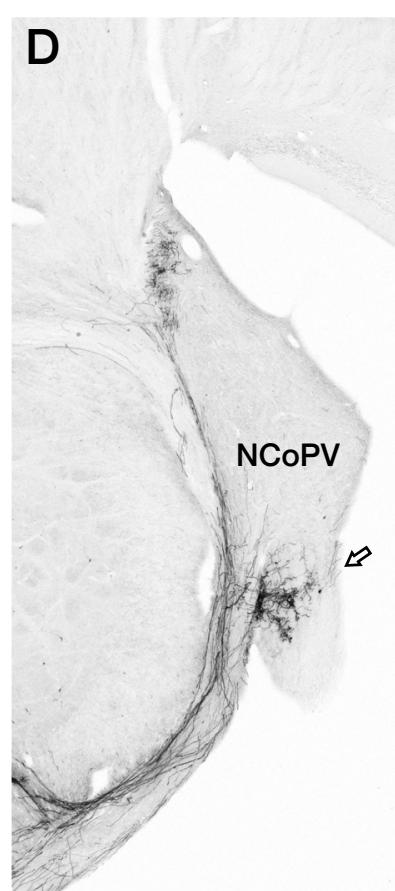

$\mathrm{H}$

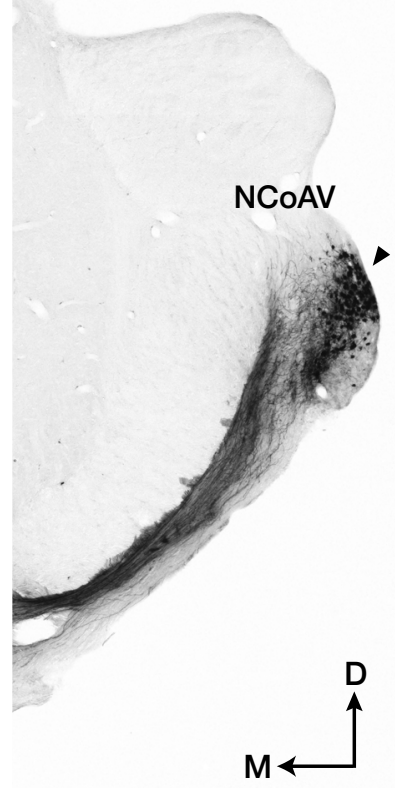

Figura 32. Distribución de los elementos marcados en los NCoi. Microfotografías que muestran la distribución de los elementos marcados en una serie de secciones coronales de los NCoi del caso L04, cuya zona de inyección de BDA en el limbo lateral de la OSL se muestra en las figuras 29C y 30C. Las secciones aparecen ordenadas de la más caudal a la más rostral, y están separadas por intervalos regulares de $320 \mu \mathrm{m}$, salvo las secciones $\mathbf{E}$ y F, cuya separación es de $280 \mu \mathrm{m}$. La reconstrucción tridimensional de la distribución de las neuronas marcadas en este mismo caso se muestra en la Fig. 31 y en el Vídeo suplementario 2. Los elementos marcados en el núcleo coclear dorsal ( $\mathrm{NCoD}$ ) (flechas negras en $\mathbf{A}-\mathbf{C}$ ) son campos terminales formados por colaterales del axón de las neuronas multipolares planas marcadas (ver también Doucet y Ryugo, 2003). Las neuronas marcadas ocupan una franja estrecha, tanto en el NCoPV (flechas huecas en B-D), como en el NCoAV (puntas de flecha negras en F-H). La barra de aumento de $\mathbf{E}$ sirve para todas las fotografías. 
Las figuras 32, 35 y 37 ilustran secciones coronales del NCoPVi, el NCoAVi, el NMCTi y el NVCTC del caso L04, que usaremos como representativo. Igual que en otros casos, dentro de cada núcleo las neuronas marcadas se repartieron prácticamente por toda la extensión rostrocaudal del núcleo, y en cada sección ocuparon un territorio bien definido.

A continuación, describiremos primero las características morfológicas y topográficas de cada uno de los tipos neuronales marcados; posteriormente prestaremos atención a la tonotopía y al número de las neuronas marcadas.

\subsubsection{Neuronas marcadas en el NCoV}

En el NCoVi se marcaron dos tipos neuronales que difieren en sus características morfológicas y su distribución: neuronas multipolares planas y neuronas esféricas.

\subsubsection{Neuronas multipolares planas}

Las neuronas multipolares planas marcadas en nuestros experimentos poseyeron las características morfológicas descritas por otros autores (Smith y Rhode, 1989; Doucet y Ryugo, 1997). Tienen el soma poligonal y de él parten hasta 5 troncos dendríticos principales. Las dendritas son largas, rectilíneas, suelen dividirse 1 ó 2 veces para generar ramas secundarias y terciarias cada vez más delgadas, se disponen en un espacio aplanado y paralelo a los planos de isofrecuencia, y suelen entremezclarse con axones terminales marcados. En nuestro material, la forma de las neuronas multipolares planas se apreció mejor en las secciones más caudales de los casos con zona de inyección situada en la porción más ventral del limbo lateral de la OSL, pues en ellos las neuronas marcadas ocuparon una región aproximadamente vertical, paralela al plano de corte, y se ven más o menos "de cara" (Fig. 33A). Sin embargo, en los demás casos, en cada sección las neuronas marcadas se encontraron en una franja más o menos horizontal (Figs. 32B-D [flechas huecas], 33C-D). En tales secciones, las neuronas se ven "de canto" o "de lado" y ofrecen un aspecto más o menos bipolar, con un soma ovalado del que parten dendritas opositopolares que se dirigen medial y lateralmente (Fig. 33B-D). Dentro de esta franja, las neuronas se dispusieron paralelas unas a otras (Fig. 33B).

Es bien conocido que las neuronas multipolares planas del NCoPV inervan al NCoD de su mismo lado (Doucet y Ryugo, 2003). En consecuencia, en nuestros experimentos se marcaron los axones de las neuronas multipolares planas y sus colaterales dorsales que alcanzan al NCoD (Fig. 32A-C). El axón de muchas de estas neuronas viaja medialmente hasta alcanzar el borde medial de NCoPV, punto en el que se ramifica: la rama principal se incorpora al cuerpo trapezoide, mientras que una colateral más delgada viaja dorsalmente hacia el NCoD (Fig. 33E). Sin embargo, hemos observado neuronas cuyo axón recorre dorsalmente distancias variables (en ocasiones, hasta varios cientos de micrómetros) dentro del NCoPV antes de dirigirse medialmente hacia el cuerpo trapezoide (Fig. 33D, F); en estas neuronas, la bifurcación del axón se produce a un nivel considerablemente más dorsal que el nivel en el que se encuentra el soma (Fig. 33D). 

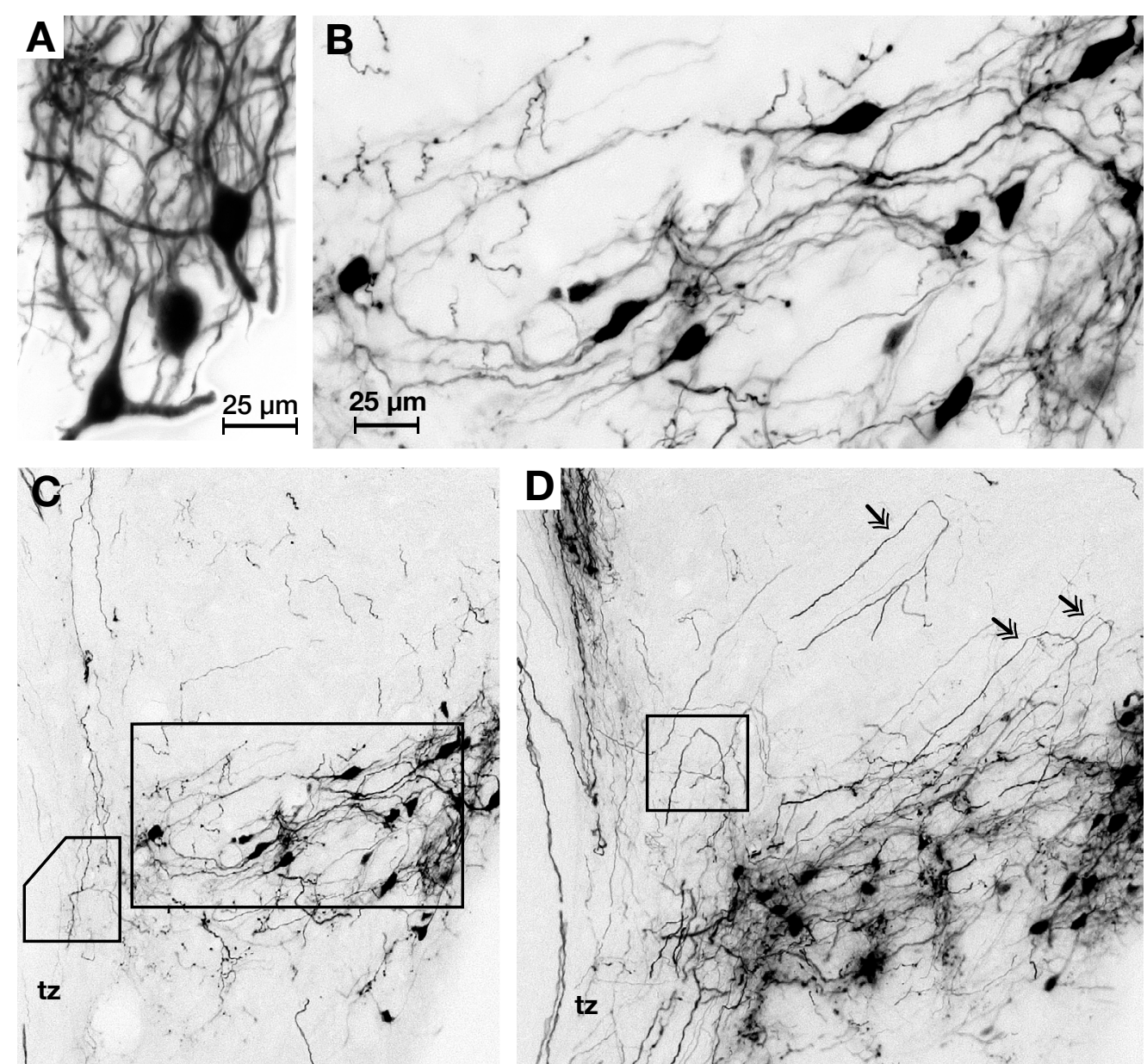

tz
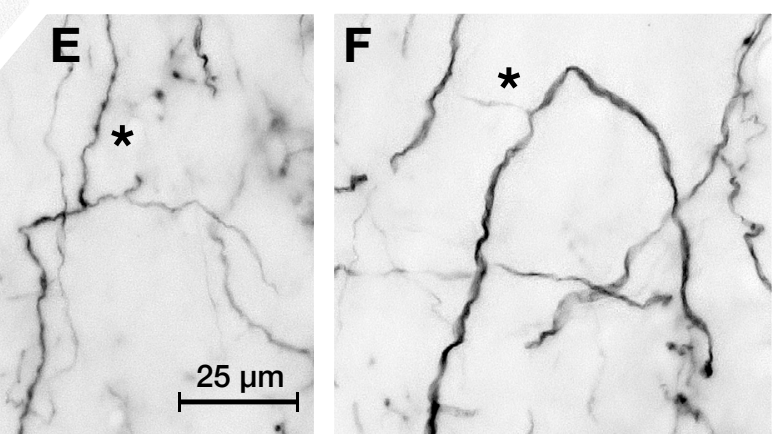

Figura 33. Neuronas multipolares planas marcadas en el NCoPVi. (A) Neuronas multipolares planas vistas "de cara" en una sección coronal muy caudal del NCoPV del caso L01, cuya zona de inyección se muestra en las figuras 29C y 30D. Obsérvese la forma claramente poligonal del soma. Pulsando en este enlace Vídeo suplementario 3 , puede verse un vídeo de la distribución de las neuronas marcadas en este caso. (B-F) Elementos marcados en el NCoPVi del caso L08, cuya zona de inyección en el limbo central de la OSL se ilustra en la figura 29C. Pulsando en este enlace Vídeo suplementario 3, puede verse un vídeo de la distribución de las neuronas marcadas en este caso. (B y C) Neuronas multipolares planas vistas "de canto" en una sección coronal del NCoPV. Nótese la apariencia bipolar y la disposición paralela de las neuronas. La imagen B muestra a mayor aumento el área rectangular delimitada en C. (D) En esta imagen, además de la morfología y la distribución de las neuronas multipolares planas marcadas, se aprecia cómo el axón de algunas de estas neuronas se dirige dorsalmente antes de incurvarse lateralmente hacia el cuerpo trapezoide (flechas dobles). (E y F) Detalle del punto en el que el axón de neuronas multipolares planas se bifurca para dar lugar a una rama que se incorporará al cuerpo trapezoide y otra dirigida dorsalmente hacia el NCoD (asterisco). Las imágenes $\mathbf{E}$ y $\mathbf{F}$ representan, respectivamente, los axones delimitados en las figuras $\mathbf{C}$ y $\mathbf{D}$. La barra de aumento de $\mathbf{C}$ sirve también para $\mathbf{D}$, y la de $\mathbf{E}$ sirve también para $\mathbf{F}$. 
Aunque las neuronas multipolares planas son un tipo neuronal característico del NCoPV, en todos nuestros experimentos se marcaron también algunas en el NCoAV (ver más abajo).

\subsubsection{Neuronas esféricas}

Las neuronas esféricas marcadas reunieron las características morfológicas típicas de las neuronas en arbusto (Brawer y cols., 1974; Cant y Morest, 1979a; Lauer y cols., 2013). El soma presenta contorno liso y redondo o ligeramente ovalado (Fig. 34), con un diámetro máximo medio de $15 \mu \mathrm{m}$ (rango 12-22 $\mu \mathrm{m}$ ), y un diámetro perpendicular al diámetro máximo de $13 \mu \mathrm{m}$ (rango 12-17 $\mu \mathrm{m}$ ). Poseen una o dos dendritas gruesas, lisas, sinuosas y de calibre más o menos constante, que a unas $40 \mu \mathrm{m}$ (rango 8-77 $\mu \mathrm{m}$ ) del soma explotan en un único ramillete o penacho de finos apéndices, que les proporciona su conocido aspecto arbustiforme (Fig. 34B-D). El axón suele nacer del extremo del soma opuesto al arranque de la dendrita y se dirige medialmente hacia el cuerpo trapezoide (Fig. 34C).

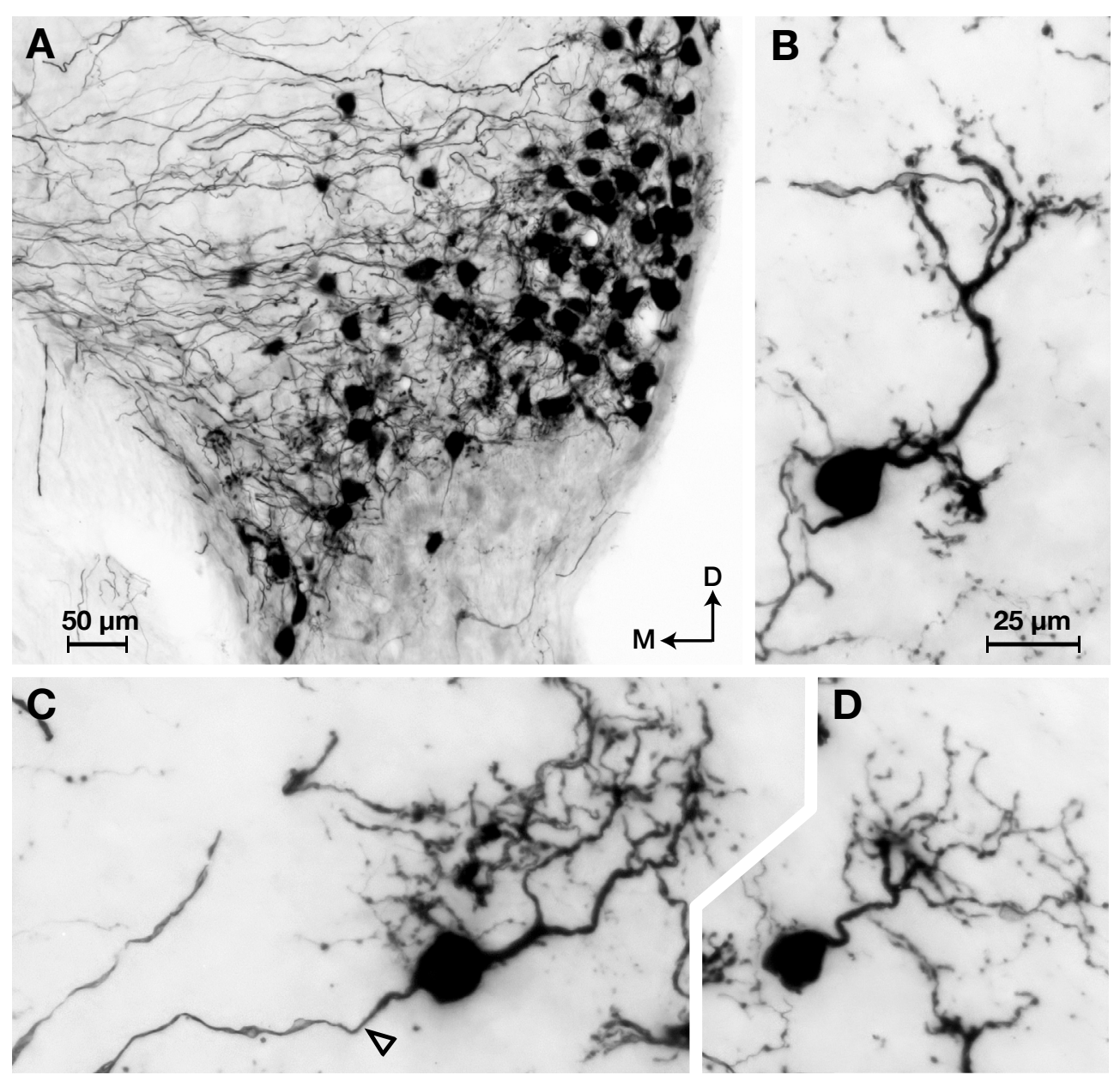

Figura 34. Neuronas esféricas marcadas en el NCoAVi. (A) Microfotografía de una sección coronal del NCoAVi del caso L04 (cuya zona de inyección se muestra en las figuras 29C y 30C) en la que pueden verse abundantes neuronas esféricas marcadas que ocupan un área bien definida. La reconstrucción tridimensional de la distribución de las neuronas marcadas en este mismo caso se muestra en la Fig. 31 y en el Vídeo suplementario 3. (B-D) Detalles de neuronas esféricas típicas marcadas en el NCoAV. La punta de flecha hueca en $\mathbf{C}$ señala el axón de la neurona. La barra de aumento de $\mathbf{B}$ sirve también para $\mathbf{C}$ y $\mathbf{D}$. 
Aunque en el NCoAV se han identificado dos tipos de neuronas arbustiformes (neuronas esféricas y neuronas globulares), nuestros datos sugieren fuertemente que las células marcadas en nuestros casos son neuronas esféricas por tres motivos: 1) En nuestros experimentos se marcaron plexos de axones terminales en la región lateral de la OSMi y en la región medial de la OSMc, que son blancos bien conocidos del axón de las neuronas esféricas (Cant y Casseday, 1986; Smith y cols., 1993; Karino y cols., 2011). 2) En nuestros casos con zona de inyección confinada a la OSL nunca se marcaron cálices de Held en el NMCTc, que son la especialización sináptica característica de las neuronas globulares (Morest, 1968a; Kuwabara y cols., 1991; Smith y cols., 1991; Sätzler y cols., 2002; Borst y cols., 2012). Y 3) Las neuronas de aspecto arbustiforme se marcaron exclusivamente en el NCoAVi, que es la distribución normal de las neuronas esféricas, mientras que las neuronas globulares se reparten por el NCoAV y el NCoPV (Cant y Morest, 1979a, b; Tolbert y cols., 1982; Hackney y cols., 1990).

En cada caso, las neuronas esféricas marcadas se agruparon en un territorio estrecho y aproximadamente horizontal que recorre el núcleo rostrocaudalmente, de manera que en cada sección coronal las neuronas marcadas ocuparon una franja bien definida (Figs. 32F-H [puntas de flecha], 34A). Por lo general, las neuronas se encontraron embebidas en un plexo de axones terminales marcados.

Figura 35. Distribución de las neuronas marcadas en el NMCTi. Microfotografías que muestran la distribución de los elementos marcados en una serie de secciones coronales del NMCTi del caso L04, cuya zona de inyección se muestra en las figuras 29C y 30C. Las secciones aparecen ordenadas de la más caudal a las más rostral y están separadas por intervalos de entre $320 \mu \mathrm{m}$ y $400 \mu \mathrm{m}$. La reconstrucción tridimensional de la distribución de las neuronas marcadas en este mismo caso se muestra en la Fig. 31 y en el Vídeo suplementario 2. Obsérvese que las neuronas marcadas se disponen en una estrecha franja vertical que mantiene su posición lateromedial bastante constante a lo largo de todo el eje rostrocaudal del núcleo. En $\mathbf{B}$ y $\mathbf{C}$ se aprecian dendritas que se extienden verticalmente más allá del límite ventral del núcleo. La barra de aumento de $\mathbf{E}$ sirve para todas las fotografías.
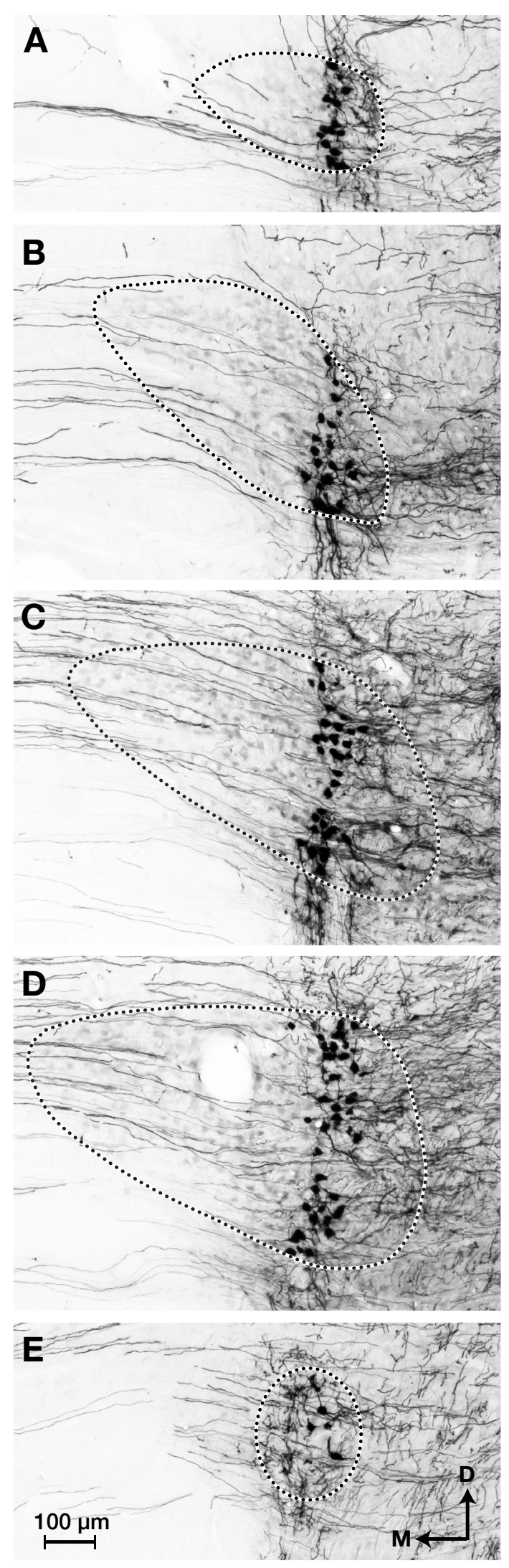


\subsubsection{Neuronas marcadas en el NCoVc}

En la mayor parte de los experimentos, el NCoVc apareció prácticamente desprovisto de neuronas marcadas. Sin embargo, en los casos L13 y L14, cuya zona de inyección afectó a la región de frecuencias más altas de la OSL (Figs. 29C, 30A), hallamos un número apreciable de neuronas marcadas en el NCoVc (ver más abajo). A pesar de que muchas de estas neuronas presentaron un relleno incompleto, que impidió su identificación, la mayoría parecieron esféricas, aunque no podemos descartar que entre ellas hubiera alguna una multipolar.

\subsubsection{Neuronas marcadas en el NMCT}

Las neuronas marcadas en el NMCTi presentaron las características propias de las neuronas principales (Kuwabara y Zook, 1991; Sommer y cols., 1993; Smith y cols., 1998). El soma suele ser redondeado o ligeramente ovalado, con un diámetro máximo de 15-19 $\mu \mathrm{m}$. Poseen 1 ó 2 dendritas relativamente gruesas que se adelgazan a medida que se alejan del soma, y que suelen generar ramas secundarias, terciarias e incluso más distales cada vez más cortas y delgadas (Fig. 36). Son raras las dendritas que terminan en ramilletes de apéndices y, cuando esto sucede, los apéndices son más escasos, largos y rectilíneos que los de las neuronas

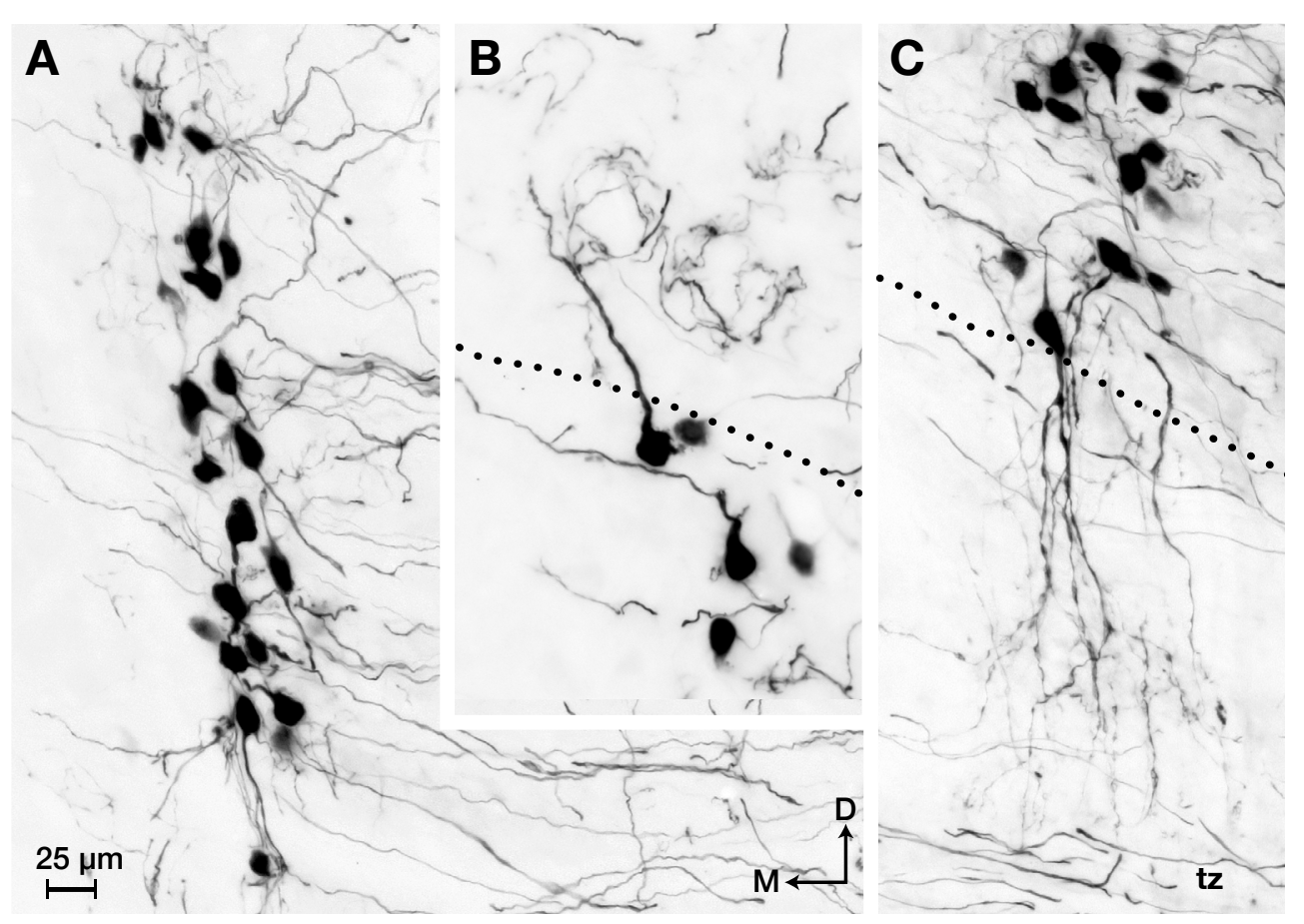

Figura 36. Neuronas principales marcadas en el NMCTi. (A) Detalle de la columna de neuronas marcadas en una sección coronal del caso L07, cuya zona de inyección de BDA en el limbo central de la OSL se muestra en las figuras 29C y 30B. Obsérvese la orientación predominantemente vertical de las dendritas. (B) Detalle de una neurona marcada en la porción más dorsal del NMCT, cuya dendrita se dirige dorsalmente más allá del límite del núcleo, indicado por la línea de puntos. Caso L10, cuya zona de inyección de BDA en la OSL se muestra en la figura 29C. (C) Detalle de neuronas marcadas en la porción más ventral del NMCT. Se aprecia una neurona cuyas dendritas se dirigen ventralmente más allá del límite del núcleo, indicado por la línea de puntos, hasta introducirse en la porción más ventral del cuerpo trapezoide (tz). Caso L07. La barra de aumento de A sirve para todas las fotografías. 
arbustiformes del NCoV (comparar las figuras 34B-D y 36B). Las dendritas pueden alcanzar una longitud considerable: hemos observado dendritas cuya primera bifurcación ocurre a más de $100 \mu \mathrm{m}$ del soma. En general, las dendritas son relativamente rectas y se disponen en un plano aproximadamente parasagital, por lo que en las secciones coronales destacan especialmente las dendritas dirigidas dorsal o ventralmente; las dendritas orientadas medial o lateralmente son muy escasas. Es llamativo que las neuronas situadas más dorsalmente poseen dendritas dirigidas sobre todo en dirección dorsal, que llegan a superar los límites del núcleo, igual que las neuronas ventrales envían sus dendritas ventralmente hasta que se salen del núcleo y llegan en ocasiones prácticamente hasta la superficie ventral del tronco del encéfalo (Figs. 35, 36B, C).

En cada experimento, las neuronas marcadas ocuparon una estrecha franja vertical que recorre rostrocaudalmente todo el núcleo (Figs. 31, 35; Vídeo suplementario 2). Así, en cada sección coronal las neuronas marcadas formaron una columna en la que se entremezclaron los somas alineados verticalmente y las dendritas paralelas unas a otras (Figs. 35, 36A).

Figura 37. Distribución de los elementos marcados en el NVCTc. Microfotografías que muestran la distribución de los elementos marcados en una serie de secciones coronales del NVCT del caso L04, cuya zona de inyección de BDA en el limbo lateral de la OSL contralateral se muestra en las figuras $29 \mathrm{C} \mathrm{y}$ 30C. Las secciones aparecen ordenadas de la más caudal a la más rostral, y están separadas por intervalos regulares de $320 \mu \mathrm{m}$, salvo las secciones $\mathbf{D}$ y $\mathbf{E}$, cuya separación es de 640 $\mu \mathrm{m}$. La reconstrucción tridimensional de la distribución de las neuronas marcadas en este mismo caso se muestra en la Fig. 31 y en el Vídeo suplementario 2. Obsérvese que los elementos marcados (neuronas y axones) se disponen en una estrecha franja muy ventral y que mantiene su posición lateromedial bastante constante a lo largo de todo el eje rostrocaudal del núcleo. La barra de aumento de $\mathbf{E}$ sirve para todas las fotografías.
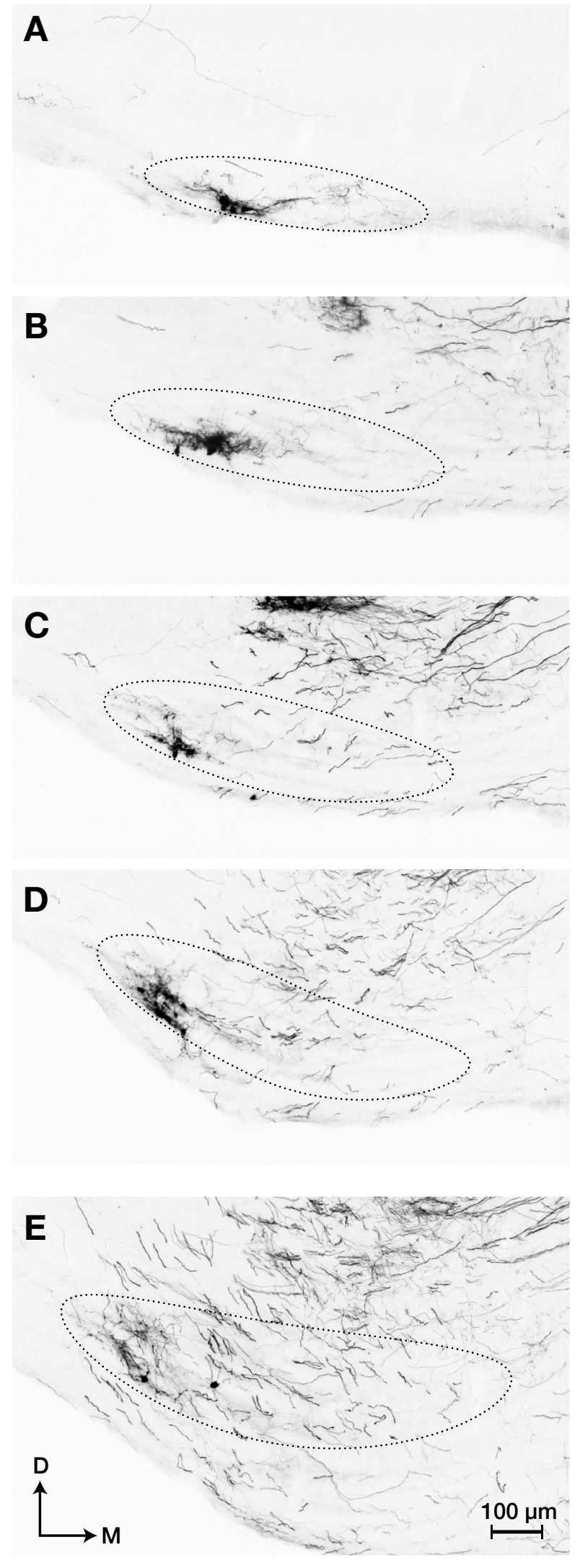


\subsubsection{Neuronas marcadas en el NVCT}

Las neuronas multipolares pequeñas se marcaron exclusivamente en el NVCTc a la zona de inyección. En cada caso, se agruparon en un territorio estrecho que recorre toda la extensión rostrocaudal del núcleo (Figs. 31, 37; Vídeo suplementario 2). En cada sección coronal, las neuronas y fibras terminales marcadas ocuparon una franja más o menos horizontal situada en el tercio ventral del núcleo (Fig. 37). En muchas secciones las neuronas se dispusieron en una única hilera horizontal (Fig. 37A-C), mientras que en otras formaron dos hileras separadas por fascículos del cuerpo trapezoide (Fig. 37D-E).

En todos nuestros casos, las neuronas marcadas en el NVCTc se hallaron embebidas en un plexo de axones, lo que en muchas secciones dificultó su análisis (Figs. 37, 38A). Se trata de neuronas multipolares pequeñas, con diámetros máximos que oscilan entre 8 y 15 $\mu \mathrm{m}$. En secciones coronales el soma suele aparecer ovalado o estrellado, con su eje mayor frecuentemente horizontal, paralelo a los fascículos del cuerpo trapezoide que atraviesan el núcleo (Fig. 38). Del soma parten entre 2 y 5 dendritas relativamente gruesas en su porción más proximal y que se adelgazan a medida que se alejan del soma (Fig. 38B-D). En general, las dendritas principales se dividen en dos prolongaciones secundarias de las que, a su vez, nacen dendritas terciarias de menor calibre. Las dendritas suelen carecer de espinas. Muchas dendritas se extienden medial o lateralmente, paralelas a los fascículos del cuerpo trapezoide y, por tanto, a la superficie ventral del tegmento pontino (Fig. 38A-C). Sin embargo, también se observan dendritas orientadas perpendicularmente al cuerpo trapezoide (Fig. 38D).

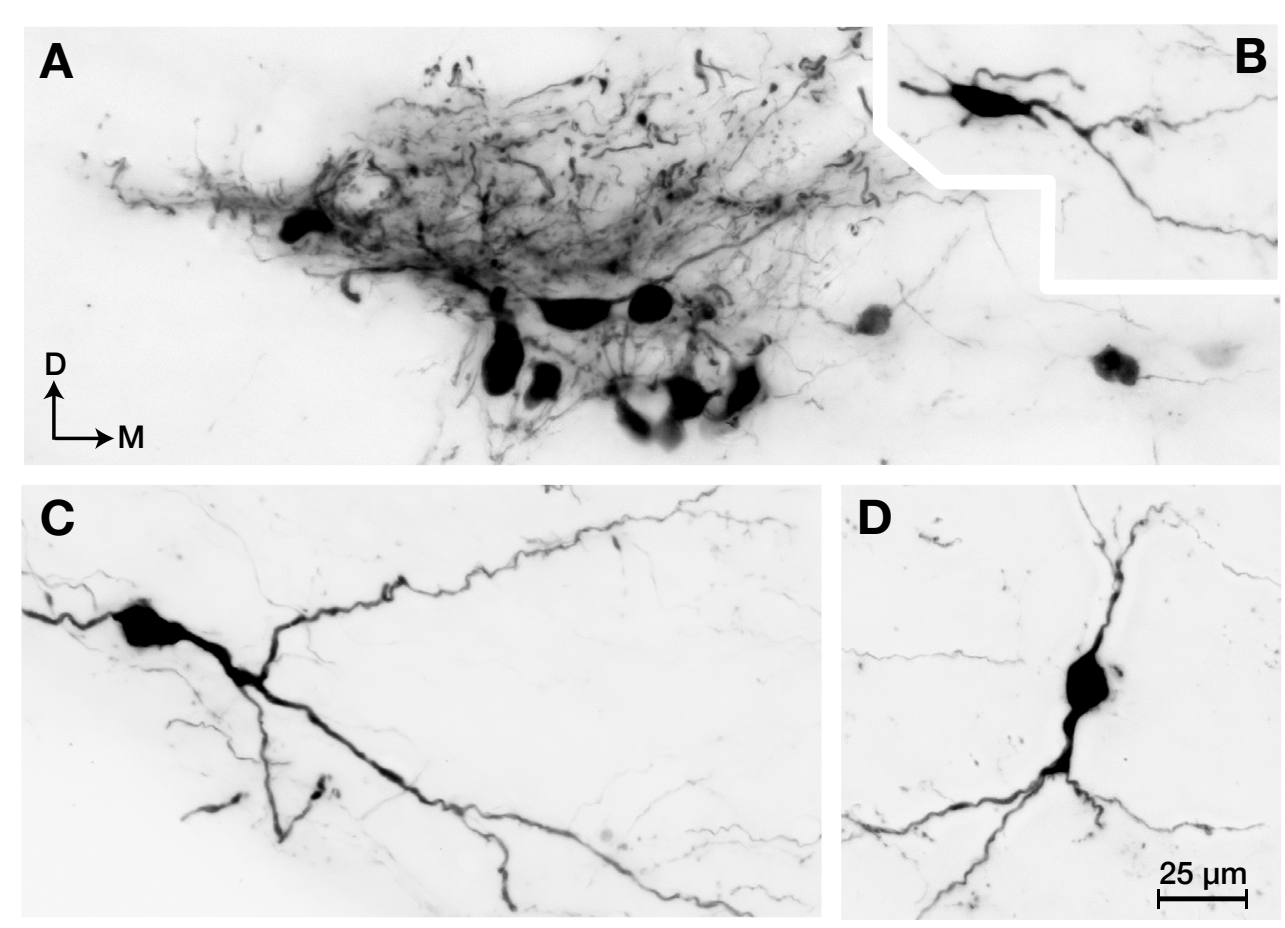

Figura 38. Neuronas multipolares pequeñas marcadas en el NVCTc. (A) Detalle de neuronas multipolares pequeñas situadas en el tercio ventral del NVCT y embebidas en un plexo de axones marcados. Caso L01, cuya zona de inyección se muestra en las figuras 29C y 30D. (B-D) Ejemplos de neuronas multipolares pequeñas marcadas. La barra de aumento de $\mathbf{D}$ sirve para todas las fotografías. 


\subsubsection{Distribución de las neuronas marcadas}

La posición de los somas marcados en el NCoVi, el NMCTi y el NVCTc varió en función de la posición de la zona de inyección con respecto al eje tonotópico de la OSL. La figura 39 y el Vídeo suplementario 3 ilustran la distribución de las neuronas marcadas en el NCoVi de varios casos representativos. En el caso L01, en el que el trazador se inyectó en la región más ventral del limbo lateral de la OSL (región de frecuencias bajas; Fig. 39A), las neuronas marcadas en el NCoPV se encontraron claramente separadas de las marcadas en el NCoAV. Las del NCoPV se situaron muy próximas a la superficie ventrocaudal del núcleo, y las del NCoAV muy próximas a la superficie ventrorrostral (Fig. 39A'-A"; Vídeo suplementario 3). A medida que la zona de inyección se desplazó hacia regiones que procesan sonidos más agudos, las neuronas marcadas en el NCoPV se desplazaron dorsal y rostralmente, y las del NCoAV se movieron dorsal y caudalmente, de manera que los dos grupos de neuronas marcadas se aproximaron
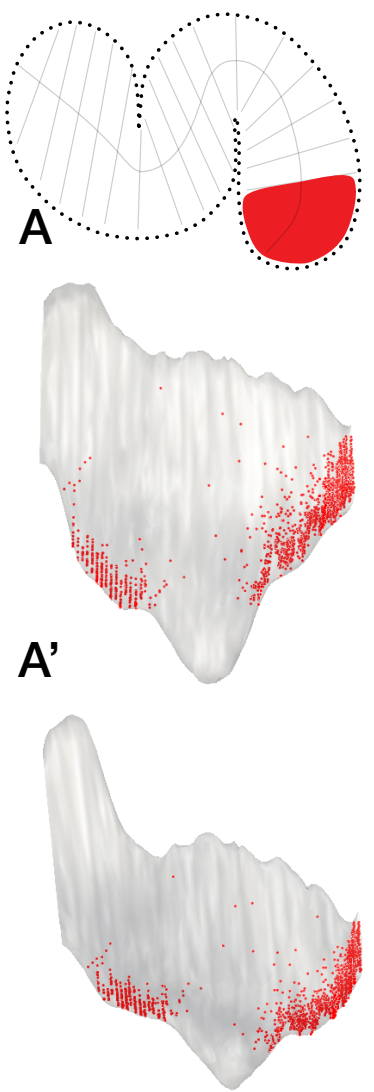

A"

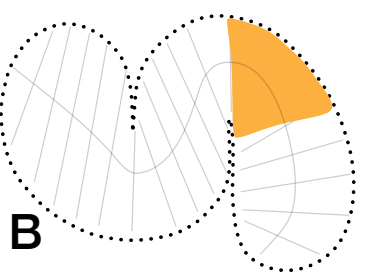

$B^{\prime}$
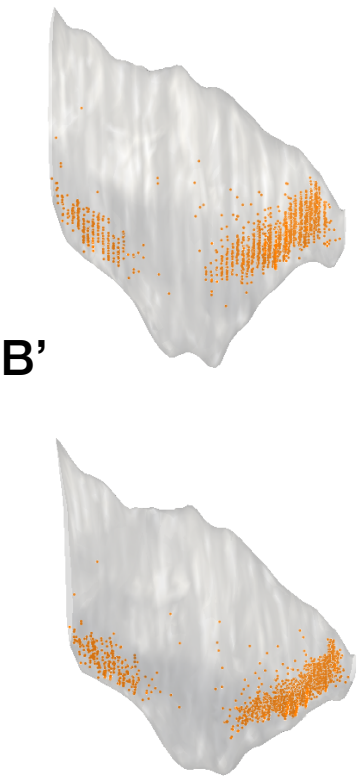

B"
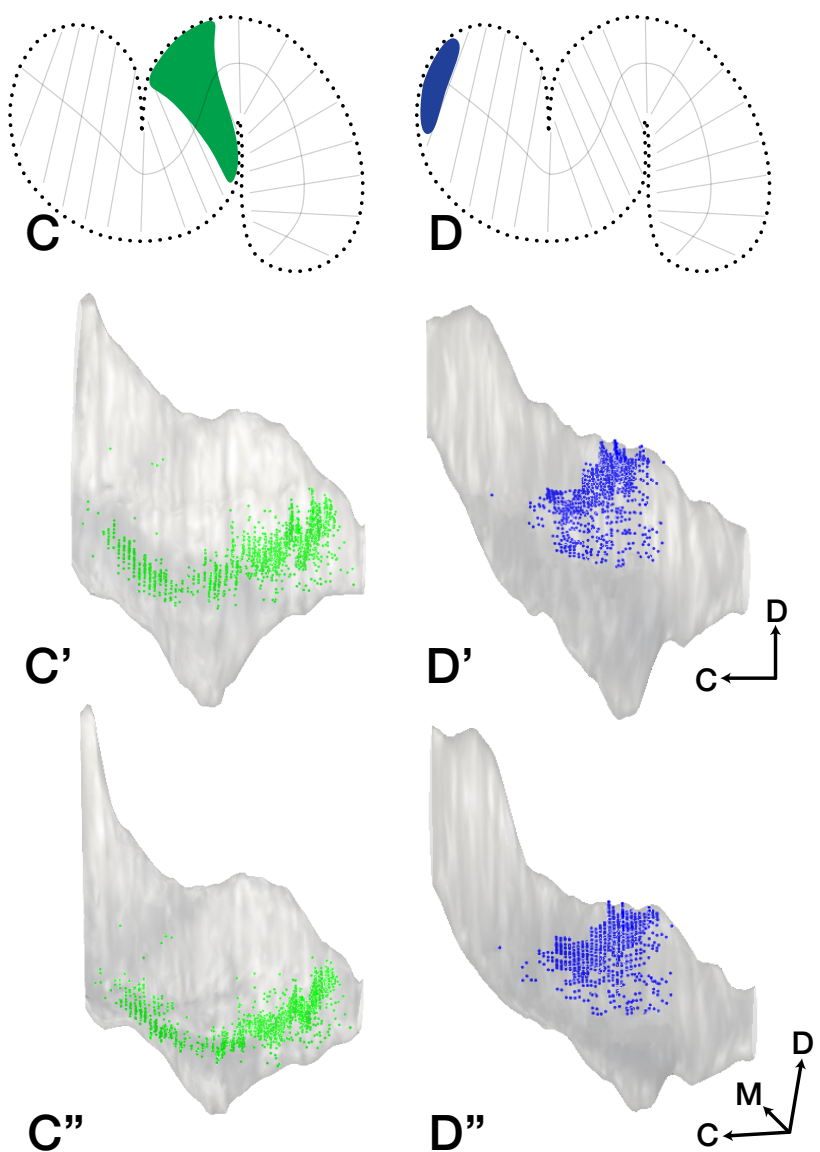

Figura 39. Topografía de las neuronas marcadas en el NCoVi. Reconstrucciones tridimensionales de los núcleo coclear ( $\mathrm{NCo}$ ) del lado derecho de cuatro casos representativos. Cada neurona marcada se ha indicado con un punto. Cada columna ilustra un caso, cuya zona de inyección se representa en la fila superior. En la segunda fila se muestra una visión lateral de los NCo. A fin de que se aprecie mejor la estrechez de las franjas ocupadas por las neuronas, en la tercera fila la imagen inferior se ha rotado ligeramente, de manera que los NCo se observan desde un punto situado por fuera, por encima y por detrás de ellos. Obsérvese cómo al desplazarse la zona de inyección a lo largo del eje tonotópico de la OSL, cambia la posición dorsoventral de las neuronas marcadas en el NCoPV y el NCoAV. (A-A') Caso L01. (B-B') Caso L04. (C-C’) Caso L08. (D-D’) Caso L14. 
progresivamente (Fig. 39B'-B", C'-C"; Vídeo suplementario 3). En el caso L14, las neuronas marcadas aparecieron agrupadas en una única región que abarcó la porción más dorsal y rostral del NCoPV y se continuó con la porción más dorsal del NCoAV (Fig. 39D'-D”), de manera que no queda claro dónde se encuentra el límite entre ambos núcleos. En este caso, el grupo de neuronas marcadas se situó inmediatamente debajo de la lámina de granos que separa al NCoD del NCoV. Del análisis de todos estos casos se concluye que las neuronas del NCoAVi que inervan a la OSL se reparten por todo el núcleo, mientras que las neuronas del NCoPVi

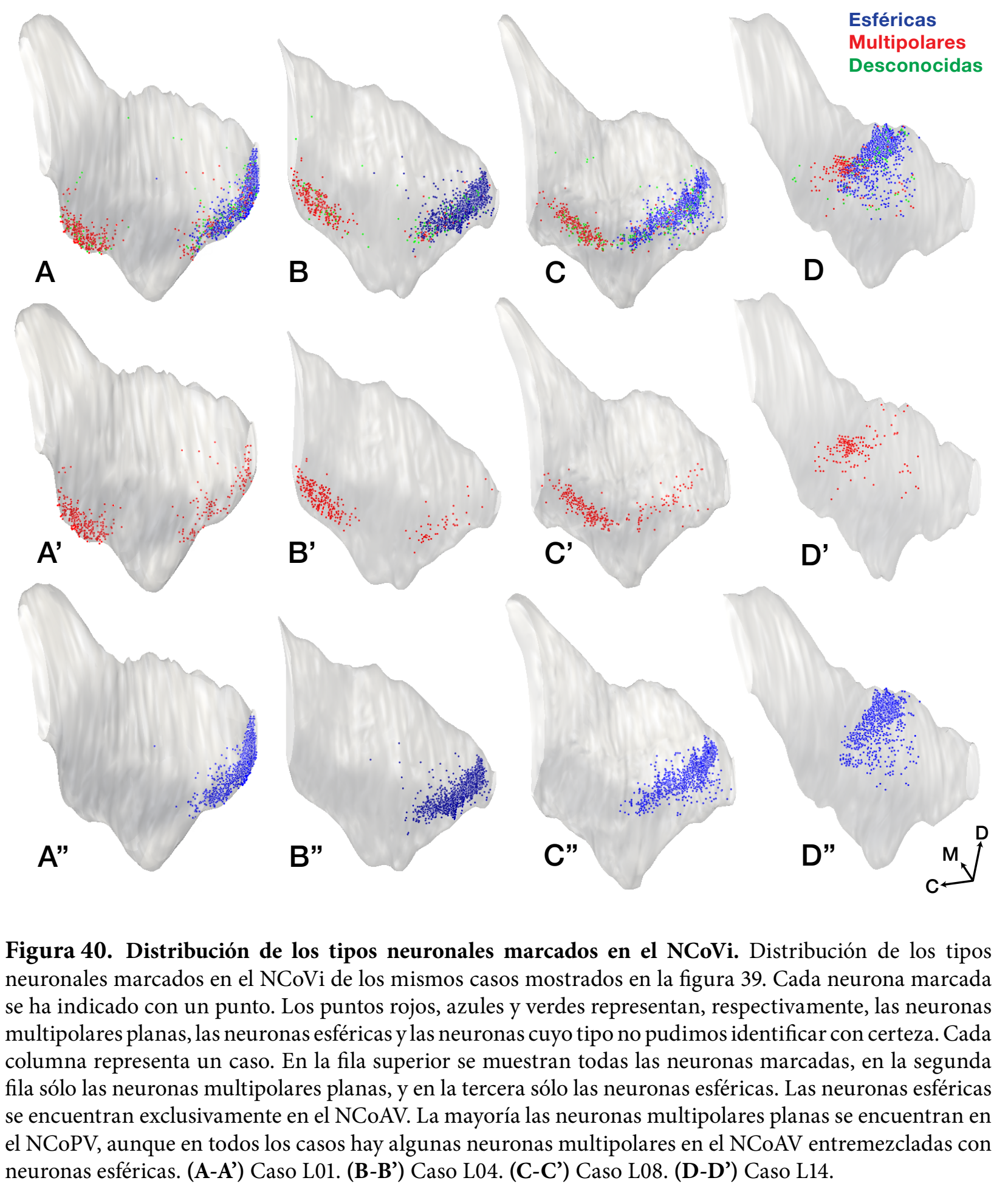


que inervan a la OSL ocupan la mayor parte del NCoPV, pero dejan libre su región más dorsal y caudal, que es el territorio ocupado por las células en pulpo (Saldaña y cols, 1987). Dado que el NCoV recibe inervación topográfica de todas las regiones de la cóclea, estos resultados confirman que, tal como sugería la figura 29B, la OSL de la rata contiene una representación completa de frecuencias.

En la figura 40 se muestra la distribución de los tipos concretos de neuronas marcadas en los mismos casos ilustrados en la figura 39. En cada caso, se han marcado en color rojo las neuronas multipolares planas y en color azul las neuronas esféricas. Los puntos verdes representan a las neuronas cuyo tipo no pudimos identificar con certeza, bien por el relleno incompleto del soma o las dendritas, o bien por la superposición de elementos marcados. Como puede verse, las neuronas esféricas marcadas se hallaron exclusivamente en el NCoAV. Aunque la mayor parte de las neuronas multipolares planas se encontraron en el NCoPV, hallamos también algunas en el NCoAV, entremezcladas con las neuronas esféricas. Por lo tanto, en nuestros experimentos el NCoPV contuvo únicamente neuronas multipolares planas marcadas, mientras que el NCoAV contuvo una mezcla de neuronas multipolares planas y neuronas esféricas.

En los casos con zona de inyección en la región de frecuencias más altas de la OSL, la distribución de las neuronas marcadas en el NCoVc fue más amplia que la de las neuronas marcadas ipsolateralmente (no ilustrado).

La topografía de las neuronas marcadas en el NMCT y el NVCT se ajustó a la conocida organización tonotópica lateromedial de estos núcleos. Así, en los casos en los que el trazador se inyectó en la región más ventral del limbo lateral de la OSL, las neuronas marcadas se encontraron en el extremo más lateral del NMCT y el NVCT. Por el contrario, en los casos con zona de inyección más medial, las neuronas marcadas se hallaron en porciones más mediales del NMCT y el NVCT (Fig. 41).

Figura 41. Topografía de las neuronas marcadas en el NMCTi y el NVCTc. Esquemas de la posición de las neuronas marcadas retrógradamente en el NVCTc (columna de la izquierda) y en el NMCTi (columna de la derecha) de los mismos casos ilustrados en la figura 39. Cada fila corresponde a un caso, identificado con la misma letra y el mismo color que en la figura 39. Para cada caso, se ha seleccionado una sección del tercio rostrocaudal central del núcleo y en ella se han representado con sendos puntos todas las neuronas marcadas en cuatro secciones adyacentes. (A-A') Caso L01. (B-B') Caso L04. (C-C') Caso L08. (D-D') Caso L14.

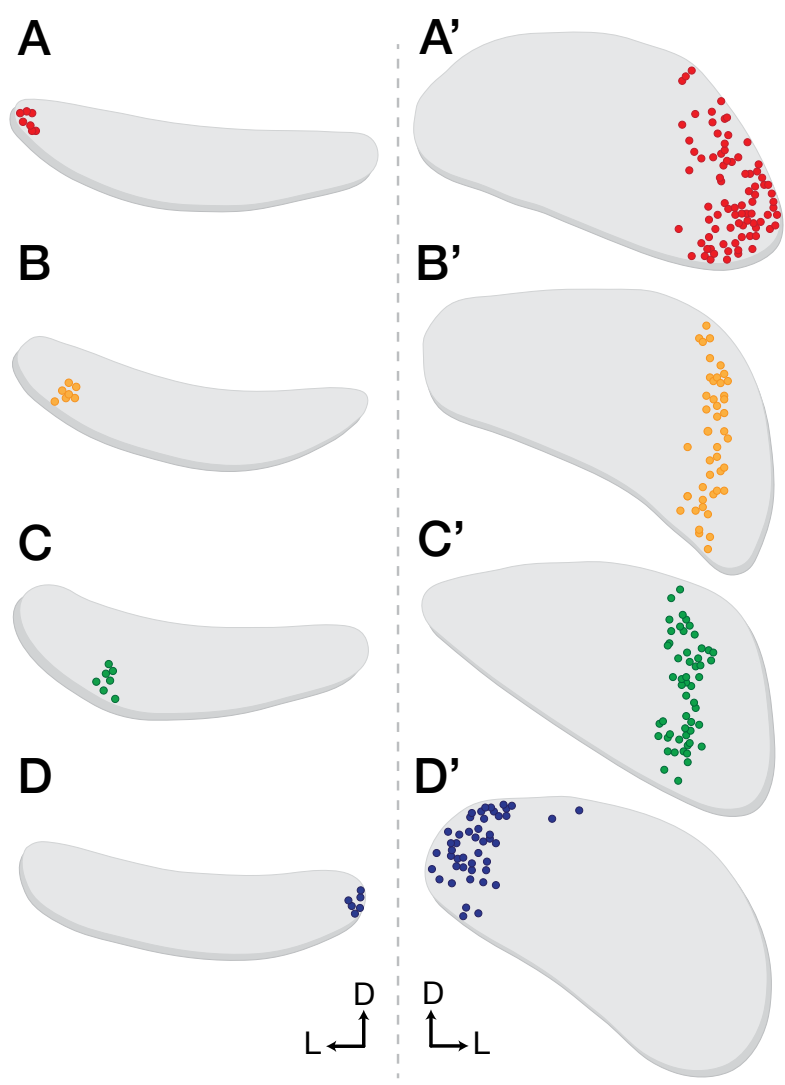

NVCTC

$\mathrm{NMCTi}$ 
Comparando los diversos casos, se observa una llamativa discrepancia entre la posición de la zona de inyección a lo largo del eje tonotópico de la OSL y la posición de las neuronas marcadas a lo largo del eje tonotópico de los distintos núcleos (Tabla 3, Fig. 42). Así, a desplazamientos muy grandes de la zona de inyección en la mitad o los dos tercios laterales de la OSL le corresponden desplazamientos mucho menores de las neuronas marcadas. Por ejemplo, en el caso L08 la zona de inyección afectó a la región comprendida entre el 47 y el $60 \%$ del eje tonotópico de la OSL (que, según el modelo representado en la figura 29B, podría procesar sonidos de unos $11 \mathrm{kHz}$ ). Sin embargo, las neuronas marcadas en este caso ocuparon regiones correspondientes a porcentajes mucho menores del eje tonotópico de sus respectivos núcleos: $20-36 \%$ en el NCoAVi, $29-43 \%$ en el NCoPVi, $21-31 \%$ en el NMCTi, y $24-33 \%$ en el NVCTc. Estos datos sugieren que la representación de frecuencias es bastante similar en el NCoAV, el NCoPV, el NMCT y el NVCT, pero claramente distinta de la de la OSL. Mientras que en la OSL se dedica algo más de la mitad del eje tonotópico del núcleo a procesar sonidos de hasta aproximadamente $11 \mathrm{kHz}$, en los otros núcleos estos mismos sonidos se procesan en un tercio de su eje tonotópico. De forma inversa, en el caso L14, cuya zona de inyección afectó al $5 \%$ más alto de eje tonotópico de la OSL, las neuronas marcadas ocuparon sendas franjas que abarcaron aproximadamente el $20 \%$ del eje tonotópico del NCoAVi, el NCoPVi y el NMCTi.

De estos datos se desprende que la representación de frecuencias en la OSL de la rata es distinta que la de los núcleos que la inervan. En la OSL parece existir una relativa expansión en la representación de las frecuencias de la parte media-baja del espectro (inferiores a, como mínimo, $11 \mathrm{kHz}$ ), y una relativa compresión en la representación de las frecuencias agudas.

Tabla 3. Discrepancia entre la posición de las zonas de inyección en la OSL y la distribución de las neuronas marcadas retrógradamente con relación al eje tonotópico de cada núcleo. Valores expresados en porcentaje del eje tonotópico de cada núcleo.

\begin{tabular}{|c|c|c|c|c|c|}
\hline \multirow[b]{2}{*}{ Caso } & \multirow{2}{*}{$\begin{array}{c}\begin{array}{c}\text { Zona de } \\
\text { inyección }\end{array} \\
\text { OSL }\end{array}$} & \multicolumn{4}{|c|}{ Franja ocupada por las neuronas marcadas } \\
\hline & & NCoAVi & NCoPVi & $\mathrm{NMCTi}$ & NVCTC \\
\hline L01 & $0-15 \%$ & $0-12 \%$ & $0-21 \%$ & $0-22 \%$ & $0-8 \%$ \\
\hline L04 & $25-40 \%$ & $12-28 \%$ & $7-29 \%$ & $13-18 \%$ & $12-18 \%$ \\
\hline L08 & $47-60 \%$ & $20-36 \%$ & $29-43 \%$ & $21-31 \%$ & $24-33 \%$ \\
\hline L14 & $95-100 \%$ & $78-100 \%$ & $79-100 \%$ & $81-100 \%$ & $95-100 \%$ \\
\hline
\end{tabular}




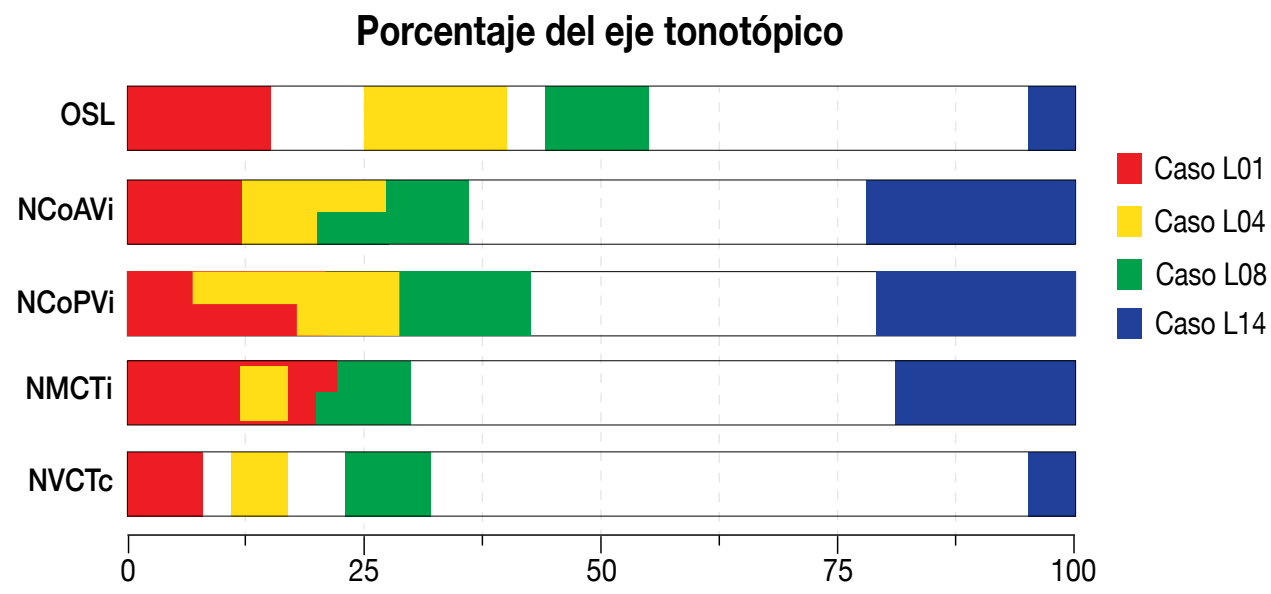

Figura 42. Discrepancia entre la posición de las zonas de inyección en la OSL y la distribución de las neuronas marcadas retrógradamente con relación al eje tonotópico de cada núcleo. Las cinco barras horizontales representan el eje tonotópico de la OSL, el NCoAV, el NCoPV, el NMCT y el NVCT. En cada barra, se ha situado a la izquierda (valor 0) el extremo del núcleo que procesa los sonidos más graves (el extremo ventral del limbo lateral de la OSL, el extremo ventrorrostral del NCoAV, el extremo ventrocaudal del NCoPV y el extremo lateral del NMCT y el NVCT), y a la derecha (valor 100) el extremo del núcleo que procesa los sonidos más agudos (el extremo dorsal del limbo medial de la OSL, el extremo dorsocaudal del NCoAV, el extremo dorsorostral del NCoPV y el extremo medial del NMCT y el NVCT). La barra superior representa la posición de la zona de inyección en la OSL de los mismos casos ilustrados en las figuras 39-41; cada caso se ha indicado con el mismo color que en las figuras anteriores. En las otras cuatro barras se muestra la posición de la franja ocupada por las neuronas marcadas retrógradamente en estos mismos casos. Obsérvese que las frecuencias procesadas en el tercio tonotópico inferior del NCoAVi, el NCoPVi, el NMCTi y el NVCTc parecen ocupar un porcentaje mucho mayor del eje tonotópico de la OSL. Por el contrario, las frecuencias más altas parecen estar más comprimidas en la OSL que en el NCoAVi, el NCoPVi y el NMCTi.

\subsubsection{Número de neuronas marcadas}

Hemos contado el número de neuronas marcadas en los cuatro casos ilustrados en la figuras 39-41. En la tabla 4 se recoge el número de neuronas marcadas en cada núcleo, sin distinguir entre tipos neuronales. Un análisis sistemático de estos datos revela algunas conclusiones interesantes:

1. El número total de neuronas marcadas fue bastante similar en los casos L01, L04 y L08, y algo menor en el caso L14, como cabía esperar a la vista del tamaño de las zonas de inyección (Figs. 29C, 30). En los tres primeros casos la zona de inyección afectó a más del $10 \%$ del eje tonotópico de la OSL, mientras que en el caso L14 afectó sólo al $5 \%$ del eje tonotópico. Este dato sugiere que la eficacia del trazador varió muy poco de unos experimentos a otros.

2. Al comparar entre casos, el porcentaje de neuronas marcadas en cada uno de los núcleos fue notablemente similar. La única excepción a esta norma fueron las neuronas marcadas en el NCoVc, cuyo número fue reseñable sólo en el caso L14, el de frecuencias más altas. 
3. En todos los casos, el núcleo con más neuronas marcadas fue el NCoAV, que contuvo casi la mitad del total, seguido del NMCT, con aproximadamente un tercio de las neuronas marcadas. El NCoPV y el NVCT contuvieron en torno a un $10 \%$ y un $5 \%$ de las neuronas marcadas, respectivamente.

Tabla 4. Número y porcentaje de neuronas marcadas retrógradamente en núcleos auditivos troncoencefálicos después de inyectar BDA en la OSL.

\begin{tabular}{ccccccc}
\hline Caso & NCoPVi & NCoAVi & NCoVc & NMCTi & NVCTc & Total \\
\hline L01 & 312 & 1291 & 7 & 955 & 165 & 2730 \\
& $(11,4 \%)$ & $(47,3 \%)$ & $(0,3 \%)$ & $(35,0 \%)$ & $(6,0 \%)$ & \\
L04 & 264 & 1312 & 17 & 955 & 169 & 2717 \\
& $(9,7 \%)$ & $(48,3 \%)$ & $(0,6 \%)$ & $(35,1 \%)$ & $(6,2 \%)$ & \\
L08 & 295 & 1342 & 2 & 1217 & 153 & 3009 \\
& $(9,8 \%)$ & $(44,6 \%)$ & $(0,1 \%)$ & $(40,4 \%)$ & $(5,1 \%)$ & \\
L14 & 192 & 964 & 113 & 632 & 80 & 1981 \\
& $(9,7 \%)$ & $(48,7 \%)$ & $(5,7 \%)$ & $(31,9 \%)$ & $(4,0 \%)$ & \\
\hline
\end{tabular}

En la tabla 5 se recoge el número de neuronas marcadas en el NCoVi de cada caso, distinguiendo entre multipolares planas, neuronas esféricas y neuronas cuyo tipo no pudimos identificar. Como dijimos más arriba, todas las neuronas identificadas en el NCoPV fueron multipolares planas, mientras que en el NCoAV hallamos una mezcla de neuronas multipolares planas y neuronas esféricas.

Teniendo en cuenta únicamente el número de neuronas identificadas, se concluye que de las neuronas del NCoV que inervan a la OSL ipsolateral, las neuronas multipolares planas representan aproximadamente el 20-30 \%, y las esféricas el 70-80 \% (Tabla 6).

Tabla 5. Número de neuronas marcadas retrógradamente en el NCoV, clasificadas por tipos neuronales.

\begin{tabular}{|c|c|c|c|c|c|c|c|c|}
\hline & \multicolumn{3}{|c|}{ NCoPVi } & \multicolumn{4}{|c|}{ NCoAVi } & \multirow[t]{2}{*}{ NCoVi } \\
\hline & N. Multipolar & Desconocido & Total & N. Esférica & N. Multipolar & Desconocido & Total & \\
\hline L01 & 272 & 40 & $\begin{array}{c}312 \\
(19,5 \%)\end{array}$ & 983 & 129 & 179 & $\begin{array}{c}1291 \\
(80,5 \%)\end{array}$ & 1603 \\
\hline LO4 & 230 & 34 & $\begin{array}{c}264 \\
(16,8 \%)\end{array}$ & 1161 & 47 & 104 & $\begin{array}{c}1312 \\
(83,2 \%)\end{array}$ & 1576 \\
\hline L08 & 225 & 70 & $\begin{array}{c}295 \\
(18 \%)\end{array}$ & 1011 & 76 & 255 & $\begin{array}{l}1342 \\
(82 \%)\end{array}$ & 1637 \\
\hline L14 & 172 & 20 & $\begin{array}{c}192 \\
(16,6 \%)\end{array}$ & 856 & 24 & 84 & $\begin{array}{c}964 \\
(83,4 \%)\end{array}$ & 1156 \\
\hline
\end{tabular}


Tabla 6. Número de neuronas multipolares planas y esféricas marcadas retrógradamente en el NCoVi.

\begin{tabular}{cccc}
\hline Caso & N. Multipolares & N. Esféricas & Total \\
\hline L01 & 401 & 983 & 1384 \\
& $(29,0 \%)$ & $(71,0 \%)$ & \\
L04 & 277 & 1161 & 1438 \\
& $(19,3 \%)$ & $(80,7 \%)$ & \\
L08 & 301 & 1011 & 1312 \\
& $(23,0 \%)$ & $(77,0 \%)$ & 1052 \\
L14 & 196 & 856 & \\
& $(18,7 \%)$ & $(81,3 \%)$ & \\
\hline
\end{tabular}

Para deducir el número total de neuronas multipolares planas y neuronas esféricas que inervan a la OSL, puede asumirse que todas las neuronas de tipo neuronal desconocido marcadas en el NCoPV son multipolares, y las neuronas no identificadas marcadas en el NCoAV se reparten siguiendo el mismo porcentaje que las neuronas identificadas en marcadas en él. Así, por ejemplo, en el caso L01 se marcaron en el NCoPV 40 neuronas de tipo desconocido, que asumimos que son multipolares, y 179 neuronas de tipo desconocido en el NCoAVi. Como en este caso las neuronas multipolares y esféricas representaron el $23 \%$ y el $77 \%$, respectivamente, de las neuronas identificadas en el NCoAV, guardando esta proporción hemos calculado que las 179 neuronas de tipo desconocido del NCoAV, 41 son multipolares y 138 son esféricas. La tabla 7 y la figura 43 recogen los datos sobre el número de neuronas de cada tipo calculado con este procedimiento.

Puede concluirse, por tanto, que la principal fuente de proyección a la OSL de la rata son las neuronas esféricas del NCoAVi, que representan aproximadamente el $45 \%$ de las aferencias de origen troncoencefálico, mientras que el número de neuronas multipolares planas que inervan a la OSL es aproximadamente tres veces menor.

Tabla 7. Número de neuronas marcadas retrógradamenteen núcleosauditivostroncoencefálicos clasificadas por tipos neuronales.

\begin{tabular}{ccccccc}
\hline Casos & N. Multipolares & N. Esféricas & CoNc & NMCTi & NVCTc & Total \\
\hline L01 & 442 & 1121 & 7 & 955 & 165 & 2690 \\
& $(16,4 \%)$ & $(41,2 \%)$ & $(0,3 \%)$ & $(35,0 \%)$ & $(6,1 \%)$ & \\
L04 & 301 & 1241 & 17 & 955 & 169 & 2680 \\
& $(11,3 \%)$ & $(46,3 \%)$ & $(0,6 \%)$ & $(35,5 \%)$ & $(6,3 \%)$ & \\
L08 & 360 & 1207 & 2 & 1217 & 153 & 3009 \\
& $(12,3 \%)$ & $(41,0 \%)$ & $(0,1 \%)$ & $(41,5 \%)$ & $(5,2 \%)$ & \\
L14 & 215 & 921 & 113 & 632 & 80 & 1981 \\
& $(11,0 \%)$ & $(46,9 \%)$ & $(5,7 \%)$ & $(32,3 \%)$ & $(4,1 \%)$ & \\
Total & 1318 & 4490 & 139 & 3759 & 567 & 10273 \\
& $(12,8 \%)$ & $(43,7 \%)$ & $(1,4 \%)$ & $(36,6 \%)$ & $(5,5 \%)$ & \\
\hline
\end{tabular}




\section{Proporción de neuronas marcadas}

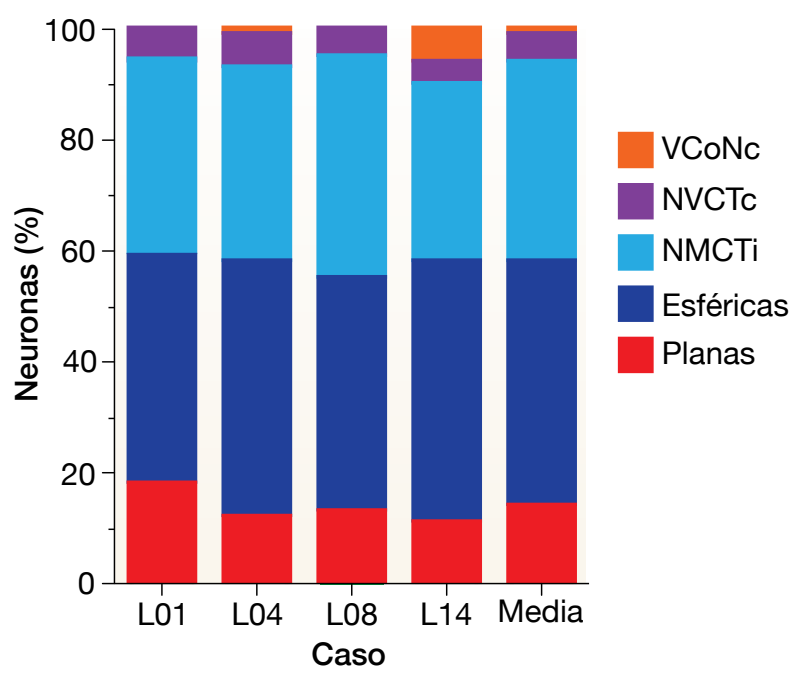

Figura 43. Contribución relativa de los diferentes tipos neuronales a la inervación de la OSL. Histograma que ilustra la proporción de neuronas de cada tipo marcadas en los cuatro casos ilustrados en las figuras 39-41. Obsérvese que las proporciones apenas varían de unos casos a otros.

Para comprobar matemáticamente si la contribución de los diferentes tipos neuronales a la inervación de la OSL varía de unos casos a otros, hemos aplicado la prueba estadística de Chi-cuadrado, que permite comparar la proporción de neuronas marcadas entre los distintos casos, y compara también cada caso con los valores medios de todos los casos. Ninguna de las comparaciones arrojó diferencias estadísticamente significativas. En consecuencia, la proporción de neuronas marcadas en los diversos núcleos fue prácticamente idéntica en todos los casos. Esto implica que todas las regiones de la OSL reciben una combinación similar de impulsos. Por lo tanto, teniendo en cuenta sus aferencias, la OSL de la rata no parece contener regiones funcionalmente especializadas.

"Dado que todas las regiones de la OSL de la rata reciben una combinación similar de impulsos, este núcleo no parece contener regiones funcionalmente especializadas".

\subsection{Axones marcados en el COS}

En todos los casos con inyección de BDA en la OSL de la rata, encontramos abundantes axones terminales marcados en una enorme variedad de centros nerviosos: en el NCoV y el NCoD ipsolaterales, en la mayor parte de los núcleos del complejo olivar superior (COS) ipsolateral, en el NVCTc y la oliva superior medial contralateral (OSMc), en los núcleo ventral y dorsal del lemnisco lateral y el $\mathrm{Cl}$ de ambos lados, y en el tálamo auditivo contralateral. En nuestros experimentos se marcaron también los axones de las neuronas olivococleares laterales. Además hallamos abundantes axones de paso marcados en el cuerpo trapezoide, pero no en la estría acústica dorsal, ni en la intermedia. Dado que nuestro objetivo es investigar 
los circuitos que intervienen en la codificación de las pistas auditivas biauriculares, limitaremos nuestro análisis a los axones terminales marcados en el COS de ambos lados; los demás axones marcados serán mencionados sólo cuando resulten relevantes para nuestros fines.

Aunque nuestro material no se presta al análisis de fibras individuales, examinamos la trayectoria que siguen los axones de los diferentes tipos neuronales marcados. A pesar de que los axones de las neuronas esféricas fueron reconocibles por su calibre, su posición en el cuerpo trapezoide y el modo en el que cruzan la línea media, no encontramos en ninguno de los dos lados disposiciones u orientaciones que hicieran pensar en trayectorias compatibles con las líneas de retraso preconizadas en el modelo de Jeffress (1948).

\subsubsection{Organización general del COS}

El COS de la rata está integrado por varias agrupaciones neuronales que difieren en sus características citoarquitectónicas, neuroquímicas y electrofisiológicas. El análisis detallado de estas características, que claramente excede los límites de este Trabajo, ha sido objeto de múltiples estudios anteriores (Irving y Harrison, 1967; Harrison y Feldman, 1970; Casey y Feldman, 1982, 1988; White y Warr, 1983; Osen y cols., 1984; Faye-Lund, 1986; Lu y cols., 1987; Grandes y Streit, 1989; Casey, 1990; Kuwabara y cols., 1991; Kuwabara y Zook, 1991; Vetter y Mugnaini, 1992; Friauf, 1993; Kandler y Friauf, 1995; Robertson, 1996; Warr y Beck, 1996; Caicedo y cols., 1998; Rietzel y Friauf, 1998; Yao y Godfrey, 1998; Sato y cols., 1999; Kudo y cols., 2000; Kulesza y Berrebi, 2000; Saldaña y Berrebi, 2000; Kulesza y cols., 2002, 2003; Blaesse y cols., 2005; Lukose y cols., 2011; Ehmann y cols., 2013). Aquí vamos únicamente a comentar aquellos aspectos de la organización del COS esenciales para interpretar la distribución de los campos axónicos terminales marcados en nuestros experimentos.

La figura 44 muestra secciones coronales representativas del COS de la rata. Las tres fotografías de la izquierda ilustran secciones de un nivel que incluye la porción central de la OSL (Fig. 44A-C), y las tres fotografías de la derecha corresponden a un nivel más rostral del COS (Fig. 44D-F). En cada columna, la sección superior está teñida con el método de Nissl (Fig. 44A, D), la sección central se ha teñido con una técnica de inmunoperoxidasa para visualizar la calbindina (CB) (Fig. 44B, E), y la inferior se ha procesado con un método de inmunofluorescencia para revelar el transportador de glicina de tipo 2 (GlyT2) (Fig. 44C, F).

EI NMCT se reconoce porque sus neuronas, bien teñidas con el método de Nissl y muy inmunorreactivas para la $\mathrm{CB}$, se disponen en hileras paralelas separadas por los fascículos del cuerpo trapezoide (Fig. 44A, B, D, E). En las secciones caudales, la OSL destaca por su neuropilo intensamente inmunorreactivo para la CB y el GlyT2 (Fig. 44B, C), que representa la proyección procedente del NMCT. Algo similar sucede con el núcleo parolivar superior (NPS), situado entre el NMCT y la OSL, que también es inervado por el NMCT y, en consecuencia, posee un neuropilo intensamente inmunoteñido (Fig. 44B, C). Además, el NPS contiene las neuronas más grandes de todo el COS, que suelen encontrarse bastante dispersas y cuyos somas se orientan verticalmente (Fig. 44A). La OSM se reconoce por la típica disposición en 
empalizada de sus neuronas de soma alargado y horizontal (Fig. 44A, D) y porque su neuropilo muestra una inmunotinción para la CB mucho más débil que la de la OSL o el NPS (Fig. 44B). Por último, el núcleo laterales del cuerpo trapezoide (NLCT) y el NVCT poseen características citoarquitectónicas y neuroquímicas menos distintivas, pero pueden delinearse por sus límites relativamente nítidos y por su posición con respecto a los demás núcleos del complejo (Fig. $44 \mathrm{~A}, \mathrm{C})$.
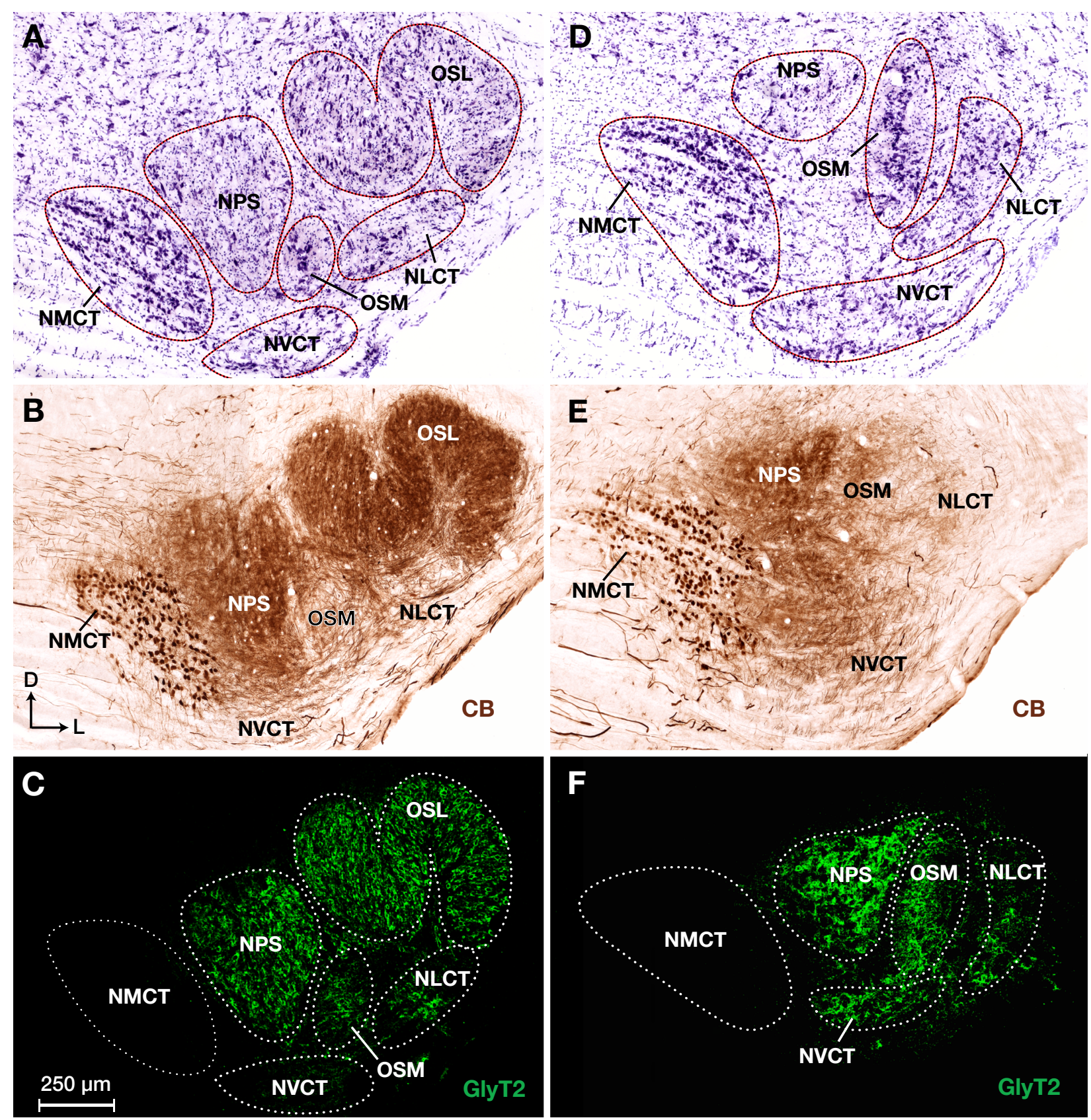

Figura 44. Secciones coronales del COS de la rata. Las tres fotografías de la izquierda ilustran secciones de un nivel que incluye la porción central de la OSL y las tres fotografías de la derecha corresponden a un nivel más rostral del COS. En cada columna la sección superior está teñida con el método de Nissl (A, D), la sección central se han teñido inmunocitoquímicamente para visualizar la calbindina (CB) (B, E) y la inferior se ha procesado con un método de inmunofluorescencia para revelar el transportador de glicina de tipo 2 (GlyT2) (C, F). La barra de aumento de $\mathbf{C}$ sirve para todas las fotografías. 
Los seis núcleos que acabamos de mencionar aparecen en secciones caudales del COS, y en ellas ofrecen su posición y su aspecto característicos (Fig. 44A-C). Sin embargo, la apariencia del COS cambia sustancialmente a niveles rostrales. En las secciones rostrales no aparece la OSL, el NPS es más pequeño y ocupa una posición muy dorsal, la OSM aparece como una poderosa columna de neuronas de aproximadamente $0,5 \mathrm{~mm}$ de altura, y el NLCT y el NVCT ocupan la mayor parte de la región ventrolateral del complejo (Fig. 44D-E). En apartados posteriores de este Trabajo, para ilustrar las porciones caudales y rostrales del COS, emplearemos secciones tomadas de niveles similares a los mostrados en la figura 44.

\subsubsection{Campos terminales marcados en el COS: Patrón general}

Las figuras 45 y 46 muestran secciones coronales del COS del caso L07, que recibió una inyección de BDA en el limbo central de la OSL derecha. Utilizaremos este caso como ejemplo representativo para ilustrar el patrón general de marcado en el COS. Tal como describimos en el apartado 1.3.2, en cada sección del NMCTi se aprecian numerosas neuronas marcadas retrógradamente que forman una columna vertical (Figs. 45, 46B, D). En el COSi se observan también tres densos plexos aplanados de fibras terminales marcadas (Fig. 45). El primero de ellos, de orientación aproximadamente parasagital, recorre toda la extensión rostrocaudal y

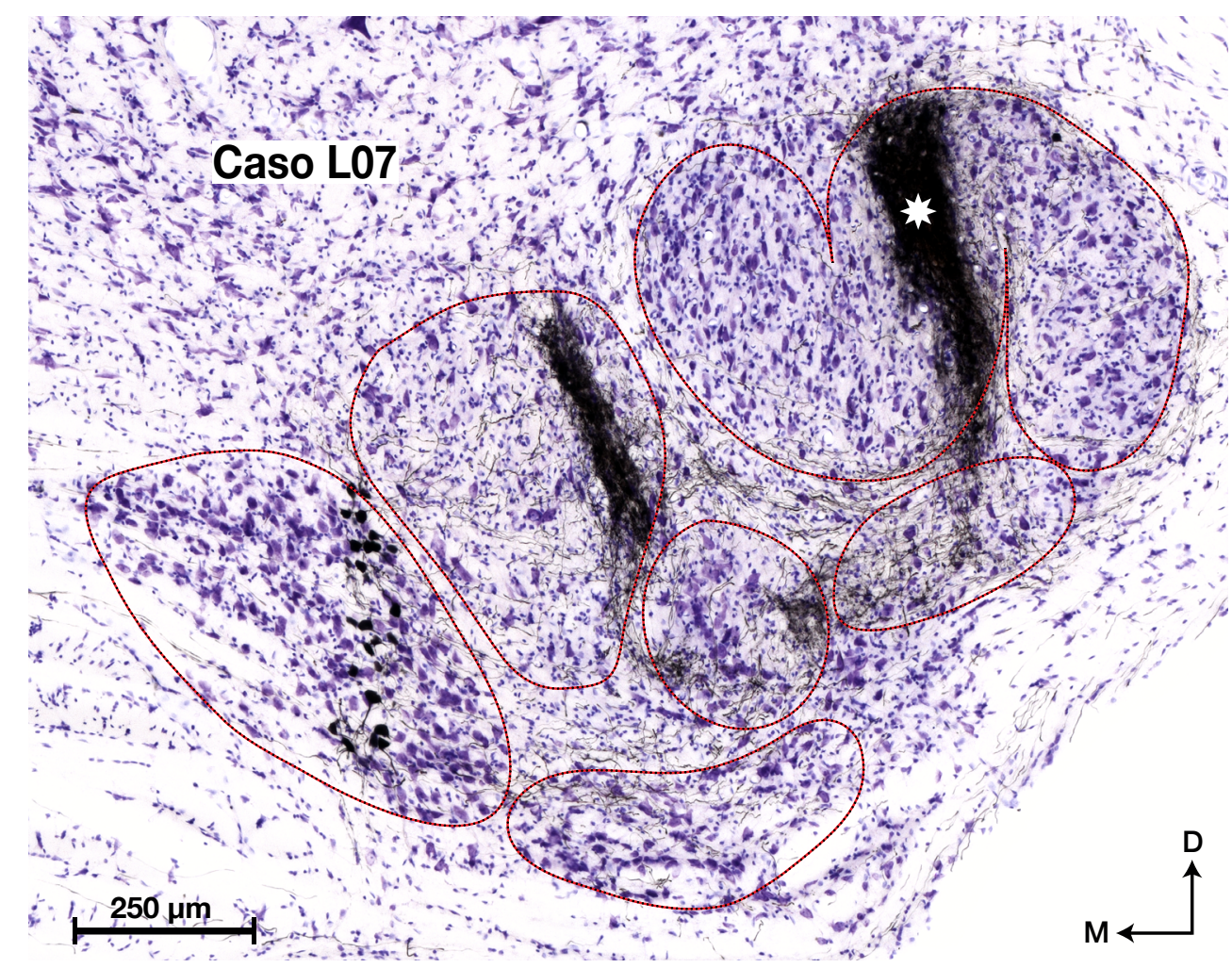

Figura 45. Patrón general de marcado en el COS. Microfotografía de una sección coronal del COS del caso L07, en el que se inyectó BDA en el limbo central de la OSL. El asterisco indica el centro de la zona de inyección. Pueden observarse una columna de neuronas marcadas en el NMCT, un plexo vertical de axones terminales en el NPS, y dos plexos de axones terminales en la OSM. Esta misma sección se muestra a mayor aumento en la figura 46F. Sección contrastada con el método de Nissl. 
dorsoventral del NPS, de modo que en cada sección coronal aparece como una estrecha franja vertical sumamente densa y de límites muy nítidos (Figs. 45, 46B, D, F, G). Los otros dos plexos se encuentran en la OSM, poseen una orientación aproximadamente horizontal y también recorren toda la extensión rostrocaudal del núcleo (Figs. 45, 46B, D). Uno de estos plexos se sitúa en la mitad medial de la OSM y el otro en la mitad lateral, y aparecen siempre a la misma altura dorsoventral y claramente alineados o enfrentados (Fig. 45, 46B, D). En la mayoría de las secciones estos dos plexos están nítidamente separados y se sitúan a uno y otro lado de la columna formada por los somas de las neuronas de la OSM, de manera que parecen inervar sólo a las dendritas mediales o laterales (Fig. 46F). Sin embargo, en algunas secciones los dos plexos se unen hasta formar uno solo que abarca tanto a las regiones ocupadas por las dendritas, como a la zona ocupada por los somas (Fig. 46G).

En el COSc se encuentran elementos marcados en dos núcleos. Por una parte, en el NVCT se observan tanto neuronas, como axones terminales. Los axones terminales marcados en el NVCT ya los describimos e ilustramos en el apartado 1.3.3 y como no parecen formar parte de los circuitos implicados en la detección de las DIT, no volveremos a considerarlos en estos resultados. Por otra parte, en la OSM se aprecia un plexo de axones terminales marcados en la región ocupada por las dendritas mediales de las neuronas del núcleo (Fig. 46A, E). Igual que en el lado ipsolateral, el plexo de la OSMc se extiende a lo largo de toda la extensión rostrocaudal del núcleo y conserva una densidad similar a todos los niveles (Fig. 46A, C).

Una de las cuestiones fundamentales para interpretar estos resultados es deducir a qué tipo neuronal pertenece cada uno de los campos terminales marcados. Debido al carácter bidireccional del BDA y a su capacidad para generar transporte colateral, en principio cada axón marcado puede pertenecer o bien a neuronas de la zona de inyección en la OSL, o bien a las neuronas que inervan a la OSL, ya identificadas en el apartado 1.3: neuronas multipolares planas y neuronas esféricas del NCoVi, neuronas principales del NMCTi, y neuronas multipolares pequeñas del NVCTc. Analizando críticamente los datos disponibles en la literatura y los derivados de nuestros propios experimentos, puede deducirse la contribución de cada tipo neuronal al patrón de marcado observado.

Es sumamente improbable que los campos terminales marcados en el COS en los casos con inyección de BDA en la OSL pertenezcan a neuronas de la propia OSL porque: a) que sepamos, no se han demostrado proyecciones de la OSL a ningún otro núcleo del COS ipso o contralateral; y b) en los casos de nuestro laboratorio con inyecciones de BDA limitadas al NPS, la OSM o el NVCT, la OSL careció de neuronas marcadas retrógradamente. Es también poco probable que los axones marcados pertenezcan a neuronas del NVCTc, pues aunque este núcleo inerva a la OSL, no parece inervar a otros núcleos del COS (Warr y Beck, 1996; GómezNieto y cols., 2008). Podemos descartar también que pertenezcan a las neuronas multipolares planas, porque si bien sus axones inervan al NLCTi, al NVCTc y al NPSc, no parecen inervar a la OSM de ninguno de los dos lados, ni al NPS de su mismo lado (Doucet, 2003, 2006; Darrow, 2012; nuestros propios casos no publicados con inyección de BDA en el NCoD de la rata). 

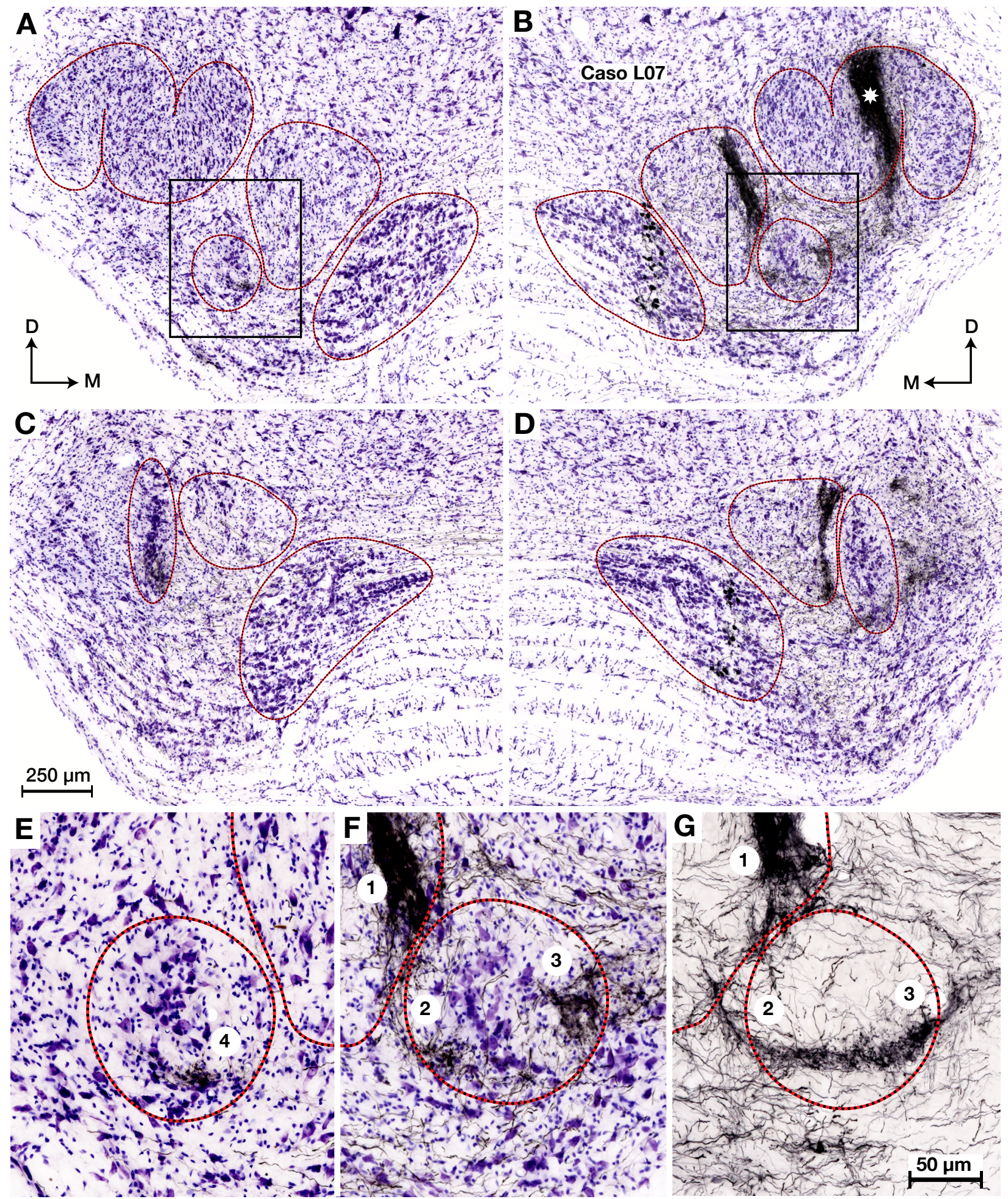

Figura 46. Distribución de los plexos de axones terminales en el COS. (A, B) Microfotografías de la porción caudal del COS del lado izquierdo (A) y el COS del lado derecho (B) del caso L07, en el que se inyectó BDA en el limbo central de la OSL derecha. El asterisco indica el centro de la zona de inyección. En el COSi se aprecia un campo terminal de axones marcados en el NPS, y otros dos campos terminales en la OSM (A), mientras que en el COSc únicamente se aprecia un campo terminal marcado en la porción medial de la OSM. Las áreas enmarcadas de A y B se muestran a mayor aumento en $\mathbf{E}$ y $\mathbf{F}$, respectivamente. (C, D) Microfotografías de la porción rostral del COS del lado izquierdo (C) y el COS del lado derecho (D) del mismo caso. Los mismos plexos que se veían en las secciones caudales (A y B) se aprecian también en las rostrales, en las que conservan su posición y orientación y muestran una densidad similar. (E) Detalle del plexo terminal $>>>$ 
Descartadas las neuronas de la OSL, las del NVCTc y las neuronas multipolares planas, lo más probable es que los plexos terminales marcados en nuestros experimentos pertenezcan a neuronas esféricas y/o a neuronas principales del NMCTi. Las neuronas esféricas son una conocida fuente de inervación bilateral para la OSM (ver referencias en la Introducción). Sus axones terminan en las dendritas laterales de las neuronas de la OSMi y en las dendritas mediales de las neuronas de la OSMc. Por su parte, las neuronas principales del NMCT son conocidas por inervar densamente a múltiples núcleos del COS ipsolateral, entre los que se incluyen el NPS y la OSM (ver referencias en la Introducción).

Tabla 8. Interpretación de la procedencia de los plexos de axones marcados en el COS

\begin{tabular}{ccccc}
\hline \multirow{2}{*}{$\begin{array}{c}\text { Fuente de } \\
\text { inervación }\end{array}$} & NPSi & OSMi (medial) & OSMi (lateral) & OSMc (medial) \\
\cline { 2 - 5 } OSL & & & \\
N. Multipolar & & & $X$ & $X$ \\
N. Esférica & & $X$ & $?$ & \\
NMCTi & $X$ & & & \\
NVCTC & & & & \\
\hline
\end{tabular}

Todos estos datos nos llevan a una serie de conclusiones sobre la procedencia de los plexos de axones terminales marcados en nuestros experimentos que coinciden con las alcanzadas por otros investigadores que realizaron experimentos similares (Warr y cols., 1997; Cantos y cols., 2003). Las conclusiones, recogidas de modo resumido en la tabla 8 y la figura 47, son las siguientes:

1. Los axones marcados en el NPSi pertenecen con toda probabilidad a neuronas principales del NMCTi.

2. Los axones marcados en la mitad medial de la OSMi deben de tener su origen en neuronas del NMCTi.

3. El plexo de la mitad lateral de la OSMi probablemente está formado por axones de neuronas esféricas, aunque no podemos descartar que entre ellos se encuentre algún que otro axón del NMCTi.

4. Los axones marcados en la mitad medial de la OSMc pertenecen a neuronas esféricas.

$>>>$ marcado en la OSMc. El campo terminal, indicado con el número 4, queda restringido a la región ocupada por las dendritas mediales. (F) Detalle de los plexos terminales marcados en el COSi. Se han indicado con números el plexo marcado en el NPS (1), el plexo de la región medial de la OSM (2) y el plexo de la región lateral de la OSM (3). Obsérvese que los campos terminales medial y lateral de la OSM (2 y 3) están claramente separados y dejan libre la región ocupada por los somas de las neuronas del núcleo. (G) Fotografía de una sección próxima a la mostrada en $\mathbf{F}$ en la que, además del plexo de axones marcados en el NPS (1), puede verse que los plexos medial (2) y lateral (3) de la OSMi se unen formando un único campo terminal que abarca toda la anchura del núcleo. Las secciones A-F están contrastadas con el método de Nissl. La barra de aumento de $\mathbf{C}$ sirve también para $\mathbf{A}, \mathbf{B}$ y $\mathbf{D}$, y la barra de $\mathbf{G}$ sirve también para $\mathbf{E}$ y $\mathbf{F}$. 


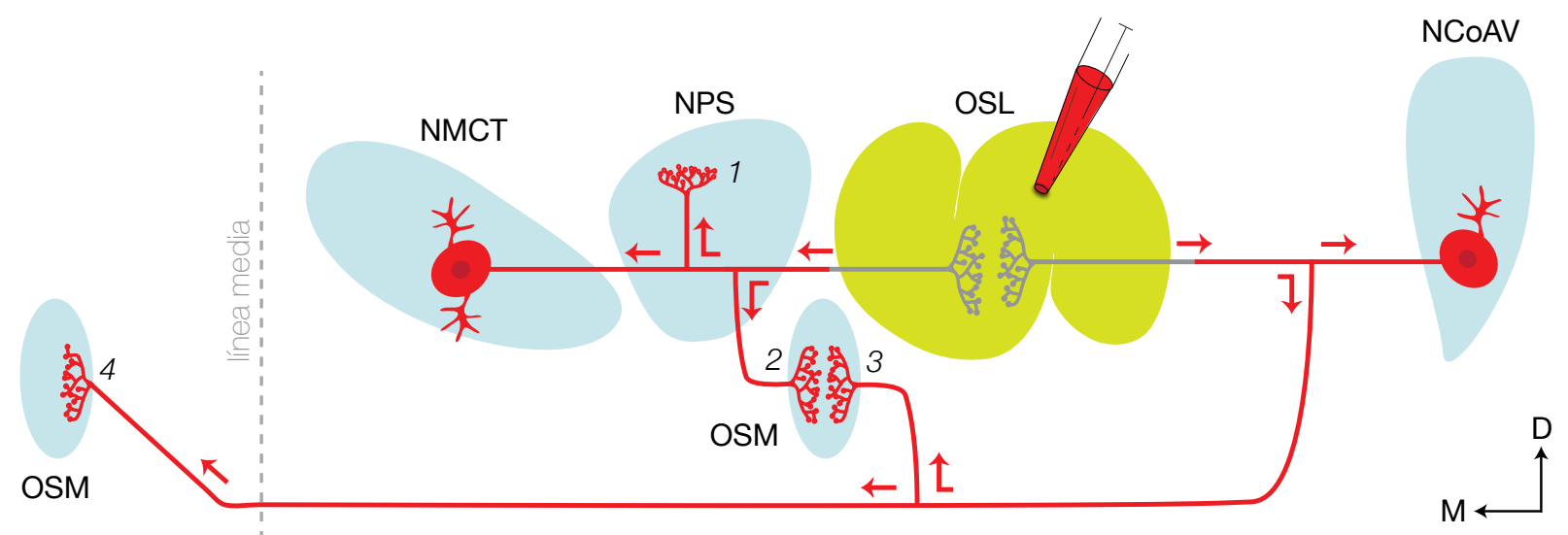

Figura 47. Interpretación de la procedencia de los plexos de axones terminales marcados en el COS ipso y contralateral. Descartada la hipótesis de que los campos terminales marcados en el COS pertenezcan a neuronas de la zona de inyección en la OSL (ver el texto), la explicación más plausible es que estén formados por ramas colaterales del axón de neuronas que inervan a la zona de inyección. Los campos terminales marcados en el NPS (1) y en la mitad medial de la OSM (2) seguramente pertenecen a las neuronas del NMCT marcadas retrógradamente. Por otro lado, los campos terminales de la mitad lateral de la OSMi (3) y de la mitad medial de la OSMc (4) seguramente pertenecen a las neuronas esféricas del NCoAVi marcadas retrógradamente. En ambos tipos celulares, el trazador captado en la zona de inyección (representada por la micropipeta llena de trazador rojo que penetra en la OSL) es transportado por el axón en sentido retrógrado hasta que llega a una bifurcación; en este punto, parte del trazador continúa viajando hacia el soma, mientras que el resto se introduce en la colateral axónica, por la que viaja anterógradamente hasta las porciones terminales. Las flechas indican la dirección del transporte del trazador.

Todos estos resultados indican que, tal como habíamos vaticinado en nuestro Diseño Experimental, la inyección de BDA en la OSL de la rata marca las tres fuentes principales de inervación de la OSM: la proyección de las neuronas esféricas del NCoAVi, que inervan a las dendritas laterales; la proyección de las neuronas esféricas del NCoAVc, que inervan a las dendritas mediales; y la proyección de las neuronas principales del NMCTi, que, según nuestros resultados, parecen inervar preferentemente a las dendritas mediales. Además, dado que los dos plexos de la OSMi y el plexo de la OSMc abarcaron toda la extensión rostrocaudal del núcleo, puede concluirse que, en conjunto, tanto las neuronas esféricas como las neuronas principales del NMCT inervan a todas las porciones rostrocaudales de la OSM.

"La inyección de BDA en la OSL de la rata revela las tres principales aferencias de la OSM: la proyección de las neuronas esféricas ipsolaterales, que inervan a las dendritas laterales; la proyección de las neuronas esféricas contralaterales, que inervan a las dendritas mediales; y la proyección del NMCTi, que inerva a las dendritas mediales.". 


\subsubsection{Topografía (tonotopía) de los campos terminales marcados en el COS}

Dentro de cada núcleo del COS ipso y contralateral, la posición de cada uno de los plexos de axones terminales marcados varió en función de la posición de la zona de inyección a lo largo del eje tonotópico de la OSL. La figura 48 muestra fotografías del COS derecho de seis casos representativos. De cada caso, se ha seleccionado una sección de la porción central de la OSL en la que la zona de inyección es bien visible. Los casos se han ordenado según la posición de la zona de inyección con respecto al eje tonotópico del núcleo: en el caso L13, la zona de inyección afectó al extremo dorsal del limbo medial (la región que procesa los sonidos más agudos); los casos siguientes poseen zonas de inyección situadas en puntos cada vez más laterales de la OSL, hasta llegar al caso L01, en el que la zona de inyección afectó al extremo ventral del limbo lateral (donde se procesan los sonidos más graves). Por razones prácticas, en los próximos párrafos describiremos de modo separado la distribución de los plexos de fibras marcadas núcleo por núcleo.

\subsubsection{Campos terminales marcados en el NPS}

En las imágenes 48A-D se aprecia un claro plexo que recorre el NPS dorsoventralmente. En el caso L13, el plexo se encuentra en la región más medial del NPS; en los casos L10 y L07 ocupa posiciones progresivamente más laterales, y en el caso L04 se sitúa en la región más lateral del NPS. Por el contrario, en los casos L02 y L01 el NPS aparece prácticamente desprovisto de axones terminales marcados.

De estos datos se derivan tres conclusiones:

1. EI NPS posee una organización tonotópica lateromedial, en la que las neuronas que procesan sonidos progresivamente más agudos ocupan posiciones más mediales. Esta conclusión es coherente con estudios anteriores de las conexiones y las propiedades electrofisiológicas del NPS de la rata (Banks y Smith, 1992; Sommer y cols., 1993; Kelly y cols., 1998; Saldaña y Berrebi, 2000; Kulesza y cols., 2003; Saldaña y cols., 2009).

2. EI NPS de la rata no parece contener una representación completa de frecuencias. El que en los casos con inyección en la mitad ventral del limbo lateral (casos L02 y L01) el núcleo aparezca desprovisto de axones marcados sugiere que en el NPS no se procesan los sonidos más graves.

3. Si, como concluimos en el apartado anterior, los axones marcados en el NPS pertenecen a neuronas del NMCT de su mismo lado, nuestros resultados sugieren que este último núcleo posee dos tipos de neuronas principales: las que inervan al NPS, y las que no lo inervan.

Para averiguar cuántas neuronas del NMCT inervan al NPS y cuántas no lo inervan, hemos inyectado BDA en el borde lateral del NPS, porque con ello deberían marcarse las más laterales de las neuronas del NMCT que inervan al NPS. La Fig. 49A muestra una zona de inyección en el borde lateral del NPS que no afectó a los núcleos vecinos (caso S01). Como cabía esperar, en el NMCT se marcaron abundantes neuronas distribuidas en una nítida franja vertical situada 

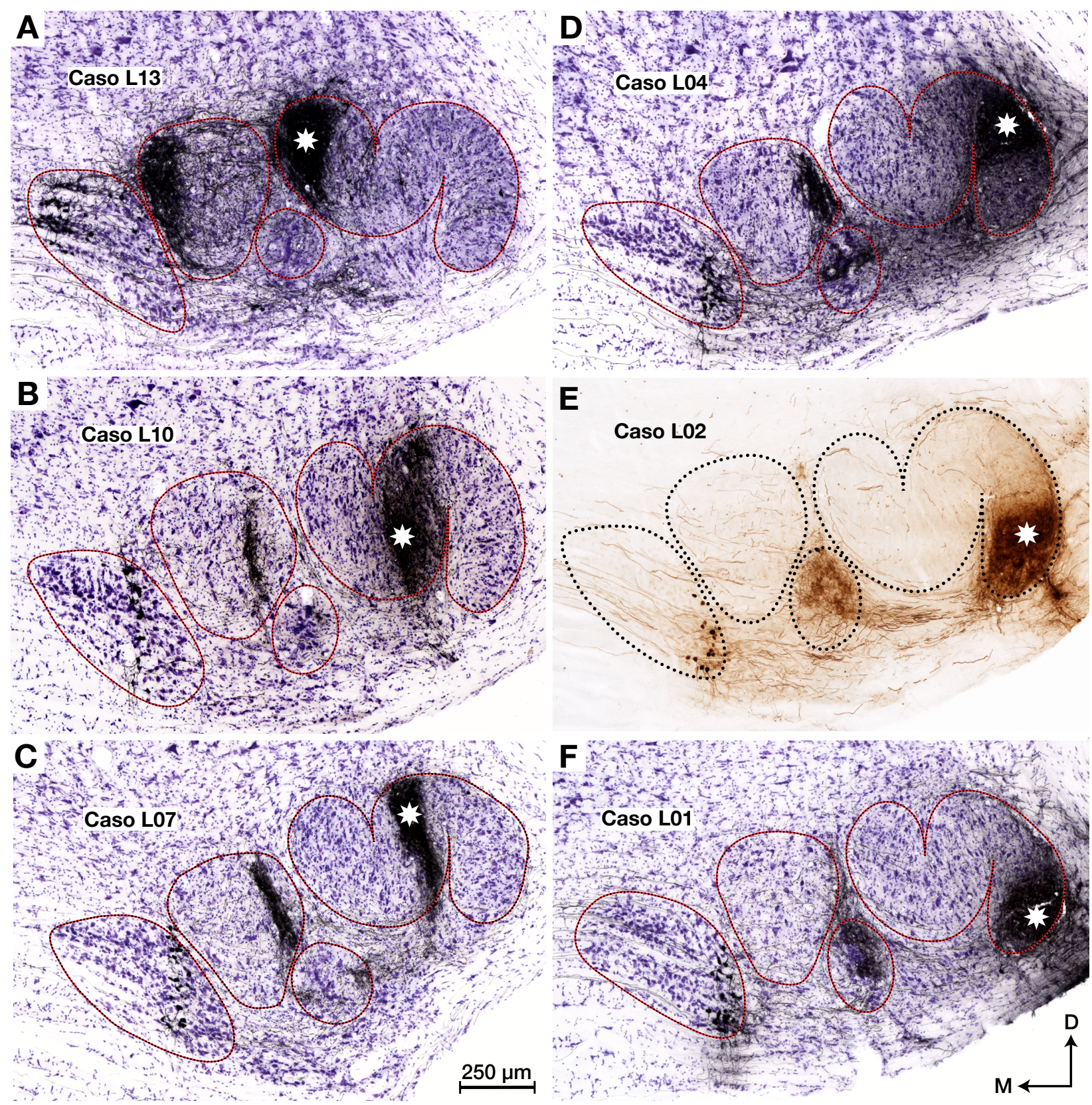

Figura 48. Topografía de los campos terminales marcados en el COS. Microfotografías de sendas secciones coronales que incluyen el centro de la zona de inyección de BDA en la OSL de seis casos representativos. El asterisco indica el centro de cada zona de inyección. Los casos se han ordenado tonotópicamente, desde el caso L13, cuya zona de inyección afectó al extremo dorsal del limbo medial, hasta el caso L01 con zona de inyección situada en el extremo ventral del limbo lateral. La posición de las neuronas marcadas en el NMCT sigue la conocida organización tonotópica del núcleo (ver, p. ej., la figura 41). Obsérvese que sólo se marca un plexo de axones terminales en el NPS en los casos L13, L10, L07 y L04, y que el plexo es tanto más medial cuanto más medial es la zona de inyección. Por el contrario, sólo se marcan los plexos de axones terminales en la OSM en los casos L07, L04, L02 y L01. Todas las secciones, menos la E, están contrastadas con el método de Nissl. La barra de aumento de $\mathbf{C}$ sirve para todas las secciones. 
en el tercio lateral del núcleo (Fig. 49B), y cuya posición, igual que en todos los casos, se mantiene constante a lo largo de toda la extensión rostrocaudal del NMCT (no ilustrado). En cada sección puede verse a la derecha de la banda de neuronas marcadas (lateralmente) un grupo de neuronas que no contienen el trazador y que seguramente son las que no inervan al NPS. El análisis cuantitativo de las neuronas marcadas y las no marcadas en secciones contrastadas con el método de Nissl (una de cada cuatro secciones) revela que de las aproximadamente 6100 neuronas que posee el núcleo, las neuronas laterales no marcadas representan el $18,5 \%$ (unas 1130 neuronas).

En la figura 49A puede verse en la OSL el plexo formado por colaterales del axón de las neuronas del NMCT marcadas. Según el modelo de la organización tonotópica de la OSL mostrado en la figura 29B, el borde lateral de este plexo corresponde a una frecuencia de unos $10 \mathrm{kHz}$. Es llamativo que el limbo lateral carece de axones marcados, lo que sugiere que las neuronas del NMCT que inervan al NPS no inervan al limbo lateral de la OSL. Si esto es cierto, en los casos con

Figura 49. El NMCT posee dos tipos de neuronas que difieren en sus relaciones con el NPS. (A) Zona de inyección de BDA en la región más lateral del NPS. El asterisco indica el centro de la zona de inyección. Obsérvense las neuronas marcadas retrógradamente en el tercio lateral del NMCT y sus colaterales axónicas marcadas en el limbo central de la OSL. El limbo lateral de la OSL aparece desprovisto de axones marcados. (B) Detalle del NMCT en una sección algo más rostral del mismo caso contrastada con el método de Nissl. La línea vertical de puntos marca el límite entre el borde lateral de la franja ocupada por las neuronas marcadas y la región más lateral del NMCT, cuyas neuronas no están marcadas. (C) Sección similar a la mostrada en $\mathbf{B}$, pero procedente del caso L01, cuya zona de inyección se encuentra en el extremo más ventral del limbo lateral de la OSL (ilustrada en las Figs. 29C, 30D y 48F). Las neuronas marcadas ocupan la región más lateral del NMCT y parecen corresponder a neuronas laterales no marcadas en $\mathbf{B}$. La línea vertical de puntos, alineada con la de la figura B, coincide con el límite medial de la región ocupada por las neuronas marcadas. La barra de aumento de $\mathbf{C}$ sirve también para $\mathbf{B}$.
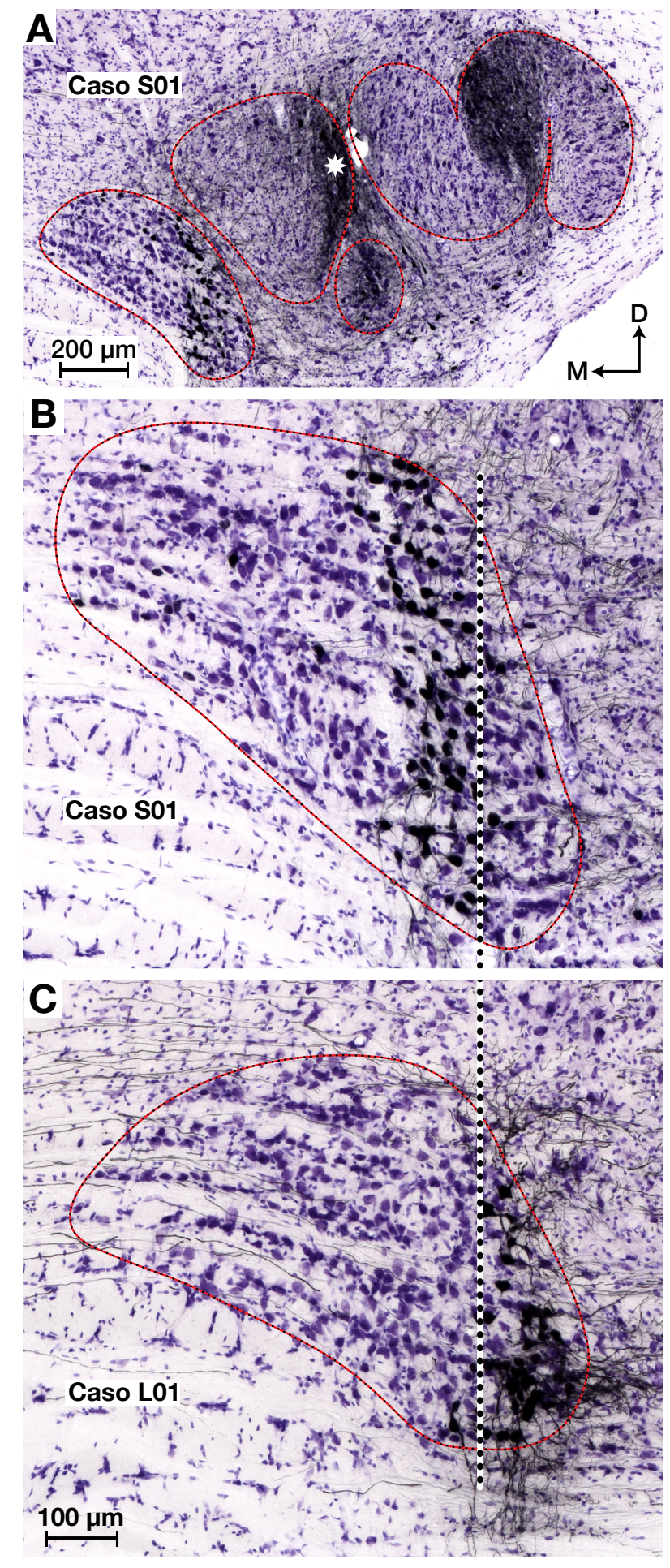
inyección de BDA en el limbo lateral de la OSL deberían marcarse en el NMCT neuronas más laterales que las que inervan al NPS. En efecto, en el caso L01 (cuya zona de inyección se muestra en las figuras 29C, 30D y 48F) las neuronas marcadas ocupan el vértice ventrolateral del NMCT (Fig. 49C), de modo que parecen corresponder a neuronas que no se marcaron en el caso S01 (Fig. 48B). La figura 50 ilustra esquemáticamente los dos tipos de neuronas de NMCT definidos por sus relaciones con el NPS.

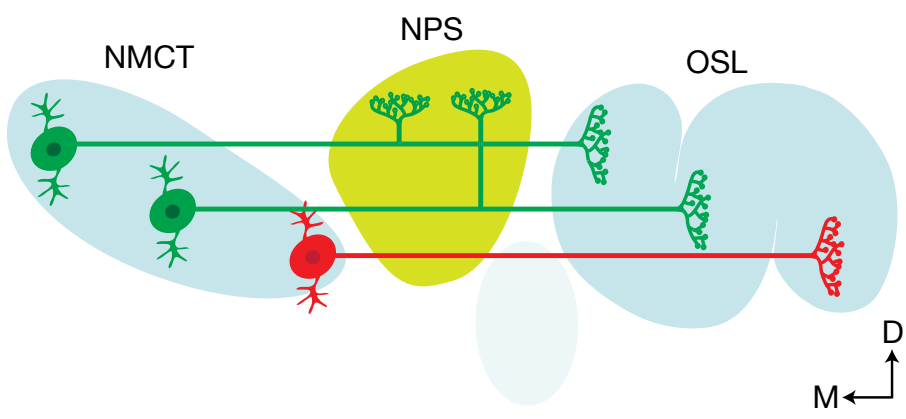

Figura 50. Representación esquemática de los dos tipos de neuronas del NMCT definidos por sus relaciones con el NPS. Todas las neuronas principales del NMCT inervan a la OSL. Las neuronas que inervan a los limbos medial y central (representadas en color verde) inervan también al NPS. Sin embargo, las neuronas situadas en la región más ventrolateral del NMCT, que son las que inervan al limbo lateral de la OSL y que se han representado en rojo, no inervan al NPS.

"Las conexiones del NPS de la rata sugieren que el núcleo posee una organización tonotópica lateromedial, pero incompleta, pues en él no se procesan los sonidos más graves. El NPS es inervado por la mayoría de las neuronas del NMCT, pero no por las neuronas más ventrolaterales".

\subsubsection{Campos terminales marcados en la OSMi}

En la figura 48 puede verse la OSM de los seis casos representativos con inyección de BDA en distintas regiones tonotópicas de la OSL. Resulta evidente que no hay plexos de axones marcados en la OSM en todos los casos: aparecen en los casos L07, L04, L02 Y L01, cuya zona de inyección se encuentra en el limbo lateral o en la porción más dorsal del limbo central, pero no en los casos L13 y L10, cuya zona de inyección afecta a la porción ventral del limbo central o al limbo medial. Por ello, a partir de ahora en este apartado limitaremos nuestro análisis a aquellos casos en los que sí se marcaron campos terminales en la OSM.

La figura 51 ilustra la OSMi de tres casos, cuyazona de inyección se muestra esquemáticamente en la esquina inferior derecha de cada panel. Las fotografías muestran secciones de la porción rostral de la OSMi, en la que se aprecian mejor las diferencias entre casos. En todos ellos se observan en la OSMi los plexos de axones terminales medial y lateral descritos más arriba, y que en algunas secciones parecen confluir en un único plexo más o menos horizontal que abarca toda la anchura del núcleo. La posición dorsoventral de estos campos terminales marcados dependió de la posición de la zona de inyección a lo largo del eje tonotópico de la OSL. En el caso L09, los plexos lateral y medial fueron relativamente aplanados, poseyeron 
una orientación dorsolateral-ventromedial (paralela a la orientación de las dendritas a las que inervan), se encontraron alineados y se situaron en la porción ventral del núcleo (Fig. 51A); los dos tercios dorsales de la OSMi carecieron de axones terminales marcados. En el caso LO4, la orientación de los plexos fue parecida a la del caso anterior, pero se hallaron en el tercio dorsoventral central de la OSMi, sin afectar, por tanto, ni a las neuronas más dorsales, ni a las más ventrales (Fig. 51B). Por último, en el caso L02, los plexos, claramente alineados, ocuparon la porción más dorsal de la OSMi y dejaron libre el resto del núcleo (Fig. 51C).

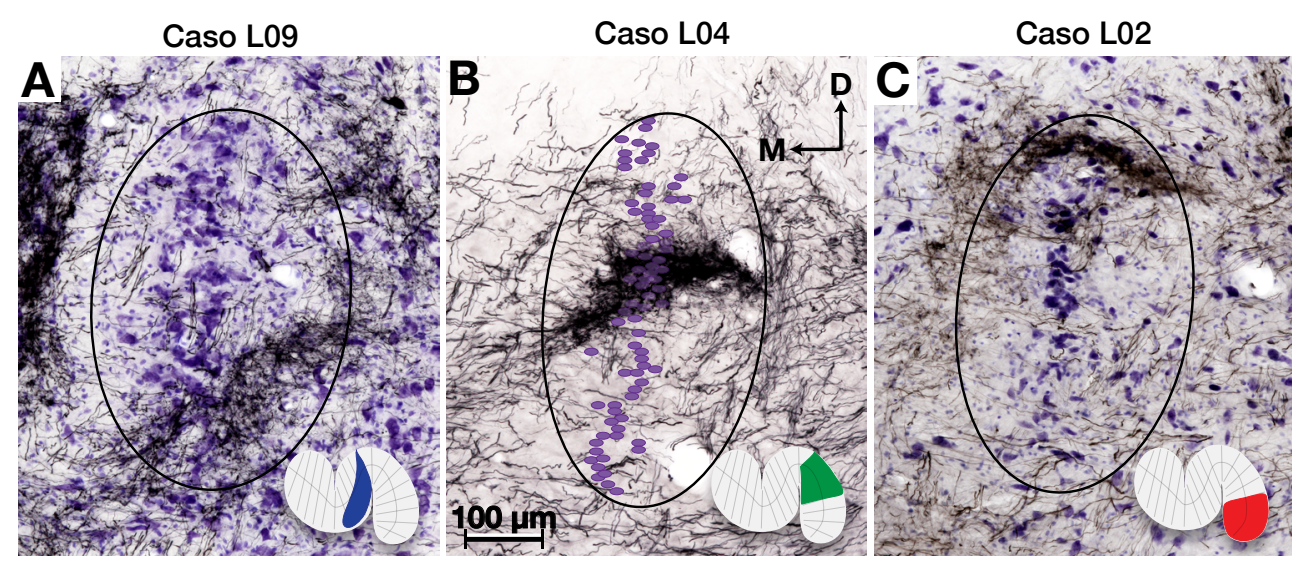

Figura 51. Topografía de los campos terminales marcados en la OSMi. Microfotografías de sendas secciones rostrales de la OSMi de los casos L09, L04 y L02, cuyas zonas de inyección se ilustran esquemáticamente en el ángulo inferior derecho de cada panel. En cada sección se observa el plexo de la mitad lateral del núcleo alineado con el plexo de la mitad lateral. La posición dorsoventral de los plexos varía con la posición de la zona de inyección a lo largo del eje tonotópico de la OSL. Las secciones A y C están contrastadas con violeta de cresilo. En la sección B se ha marcado con un óvalo morado la posición que ocupa cada uno de los somas de la OSM presentes en la sección adyacente, contrastada con violeta de cresilo. La barra de aumento de $\mathbf{B}$ sirve para las tres fotografías.

De estos datos se derivan cuatro conclusiones:

1. La OSM de la rata posee una organización tonotópica dorsoventral, en la que las neuronas que procesan sonidos progresivamente más agudos ocupan posiciones más ventrales. Esta conclusión es coherente con estudios anteriores de las conexiones y las propiedades electrofisiológicas de la OSM (Guinan y cols., 1972 [gato]; Adams, 1979 [gato]; Roth y cols., 1978 [gato]; Kelly y cols., 1998 [rata]; Day y Semple, 2011 [jerbo]).

2. Cada neurona de la OSM parece ser excitada e inhibida por neuronas ipsolaterales que procesan sonidos de la misma frecuencia. En otras palabras, las proyecciones que la OSM recibe de las neuronas esféricas ipsolaterales y de las neuronas del NMCT son estrictamente tonotópicas.

3. La OSM no parece contener una representación completa de frecuencias. El que en los casos con inyección en el limbo medial (caso L13) o en la mitad ventral del limbo central (caso L10) el núcleo apareciera desprovisto de axones marcados sugiere que en la OSM no se procesan los sonidos más agudos. 
4. Si, como concluimos en el apartado 1.4.2, los axones marcados en la OSMi pertenecen a neuronas del NMCT de su mismo lado y a neuronas esféricas ipsolaterales, nuestros resultados sugieren que hay dos tipos de neuronas principales del NMCT y dos tipos de neuronas esféricas: las que inervan a la OSM ipsolateral, y las que no la inervan. Teniendo en cuenta la topografía de las conexiones entre estos núcleos, puede concluirse que la OSM es inervada por las neuronas del tercio lateral del NMCT, y por las neuronas esféricas del tercio ventral del NCoAV. La figura 52 ilustra esquemáticamente los dos tipos de neuronas de NMCT y los dos tipos de neuronas esféricas definidos por sus relaciones con la OSM ipsolateral.

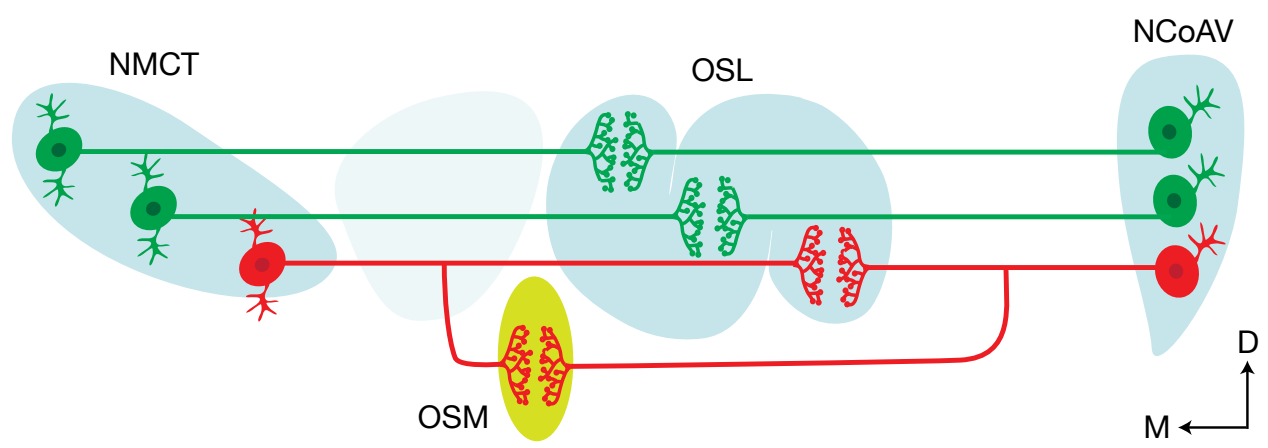

Figura 52. Representación esquemática de los dos tipos de neuronas del NMCT y los dos tipos de neuronas esféricas definidos por sus relaciones con la OSM. Todas las neuronas principales del NMCT y todas las neuronas esféricas inervan a la OSL. Sin embargo, sólo las neuronas del NMCT más ventrolaterales y las neuronas esféricas más ventrales (representadas en color rojo) inervan también a la OSMi. Las neuronas representadas en color verde, que son la mayoría, no inervan la OSMi.

Del análisis de los datos anteriores, se desprende que la representación de frecuencias del NPS es esencialmente complementaria de la representación de frecuencias de la OSM: en el NPS se procesan sobre todo sonidos de frecuencia alta, mientras que la OSM se encarga de sonidos más graves. No obstante, puede existir un cierto solapamiento en el espectro sonoro procesado por estos dos núcleos. En nuestros experimentos con inyección de BDA en la porción dorsal de los limbos lateral y central se marcaron axones terminales tanto en el NPSi, como en la OSMi. Según el mapa tonotópico mostrado en la figura 29B, en tales experimentos la zona de inyección debió de haber afectado a neuronas con una frecuencia característica de entre 8 y $12 \mathrm{kHz}$. Por otra parte, si algo más del $80 \%$ de las neuronas del NMCT inervan al NPS, y aproximadamente el $33 \%$ de las neuronas inervan a la OSM, tiene que existir una población de neuronas del NMCT que inervan tanto al NPS, como a la OSM, y que podrían representar en torno al $15 \%$ de las neuronas del núcleo. Precisamente, estas neuronas que comparten los dos blancos son las que inervan a la región dorsal de los limbos lateral y central de la OSL.

"Las conexiones de la OSM de la rata sugieren que el núcleo posee una organización tonotópica dorsoventral, pero incompleta, pues en él no se procesan los sonidos más agudos. La OSM es inervada por neuronas del tercio lateral del NMCTi y por neuronas esféricas del tercio ventral del NCoAV". 


\section{CASOS CON INYECCIÓN DE BDA EN LA OSL DEL JERBO}

Con el objeto de averiguar si el patrón de inervación de la OSM de la rata que acabamos de describir es compartido por mamíferos que oyen fundamentalmente sonidos graves, hemos realizado experimentos con jerbos, pequeños roedores cuyo rango auditivo es más similar al humano que el de la rata y que en las últimas décadas se han convertido en un modelo predilecto para estudios de audición espacial (Brand y cols., 2002; Pecka y cols., 2008; Carr y MacLeod, 2010; Jercog y cols., 2010; Lesica y cols., 2010; Mathews y cols., 2010; Day y Semple, 2011; Khurana y cols., 2012; Siveke y cols., 2012; Portfors y von Gersdorff, 2013; Stange y cols., 2013; Lehnert y cols., 2014; Myoga y cols., 2014; Roberts y cols., 2014). Como estos experimentos poseen fines de confirmación, no describiremos de modo exhaustivo los resultados, sino que nos limitaremos a compararlos con los obtenidos con ratas, poniendo el énfasis en las semejanzas y diferencias que pueden tener implicaciones funcionales.
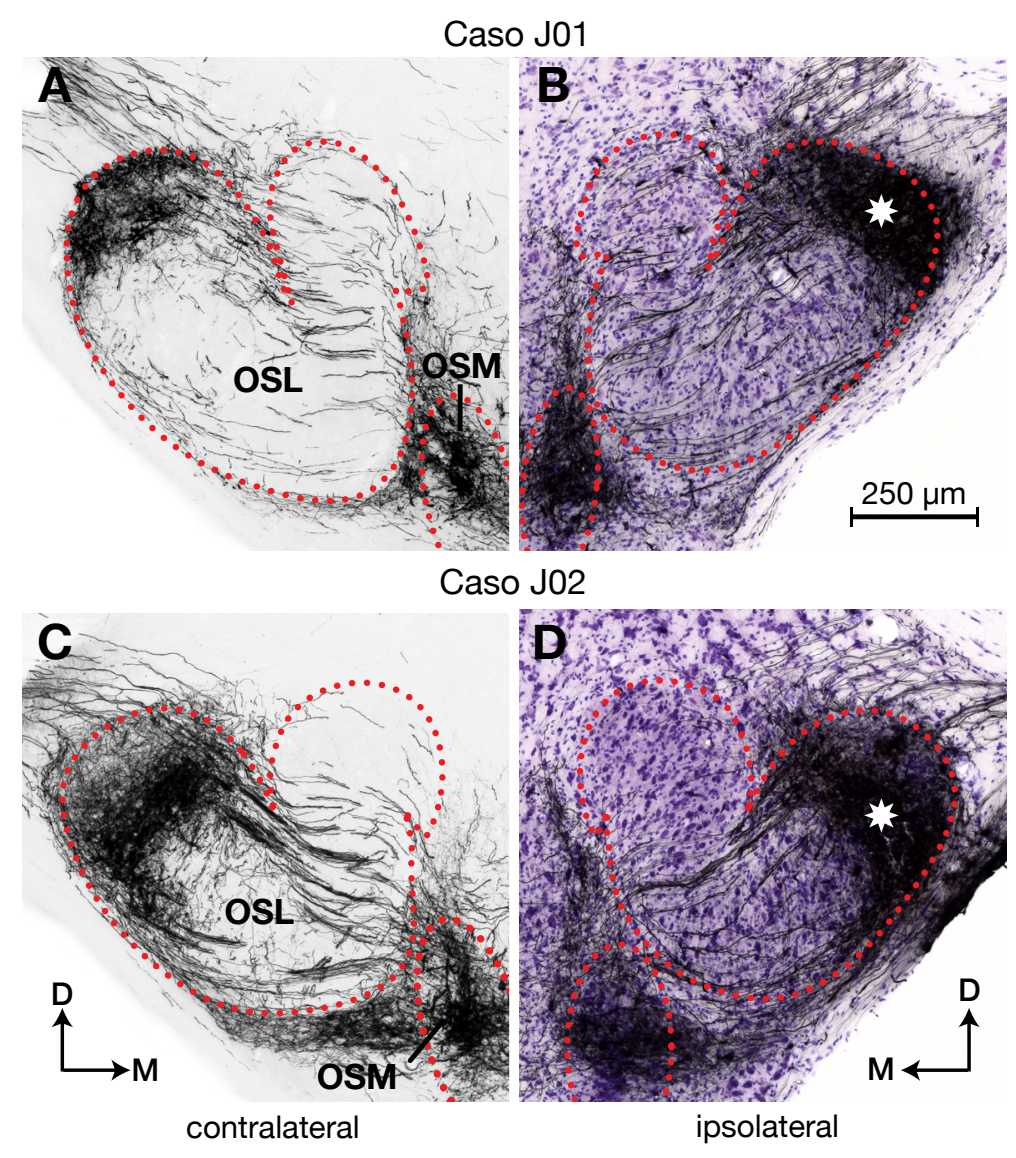

Figura 53. Zonas de inyección de BDA en la OSL del jerbo y axones marcados en la OSLc. (B, D) Microfotografías de la porción central de la zona de inyección de BDA en la OSL de nuestros dos casos. El asterisco indica el centro de la zona de inyección. Ambas zonas de inyección afectan a la región dorsal del limbo lateral del núcleo, que procesa sonidos muy graves. Secciones contrastadas con violeta de cresilo. (A, C) Microfotografías de la OSLc de los mismos casos. En cada caso, la OSLc contiene un denso plexo de axones terminales que ocupa un área simétrica a la de la zona de inyección. La barra de aumento de $\mathbf{B}$ sirve para las cuatro fotografías. 


\subsection{Zonas de inyección de BDA en la OSL}

Hemos obtenido dos casos exitosos con inyección de BDA limitada a la región dorsal del limbo lateral de la OSL del jerbo, donde se procesan los sonidos más graves (Sanes y cols., 1989; 1990). En el primero de ellos (caso J01) la zona de inyección afectó al extremo dorsal del limbo lateral (Fig. 53B), y en el segundo (caso J02), la zona de inyección fue ligeramente más ventromedial (Fig. 53D).

\subsection{Neuronas marcadas retrógradamente}

Los resultados fueron cualitativamente muy similares a los obtenidos con ratas, con una notable diferencia. Además de los cuatro tipos neuronales marcados en la rata (neuronas multipolares planas y esféricas del NCoVi, neuronas principales del NMCTi y neuronas multipolares pequeñas del NVCTc), en el jerbo se marcaron abundantes neuronas esféricas en el NCoAVc.

La figura 54 muestra secciones coronales de tres niveles rostrocaudales de los NCo de ambos lados del caso J02. En el NCoPVi se marcaron los somas de neuronas multipolares planas, y sus colaterales axónicas pueden apreciarse en el NCoD (Fig. 54B). En el lado contralateral, el NCoPV y el NCoD estuvieron desprovistos de elementos marcados (Fig. 54A), lo que demuestra que, igual que en la rata, las neuronas multipolares planas inervan sólo a la OSL de su mismo lado. En el NCoAV de ambos lados se marcaron abundantes neuronas. Mientras que en las porciones caudales del NCoAVi hallamos algunas neuronas multipolares intercaladas entre las neuronas esféricas (Fig. 54D), en las porciones rostrales del NCoAVi (Fig. 54F) y en todo el NCoAVc (Fig. 54C, E) hallamos sólo neuronas esféricas. En ambos lados las neuronas marcadas ocuparon un área aproximadamente horizontal bien definida, simétrica y situada en la región ventral del núcleo, aunque sin alcanzar su superficie ventral. En el caso J01 las neuronas marcadas ocuparon posiciones más ventrales que las del caso J02 (Fig. 55). Estos datos demuestran que, a diferencia de lo que sucede en la rata, y tal como habían propuesto Kil y cols. (1995) y Russell y Moore (1995), la región de frecuencias bajas de la OSL del jerbo recibe una proyección claramente bilateral de las neuronas esféricas del NCoAV.

Igual que en la rata, hallamos neuronas marcadas en el NMCTi y en el NVCTC. En ambos casos se hallaron en la región lateral del núcleo (Figs. 55) y fueron un poco más laterales en el caso J01, que en el J02.

\subsection{Axones marcados en el COS}

La principal diferencia entre los resultados obtenidos con ratas y los obtenidos con jerbos fue la distribución de los axones marcados en el COSc. La figura 55 muestra una fotografía a bajo aumento de una sección del caso J01 que incluye la zona de inyección en la OSL. A primera vista puede apreciarse la simetría en la distribución de los axones marcados en el COS. Es especialmente llamativo el plexo de axones marcados en la OSLc. En la figura 53A, C se muestran 

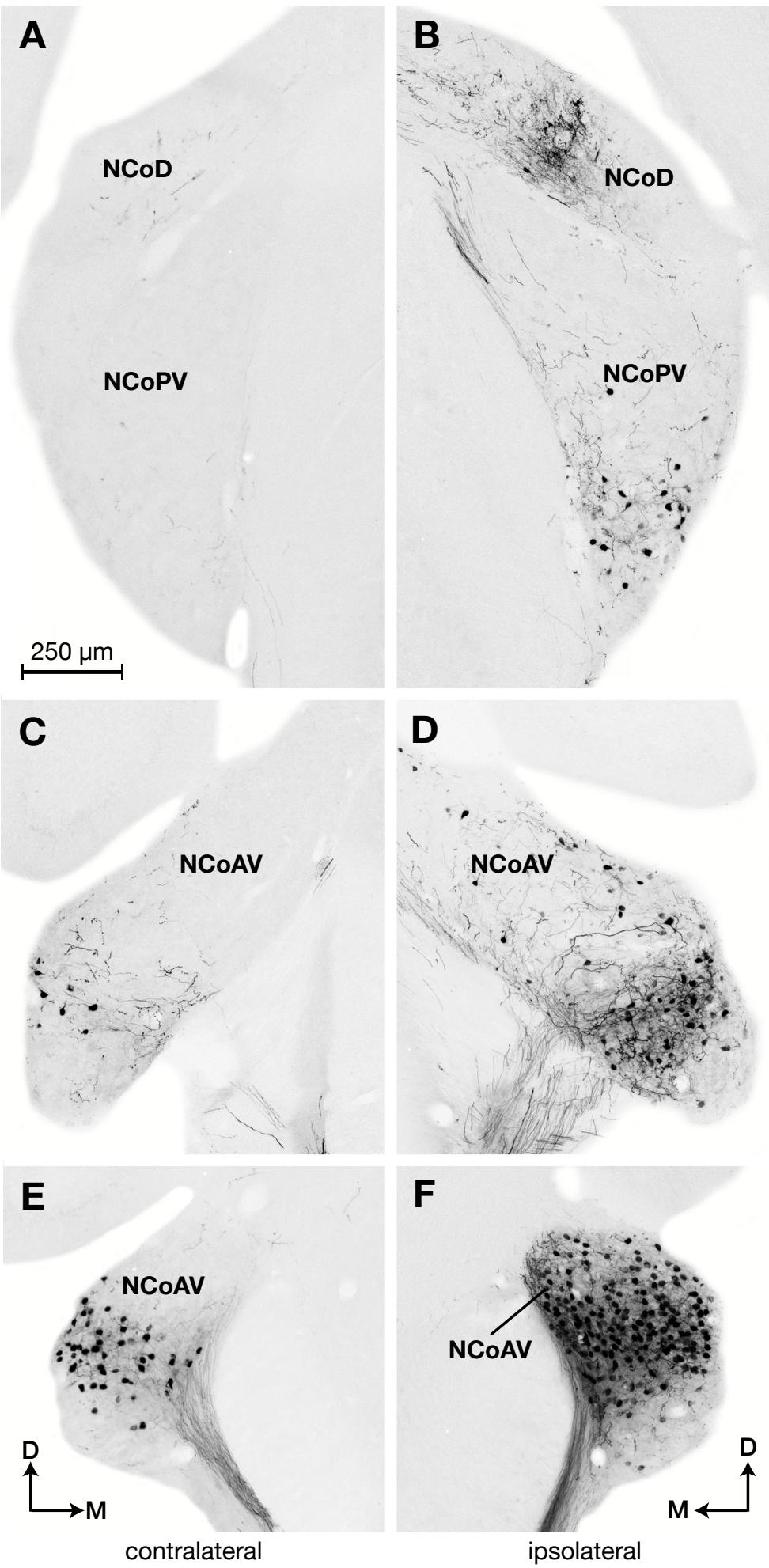

Figura 54. Distribución de los elementos marcados en los NCo de ambos lados. Microfotografías que muestran la distribución de los elementos marcados en una serie de secciones coronales de los NCo del caso J02, cuya zona de inyección de BDA en el limbo lateral de la OSL se muestra en la figura 57D. La columna de la izquierda muestra los NCo contralaterales y la de la derecha, los ipsolaterales. En cada columna, las secciones aparecen ordenadas de la más caudal a las más rostral. La fila superior y la segunda fila están separadas por $960 \mu \mathrm{m}$, y la segunda fila y la fila inferior por $640 \mu \mathrm{m}$. Sólo hay neuronas marcadas en el NCoPVi (B), pero no en el NCoPVc (A). Los elementos marcados en el $\mathrm{NCoDi}$ (B) son campos terminales formados por colaterales del axón de las neuronas multipolares planas marcadas en el NCoPVi. Obsérvense las neuronas esféricas marcadas en el NCoAVc $(\mathbf{C}, \mathbf{E})$, cuya distribución es simétrica a la de las neuronas marcadas en el NCoAVi (D, F). La barra de aumento de A sirve para todas las fotografías. 
detalles de la OSLc de nuestros dos casos. En cada caso, la OSLc contuvo un denso plexo de axones terminales marcados cuya posición y extensión coincidieron de manera precisa con las de la correspondiente zona de inyección. Por razonamientos análogos a los que utilizamos con las ratas, concluimos que estos plexos de la OSLc están formados por una mezcla de axones de neuronas esféricas ipsolaterales y de neuronas esféricas contralaterales. El que el plexo de la OSLc fuera exactamente simétrico de la zona de inyección es especialmente relevante porque demuestra que las proyecciones de las neuronas esféricas a la OLSi y a la OSLc son estrictamente tonotópicas y simétricas, una idea reforzada por la simetría en la distribución de las neuronas esféricas en el NCoAVi y el NCoAVc (Figs. 54C-F, 55).

Otra diferencia notable entre las dos especies utilizadas fue que en la OSMc del jerbo hallamos campos terminales no sólo sobre las dendritas mediales, sino también sobre las dendritas laterales, un hallazgo sin duda relacionado con el hecho de que en cada experimento se marcaron abundantes neuronas esféricas en el NCoAV de ambos lados. Dado el conocido patrón de proyección de las neuronas esféricas, el plexo de la mitad lateral de la OSMc pertenece con toda probabilidad a las neuronas esféricas del NCoAVc, y el de la mitad medial a las neuronas esféricas del NCoAVi a la zona de inyección.

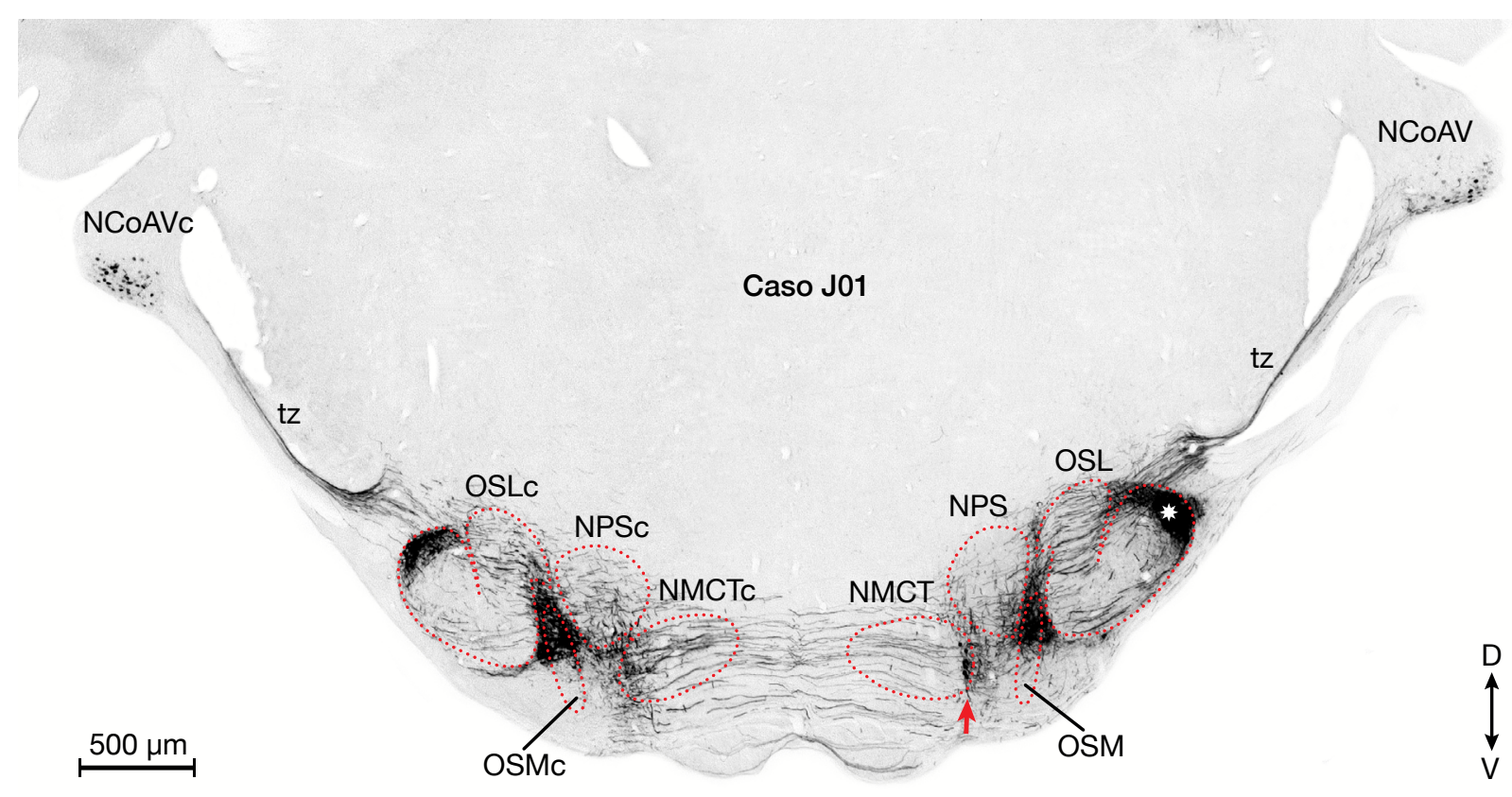

Figura 55. Microfotografía panorámica de una sección coronal que incluye la zona de inyección, el COSc y los NoC del caso J01. La zona de inyección en el extremo dorsal del limbo lateral de la OSL derecha está indicada con el asterisco. Puede apreciarse la distribución simétrica del marcado en la OSL (el plexo de axones de la OSLc con respecto a la zona de inyección en la OSL), en la OSM, y en el NCoAV, y la ausencia de axones terminales marcados en el NPS de ambos lados. La flecha señala la columna de neuronas marcadas en el extremo lateral del NMCTi; el NMCTc carece de neuronas marcadas. 
En la OSMi encontramos una diferencia apreciable con respecto a los experimentos realizados con ratas. En el jerbo hallamos gruesos botones sinápticos marcados en torno al soma y las porciones más proximales de las dendritas (no ilustrado). Por su morfología y distribución, que recuerdan a la de los botones glicinérgicos de la OSM del jerbo (Kapfer y cols., 2002; Werthat y cols., 2008; Couchman y cols., 2010; Hassfurth y cols., 2010), concluimos que estos botones gruesos pertenecen a neuronas principales del NMCT. Estos botones gruesos se hallaron sólo en la porción más dorsal del plexo terminal, lo que indica que, igual que en la rata, la proyección del NMCT a la OSM es estrictamente tonotópica.

"La región de frecuencias más bajas de la OSL del jerbo recibe proyecciones bilaterales, simétricas $y$ estrictamente tonotópicas de neuronas esféricas del NCoAV". 


\section{DISCUSIÓN}


Esta tesis representa un estudio histológico sistemático y exhaustivo de algunas de las principales conexiones del complejo olivar superior de los mamíferos. Nuestra herramienta fundamental ha sido la inyección del trazador neuroanatómico bidireccional dextrano biotinado (BDA) en la oliva superior lateral (OSL) y los resultados de cada experimento se han convertido en una fuente riquísima de información. Por una parte, los experimentos han revelado que la OSL de la rata es inervada por cuatro tipos neuronales situados en tres núcleos auditivos troncoencefálicos y han proporcionado información valiosa sobre estos tipos neuronales y sobre los núcleos en los que residen: las neuronas esféricas y las neuronas multipolares planas del núcleo coclear ventral (NCoV), las neuronas principales del núcleo medial del cuerpo trapezoide (NMCT), y las neuronas multipolares pequeñas del núcleo ventral del cuerpo trapezoide (NVCT). Por otra, nuestros casos han puesto de manifiesto cómo algunos de los tipos neuronales que inervan a la OSL inervan también a otros núcleos del complejo olivar superior, como el núcleo parolivar superior (NPS) o la oliva superior medial (OSM), enriqueciendo nuestro conocimiento sobre ellos. Esta Discusión está estructurada en varios apartados. Comienza con unas breves consideraciones técnicas sobre los métodos empleados en los experimentos. A ellas les sigue una discusión detallada de las fuentes de proyección a la OSL, en la que prestamos especial atención a los tipos neuronales que intervienen. A continuación, analizamos de modo sucinto lo que nuestras observaciones nos dicen sobre el núcleo parolivar superior (NPS), para terminar la Discusión centrándonos en la inervación de la OSM y las implicaciones funcionales que de ella se derivan.

\section{CONSIDERACIONES TÉCNICAS}

La principal herramienta de nuestro Trabajo ha sido el trazador neuroanatómico BDA. Introducido hace algo más de 20 años para el estudio de conexiones en el sistema nervioso central (Brandt y Apkarian, 1992; Veenman y cols., 1992; Rajakumar y cols., 1993; Wouterlood y Jorritsma-Byham, 1993), en este tiempo se ha convertido en el trazador predilecto para múltiples estudios de conexiones nerviosas debido a sus numerosas cualidades (revisadas por: Kobberty cols., 2000; Vercelli y cols., 2000; Raju y Smith, 2006; Reiner y Honig, 2006; Lanciego y Wouterlood, 2011).

No en vano, durante los últimos dos decenios nuestro grupo de investigación lo ha empleado ampliamente para estudiar conexiones del sistema auditivo de los mamíferos aprovechando su eficacia como trazador anterógrado (Feliciano y cols., 1995; Saldaña y cols., 1996, 2009; López y cols., 1999; Aparicio y cols., 2010; Viñuela y cols., 2011; Aparicio y Saldaña, 2014) y como trazador retrógrado (Merchán y cols., 1994; Saldaña y Berrebi, 2000; Saldaña y Merchán, 2005; Saldaña y cols., 2009; Viñuela y cols., 2011; Aparicio y Saldaña, 2014).

Siguiendo los protocolos habituales de nuestro laboratorio, la mayor parte de los experimentos los realizamos con BDA de $10.000 \mathrm{Da}$. Sin embargo, existe un BDA de menor peso molecular (3.000 Da) al que frecuentemente se le ha supuesto la virtud -no demostrada 
sistemáticamente- de ofrecer un mejor transporte retrógrado que el dextrano de 10.000 Da (Fritzsch, 1993). En un intento de mejorar el relleno de las neuronas marcadas retrógradamente, en algunos de nuestros experimentos reemplazamos el BDA de 10.000 Da por BDA de 3.000 Da o por una mezcla de ambos a partes iguales. El análisis riguroso de los resultados no reveló diferencias sistemáticas entre los trazadores inyectados pues, aunque observamos diferencias de calidad en el marcado anterógrado y retrógrado entre experimentos, éstas no pudieron ser atribuidas a la elección del trazador. Por lo tanto, en nuestro modelo experimental (inyección del trazador en núcleos auditivos del tronco del encéfalo de ratas albinas adultas) el usar BDA de 3.000 Da no parece comportar ninguna ventaja que compense su precio, muy superior al del BDA de $10.000 \mathrm{Da}$. Cuando ya habíamos realizado casi todos nuestros experimentos, se publicó una comparación sistemática entre los dos trazadores que empleó como modelo las conexiones entre la corteza cerebral visual y el tálamo de ratas macho adultas de la cepa Holtzman (Ling y cols., 2012). Estos autores concluyeron que "el dextrano de 3.000 Da fue superior en todos los aspectos", algo que no coincide con nuestra experiencia. Sin embargo, el pequeño tamaño de nuestra muestra (fueron pocos los casos en los que inyectamos del BDA de 3.000 da), las diferencias entre el modelo experimental de Ling y cols. (2012) y el nuestro, y ciertos detalles técnicos de su protocolo -ellos inyectaron los trazadores por presión, mientras que nosotros lo hicimos iontoforéticamente-, sugieren que seamos cautos a la hora de comparar nuestras conclusiones con las suyas. El cualquier caso, el BDA, con independencia de su peso molecular, ha demostrado en nuestros experimentos ser un instrumento extraordinariamente valioso y capaz de proporcionar resultados que sería muy difícil obtener por otros medios, en particular aquéllos derivados del transporte colateral. Incidiremos en este último aspecto en una sección posterior de esta Memoria.

\section{FUENTES DE PROYECCIÓN A LA OSL}

\subsection{Generalidades}

La primera parte de nuestro estudio ha analizado la morfología y distribución de las neuronas que inervan a la OSL de la rata. En todos nuestros experimentos con inyección de BDA en la OSL, hallamos abundantes neuronas marcadas retrógradamente en el núcleo coclear posteroventral ipsolateral (NCoPVi), el núcleo coclear anteroventral ipsolateral (NCoAVi), el núcleo medial del cuepo trapezoide ipsolateral (NMCTi) y el núcleo ventral del cuerpo trapezoide contralateral (NVCTc). Además, únicamente en los casos en los que se depositó el trazador en la zona de frecuencias más altas de la OSL, se marcó un número apreciable de neuronas en el NCoVc. El mayor número de neuronas marcadas (algo más del $45 \%$ del total) lo encontramos sistemáticamente en el NCoAVi, y el segundo, en el NMCTi (algo más del 35 \%). Juntos, estos dos núcleos contienen más del $80 \%$ de las neuronas troncoencefálicas que inervan a la OSL de la rata. Estos datos confirman investigaciones previas en otros mamíferos, en las que se consideró al NCoAV y al NMCT como las fuentes predominantes, cuando no únicas, de inervación para la OSL (Glendenning y cols., 1985 [gato]; Shneiderman y Henkel, 1985 [gato]; Spangler y cols., 1985 [gato]; Cant y Casseday, 1986 [gato]; Casseday y cols., 1988 [murciélago de herradura]; Henkel y Gabriele, 1999 [hurón]; para referencias adicionales, ver Thompson y Schofield, 2000; Yin, 2002). 
En nuestros experimentos, la proporción de neuronas marcadas en el NCoPV fue bastante constante (en torno a un 10\%), de manera que la contribución de este núcleo a la inervación de la OSL de la rata, aun siendo significativa, resulta mucho menor que la del NCoAV. Las neuronas marcadas en el NVCTc representaron aproximadamente el $5 \%$ de todas las neuronas marcadas en núcleos auditivos troncoencefálicos. Esto convierte al NVCT en la fuente de proyección a la OSL menos importante desde el punto de vista cuantitativo. Por otra parte, la presencia de neuronas marcadas en el NCoPVi y el NVCTc de nuestros casos J01 y J02 indica que las proyecciones de estos núcleos a la OSL existen también en el jerbo y pueden ser una característica compartida por otros muchos mamíferos.

Un hallazgo relativamente inesperado de nuestros experimentos fue un número apreciable de neuronas marcadas en el NCoVc en los casos L13 y L14, cuyas zonas de inyección afectaron al extremo dorsal del limbo medial de la OSL de la rata, pero no en los demás casos. En el caso L14, estas neuronas representaron algo más de $5 \%$ de todas las neuronas marcadas, un porcentaje similar al de las neuronas marcadas en el NVCTc. En la literatura pueden encontrarse descripciones esporádicas de proyecciones directas del NCoV a la OSLc (Goldberg y Brown, 1969 [perro]; Warr, 1972, 1982 [gato]; Glendenning y cols., 1985 [gato]; Zook y Leake, 1989 [murciélago bigotudo]; Müller, 1990 [gerbo]; Russell y Moore, 1995 [jerbo]). En el gato, igual que en la rata, esta proyección parece inervar selectivamente a la región de la OSL dedicada al procesamiento de sonidos agudos (Warr, 1972, 1982; Glendenning y cols., 1985). Sin embargo, en el jerbo se ha descrito una llamativa proyección bilateral a la mayor parte del limbo lateral de la OSL, pero que deja libre su extremo dorsal (Kil y cols., 1995 [ver sus figuras 10 y 11]; Russell y Moore, 1995 [sus figuras 2 y 3]). Curiosamente, en nuestros dos casos con inyección en la OSL del jerbo (casos J01 y J02), cuya zona de inyección afectó a la porción más dorsal del limbo lateral, se marcaron abundantes neuronas en la región de frecuencias bajas del NCoAV de ambos lados, y la OSLc contuvo un denso plexo de axones marcados simétrico a la zona de inyección. Por lo tanto, nuestros experimentos ratifican la proyección del NCoAV a la OSLc del jerbo y sugieren que es más amplia de lo que se pensaba, pues puede abarcar a todo el limbo lateral.

\subsection{Tipos neuronales que inervan a la OSL}

\subsubsection{Neuronas esféricas del NCoAV}

En todos nuestros experimentos sin excepción, las neuronas marcadas más abundantes fueron las neuronas esféricas del NCoAV, fácilmente reconocibles por las características morfológicas del soma y las dendritas y por su ubicación (ver referencias en la Introducción). Nuestros datos sugieren que, aunque todas ellas inervan a la OSLi, en la rata hay dos tipos de neuronas esféricas que difieren en sus proyecciones: neuronas esféricas que inervan a la OSM de ambos lados (que se marcaron en los casos con inyección en el limbo lateral o la porción dorsal del limbo central y ocupan la porción más ventral del NCoAV), y neuronas esféricas que no inervan a la OSM (que se marcaron en los demás casos y residen en los dos tercios dorsales del NCoAV). 
La existencia de dos tipos de neuronas esféricas fue propuesta por Osen (1969a, b): sus esféricas grandes y sus esféricas pequeñas del NCoAV del gato son citológicamente muy similares, pero difieren en el tamaño del soma y en su distribución dentro del núcleo. Desde entonces, la existencia de dos tipos de esféricas ha sido objeto de recurrentes discusiones citoarquitectónicas: mientras que Cant y Morest (1979a) cuestionaron que se tratara de dos tipos neuronales diferentes en el gato, y Hackney y sus colaboradores negaron una diferencia morfométrica clara en el cobaya (Hackney y Pick, 1986; Hackney y cols., 1990), otros autores las reconocieron sin dificultad en el ratón (Trune, 1982a, b; Webster y Trune, 1982) y la chinchilla (Fleckeisen y cols., 1991). Estos últimos autores enfatizaron las diferencias citológicas en secciones teñidas con el método de Nissl refiriéndose a los dos tipos como esféricas "grandes y oscuras" y esféricas "pequeñas y pálidas" (Fleckeisen y cols., 1991).

La cuestión del tamaño de las neuronas esféricas podría haber resultado anecdótica si no hubiera sido porque desde un principio Osen (1969b) puso en relación la diferente distribución de los dos tipos de neuronas esféricas con su patrón de proyecciones: Osen sugirió que las esféricas grandes, que se encuentran en el polo rostral del NCoAV - una región que recibe inervación sólo de la mitad o los dos tercios apicales de la cóclea- inervan a la OSM de ambos lados, en tanto que las esféricas pequeñas, situadas más caudalmente -en una región inervada por toda la cóclea - inervan a la OSL de su mismo lado. Poco después Brownell (1975) notó que el número de axones de calibre mediano (atribuidos a las neuronas esféricas) que cruzan la línea media en el cuerpo trapezoide del gato es aproximadamente la mitad que el número de neuronas esféricas calculado por Osen (1970), lo que sugiere que sólo la mitad de las esféricas inervan a la OSMc. La confirmación experimental la obtuvieron Cant y Casseday (1986) con inyecciones de HRP libre o conjugada con aglutinina de germen de trigo (WGA-HRP) en el complejo olivar superior (COS) del gato: cuando inyectaron el trazador en la OSM, se marcaron retrógradamente neuronas esféricas en el polo rostral del NCoAV de ambos lados, pero en los casos con inyección en la OSL, las neuronas marcadas fueron solo ipsolaterales y se encontraron en un territorio más amplio del NCoAV, incluido el polo rostral. Esto les llevó a concluir que mientras que la OSM es inervada por un único tipo celular, la OSL es inervada por dos, lo que concuerda bien con la propuesta de Osen (1969b). En la misma dirección apuntan los experimentos en los que se inyectó HRP en el NCoAV del jerbo: cuando la zona de inyección afectó a la porción más rostral del núcleo, se marcó anterógradamente una densa proyección al limbo lateral de la OSL y a la OSM de ambos lados, mientras que en los casos con inyección en la región caudal del NCoAV se marcó el limbo medial de la OSL, pero no la OSMi, ni la OSMc (Müller, 1990; Russell y Moore, 1995). Aunque nosotros no hemos observado diferencias en el tamaño de los somas marcados retrógradamente, nuestros resultados apoyan fuertemente la existencia de dos tipos de neuronas esféricas en la rata y además demuestran que su diferencia no es tanto topográfica (ocupar una posición más o menos caudal dentro del NCoAV), como tonotópica. Mientras que Osen $(1969 a, b)$ defendió que las neuronas esféricas pequeñas procesan sonidos de todo el rango de frecuencias del animal, y Cant y Casseday (1986) atribuyeron esta cualidad también a las neuronas esféricas grandes, nuestros resultados en la rata y los de Müller (1990) y Russell y Moore (1995) en el jerbo sugieren que los dos tipos de neuronas esféricas (las que inervan y las que no inervan a la OSM) intervienen en el procesamiento de rangos de frecuencias separados 
y complementarios. Será necesario dilucidar en el futuro si las discrepancias entre nuestras conclusiones y las Osen $(1969 a$, b) y Cant y Casseday (1986) se deben a diferencias genuinas entre carnívoros y roedores y si son el fruto de disparidades en la interpretación de los resultados.

Aunque hay abundantes datos sobre las características morfofuncionales de las neuronas esféricas grandes del gato (p. ej., Smith y cols., 1993; Beckius y cols., 1999; Karino y cols., 2011), de las proyecciones de las esféricas pequeñas lo único que se sabe es que inervan a la OSL (Cant y Benson, 2003). En nuestros casos con inyección en el limbo medial de la OSL, en los que deberían haberse marcado las colaterales del axón de las neuronas esféricas que no inervan a la OSM, encontramos axones marcados en los mismos núcleos que en los casos con inyección en el limbo lateral y además en el NPS, que no es inervado por neuronas esféricas. Esta observación indica que las neuronas esféricas que no inervan a la OSM no proyectan a ningún núcleo que no sea blanco también de las esféricas que sí inervan a la OSM, pero por desgracia no aporta información adicional sobre el destino de las neuronas "esféricas pequeñas". No podemos descartar, por lo tanto, que la principal diferencia entre los dos tipos de esféricas sea su relación con la OSM.

\subsubsection{Neuronas principales del NMCT}

En nuestros experimentos, todas las neuronas marcadas en el NMCT presentaron las características propias de las neuronas principales. Este dato sugiere que si el NMCT de la rata posee neuronas distintas de las principales, no inervan a la OSL, a diferencia de lo que sucede en el gato (Glendenning y cols., 1985).

En nuestros casos predominaron las neuronas con dendritas poco ramificadas y de calibre decreciente a medida que se alejan del soma (ver también la figura 1C de Banks y Smith, 1992), y las neuronas claramente arbustiformes fueron escasas. Por tanto, las neuronas principales de la rata parecen algo distintas de las de otras especies, en las que se ha descrito a estas neuronas como arbustiformes y se las ha comparado con neuronas esféricas y globulares del NCoV (p. ej., Cant, 1991 [gato]; Kuwabara y Zook, 1991 [ratón, jerbo, murciélago bigotudo y murciélago moreno]; Smith y cols., 1998 [gato]).

Un rasgo muy pronunciado de las neuronas del NMCT marcadas en nuestros experimentos, tanto en la rata, como en el jerbo, fue la nítida orientación de las dendritas, queadoptan trayectorias variadas dentro de un territorio estrictamente parasagital que parece corresponder a un plano de isofrecuencia. Este atributo contrasta fuertemente con descripciones anteriores, en las que se afirmó que las dendritas de las neuronas del NMCT carecen de orientación preferente (Ollo y Schwartz, 1979 [ratón]; Kuwabara y cols., 1991 [ratón, jerbo, murciélago bigotudo y murciélago moreno]), o incluso que se orientan horizontalmente, paralelas a las fibras del cuerpo trapezoide (Morest, $1968 b$ [gato]; Mylius y cols., 2013 [jerbo]). En muchas de nuestras neuronas, las dendritas se extienden dorsal o ventralmente más allá de los límites del territorio ocupado por los somas, algo ya notado por (Sommer y cols., 1993). Lo que no hemos observado en nuestro material son dendritas que se dirijan medialmente para cruzar la línea media (Kuwabara y cols., 1991). 
Aun cuando todas las neuronas principales inerven a la OSL, el NMCT de la rata parece poseer varias poblaciones de neuronas principales que difieren en sus conexiones con otros núcleos del COS. Según nuestros datos, algo más del $80 \%$ de las neuronas principales inervan al NPS, y un tercio de todas las neuronas principales inervan a la OSM, lo que significa que aproximadamente un $15 \%$ inervan tanto al NPS, como a la OSM. Estos tres tipos de neuronas, claramente segregados dentro del núcleo, los tratamos a continuación.

Las neuronas del NMCT que inervan al NPS se sitúan en las cuatro quintas partes mediales del NMCT y son con mucho las más comunes. De hecho, 21 de las 25 neuronas marcadas intracelularmente por Banks y Smith (1992) en el NMCT de la rata inervaban al NPS. También enviaban ramas colaterales para el NPS las 10 neuronas marcadas intracelularmente por Sommer y cols. (1993), lo que les llevó a considerar al NPS como un blanco "obligatorio" del NMCT de la rata. De las 10 neuronas estudiadas por Sommer y cols., en 5 de ellas se identificó la frecuencia característica, que osciló entre 14 y $47 \mathrm{kHz}$, lo que apoya nuestra hipótesis de que las neuronas principales que inervan al NPS (y por ende el propio NPS) participan en el procesamiento de sonidos agudos (ver más abajo). El NPS es también un destino común del axón de neuronas principales del ratón, el jerbo y el murciélago moreno (Kuwabara y Zook, 1992). Sin embargo, en nuestros casos $\mathrm{J} 01$ y J02, cuyas zonas de inyección afectaron a la porción de frecuencias bajas de la OSL, no hallamos axones marcados en el NPS, lo que demuestra que, igual que en la rata, las neuronas del NMCT del jerbo que procesan los sonidos más graves no inervan al NPS.

Las neuronas del NMCT que inervan a la OSM son las más ventrolaterales e inervan también al limbo lateral de la OSL. El hecho de que las neuronas que inervan a la OSM ocupen posiciones laterales dentro del NMCT ya había sido notado por Philip H. Smith y sus colaboradores. De las 20 neuronas principales de la rata que analizaron Banks y Smith (1992), 12 poseían colaterales que inervaban a la OSM; entre estas 12 neuronas se incluían las 8 situadas en el tercio lateral del núcleo y 4 de las 9 situadas en el tercio central, pero ninguna de las 3 neuronas del tercio medial. De modo similar, 3 de las 6 neuronas del NMCT del gato marcadas por Smith y cols. (1998) enviaban colaterales para la OSM. Un dato muy interesante de este último estudio es que las tres neuronas que inervaban a la OSM fueron precisamente las de menor frecuencia característica $(635,6.300$ y $13.000 \mathrm{~Hz})$, mientras que otra neurona cuya frecuencia característica fue de $13.500 \mathrm{~Hz}$ carecía de colaterales para la OSM (Smith y cols., 1998). Este dato sugiere que el límite de frecuencias entre las neuronas principales del gato que inervan a la OSM y las que no lo inervan puede situarse entre 13 y $13,5 \mathrm{kHz}$, una cifra llamativamente próxima a los aproximadamente $12 \mathrm{kHz}$ que nuestros experimentos sugieren como límite superior para las neuronas que inervan a la OSM de la rata.

En cuanto a las neuronas del NMCT que inervan al NPS y a la OSM, pueden ser la población menos abundante y son las más laterales de las neuronas que inervan al NPS. La literatura recoge varios ejemplos de neuronas de este tipo, tanto en la rata (Smith y cols., 1998 [ver sus figuras 7 y 8]), como en otros mamíferos (Kuwabara y cols., 1991 [su figura 2]; Kuwabara y Zook, 1992 [sus figuras 2, 3 y 5]). Por desgracia, Sommer y cols. (1993) no pudieron aportar datos sobre la frecuencia característica y la posición de la única neurona que encontraron que inerva al NPS y a la OSM. 
Aunque hemos limitado nuestro análisis de las conexiones del NMCT a las proyecciones que envía a la OSL, la OSM y el NPS, no debe olvidarse que las neuronas principales pueden inervar a otros muchos blancos de su mismo lado, entre los que se incluyen el núcleo lateral del cuerpo trapezoide (NLCT), los núcleos cocleares (NCo) y el núcleo ventral del lemnisco lateral (ver referencias en la Introducción). No podemos descartar, por tanto, que un análisis más detallado de las conexiones del NMCT permita definir nuevas poblaciones de neuronas principales que difieran en otras conexiones.

Un aspecto interesante de la citoarquitectura del NMCT sería establecer si los tipos de neuronas principales definidos por nosotros difieren en otras características morfológicas o neuroquímicas. En el jerbo, las neuronas de la mitad lateral del NMCT poseen somas mayores que las de la mitad medial (Pasic y cols., 1994; Gleich y Strutz, 2002). Un estudio ultraestructural preliminar sugiere que las neuronas del extremo ventrolateral del NMCT de la rata poseen el soma más pequeño y menos recubierto de botones sinápticos que las neuronas mediales (Izaskun Elezgarai, comunicación personal). Este último dato es especialmente relevante a la vista de observaciones recientes que demuestran que las neuronas mediales transmiten más fielmente que las laterales los potenciales de acción del cáliz de Held (Leão y cols., 2006), y que esta fidelidad está directamente relacionadas con la forma y la complejidad de los cálices (Grande y Wang, 2011). Se ha comprobado también que dentro del NMCT existen gradientes lateromediales en la expresión de los canales de potasio Kv3.1b (Li y cols., 2001; von Hehn y cols., 2004; Strumbos y cols., 2010), Kv1.1 (Leao y cols., 2006) y Kv1.3 (Gazula y cols., 2010), así como en la amplitud de las corrientes de salida de potasio (Brew y Forsythe, 2005). Además, es posible que la expresión del receptor metabotrópico de glutamato de tipo 2/3 sea menor en las neuronas laterales que en el resto del núcleo (Izaskun Elezgarai, comunicación personal). Por último, se ha comprobado que las neuronas laterales responden con más lentitud, tanto a los estímulos in vivo (Tolnai y cols., 2008), como a la corriente inyectada in vitro (Leão y cols., 2006). Harán falta nuevos estudios para determinar en qué medida estas y otras propiedades aún por descubrir que varían sistemáticamente con la posición lateromedial de las neuronas guardan relación con los tipos identificados por nosotros a partir de sus proyecciones.

\subsubsection{Neuronas multipolares planas del NCoV}

Las neuronas multipolares del NCoV parecen estar presentes en todas las especies de mamíferos. Se han descrito con diferentes técnicas, lo que ha propiciado que se les asignaran nombres muy diversos. En las secciones teñidas con el método de Nissl poseen aspecto multipolar (p. ej., Osen, 1969a, b), mientras que cuando están impregnadas con el método de Golgi, aparecen estrelladas (p. ej., Lorente de Nó, 1933; Brawer y cols., 1974). Las neuronas multipolares constituyen una población heterogénea. Para las que inervan a la OSL, nosotros hemos adoptado el descriptivo nombre de neuronas multipolares planas, propuesto por Doucet y Ryugo (1997, 2003, 2006). Estas mismas neuronas han recibido otros nombres derivados de los resultados obtenidos con diferentes métodos: corresponden a las neuronas multipolares de tipo I del gato identificadas ultraestructuralmente (Cant, 1981), a las neuronas con patrón de 
respuesta en dientes de sierra o "choppers" (Smith y Rhode, 1989) y a las neuronas estrelladas T, denominadas así por Oertel y cols. (1990) porque, a diferencia de otras neuronas estrelladas, su axón viaja por el cuerpo trapezoide. Una característica de las neuronas multipolares planas observada en diversas especies es que su axón emite ramas colaterales que inervan al núcleo coclear dorsal (NCoD) (Oertel y cols., 1990; Doucet y Ryugo, 1997, 2003, 2006; Ostapoffy cols., 1999; Oertel y cols., 2011), razón por la que también se las ha denominado neuronas ventrotuberculares (p. ej., Ostapoff y cols., 1999).

En nuestros experimentos, las neuronas multipolares planas marcadas se encontraron sobre todo en el NCoPV, aunque también hallamos algunas en el NCoAV, intercaladas entre las neuronas esféricas. La distribución de las neuronas multipolares planas vista por nosotros coincide con la descrita en estudios anteriores realizados con ratas (Doucet y Ryugo, 1997, 2003, 2006) y ratones (Oertel y cols., 1990, 2011; Darrow y cols., 2012), pero difiere de la descrita en el gato, en el que prácticamente todas las neuronas ventrotuberculares se sitúan en el NCoAV (Ostapoffy cols., 1999).

Nuestros experimentos sugieren que la proyección de las neuronas multipolares planas a la OSL es tonotópica y que alcanza a todas las regiones de ésta. Existe, pues, una discrepancia entre nuestros resultados y los de Doucet y Ryugo (2003). Estos autores inyectaron BDA en el $\mathrm{NCoD}$ de la rata $\mathrm{y}$, aprovechando el transporte colateral del trazador, marcaron las neuronas multipolares planas y sus axones terminales en la OSL (Fig. 18). En ninguno de sus casos se marcaron axones de neuronas multipolares planas en el limbo lateral de la OSL, lo que les llevó a concluir que quizá esta región de la OSL no es inervada por el NCoPV. Nuestros casos L01-L04, J01 y J02, cuyas zonas de inyección afectaron exclusivamente al limbo lateral, demuestran que tanto en la rata, como en el jerbo, esta región de la OSL sí recibe inervación del NCoPV. Además, en cada uno de estos casos, se marcó en la parte más lateral y ventral del NCoD el campo terminal formado por las colaterales del axón de las neuronas multipolares planas. Lo más probable, por tanto, es que en contra de lo que Doucet y Ryugo (2003) afirmaron, en ninguno de sus experimentos la zona de inyección de BDA afectara a las regiones más laterales del NCoD, que son las que procesan los sonidos de frecuencias bajas codificados en el limbo lateral de la OSL. Dado que la OSL de la rata dedica un volumen desproporcionadamente grande a procesar las frecuencias de la parte inferior del espectro, habría bastado con que Doucet y Ryugo (2003) hubieran desplazado un poco más sus inyecciones en el NCoD lateralmente, para que el campo terminal en la OSL se hubiera situado en el limbo lateral.

\subsubsection{Neuronas multipolares pequeñas del NVCTc}

En nuestros experimentos con ratas y con jerbos se marcaron en la porción más ventral del NVCTc neuronas pequeñas de aspecto multipolar y sin ninguna peculiaridad morfológica reseñable. Después de haber inyectado HRP o WGA-HRP en la OSL del gato, Glendenning y cols. (1985) no encontraron ninguna neurona marcada en el COSc, a pesar de que las buscaron expresamente. Sin embargo, en experimentos similares Shneiderman y Henkel (1985) hallaron algunas neuronas débilmente marcadas en el NVCT de ambos lados, pero no aportaron 
datos sobre sus características. Los principales datos sobre la proyección del NVCT a la OSL proceden de estudios de trazado anterógrado. Mientras que Spangler y cols. (1985) hallaron autorradiográficamente una proyección del NVCT a la zona que rodea a la OSLc del gato, pero no a la propia OSL, la proyección a la OSLc fue demostrada inequívocamente por Warr y Beck (1996) mediante el trasporte anterógrado de una mezcla de BDA y leucina tritiada inyectada en el NVCT de la rata, y posteriormente confirmada por Gómez-Nieto y cols. (2008). En palabras de Warr y Beck (1996), se trató de una proyección sorprendente por su densidad, similar o superior a la de las demás proyecciones del NVCT.

EI NVCT consta de un conjunto heterogéneo de neuronas que difieren en sus rasgos morfológicos, en sus conexiones nerviosas, en su posición dentro del núcleo, y en sus propiedades electrofisiológicas. En estudios que combinaron registros intracelulares e inyecciones intracelulares de biocitina en rodajas frescas, Donald Robertson distinguió tres tipos neuronales en el NVCT de la rata atendiendo a su fisiología y morfología (Robertson, 1996; Wang y Robertson, 1997). Las neuronas marcadas en nuestros experimentos guardan algunas similitudes con el tipo al que Robertson denominó AHP1, compuesto por neuronas relativamente pequeñas, situadas en la parte ventral del núcleo y que poseen dendritas delgadas, carentes de espinas y sin orientación preferente. Los axones de las neuronas AHP1 marcadas por Robertson (1996) siguieron trayectorias variadas, lo que indica que esta categoría puede englobar a más de un tipo neuronal. No obstante, el axón de al menos una neurona AHP1 se dirigió medialmente hacia el NMCT, una trayectoria compatible con el hecho de que pudiera cruzar la línea media. Basándose en sus propiedades intrínsecas de membrana, Robertson (1996) propuso que las neuronas AHP1 son idóneas para llevar a cabo una integración temporal y espacial de los niveles globales de la información aferente relacionada con la intensidad el estímulo. En este contexto, conviene tener en cuenta que la porción ventral del NVCT es inervada, al menos, por las neuronas multipolares planas del NCoPVc (Doucet y Ryugo, 2003, 2006; Darrow y cols., 2012; nuestros propios experimentos [no ilustrado]), por la proyección descendente del colículo inferior (Cl) (Caicedo y Herbert, 1993; Thompson y Thompson, 1993; Vetter y cols., 1993; Schofield y Cant, 1999), y por la proyección directa de la corteza cerebral auditiva (Feliciano y cols., 1995; Mulders y Robertson, 2000).

En la rata, además de la proyección a la OSLc, se han identificado al menos otras cinco proyecciones del NVCT, que podrían originarse en sendos tipos neuronales:

1. La proyección a la cóclea está formada por el axón de las neuronas olivococleares mediales, que son de tamaño mediano, se encuentran en la porción dorsal del NVCT y poseen dendritas dirigidas ventralmente (White y Warr, 1983; Aschoff y Ostwald, 1987; Vetter y Mugnaini, 1992; Mulders y Robertson, 2000). Estas características contrastan fuertemente con las de las neuronas marcadas en nuestros experimentos, que son pequeñas, ocupan la porción más ventral del núcleo y carecen de una orientación dendrítica definida. Esto, unido al hecho de que en nuestros experimentos no se marcaron axones del haz olivococlear cruzado, por el que viajan los axones de las neuronas olivococleares mediales (Osen y cols., 1984; Maison y cols., 2003; Gómez-Nieto y cols., 2014), permite descartar que las neuronas del NVCT que inervan a la OSLc sean olivococleares. 
2. La proyección al Cli parte también de neuronas situadas en la región dorsal del NVCT, donde se entremezclan con las neuronas olivococleares mediales (Faye-Lund, 1986; Aschoffy Ostwald, 1988). Esto, unido al hecho que no se ha encontrado ninguna neurona olivocolicular que envíe también proyecciones al lado contralateral (Schofield, 2002), nos hace pensar que tampoco nuestras neuronas son las mismas que inervan al Cli.

3. El NVCT contiene también numerosas neuronas que inervan los NCo de ambos lados y que constituyen una de sus principales aferencias de origen no coclear (Osen y cols., 1984; Faye-Lund, 1986; Spangler y cols., 1987). En la rata es especialmente llamativa la proyección que termina en forma de densos campos terminales con abundantes botones sinápticos limitados a la capa molecular del NCoDc (Warr y Beck, 1996). Aunque en nuestros experimentos sí se marcaron axones en el NCoDi a la zona de inyección (y contralateral, por tanto, a las neuronas del NVCT marcadas), se trató de colaterales del axón de las neuronas multipolares planas cuya morfología fue claramente distinta de la de los axones del NVCT, por lo que también podemos descartar que nuestras neuronas marcadas sean las mismas que inervan al NCoD.

4. Recientemente se ha descubierto que el NVCT de la rata posee neuronas que inervan selectivamente a las neuronas de la raíz coclear de ambos lados (Gómez-Nieto y cols., 2008, 2014), que constituyen el primer eslabón del circuito que media el reflejo de sobresalto auditivo. Mientras que por su pequeñez estas neuronas del NMVCT se parecen las marcadas en nuestros experimentos, creemos que se trata de dos tipos neuronales diferentes porque la proyección de NVCT a la raíz coclear es claramente bilateral, en tanto que la proyección a la OSL es solamente contralateral. Además, en nuestros experimentos nunca se marcaron axones terminales en la raíz coclear de ninguno de los dos lados, pero sí otras muchas colaterales del axón de las neuronas que inervan a la OSL.

5. El 29 de julio de este mismo año se publicó un artículo en el que se muestra que el NVCT del ratón poseen neuronas que envían una densa proyección glicinérgica al NMCT de su mismo lado (Albrecht y cols., 2014). Si la rata contuviera neuronas semejantes y se tratara de las mismas neuronas que inervan a la OSLc, en nuestros experimentos deberíamos haber encontrado abundantes axones terminales en el NMCTc a la zona de inyección, algo que no ocurrió.

A la vista de estas reflexiones, puede concluirse que las neuronas del NVCT que inervan a la OSLc son distintas de las que inervan a otros núcleos. Está claro que la información sobre las neuronas multipolares pequeñas del NVCT que inervan a la OSL es todavía muy rudimentaria y prácticamente se limita a los detalles aportados por esta Tesis. Serán necesarios más estudios morfológicos y funcionales para caracterizarlas.

\subsubsection{Las neuronas globulares no inervan a la OSL}

Un aspecto aún no aclarado de las conexiones de la OSL es si recibe proyecciones directas de las neuronas globulares del NCoV. Los datos que apoyan esta posibilidad proceden de experimentos con inyección intraaxónica de un trazador en el cuerpo trapezoide. Friauf y Ostwald (1988) describieron que algunas neuronas del NCoV de la rata caracterizadas 
electrofisiológicamente como arbustiformes y que generaban un cáliz de Held en el NMCTc inervaban mediante colaterales axónicas al NLCTi y la OSLi. Por su parte, Kuwabara y cols. (1991), en un estudio llevado a cabo con rodajas del tronco del encéfalo de ratones, jerbos y tres especies de murciélagos, notaron que de las 98 colaterales del axón de neuronas globulares que analizaron en el COSi, 18 alcanzaron la OSL, donde se ramificaron; estos mismo autores incluso ilustraron un axón que emitía una colateral para la OSLc (ver su Fig. 5C). Por último, Smith y cols. (1991) observaron que 1 de los 15 axones de neuronas globulares del gato que analizaron emitió una rama colateral que inervó la porción más caudal de la OSLi antes de alcanzar la región periolivar dorsal.

Aunque estos estudios parecen demostrar que las neuronas globulares sí inervan a la OSLi, nuestros datos indican lo contrario porque en nuestros casos con zonas de inyección de BDA restringida a la OSL no se marcaron neuronas globulares. Esta afirmación se basa en dos hechos: por una parte, aunque las neuronas esféricas y las globulares poseen un aspecto similar, difieren en su distribución y en nuestros experimentos no se marcaron neuronas arbustiformes en el NCoPV, donde abundan las neuronas globulares; por otra parte, si las neuronas globulares inervaran a la zona de inyección, en nuestros experimentos deberían haberse marcado cálices de Held en el NMCTc, y esto no sucedió a pesar de que sí se marcaron las colaterales de otros axones más delgados, como los de las neuronas esféricas.

Para tratar de resolver esta cuestión, hemos inyectado BDA en el NMCT de la rata con el objeto de marcar los axones de las neuronas globulares y sus colaterales. En la figura 56C se muestra la zona de inyección del caso T01, situada en la mitad caudal del NMCT y que no afectó a ningún núcleo vecino. Como cabía esperar, en el NCoVc se marcaron retrógradamente abundantes células con el aspecto típico de neuronas arbustiformes (Fig. 56A, B). El que muchas de ellas se encontraran en el NCoPV (Fig. 56A) demuestra que no se trata de neuronas esféricas, sino globulares. Esta conclusión se ve reforzada también por calibre de los axones marcados en el cuerpo trapezoide (Fig. 56A, D-G), considerablemente más gruesos que los de las neuronas esféricas y multipolares (comparar con las Figs. 32, 45, 48). En el lado ipsolateral al soma, los axones marcados emitieron ramas colaterales relativamente gruesas dirigidas dorsalmente (Fig. 56D, E, G). Estas colaterales inervaron tanto al NLCT (Fig. 56G), como a un territorio aplanado en sentido rostrocaudal, de no más de 200 ó $300 \mu \mathrm{m}$ de espesor, situado justo detrás de la OSL (Fig. 56D, E), pero no parecieron penetrar en la OSL propiamente dicha. De hecho, en la mayoría de las secciones, la OSL estuvo desprovista de axones marcados. En la figura 56F, H puede verse la sección de la OSL en la que más axones marcados hallamos dentro de la OSL, cuya densidad no es en absoluto comparable a la vista en el NLCT o la región situada tras la OSL.

En resumen, los resultados de todos nuestros experimentos sugieren que las neuronas globulares no son una fuente significativa de proyecciones para la OSL de la rata, aunque sí inervan densamente los territorios situados inmediatamente detrás y debajo de ella. Esta conclusión es consistente con el hecho de que prácticamente todos los estudios anteriores que marcaron el axón de neuronas globulares individuales coincidieran en señalar a las regiones periolivares situadas ventralmente a la OSL como su principal blanco ipsolateral (Friaufy Ostwald, 1988; Spirou y cols., 1990; Kuwabara y cols., 1991; Smith y cols., 1991). 


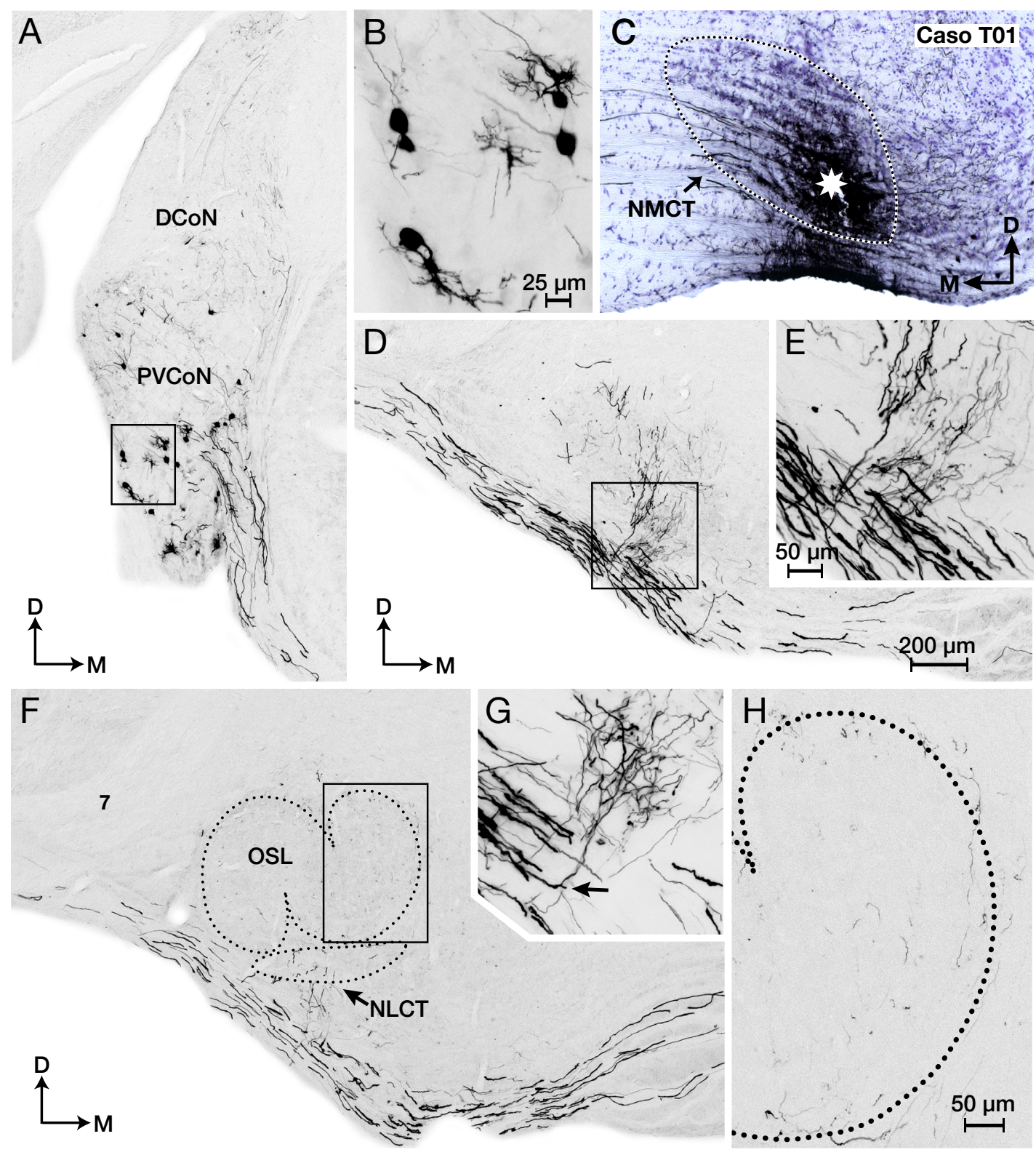

Figura 56. Las neuronas globulares del NCoV no inervan a la OSL. Microfotografías de secciones coronales del caso T01, en el que se inyectó BDA en el NMCT derecho de la rata. (A) Imagen panorámica de una sección de la parte caudal del NCoPV y del NCoD contralaterales a la zona de inyección. El NCoPV contiene numerosas neuronas arbustifomes marcadas retrógradamente. (B) Detalle de neuronas arbustiformes típicas, situadas en el área enmarcada en A. (C) Fotografía de la zona de inyección de BDA, cuyo centro se ha indicado con un asterisco blanco. (D) Sección tomada de un nivel ligeramente más caudal que la OSLc. En el cuerpo trapezoide se han marcado numerosos axones de neuronas globulares, reconocibles por su grosor, y que emiten ramas colaterales que se dirigen dorsalmente para inervar a la región que queda detrás de la OSL. (E) Detalle del área enmarcada en $\mathbf{D}$, en el que se aprecian las colaterales del axón de las neuronas globulares que inervan a la región situada detrás de la OSL. (F) Sección que incluye la OSL del lado opuesto a la zona de inyección. Obsérvese que, a pesar de los muchos axones de neuronas globulares marcados en el cuerpo trapezoide, la OSL aparece prácticamente desprovista de axones marcados. (G) Detalle del punto en el que los gruesos axones de las neuronas globulares generan ramas colaterales que se dirigen dorsalmente para inervar al NLCT y a la región situada detrás de la OSL. (H) Detalle del área enmarcada en $\mathbf{F}$, en el que se aprecia el limbo medial de la OSL con poquísimas fibras terminales marcadas. La barra de aumento de $\mathbf{D}$ sirve también para $\mathbf{A}, \mathbf{C}$ y $\mathbf{F}$, y la barra de $\mathbf{B}$ sirve también para $\mathbf{G}$. 


\subsection{Destino de las proyecciones troncoencefálicas que inervan a la OSL}

Un aspecto de gran relevancia funcional es averiguar si los cuatro tipos neuronales troncoencefálicos que inervan a la OSL comparten dianas dentro del núcleo o si inervan a tipos neuronales diferentes. La penosa escasez de datos sobre las neuronas multipolares pequeñas del NVCT hace que no podamos siquiera especular acerca del destino de sus axones, de modo que limitaremos la reflexión a los otros tres tipos neuronales.

Aunque, como vimos en la Introducción, la OSL de la rata puede contener varios tipos diferentes por su morfología, puede convenirnos agrupar las neuronas en sólo tres categorías: neuronas que inervan al Cli, neuronas que inervan al Clc, y neuronas olivococleares laterales. Estos tres tipos poseen campos dendríticos aplanados que se extienden rostrocaudalmente con una orientación perpendicular al contorno de la OSL y coincidente con la de los axones que inervan a la OSL, de manera que en principio cualquiera de los tres tipos de neuronas de la OSL podría ser un blanco perfecto de las neuronas esféricas, las multipolares planas, y las neuronas del NMCT

La inervación glicinérgica de la OSL es tan densa, que cuesta imaginar que dentro del núcleo pueda haber neuronas que se escapen de su efecto. De hecho, un estudio reciente in vitro ha demostrado que en el ratón tanto las neuronas olivocoliculares, como las olivococleares reciben sinapsis glicinérgicas capaces de generar potenciales postsinápticos inhibidores (Sterenborg $y$ cols., 2010). Se ha propuesto que, a diferencia de los otros tipos neuronales de la OSL, las neuronas olivococleares laterales del jerbo y el cobaya carecen de sinapsis axosomáticas (Helfert y cols., 1988, 1992), pero eso no excluye que puedan ser inhibidas a través de sinapsis axondendríticas. Puede, por tanto, concluirse que muy probablemente las neuronas principales del NMCT actúen sobre todos los tipos neuronales de la OSL.

La pregunta que surge a continuación es si las neuronas esféricas y las multipolares planas del NCoV comparten destino en la OSL. Ambos tipos neuronales utilizan glutamato como neurotransmisor y forman sinapsis asimétricas y con vesículas redondas (Smith y cols., 1993; Darrow y cols., 2012), pero todas las neuronas de la OSL reciben abundantes sinapsis con características ultraestructurales compatibles con la neurotransmisión glutamatérgica (Cant, 1984; Helfert y Schwartz, 1986; Brunso-Bechtold y cols., 1994) y responden a la estimulación del NCoVi con corrientes postsinápticas excitadoras que pueden bloquearse con CNQX, lo que demuestra su carácter glutamatérgico (Sterenborg y cols., 2010). Sin embargo, las neuronas olivococleares responden a la excitación más lentamente y con latencias más largas que las neuronas olivocoliculares, tanto en la rata (Fujino y cols., 1997; Adam y cols., 1999, 2001), como en el ratón (Sterenborg y cols., 2010). Dado que el axón de las neuronas esféricas es algo más grueso que el de las multipolares planas (Oertel y cols., 2011), sería razonable asumir que las neuronas principales son inervadas por las neuronas esféricas, y las neuronas olivococleares laterales por las neuronas multipolares planas. Aunque esta hipótesis no se ha demostrado, hay algunos datos indirectos que la apoyan. En el ratón, se ha comprobado que las neuronas multipolares planas inervan a neuronas olivococleares mediales contralaterales (Darrow y cols., 2012), pero no existe información sobre si inervan a las neuronas olivococleares laterales. Además, el reflejo 
mediado por las neuronas olivococleares mediales se ve afectado por lesiones en el NCoPV, pero no por lesiones en otras regiones de los NCo (de Venecia y cols., 2005). Por último, en nuestros experimentos el número de neuronas multipolares planas marcadas fue aproximadamente tres veces inferior al número de neuronas esféricas marcadas. Esta proporción es sospechosamente similar a la que guardan las neuronas de la OSL de la rata, un núcleo en el que las neuronas olivococleares laterales representan aproximadamente una cuarta parte de las neuronas (Vetter y Mugnaini, 1992; Kulesza y cols., 2002).

Las posibles diferencias de inervación entre las neuronas de la OSL que proyectan al Cli y las que proyectan al Clc sólo se han estudiado en el jerbo. En esta especie, los botones axosomáticos excitadores son significativamente más abundantes en las neuronas de proyección directa (Brunso-Bechtold y cols., 1994).

\section{4. ¿Contiene la OSL regiones funcionalmente distintas?}

El que en nuestros experimentos la proporción de neuronas esféricas, multipolares planas, principales del NMCT y multipolares pequeñas marcadas se mantuviera contante al cambiar la posición de la zona de inyección a lo largo del eje tonotópico de la OSL fue uno de los resultados que menos cabía esperar cuando comenzamos nuestro estudio. La literatura recoge numerosísimos ejemplos de diferencias regionales dentro de la OSL referidas a cualidades morfológicas, electrofisiológicas, bioquímicas u ontogenéticas, y que parecen estar presentes en todo tipo de mamíferos. Quizás el ejemplo mejor conocido sea la OSL del jerbo. En este núcleo, se han notado diferencias tan llamativas entre los limbos medial (frecuencias altas) y lateral (frecuencias bajas) con respecto a criterios tan dispares como la concentración de receptores de glicina (Sanes y cols., 1987; Sanes y Wooten, 1987; Koch y Sanes, 1998; Korada y Schwartz, 1999), la anchura de los árboles dendríticos (Sanes y cols., 1990; Sanes y cols., 1992), la abundancia de astrocitos y oligodendrocitos (Hafidi y cols., 1994), la expresión de proteínas asociadas a la mielina (Hafidi y cols., 1996), la expresión del receptor ionotrópico de glutamato de tipo 4 (Schwartz y Eager, 1999), o la distribución de neuronas olivococleares que contienen urocortina (Kaiser y cols., 2011), que se ha llegado a proponer que más que ser un núcleo, la OSL está en realidad compuesta por dos.

Sin llegar a los extremos del jerbo, también en la OLS de la rata se han observado diferencias regionales notables. Por citar sólo algunos ejemplos, si se comparan los limbos medial y lateral, se comprueba que el limbo medial contiene más neuronas GABAérgicas, más neuronas colinérgicas, más neuronas olivococleares, más neuronas que responden a la inyección de corriente despolarizante con múltiples potenciales de acción, menos botones sinápticos axosomáticos glicinérgicos, más neuronas que contienen urocortina, campos dendríticos más aplanados, más neuronas inmunorreactivas para el anticuerpo SMI-32, una menor expresión del receptor cannabinoide $\mathrm{R} 1$ durante el desarrollo postnatal, y más neuronas espontáneamente activas antes de que el animal empiece a oír (Vetter y cols., 1991; Vetter y Mugnaini, 1992; Rietzel y Friauf, 1998; Barnes-Davies y cols., 2004; Buras y cols., 2006; Kreinest y cols., 2009; Ouda y cols., 2012). El hecho de que todas las regiones de la OSL reciban una combinación similar de 
impulsos sugiere que estas y otras diferencias son una propiedad intrínseca de la OSL, y no algo heredado de su aferencias.

También fue inesperada la observación de que el porcentaje del volumen del núcleo dedicado a procesar los sonidos de frecuencias bajas y medias es mayor en la OSL que en el NCoAV, el NCoPV, el NMCT y el NVCT. Los sonidos que en todos estos núcleos se procesan en el tercio bajo del eje tonotópico, en la OSL de la rata ocupan al menos la mitad del eje. No creemos que este fenómeno esté directamente relacionado con la peculiar sensibilidad auditiva de la rata, que alcanza su grado máximo para los sonidos de unos $8 \mathrm{kHz}$, porque si así fuera, también en otros núcleos estaría hipertrofiada la región dedicada a esta frecuencia, y no es así. Además, la rata es también muy sensible a los sonidos de unos $32 \mathrm{kHz}$ (Kelly y Masterton, 1977; Heffner $y$ cols., 1994) y, según nuestros resultados, en la OSL de la rata no parece existir una expansión en la representación de esta frecuencia. En el jerbo, la distribución de frecuencias a lo largo del eje tonotópico es idéntica para la OSL, el NCoAV, el NCoPV y la cóclea (Müller, 1990). Todos estos datos sugieren que la singular distribución de frecuencias en la OSL de la rata es una peculiaridad propia de esta especie que debe de tener su origen en alguna función concreta que es desarrollada por neuronas de la OSL que procesan sonidos de un rango determinado de frecuencias. El hecho de que en la chinchilla y la rata las neuronas del limbo lateral de la OSL respondan a los estímulos procedentes de la línea media mientras que las del resto del núcleo no lo hacen (Finlayson y Caspary, 1991) puede ser relevante en este contexto. También puede serlo el que el limbo lateral de la OSL de otras especies posea neuronas sensibles a DIT en la estructura fina de la onda sonora (Caird y Klinke, 1983 [gato]; Joris y Yin, 1995 [gato]; Batra y cols., 1997 [conejo]; Tollin y Yin, 2005 [gato]).

\section{INERVACIÓN DEL NPS}

En nuestros experimentos con inyección de BDA en los limbos central y medial de la OSL de la rata, se marcó en el NPSi un denso plexo parasagital de axones terminales que, con toda probabilidad, está formado por colaterales del axón de las neuronas principales del NMCT marcadas retrógradamente. Hasta ahora, la información disponible sobre la proyección del NMCT al NPS procedía casi exclusivamente de la inyección intracelular de trazadores en neuronas del NMCT, que revela únicamente el axón de neuronas individuales (Kuwabara y cols., 1991; Banks y Smith, 1992; Kuwabara y Zook, 1992; Sommer y cols., 1993). En nuestros experimentos, dentro del NPS se ha marcado selectivamente la proyección de cientos de neuronas principales, lo que nos ha permitido apreciarla en su conjunto. Hay varios aspectos interesantes en nuestros resultados:

En primer lugar, nuestros casos ponen de manifiesto la extraordinaria densidad de la proyección del NMCT al NPS. Este era un resultado esperable dado que el neuropilo del NPS de la rata es intensamente inmunorreactivo para la calbindina (ver la figura 44B, E; ver también Webster y cols., 1990; Friauf, 1993; Forster y Illing, 2000; Illing y cols., 2000; Spencer y cols., 2002). Además, el NPS de la rata posee una concentración especialmente elevada de botones sinápticos glicinérgicos (ver la figura 44C, F; ver también Zafra y cols., 1995; Ehrlich y cols., 1998; 
Friaufy cols., 1999; Behrend y cols., 2002; Zeilhofer y cols., 2005; Toyoshima y cols., 2009; Cooper y Gillespie, 2011), que deben de representar en su inmensa mayoría la proyección del NMCT. Esta densa inervación glicinérgica tiene su reflejo en la peculiar fisiología de las neuronas del NPS, que se mantienen silentes mientras duran los estímulos sonoros - debido, precisamente, a la masiva inhibición tónica a la que son sometidas por parte del NMCT- y generan una respuesta de apagado ("offset") cuando cesa el estímulo (Kuwada y Batra, 1999 [conejo]; Dehmel y cols., 2002 [jerbo]; Kulesza y cols., 2003, 2007) [rata]; Kadner y cols., 2006 [rata]; Kadner y Berrebi, 2008 [rata]; Felix y cols., 2012, 2013 [ratón]).

En segundo lugar, la orientación de los plexos de axones marcados dentro del NPS confirma la organización anisótropa del núcleo, integrada por láminas parasagitales en las que se entremezclan los campos terminales de los axones aferentes (Thompson y Thompson, 1991 [cobaya]; Banks y Smith, 1992 [rata]; Sommer y cols., 1993 [rata]; Schofield, 1995 [cobaya]) dispuestos paralelos a los campos dendríticos aplanados de las neuronas del propio núcleo (Osen y cols., 1984 [chinchilla]; Saldaña y Berrebi, 2000 [rata]; Schmidt y cols., 2010 [humano]). El que en cada uno de nuestros experimentos el plexo recorriera toda la extensión rostrocaudal del núcleo es compatible con la extensión de las ramas colaterales del axón de neuronas individuales del NMCT, que dentro del NPS forman campos terminales que se extienden entre 400 y $1200 \mu \mathrm{m}$ rostrocaudalmente (Sommer y cols., 1993).

En tercer lugar, la proyección del NMCT al NPS sigue un estricto orden tonotópico lateromedial, consistente con descripciones anteriores de la topografía de las conexiones del NPS (Thompson y Thompson, 1991; Banks y Smith, 1992; Sommer y cols., 1993; Kelly y cols., 1998; Saldaña y Berrebi, 2000; Saldaña y cols., 2009) y de las características de respuesta de sus neuronas (Behrend y cols., 2002 [jerbo]; Kulesza y cols., 2003 [rata]; Felix y cols., 2012 [ratón]). La estrechez del plexo de axones marcados encaja claramente con el hecho de que las neuronas que lo originan estén perfectamente alineadas en una estrecha franja vertical, y la nitidez de los bordes lateral y medial del plexo demuestra que la tonotopía de la proyección del NMCT al NPS es impresionantemente precisa.

Por último, nuestros experimentos sugieren que el NPS no posee una representación completa de frecuencias porque únicamente se marcaron axones terminales en él en los casos con zona de inyección en los limbos medial e intermedio de la OSL de la rata, lo que demuestra que las neuronas del tercio ventrolateral del NMCT, que son las que procesan los sonidos más graves e inervan al limbo lateral de la OSL, no inervan al NPS. Esta idea se ve también fortalecida por nuestros casos $\mathrm{J} 01$ y J02, en los que tampoco se marcaron axones terminales en el NPS, a pesar de que también en el jerbo en NPS es inervado por el NMCT (Kuwabara y Zook, 1992). La aparente falta de implicación del NPS en el procesamiento de los sonidos más graves podría ser el más controvertido de nuestros resultados relacionados con el NPS, pues buena parte de los escasos estudios electrofisiológicos del NPS de los roedores han afirmado que las frecuencias procesadas dentro del núcleo cubren la mayor parte del rango auditivo de su especie (Behrend y cols., 2002 [jerbo]; Dehmel y cols., 2002 [jerbo]; Kulesza y cols., 2003) [rata]; Kadner y cols., 2006 [rata]; Kulesza y cols., 2007 [rata]; Kadner y Berrebi, 2008 [rata]; Felix y cols., 2012 [ratón]). 
Para verificar nuestra hipótesis de que el NPS de la rata no interviene en el procesamiento de sonido graves, hemos recurrido a dos tipos de experimentos de trazado adicionales. Estos experimentos exploraron las relaciones entre el NPS y el $\mathrm{Cl}$, que constituye con diferencia el principal blanco de las proyecciones del NPS de la rata (Kelly y cols., 1998; Saldaña y Berrebi, 2000; Saldaña y cols., 2009) y posee una representación completa de frecuencias (revisada por Malmierca y cols., 2008; Portfors y cols., 2011). En el Cl de la rata las neuronas sensibles a las frecuencias más bajas se encuentran en la región más dorsolateral del núcleo central (NCCl). Aprovechando este hecho, un primer experimento consistió en inyectar BDA en esta

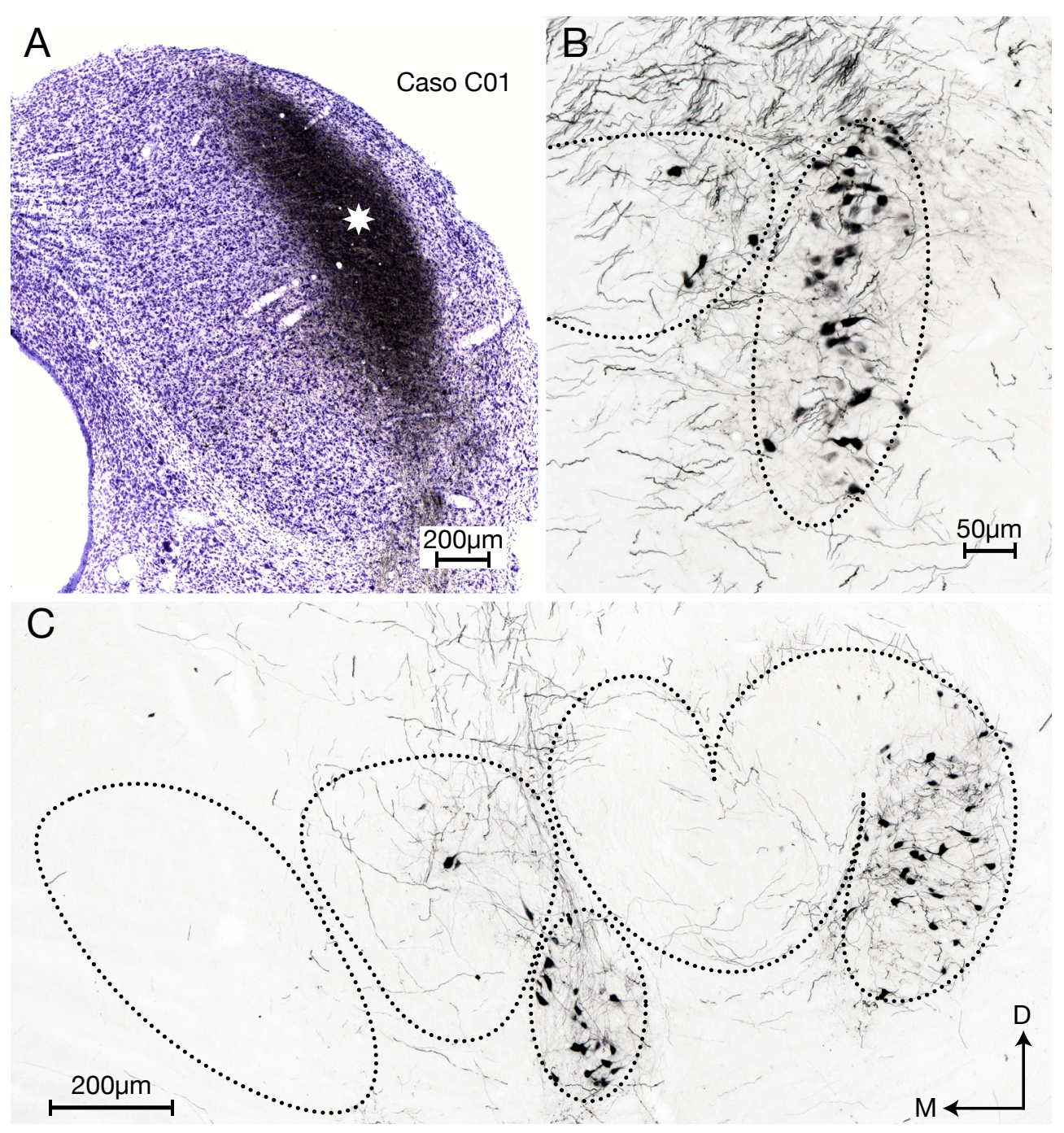

Figura 57. El NPS de la rata no inerva a la región de frecuencias bajas del CI. Microfotografías de secciones coronales del caso C01, en el que se inyectó BDA en la región más lateral del núcleo central del CI, que procesa los sonidos más graves. (A) Sección del CI que incluye el centro de la zona de inyección (asterisco). La forma alargada de la zona de inyección es consecuencia de la organización laminar del núcleo. Sección contrastada con violeta de cresilo. $(\mathbf{B}, \mathbf{C})$ Secciones rostral (B) y caudal (C) del COS ipsolateral. La abundancia de neuronas marcada retrógradamente en la OSM y en el limbo lateral de la OSL contrasta fuertemente con la escasez de neuronas en el NPS. De hecho, de todo el caso, estas fueron dos de las secciones con más neuronas marcadas en el NPS, núcleo que en la mayoría de las secciones apareció vacío. 
región dorsolateral del $\mathrm{NCCl}$. La figura 57A muestra una zona de inyección de BDA en la región dorsolateral del NCCI. En la mayor parte de las secciones de este experimento, el NPS apareció vacío, en tanto que la OSM y el limbo lateral de la OSL contuvieron numerosas neuronas marcadas (Fig. 57B, C; ver también Aitkin y Schuck, 1985; Kelly y cols., 1998 [su Fig. 1]).

El segundo experimento consistió en comparar los axones marcados en el $\mathrm{Cl}$ de un caso con inyección de BDA en la región más lateral del NPS (caso S01), con los marcados en un caso con una inyección similar centrada en la OSM (caso M01). En el caso S01, con zona de inyección en el borde lateral del NPS (Figs. 49A, 58D), los axones terminales marcados en el Cl formaron los plexos típicos de esta proyección (Saldaña y cols., 2009), pero se encontraron relativamente lejos de la región más dorsolateral del $\mathrm{NCCl}$, de modo que no parecen inervar a la región de frecuencias más bajas de este núcleo (Fig. 58B; ver también la figura 8 de Saldaña y cols., 2009). En el caso M01 la zona de inyección afectó a la OSM, si bien parte del trazador difundió

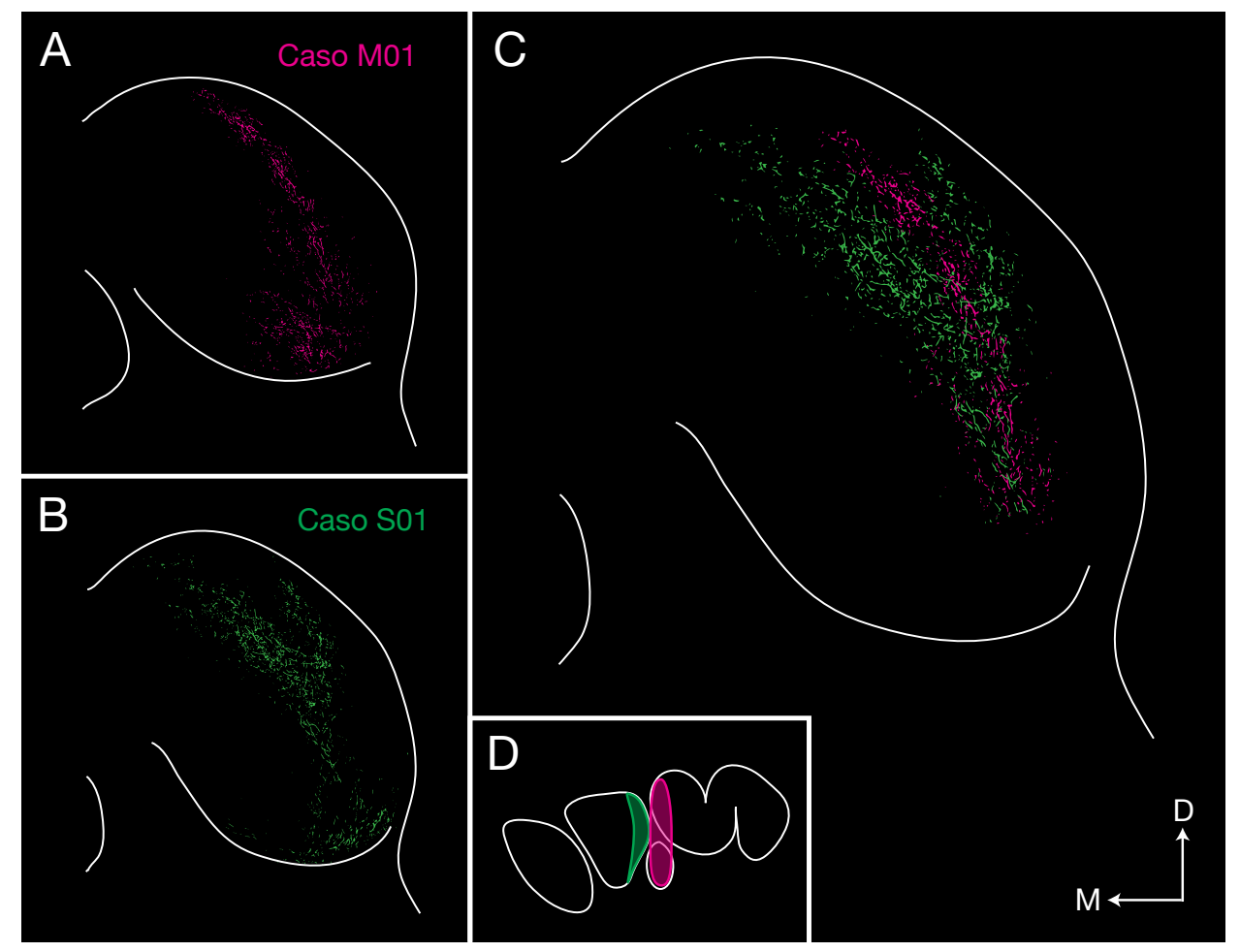

Figura 58. El NPS de la rata no inerva a la región de frecuencias bajas del CI. Pseudodibujos digitales ("Illustrator drawings") que permiten comparar los axones marcados en el CI de un caso en el que se inyectó BDA en la OSM (caso M01, ilustrado en color magenta), con los axones marcados en un caso con inyección de BDA en la región más lateral del NPS (caso S01, ilustrado en color verde). (A) Los axones de la OSM forman un denso plexo en la región más dorsolateral del NCCI. Los axones marcados ventralmente son el resultado de la inclusión de parte del limbo lateral de la OSL en la zona de inyección. (B) Los axones del NPS forman dos plexos que se unen ventralmente formando una "V". El plexo más ventromedial se encuentra en el NCCI, a cierta distancia del borde dorsolateral del núcleo, mientras que el plexo lateral se encuentra en la corteza externa del CI (para consultar el patrón que sigue la proyección del NPS al CI, ver Saldaña y cols., 2009). (C) Superposición digital de los plexos de axones visibles en A y en B. El plexo de axones del NPS (verde) no inerva a la región de frecuencias más bajas del NCCI, ocupada por el plexo de la OSM (magenta). (D) Representación esquemática de las zonas de inyección. 
dorsalmente a lo largo del trayecto de la micropipeta hasta afectar a la región más medial de la OSL (Fig. 58D). Como cabía esperar (Henkel y Spangler, 1983; Oliver y cols., 2003; Cant, 2013), el plexo de axones de la OSM se situó en la porción más dorsolateral del $\mathrm{NCCl}$ (Fig. 58A). Al superponer digitalmente los axones marcados en el $\mathrm{NCCl}$ en el caso $\mathrm{S} 01$ y los marcados en el caso M01, se comprueba que los axones de las neuronas más laterales del NPS son claramente más ventromediales que los de las neuronas de la OSM (Fig. 58C), de modo que el patrón de marcado es complementario.

Los resultados de todos nuestros experimentos refuerzan la hipótesis de que el NPS de la rata no procesa los sonidos mas graves porque: 1) no es inervado por las neuronas del NMCT más ventrolaterales; y 2) el NPS no inerva a la región de frecuencias más graves del $\mathrm{Cl}$. Además, nuestros datos sugieren que la representación incompleta de frecuencias en el NPS es aproximadamente complementaria de la de la OSM. En principio, nuestra hipótesis es difícil de reconciliar con los estudios electrofisiológicos, en los que se han descrito neuronas del NPS con frecuencias características tan bajas como $0,7 \mathrm{kHz}$ en el jerbo (Behrend y cols., 2002), $0,8 \mathrm{kHz}$ en la rata (Kadner y cols., 2006), ó $2 \mathrm{kHz}$ en el ratón (Felix y cols., 2012). No obstante, conviene tener en cuenta que en las muestras de neuronas del NPS estudiadas electrofisiológicamente predominan con diferencia las neuronas sensibles a los sonidos agudos (Dehmel y cols., 2002; Kulesza y cols., 2003, 2007; Felix y cols., 2012), lo que sí concuerda con nuestra conjetura, y también que el NPS poseen neuronas que procesan sonidos agudos pero son capaces de seguir el envoltorio de los sonidos de amplitud modulada sinusoidalmente, cuya frecuencia es siempre muy baja (Behrend y cols., 2002; Dehmel y cols., 2002; Kulesza y cols., 2003; Kadner y Berrebi, 2008; Felix y cols., 2011). En cualquier caso, de confirmarse nuestra hipótesis, el NPS constituiría una auténtica rareza, pues sería el primer núcleo auditivo conocido de los roedores especializado en el procesamiento de sonidos agudos, y esto podría convertirlo en un modelo adecuado para futuros estudios.

\section{INERVACIÓN DE LA OSM}

La segunda parte de nuestro estudio ha analizado con detalle el patrón de inervación de la OSM de la rata y ha incluido experimentos de confirmación realizados con jerbos. La inyección de BDA en la OSL nos ha permitido marcar mediante transporte colateral las principales aferencias de la OSM, procedentes de neuronas esféricas ipso y contralaterales y de neuronas principales del NMCT. Nuestros resultados indican que: 1) la OSM de la rata interviene únicamente en el procesamiento de sonidos de frecuencia grave (de no más de $12 \mathrm{kHz}$ ) y posee una clara organización tonotópica dorsoventral; 2) las aferencias que reciben sus neuronas se segregan espacialmente (las dendritas laterales son inervadas por las neuronas esféricas de su mismo lado, mientras que las dendritas mediales son el blanco de las neuronas esféricas contralaterales y de las neuronas del NMCT; y 3) cada neurona de la OSM es excitada tonotópicamente por neuronas esféricas del NCoAVi e inhibida tonotópicamente por neuronas del NMCT. 


\subsection{Diseño experimental}

Una de las facetas más innovadoras de nuestro estudio ha sido el inyectar BDA en la OSL para tratar de aprovechar el transporte colateral del trazador y así visualizar en el mismo experimento las tres principales aferencias de la OSM. La existencia y posible utilidad del transporte colateral de trazadores bidireccionales fueron notadas inicialmente por de De Olmos $y$ Heimer (1977) en experimentos en los que inyectaron peroxidasa libre (HRP) en el cerebro de ratas. Dado el carácter bidireccional de la HRP, estos autores propusieron que inyectando el trazador en uno de los núcleos inervados por una población de neuronas, podrían verse en el mismo experimento las neuronas que generan esa proyección y todas sus otras proyecciones (ver también Steward, 1981).

El transporte colateral ha resultado útil para extraer información sobre múltiples regiones del sistema nervioso central, incluido el sistema auditivo. Sin embargo, en la mayoría de las ocasiones, su uso no fue buscado, sino el fruto de una observación fortuita que permitió enriquecer las conclusiones del estudio (p. ej., Glendenning y cols., 1985; Merchán y cols., 1994; Doucet y Ryugo, 2003). Muy diferente fue el planteamiento de Shneiderman y Henkel (1985). Estos dos autores inyectaron WGA-HRP en la OSL del gato para marcar las proyecciones colaterales que inervan al propio COS y observaron sendos campos terminales en la OSMi y la OSMc, que atribuyeron correctamente a colaterales del axón de neuronas del NCoAV marcadas retrógradamente. Yendo un paso más lejos, Shneiderman y Henkel (1985) observaron que la posición dorsoventral de los campos terminales en ambas OSM guardaba relación con la posición lateromedial de la zona de inyección y la posición dorsoventral de las neuronas marcadas en el NCoAV. Por todos estos motivos, el artículo de Shneiderman y Henkel (1985) debe en justicia considerarse como un claro precursor de nuestro estudio. La principal diferencia entre el estudio de Shneiderman $y$ Henkel (1985) y el nuestro, aparte del animal experimental empleado, es la superioridad del BDA para generar zonas de inyección reducidas y, sobre todo, para marcar nítidamente los somas, las dendritas y los axones, tanto de paso, como terminales, lo que nos ha permitido apreciar detalles que pasaron inadvertidos con WGA-HRP.

Una virtud clave de nuestro estudio es que nos ha permitido comparar en un mismo experimento la distribución dentro de la OSM de los axones procedentes de las neuronas esféricas ipso y contralaterales y de las neuronas del NMCTi, sabiendo además que estábamos marcando selectivamente las proyecciones de neuronas de regiones tonotópicas equivalentes. Costaría imaginar otro diseño experimental factible que pueda proporcionar una información semejante. Inyectando un trazador anterógrado en el NCoAV puede aspirarse a marcar la proyección de las neuronas esféricas a la OSM de ambos lados (Müller, 1990; Kil y cols., 1995; Russell y Moore, 1995; Beckius y cols., 1999), pero difícilmente puede evitarse marcar las proyecciones de otros tipos neuronales que puedan "contaminar" los resultados. Además, debido a su peculiar citoarquitectura, las inyecciones de trazadores en el NCoAV, por pequeñas que sean, terminan marcando los axones de neuronas de una región tonotópica relativamente amplia (p. ej., Müller, 1990; Beckius y cols., 1999). Beckius y cols. (1999) inyectaron extracelularmente BDA en el NCoAV del gato y reconstruyeron 17 axones individuales, de los cuales describieron con detalle 7 que inervaban a la OSM de ambos lados. Este engorroso procedimiento se vio complicado por 
la dificultad de seguir un mismo axón de sección en sección, la imposibilidad de discernir axones individuales dentro de campos terminales densos, y la falta de información fiable sobre la frecuencia característica de la neurona a la que pertenece cada axón. Algunos de estos inconvenientes pueden solventarse mediante la inyección intracelular de un trazador in vivo. Smith y cols. (1993) reconstruyeron el axón de 18 neuronas esféricas del gato cuya frecuencia característica identificaron inequívocamente. Sin embargo, la inyección intracelular, cuya dificultad técnica intimida, suele generar un relleno incompleto del axón, como lo demuestra el hecho de que sólo dos de los axones se rellenaron lo suficiente como para que pudieran analizarse sus campos terminales en la OSM de ambos lados (Smith y cols., 1993). Con independencia de que el trazador se haya inyectado intra o extracelularmente, la reconstrucción de axones individuales posee el inconveniente añadido de que sólo puede obtenerse información de un número muy reducido de axones de cada animal; por esta razón, al final es necesario combinar los datos procedentes de distintos animales, y las posibles diferencias anatómicas entre ellos dificultan la extracción de conclusiones sobre la topografía de las conexiones. Además, por poderosa que resulte la reconstrucción de axones individuales, ninguno de los estudios de axones de neuronas esféricas (Rouiller y Ryugo, 1984; Smith y cols., 1993; Beckius y cols., 1999; Karino y cols., 2011) aportó información sobre la proyecciones de neuronas del NMCT, igual que ninguno de los estudios del axón de neuronas del NMCT (ver referencias en la Introducción) informó sobre el axón de las neuronas esféricas. Para obtener datos próximos a los nuestros, sería necesario inyectar trazadores anterógrados en regiones tonotópicamente equivalentes del NCoAV y del NMCT, lo que constituiría una proeza técnica. Además, habría que inyectar trazadores puramente anterógrados y que no sean captados por axones de paso, pues el NMCT es cruzado por múltiples axones cuyo destino se encuentra en el propio COS, y además el NCoAV es inervado por neuronas del NMCT.

En esta Tesis, se ha puesto de manifiesto que el transporte colateral de trazadores neuroanatómicos bidireccionales sensibles, como el BDA, es una estrategia sumamente útil para investigar conexiones nerviosas porque permite marcar de modo muy selectivo proyecciones muy difíciles de estudiar con otros medios. La eficacia y la fiabilidad del método deben basarse en un conocimiento profundo de los circuitos neuronales analizados y en una discusión rigurosa de las posible interpretaciones de los resultados obtenidos.

\subsection{La OSM contiene una representación incompleta de frecuencias}

Cuando se desplaza la zona de inyección de BDA a lo largo del eje tonotópico de la OSL de la rata, se aprecia un cambio relativamente brusco entre los experimentos en los que sí se marcan axones terminales en la OSM, y aquéllos en los que no. Basándonos en el mapa tonotópico que nos ha servido de referencia (Fig. 29B), este cambio se produce en torno a la región que procesa sonidos de unos $12 \mathrm{kHz}$, situada en la parte dorsal del limbo central y próxima al $50 \%$ del eje tonotópico del núcleo. Si consideramos conjuntamente todos estos casos con marcado en la OSM, la distribución de los axones de las neuronas esféricas ipsolaterales y las neuronas del NMCT abarcó todo la extensión rostrocaudal, pues en la OSMi del caso L01 hallamos plexos 
muy dorsales y en la del caso L09, plexos muy ventrales. No parece haber cabida, por tanto, en el núcleo para plexos de axones de neuronas esféricas o de neuronas principales que procesen sonidos más agudos. Aunque el rango espectral de los sonidos procesados en la OSM ha sido objeto de pertinaz controversia (p. ej., Osen, 1969a; Cant y Casseday, 1986; Karino y cols., 2011), nuestros datos sugieren fuertemente que la OSM de la rata no interviene en el procesamiento de sonidos de frecuencia alta.

Tampoco la OSM del jerbo parece participar en el procesamiento de los sonidos agudos. La mayor parte de las neuronas del núcleo se encargan de sonidos de no más de 3 ó 3,5 kHz (Ryan $y$ cols., 1982; Müller, 1990), si bien se han hallado ocasionalmente neuronas con una frecuencia característica de hasta 4,8 kHz (Pecka y cols., 2008). Este hecho explica el que, como vimos más arriba, únicamente se marquen axones en la OSM cuando se inyectan trazadores anterógrados en la región más rostral del NCoAV del jerbo, donde se encuentran las neuronas esféricas que procesan los sonidos más graves (Müller, 1990; Russell y Moore, 1995).

En los últimos lustros, se ha minusvalorado a la OSM de la rata aduciendo que es demasiado pequeña, que sus neuronas no están pulcramente alineadas dorsoventralmente, ni sus dendritas bien dispuestas lateromedialmente, o que carece de neuronas capaces de procesar sonidos suficientemente graves como para transmitir información sobre las diferencias interauriculares de tiempo (DIT) (p. ej., Grothe, 2000; Kapfer y cols., 2002; Wesolek y cols., 2010). En el único estudio electrofisiológico de la función de la OSM de la rata in vivo se describieron neuronas cuya frecuencia característica osciló entre 2,2 y 6,6 kHz (Inbody y Feng, 1981), lo que contribuyó a apuntalar la creencia de que en el núcleo no se procesan los sonidos mas graves. Frente a estas consideraciones, nuestros resultados demuestran que la OSM de la rata posee una disposición nítidamente columnar, que en secciones rostrales su dimensión dorsoventral es suficiente como para que las diferencias topográficas entre casos sean fácilmente discernibles, y que presenta una inequívoca segregación de impulsos entre las dendritas mediales y las laterales. Con respecto a si en el núcleo se procesan sonido graves, nuestros resultados prueban también que la OSM está conectada directa o indirectamente con la región de frecuencias bajas del NCoV, la OSL y el NMCT, tres núcleos que poseen una representación completa de frecuencias y en los que se han encontrado neuronas con frecuencias características menores de $1 \mathrm{kHz}$ (Friauf y Ostwald, 1988; Finlayson y Caspary, 1991; Tolnai y cols., 2008). Además, conductualmente, las ratas albinas y las ratas pigmentadas son capaces de percibir sonidos de tan solo $250 \mathrm{~Hz}$ (Kelly y Masterton, 1977; Heffner y cols., 1994). Todos estos datos sugieren que la OSM de la rata comparte las características típicas de la OSM de los mamíferos y en consecuencia constituye un buen modelo para estudios morfológicos y funcionales.

\subsection{Segregación de impulsos excitadores e inhibidores en las neuronas de la OSM}

Según nuestros resultados, las distintas aferencias terminan de modo preferente, si no exclusivo, en determinadas partes de las neuronas de la OSM. Nuestros datos confirman que las neuronas esféricas ipsolaterales y contralaterales inervan, respectivamente, a las dendritas laterales y las dendritas mediales, algo que se había descrito en diversas especies, incluidas la 
rata (Harrison y Irving, 1966) y el jerbo (Müller, 1990; Kil y cols., 1995; Russell y Moore, 1995, 2002). Lo que no se ha analizado previamente de modo directo es la distribución dentro de la OSM de los axones de las neuronas del NMCT, y a ella dedicamos los próximos párrafos.

En nuestros experimentos con jerbos, hallamos botones marcados relativamente gruesos y estrechamente yuxtapuestos a los somas y la porción proximal de las dendritas. Para deducir si se trata de botones del axón de las neuronas principales del NMCT, hemos detectado inmunocitoquímicamente en secciones coronales de la OSM del jerbo el transportador de glicina de tipo 2 (GlyT2), que es un eficaz marcador de botones glicinérgicos (Jursky y Nelson, 1995; Zafra y cols., 1995; Poyatos y cols., 1997; Aragón y López-Corcuera, 2003; Eulenburg y cols., 2005; Zafra y Giménez, 2008). La figura 59A muestra una imagen panorámica de la OSM en la que puede apreciarse cómo los elementos inmunorreactivos se concentran en la porción
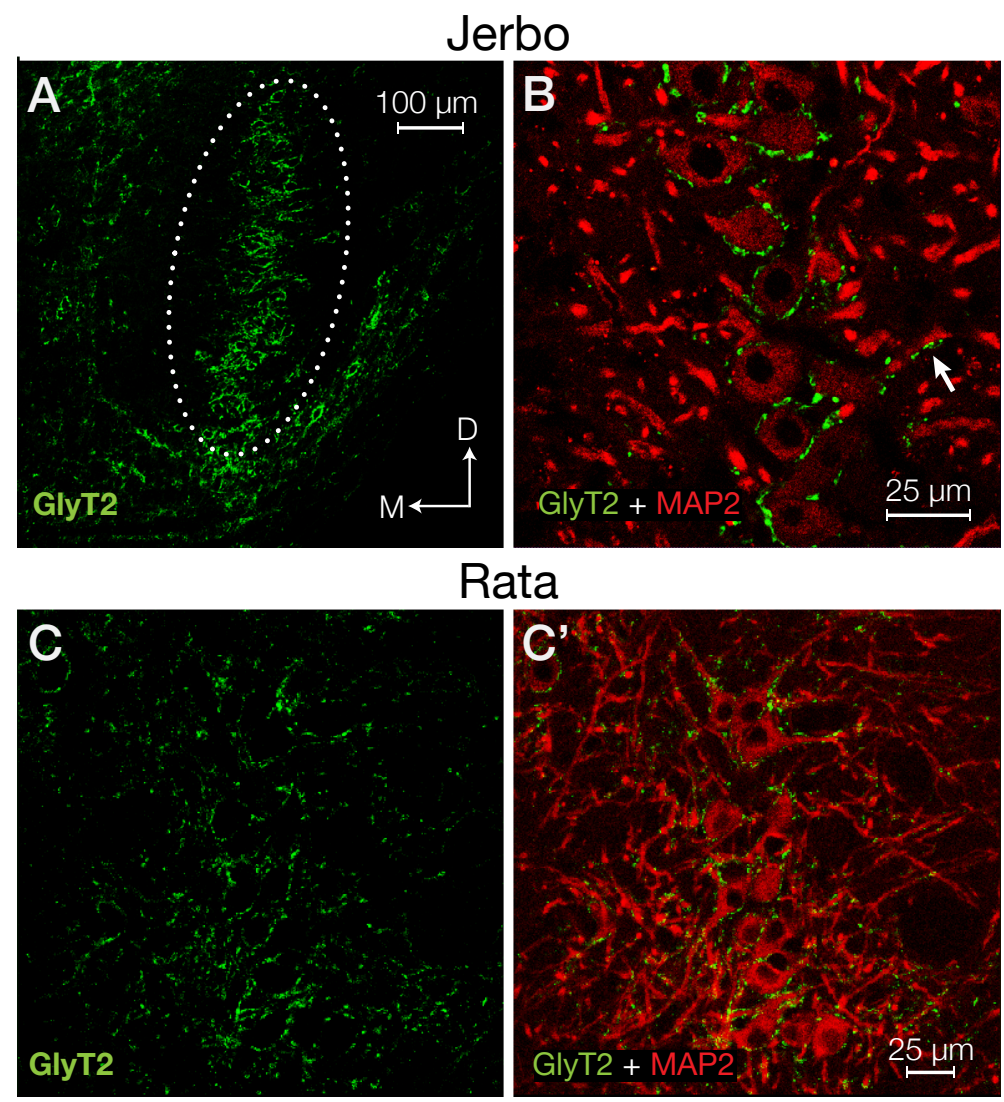

Figura 59. Secciones ópticas tomadas con un microscopio confocal a partir de secciones histológicas procesadas con un método de inmunofluorescencia para ilustrar la distribución del GlyT2 en la OSM del jerbo y de la rata. (A) En la OSM del jerbo, los botones glicinérgicos se encuentran sobre todo en contacto con el soma de las neuronas, que forman una nítida columna. (B) Detalle de la relación entre las neuronas de la OSM del jerbo, marcadas con MAP2 (rojo), y los botones glicinérgicos (verde). Obsérvese que los botones glicinérgicos se encuentran casi exclusivamente sobre los somas. La flecha blanca señala botones glicinérgicos en contacto con una dendrita. (C) Distribución de los botones glicinérgicos (verde) en la OSM de la rata. En C' puede verse el mismo campo microscópico con las neuronas marcadas con MAP2 (rojo). A diferencia del jerbo, en la rata la distribución de los botones glicinérgicos es más amplia, pues se hallan en contacto tanto con el soma, como con las dendritas (C'). La barra de aumento de $\mathbf{C}^{\prime}$ sirve también para $\mathbf{C}$. 
central del núcleo, en el área ocupada por la columna de somas neuronales. En la figura 59B se ve a mayor aumento que los botones glicinérgicos, marcados en verde, rodean a los somas neuronales, pero son muy escasos lateral o medialmente. De hecho, la mayor parte de las dendritas visibles a uno u otro lado de la columna de somas carecen de botones glicinérgicos en contacto con ellas. Estas observaciones refuerzan nuestra conclusión de que en el jerbo la proyección del NMCT termina muy predominantemente en el soma y confirman descripciones anteriores, basadas en: 1) la observación de que los botones sinápticos con vesículas planas o pleomórficas son más abundantes en el soma que en las dendritas (Russell y Moore, 2002); y 2) la detección inmunocitoquímica de la glicina (Kapfer y cols., 2002), el receptor de glicina (Kapfer y cols., 2002), la proteína postsináptica gefrina (Kapfer y cols., 2002), la calbindina (Couchman y cols., 2010), o el propio GlyT2 (Couchman y cols., 2010; Hassfurth y cols., 2010).

A diferencia de lo que sucede en el jerbo, en nuestros experimentos con ratas las fibras marcadas en la OSMi formaron en muchas secciones dos campos terminales -medial y lateral - nítidamente separados y que parecieron evitar a los somas. Como el plexo de la mitad medial de la OSMi tiene que estar formado exclusivamente por axones de neuronas principales del NMCT, nuestros resultados sugieren que en la rata la inhibición procedente del NMCT actúa fundamentalmente sobre las dendritas mediales. Esta deducción fue en cierto modo inesperada, en parte por el viejo dogma de que la inhibición suele actuar sobre el soma de las neuronas, y en parte porque la literatura contiene abundantes datos que sugieren que los somas de las neuronas de la OSM reciben una densa inervación glicinérgica, no sólo en el jerbo, como acabamos de ver, sino también en otros mamíferos. Así, por ejemplo, se han encontrado ultraestructuralmente botones sinápticos axosomáticos con características compatibles con la neurotransmisión glicinérgica en la OSM de gatos (Clark, 1969; Lindsey, 1975; Kiss y Majorossy, 1983; Schwartz, 1984; Tirko y Ryugo, 2012), hurones (Brunso-Bechtold y cols., 1990), murciélagos (Vater, 1995) y chinchillas (Perkins, 1973). Por desgracia, apenas hay datos sobre la inervación glicinérgica de la OSM de la rata. La única información publicada, basada en la detección inmunocitoquímica de la gefrina y del receptor de glicina, indica que las sinapsis glicinérgicas están muy repartidas por el soma y las dendritas y que su concentración puede ser algo mayor en las dendritas (Kapfer y cols., 2002), lo que concuerda con la escasez en nuestros experimentos de fibras marcadas relacionadas con los somas. La tesis doctoral de Christoph Kapfer incluye microfotografías electrónicas no publicadas en las que se muestra la presencia de sinapsis glicinérgicas en contacto con el soma o las dendritas de neuronas de la OSM de ratas jóvenes y de ratas adultas (Kapfer, 2003; su Fig. 29). Sin embargo, ni el artículo de Kapfer y cols. (2002), ni la tesis de Kapfer (2003) analizaron por separado las dendritas mediales y las dendritas laterales.

Para comprobar si existen diferencias en la distribución de las sinapsis glicinérgicas entre las dendritas mediales, las dendritas laterales y los somas, hemos detectado inmunocitoquímicamente el GlyT2 en secciones coronales de la OSM de la rata. Lo esperable a la vista de nuestros experimentos de trazado sería encontrar la mayor concentración de sinapsis glicinérgicas en la región del núcleo ocupada por las dendritas mediales, como sugieren también ciertas imágenes en las que se observa una mayor densidad en la mitad medial de la OSM del gato en secciones inmunoteñidas para visualizar la glicina (Adams y Mugnaini, 1990; 
[ver su Fig. 1A]; Spirou y Berrebi, 1997 [su Fig. 3]) o la calbindina (Adams y Mugnaini, 1990 [su Fig. 3A]; Matsubara, 1990 [su Fig. 2A]). La figura 59C, C' muestra una sección óptica representativa de la distribución del GlyT2 en la OSM. Del análisis de esta y otras muchas secciones similares se concluye que en la OSM de la rata las sinapsis glicinérgicas poseen una distribución muy amplia dentro del núcleo y no muestran una preferencia clara por ninguna porción de la neurona postsináptica. Hay botones glicinérgicos repartidos de modo bastante uniforme por las dendritas, tanto mediales, como laterales, y algunos se encuentran a grandes distancias del soma, que pueden superar los $100 \mu \mathrm{m}$. Se aprecian también botones inmunorreactivos en aparente contacto con el soma, si bien el número de botones axosomáticos varía enormemente de unas células a otras, pues en la misma sección pueden apreciarse somas rodeados por botones junto a otros aparentemente desprovistos de ellos.

Los resultados de la expresión del GlyT2, que no confirman nuestras predicciones, son compatibles con la distribución de la inmunotinción para la gefrina o el receptor de glicina en la OSM de la rata (Kapfer y cols., 2002) y suscitan una pregunta inmediata: ¿A qué neuronas pertenecen los botones sinápticos glicinérgicos que inervan al soma y a las dendritas laterales de las neuronas de la OSM de la rata? Una primera posibilidad es que pertenezcan a neuronas del NMCT: como en nuestros experimentos todos los axones se marcaron en un mismo color, no pudimos discernir si en el plexo de la mitad lateral hay axones procedentes del NMCT. Además, en las secciones en las que ambos plexos están unidos, sí hay fibras marcadas en la vecindad de los somas, y podrían pertenecer al menos en parte al NMCT. No obstante, parece poco probable que el axón de las neuronas del NMCT contribuya de modo relevante a la inervación de las dendritas laterales porque, si así fuera, en nuestros experimentos el plexo lateral debería haber sido sensiblemente más denso que el medial. Esta incógnita podría despejarse repitiendo la inyección de BDA en la región de frecuencias bajas de la OSL y aplicando un doble marcado fluorescente para comprobar qué botones de las fibras marcadas con BDA contienen el GlyT2 y cuál es su distribución.

Otra posibilidad es que existan otras fuentes de proyecciones glicinérgicas distintas del NMCT y que, por no inervar a la OSL, no se marcaron en nuestros experimentos. El principal candidato es el NLCT, que contiene abundantes neuronas glicinérgicas (Adams y Mugnaini, 1990; Spirou y Berrebi, 1997), es inervado por neuronas globulares del NCoAVi (Friaufy Ostwald, 1988; Spirou y cols., 1990; Kuwabara y cols., 1991; Smith y cols., 1991) y a su vez envía proyecciones a la OSMi (Cant y Hyson, 1992; Kuwabara y Zook, 1992; Roberts y cols., 2014). La estimulación del NLCT in vitro provoca en las neuronas de la OSM del jerbo efectos postsinápticos inhibidores similares a los provocadas por la estimulación del NMCT, tanto por su amplitud (Magnusson y cols., 2005), como por su rapidez (Roberts y cols., 2014). Kuwabara y Zook (1992) han sugerido que los axones de neuronas del NLCT del ratón, el jerbo y el murciélago bigotudo terminan sobre todo en torno al soma de las neuronas de la OSM, pero este aspecto aún debe ser estudiado de modo sistemático.

Además de las aferencias procedentes del NMCT y el NLCT, la OSM podría recibir inervación glicinérgica de otras fuentes aún no identificadas. Por sorprendente que parezca, en ratones diseñados genéticamente para que carezcan del NMCT persiste la inhibición glicinérgica tanto 
en la OSL, como en el NPS, y su eficacia se ve afectada muy levemente (Jalabi y cols., 2013), lo que sugiere la existencia de proyecciones glicinérgicas procedentes de núcleos ajenos al propio cos.

De los párrafos anteriores se desprende que la inhibición glicinérgica de la OSM es compleja y harán falta todavía muchos estudios antes de que sean comprendida. Nuestro estudio ha contribuido a ello en la medida en que ha demostrado que en la rata y en el jerbo la proyección del NMCT es estrictamente tonotópica y actúa sobre las mismas neuronas que la proyección de las neuronas esféricas ipsolaterales que procesan sonidos de la misma frecuencia. 


\section{CONCLUSIONES:}

1. El transporte colateral de trazadores neuroanatómicos bidireccionales sensibles, como el dextrano biotinado (BDA), es una estrategia sumamente útil para investigar conexiones nerviosas porque permite marcar de modo selectivo proyecciones muy difíciles de estudiar por otros medios. La eficacia y la fiabilidad del método deben basarse en un conocimiento profundo de los circuitos neuronales analizados y en una discusión rigurosa de las posible interpretaciones de los resultados obtenidos.

2. La oliva superior lateral (OSL) de la rata es inervada tonotópicamente por cuatro tipos neuronales troncoencefálicos: neuronas esféricas y neuronas multipolares planas del núcleo coclear ventral ipsolateral (NCoVi), neuronas principales del núcleo medial del cuerpo trapezoide ipsolateral (NMCTi), y neuronas multipolares pequeñas del núcleo ventral del cuerpo trapezoide contralateral (NVCTc). La región de la OSL que procesa sonidos de frecuencias muy altas es inervada también por neuronas esféricas contralaterales.

3. De las neuronas troncoencefálicas que inervan a la OSL de la rata, las neuronas esféricas representan cerca de la mitad, las del NMCT algo más de un tercio, y las multipolares planas del NCoV y las multipolares pequeñas del NVCT porcentajes mucho menores. Estas proporciones no varían de unas regiones tonotópicas de la OSL a otras, lo que sugiere que este núcleo no contiene regiones funcionalmente especializadas.

4. La inyección iontoforética de BDA en la OSL de la rata permite marcar en un mismo experimento las tres principales aferencias de la oliva superior medial (OSM): la proyección de las neuronas esféricas ipsolaterales, que inervan a las dendritas laterales; la proyección de las neuronas esféricas contralaterales, que inervan a las dendritas mediales; y la proyección del NMCT ipsolateral, que inerva preferentemente a las dendritas mediales. Además, en el mismo experimento se marcan también las colaterales del axón de las neuronas del NMCT que inervan al núcleo parolivar superior ipsolateral (NPSi).

5. En el núcleo coclear anteroventral (NCoAV) de la rata hay dos tipos de neuronas esféricas que difieren en sus conexiones con la OSM: aunque todas ellas inervan a la OSL, sólo las del tercio ventral del núcleo, que participan en el procesamiento de sonidos graves, inervan también a la OSM de ambos lados.

6. Las neuronas globulares del NCoV de la rata no inervan a la OSL, sino a un estrecho territorio situado caudal y ventralmente con respecto a ella y que incluye al núcleo lateral del cuerpo trapezoide

7. Aunque todas las neuronas principales del NMCT de la rata inervan a la OSL, pueden distinguirse tres tipos que difieren en sus conexiones con otros núcleos del complejo olivar superior. Las neuronas de los cuatro quintos mediales del NMCT inervan también al NPS, pero no a la OSM. Las neuronas del tercio lateral inervan también a la OSM, pero no al NPS. Las neuronas situadas en la intersección de las dos poblaciones anteriores inervan tanto al NPS, como a la OSM. 
8. Las conexiones nerviosas del NPS y las de la OSM sugieren que en la rata estos dos núcleos poseen representaciones tonotópicas incompletas y aproximadamente complementarias: el NPS se dedica a procesar sonidos de la mitad alta del espectro sonoro, y la OSM a los sonidos de la mitad baja.

9. Cada neurona de la OSM es excitada tonotópicamente por neuronas esféricas del NCoAVi e inhibida tonotópicamente por neuronas del NMCT, pero es excitada contralateralmente tanto por neuronas esféricas de su misma frecuencia.

10. La región de frecuencias más bajas de la OSL del jerbo recibe proyecciones bilaterales, simétricas y estrictamente tonotópicas de neuronas esféricas del NCoAV.

11. La inervación de la OSM del jerbo sigue un patrón similar al de la rata. 


\section{BIBLIOGRAFí́ CITADA}


Adam TJ, Schwarz DW, Finlayson PG (1999) Firing properties of chopper and delay neurons in the lateral superior olive of the rat. Exp Brain Res 124:489-502.

Adam TJ, Finlayson PG, Schwarz DW (2001) Membrane properties of principal neurons of the lateral superior olive. J Neurophysiol 86:922-934.

Adams JC (1979) Ascending projections to the inferior colliculus. J Comp Neurol 183:519-538.

Adams JC, Mugnaini E (1990) Immunocytochemical evidence for inhibitory and disinhibitory circuits in the superior olive. Hear Res 49:281-298.

Agmon-Snir H, Carr CE, Rinzel J (1998) The role of dendrites in auditory coincidence detection. Nature 393:268-272.

Aitkin L, Schuck D (1985) Low frequency neurons in the lateral central nucleus of the cat inferior colliculus receive their input predominantly from the medial superior olive. Hear Res 17:87-93.

Albrecht O, Dondzillo A, Mayer F, Thompson JA, Klug A (2014) Inhibitory projections from the ventral nucleus of the trapezoid body to the medial nucleus of the trapezoid body in the mouse. Front Neural Circuits 8:83. DOI: 10.3389/fncir.2014.00083.

Altschuler RA, Parakkal MH, Fex J (1983) Localization of enkephalin-like immunoreactivity in acetylcholinesterase-positive cells in the guinea-pig lateral superior olivary complex that project to the cochlea. Neuroscience 9:621-630.

Aparicio MA, Saldaña E (2014) The dorsal tectal longitudinal column (TLCd): a second longitudinal column in the paramedian region of the midbrain tectum. Brain Struct Funct 219:607-630.

Aparicio MA, Viñuela A, Saldaña E (2010) Projections from the inferior colliculus to the tectal longitudinal column in the rat. Neuroscience 166:653-664.

Aragón C, López-Corcuera B (2003) Structure, function and regulation of glycine neurotransporters. Eur J Pharmacol 479:249-262.

Aschoff A, Ostwald J (1987) Different origins of cochlear efferents in some bat species, rats, and guinea pigs. J Comp Neurol 264:56-72.

Aschoff A, Ostwald J (1988) Distribution of cochlear efferents and olivo-collicular neurons in the brainstem of rat and guinea pig. A double labeling study with fluorescent tracers. Exp Brain Res 71:241-251.

Ashida G, Carr CE (2011) Sound localization: Jeffress and beyond. Curr Opin Neurobiol 21:745-751.

Banks MI, Smith PH (1992) Intracellular recordings from neurobiotin-labeled cells in brain slices of the rat medial nucleus of the trapezoid body. J Neurosci 12:2819-2837.

Barnes-Davies M, Forsythe ID (1995) Pre- and postsynaptic glutamate receptors at a giant excitatory synapse in rat auditory brainstem slices. J Physiol 488:387-406.

Barnes-Davies M, Barker MC, Osmani F, Forsythe ID (2004) Kvl currents mediate a gradient of principal neuron excitability across the tonotopic axis in the rat lateral superior olive. Eur J Neurosci 19:325-333. 
Batra R, Kuwada S, Fitzpatrick DC (1997) Sensitivity to interaural temporal disparities of lowand high-frequency neurons in the superior olivary complex. I. Heterogeneity of responses. J Neurophysiol 78:1222-1236.

Batteau DW (1967) The role of the pinna in human localization. Proc R Soc Lond B Biol Sci 168:158-180.

Bear MF, Connors BW, Paradiso MA (2007) "Neuroscience: Exploring the Brain. 3a edición”. Lippincott Williams \& Wilkins, Filadelfia, Pensilvania.

Beckius GE, Batra R, Oliver DL (1999) Axons from anteroventral cochlear nucleus that terminate in medial superior olive of cat: observations related to delay lines. J Neurosci 19:3146-3161.

Begault DR (1991) Preferred sound intensity increase for sensation of half distance. Percept Mot Skills 72:1019-1029.

Behrend O, Brand A, Kapfer C, Grothe B (2002) Auditory response properties in the superior paraolivary nucleus of the gerbil. J Neurophysiol 87:2915-2928.

Békésy GV (1938) Über die Entstehung der Entfernungsempfindung beim Hören. Akustische Zeitschrift 3:21-31.

Benson CG, Cant NB (2008) The ventral nucleus of the lateral lemniscus of the gerbil (Meriones unguiculatus): organization of connections with the cochlear nucleus and the inferior colliculus. J Comp Neurol 510:673-690.

Bernstein LR (2001) Auditory processing of interaural timing information: new insights. J Neurosci Res 66:1035-1046.

Bittencourt JC, Vaughan J, Arias C, Rissman RA, Vale WW, Sawchenko PE (1999) Urocortin expression in rat brain: evidence against a pervasive relationship of urocortin-containing projections with targets bearing type 2 CRF receptors. J Comp Neurol 415:285-312.

Blackburn CC, Sachs MB (1989) Classification of unit types in the anteroventral cochlear nucleus: PST histograms and regularity analysis. J Neurophysiol 62:1303-1329.

Blackburn CC, Sachs MB (1990) The representations of the steady-state vowel sound /e/ in the discharge patterns of cat anteroventral cochlear nucleus neurons. J Neurophysiol 63:1191-1212.

Blaesse P, Ehrhardt S, Friauf E, Nothwang HG (2005) Developmental pattern of three vesicular glutamate transporters in the rat superior olivary complex. Cell Tissue Res 320:33-50.

Blauert J (1997) “Spatial Hearing: The Psychophysics of Human Sound Localization”. MIT Press, Cambridge, Massachusetts.

Blauert J (2005) “Communication Acoustics”. Springer-Verlag, Berlín.

Bledsoe SC, Jr., Snead CR, Helfert RH, Prasad V, Wenthold RJ, Altschuler RA (1990) Immunocytochemical and lesion studies support the hypothesis that the projection from the medial nucleus of the trapezoid body to the lateral superior olive is glycinergic. Brain Res 517:189-194. 
Bonham BH, Lewis ER (1999) Localization by interaural time difference (ITD): effects of interaural frequency mismatch. J Acoust Soc Am 106:281-290.

Borst JG, Soria Van Hoeve J (2012) The calyx of held synapse: from model synapse to auditory relay. Annu Rev Physiol 74:199-224.

Boudreau JC, Tsuchitani C (1968) Binaural interaction in the cat superior olive S segment. J Neurophysiol 31:442-454.

Brand A, Behrend O, Marquardt T, Mcalpine D, Grothe B (2002) Precise inhibition is essential for microsecond interaural time difference coding. Nature 417:543-547.

Brandt HM, Apkarian AV (1992) Biotin-dextran: a sensitive anterograde tracer for neuroanatomic studies in rat and monkey. J Neurosci Methods 45:35-40.

Brawer JR, Morest DK (1975) Relations between auditory nerve endings and cell types in the cat's anteroventral cochlear nucleus seen with the Golgi method and Nomarski optics. J Comp Neurol 160:491-506.

Brawer JR, Morest DK, Kane EC (1974) The neuronal architecture of the cochlear nucleus of the cat. J Comp Neurol 155:251-300.

Brew HM, Forsythe ID (2005) Systematic variation of potassium current amplitudes across the tonotopic axis of the rat medial nucleus of the trapezoid body. Hear Res 206:116-132. Bronkhorst AW (2000) The cocktail party phenomenon: A review of research on speech intelligibility in multiple-talker conditions. Acustica 86:117-128.

Bronkhorst AW, Houtgast T (1999) Auditory distance perception in rooms. Nature 397:517-520.

Brownell WE (1975) Organization of the cat trapezoid body and the discharge characteristics of its fibers. Brain Res 94:413-433.

Browner RH, Webster DB (1975) Projections of the trapezoid body and the superior olivary complex of the kangaroo rat (Dipodomys merriami). Brain Behav Evol 11:322-354.

Brugge JF (1992) An Overview of Central Auditory Processing. En "The Mammalian Auditory Pathway: Neurophysiology”, de Fay RR, Popper AN (eds.). Springer-Verlag, Nueva York, pp 34-93.

Brugge JF (2013) Anatomy and physiology of auditory pathways and cortex. En "Handbook of Clinical Neurophysiology, Vol 10: Disorders of Peripheral and Central Auditory Processing", de Celesia GG (ed.). Elsevier, Amsterdam, pp 25-59.

Brughera A, Dunai L, Hartmann WM (2013) Human interaural time difference thresholds for sine tones: the high-frequency limit. J Acoust Soc Am 133:2839-2855.

Brungart DS, Rabinowitz WM (1999) Auditory localization of nearby sources. Head-related transfer functions. J Acoust Soc Am 106:1465-1479.

Brunso-Bechtold JK, Thompson GC, Masterton RB (1981) HRP study of the organization of auditory afferents ascending to central nucleus of inferior colliculus in cat. J Comp Neurol 197:705-722. 
Brunso-Bechtold JK, Henkel CK, Linville C (1990) Synaptic organization in the adult ferret medial superior olive. J Comp Neurol 294:389-398.

Brunso-Bechtold JK, Linville MC, Henkel CK (1994) Terminal types on ipsilaterally and contralaterally projecting lateral superior olive cells. Hear Res 77:99-104.

Buras ED, Holt AG, Griffith RD, Asako M, Altschuler RA (2006) Changes inglycineimmunoreactivity in the rat superior olivary complex following deafness. J Comp Neurol 494:179-189.

Burda H, Ballast L, Bruns V (1988) Cochlea in old world mice and rats (Muridae). J Morphol 198:269-285.

Caicedo A, Herbert H (1993) Topography of descending projections from the inferior colliculus to auditory brainstem nuclei in the rat. J Comp Neurol 328:377-392.

Caicedo A, Kungel M, Pujol R, Friauf E (1998) Glutamate-induced $\mathrm{Co}^{2}+$ uptake in rat auditory brainstem neurons reveals developmental changes in $\mathrm{Ca}^{2}+$ permeability of glutamate receptors. Eur J Neurosci 10:941-954.

Caird D, Klinke R (1983) Processing of binaural stimuli by cat superior olivary complex neurons. Exp Brain Res 52:385-399.

Cajal SR (1904) “Textura del Sistema Nervioso del Hombre y de los Vertebrados”, Tomo II, Primera Parte. Imprenta y Librería de Nicolás Moya, Madrid.

Calford M, Piddington R (1988) Avian interaural canal enhances interaural delay. Journal of Comparative Physiology A 162:503-510.

Calford MB, Moore DR, Hutchings ME (1986) Central and peripheral contributions to coding of acoustic space by neurons in inferior colliculus of cat. J Neurophysiol 55:587-603.

Cant NB (1981) The fine structure of two types of stellate cells in the anterior division of the anteroventral cochlear nucleus of the cat. Neuroscience 6:2643-2655.

Cant NB (1984) The fine structure of the lateral superior olivary nucleus of the cat. J Comp Neurol 227:63-77.

Cant NB (1991) Projections to the lateral and medial superior olivary nuclei from the spherical and globular bushy cells of the anteroventral cochlear nucleus. En "Neurobiology of Hearing: The Central Auditory System”, de Altschuler RA, Bobbin RP, Clopton BM, Hoffmann WE (eds.). Raven Press, Nueva York, pp 99-119.

Cant NB (2013) Patterns of convergence in the central nucleus of the inferior colliculus of the Mongolian gerbil: organization of inputs from the superior olivary complex in the low frequency representation. Front Neural Circuits 7:29. DOI: 10.3389/fncir.2013.00029.

Cant NB, Benson CG (2003) Parallel auditory pathways: projection patterns of the different neuronal populations in the dorsal and ventral cochlear nuclei. Brain Res Bull 60:457-474.

Cant NB, Benson CG (2006) Organization of the inferior colliculus of the gerbil (Meriones unguiculatus): differences in distribution of projections from the cochlear nuclei and the superior olivary complex. J Comp Neurol 495:511-528. 
Cant NB, Casseday JH (1986) Projections from the anteroventral cochlear nucleus to the lateral and medial superior olivary nuclei. J Comp Neurol 247:457-476.

Cant NB, Hyson RL (1992) Projections from the lateral nucleus of the trapezoid body to the medial superior olivary nucleus in the gerbil. Hear Res 58:26-34.

Cant NB, Morest DK (1979a) Organization of the neurons in the anterior division of the anteroventral cochlear nucleus of the cat. Light-microscopic observations. Neuroscience 4:1909-1923.

Cant NB, Morest DK (1979b) The bushy cells in the anteroventral cochlear nucleus of the cat. A study with the electron microscope. Neuroscience 4:1925-1945.

Cantos R, López DE, Sala ML, Rueda J (2000) Study of the olivocochlear neurons using two different tracers, fast blue and cholera toxin, in hypothyroid rats. Anat Embryol (Berl) 201:245-257.

Cantos R, López DE, Merchán JA, Rueda J (2003) Olivocochlear efferent innervation of the organ of corti in hypothyroid rats. J Comp Neurol 459:454-467.

Carney LH (1990) Sensitivities of cells in anteroventral cochlear nucleus of cat to spatiotemporal discharge patterns across primary afferents. J Neurophysiol 64:437-456.

Carr CE, Konishi M (1988) Axonal delay lines for time measurement in the owl's brainstem. Proc Natl Acad Sci U S A 85:8311-8315.

Carr CE, Konishi M (1990) A circuit for detection of interaural time differences in the brain stem of the barn owl. J Neurosci 10:3227-3246.

Carr CE, MacLeod KM (2010) Microseconds matter. PLoS Biol 8:e1000405. DOI: 10.1371/journal. pbio. 1000405

Carr CE, Soares D, Smolders J, Simon JZ (2009) Detection of interaural time differences in the alligator. J Neurosci 29:7978-7990.

Casey MA (1990) The effects of aging on neuron number in the rat superior olivary complex. Neurobiol Aging 11:391-394.

Casey MA, Feldman ML (1982) Aging in the rat medial nucleus of the trapezoid body. I. Light microscopy. Neurobiol Aging 3:187-195.

Casey MA, Feldman ML (1985) Aging in the rat medial nucleus of the trapezoid body. II. Electron microscopy. J Comp Neurol 232:401-413.

Casey MA, Feldman ML (1988) Age-related loss of synaptic terminals in the rat medial nucleus of the trapezoid body. Neuroscience 24:189-194.

Caspary DM, Faingold CL (1989) Non-N-methyl-D-aspartate receptors may mediate ipsilateral excitation at lateral superior olivary synapses. Brain Res 503:83-90.

Casseday JH, Neff WD (1973) Localization of pure tones. J Acoust Soc Am 54:365-372.

Casseday JH, Covey E, Vater M (1988) Connections of the superior olivary complex in the rufous horseshoe bat Rhinolophus rouxi. J Comp Neurol 278:313-329. 
Chirila FV, Rowland KC, Thompson JM, Spirou GA (2007) Development of gerbil medial superior olive: integration of temporally delayed excitation and inhibition at physiological temperature. J Physiol 584:167-190.

Clark GM (1969) Vesicle shape versus type of synapse in the nerve endings of the cat medial superior olive. Brain Res 15:548-551.

Clause A, Kim G, Sonntag M, Weisz CJ, Vetter DE, Rübsamen R, Kandler K (2014) The precise temporal pattern of prehearing spontaneous activity is necessary for tonotopic map refinement. Neuron 82:822-835.

Cline HT (2001) Dendritic arbor development and synaptogenesis. Curr Opin Neurobiol 11:118-126.

Clopton BM, Winfield JA (1973) Tonotopic organization in the inferior colliculus of the rat. Brain Res 56:355-358.

Cochran P, Throop J, Simpson WE (1968) Estimation of distance of a source of sound. Am J Psychol 81:198-206.

Coleman PD (1963) An analysis of cues to auditory depth perception in free space. Psychol Bull 60:302-315.

Cooper AP, Gillespie DC (2011) Synaptotagmins I and II in the developing rat auditory brainstem: Synaptotagmin I is transiently expressed in glutamate-releasing immature inhibitory terminals. J Comp Neurol 519:2417-2433.

Couchman K, Grothe B, Felmy F (2010) Medial superior olivary neurons receive surprisingly few excitatory and inhibitory inputs with balanced strength and short-term dynamics. J Neurosci 30:17111-17121.

Couchman K, Grothe B, Felmy F (2012) Functional localization of neurotransmitter receptors and synaptic inputs to mature neurons of the medial superior olive. J Neurophysiol 107:1186-1198.

Culling JF, Akeroyd MA (2010) Spatial hearing. En "The Oxford Handbook of Auditory Science: Hearing", de Plack CJ (ed.). Oxford University Press, Oxford, pp 123-144.

Darrow KN, Maison SF, Liberman MC (2006) Cochlear efferent feedback balances interaural sensitivity. Nat Neurosci 9:1474-1476.

Darrow KN, Benson TE, Brown MC (2012) Planar multipolar cells in the cochlear nucleus project to medial olivocochlear neurons in mouse. J Comp Neurol 520:1365-1375.

Darwin CJ (2008) Spatial hearing and perceiving sources. En "Auditory Perception of Sound Sources”, de Yost WA, Popper AN, Fay RR (eds.). Springer Handbook of Auditory Research, Vol. 29. Springer, Nueva York, pp 215-232.

David EE, Guttman N, Van Bergeijk WA (1959) Binaural interaction of high-frequency complex stimuli. J Acoust Soc Am 31:774-782.

Day ML, Semple MN (2011) Frequency-dependent interaural delays in the medial superior olive: implications for interaural cochlear delays. J Neurophysiol 106:1985-1999. 
Day ML, Delgutte B (2013) Decoding sound source location and separation using neural population activity patterns. J Neurosci 33:15837-15847.

De Olmos J, Heimer L (1977) Mapping of collateral projections with the HRP-method. Neurosci Lett 6:107-114.

De Venecia RK, Liberman MC, Guinan JJ, Jr., Brown MC (2005) Medial olivocochlear reflex interneurons are located in the posteroventral cochlear nucleus: a kainic acid lesion study in guinea pigs. J Comp Neurol 487:345-360.

Dehmel S, Kopp-Scheinpflug C, Dorrscheidt GJ, Rübsamen R (2002) Electrophysiological characterization of the superior paraolivary nucleus in the Mongolian gerbil. Hear Res 172:18-36.

Dehmel S, Kopp-Scheinpflug C, Weick M, Dorrscheidt GJ, Rübsamen R (2010) Transmission of phase-coupling accuracy from the auditory nerve to spherical bushy cells in the Mongolian gerbil. Hear Res 268:234-249.

Doucet JR, Ryugo DK (1997) Projections from the ventral cochlear nucleus to the dorsal cochlear nucleus in rats. J Comp Neurol 385:245-264.

Doucet JR, Ryugo DK (2003) Axonal pathways to the lateral superior olive labeled with biotinylated dextran amine injections in the dorsal cochlear nucleus of rats. J Comp Neurol 461:452-465.

Doucet JR, Ryugo DK (2006) Structural and functional classes of multipolar cells in the ventral cochlear nucleus. Anat Rec A Discov Mol Cell Evol Biol 288:331-344.

Edmonds BA, Krumbholz K (2014) Are interaural time and level differences represented by independent or integrated codes in the human auditory cortex? J Assoc Res Otolaryngol 15:103-114.

Ehmann H, Hartwich H, Salzig C, Hartmann N, Clement-Ziza M, Ushakov K, Avraham KB, Bininda-Emonds OR, Hartmann AK, Lang P, Friauf E, Nothwang HG (2013) Timedependent gene expression analysis of the developing superior olivary complex. J Biol Chem 288:25865-25879.

Ehret G, Tautz J, Schmitz B (1990) Hearing through the lungs: lung-eardrum transmission of sound in the frog Eleutherodactylus coqui. Naturwissenschaften 77:192-194.

Ehrlich I, Ilic V, Lohmann C, FriaufE (1998) Development of glycinergic transmission in organotypic cultures from auditory brain stem. Neuroreport 9:2785-2790.

Englitz B, Tolnai S, Typlt M, Jost J, Rübsamen R (2009) Reliability of synaptic transmission at the synapses of Held in vivo under acoustic stimulation. PLoS One 4:e7014. DOI: 10.1371/journal. pone. 0007014

Eulenburg V, Armsen W, Betz H, Gomeza J (2005) Glycine transporters: essential regulators of neurotransmission. Trends Biochem Sci 30:325-333.

Evans EF, Nelson PG (1973) The responses of single neurones in the cochlear nucleus of the cat as a function of their location and the anaesthetic state. Exp Brain Res 17:402-427. 
Fay RR, Popper AN (2005) Introduction to sound source localization. En "Sound Source Localization", de Popper AN, Fay RR (eds.). Springer Handbook of Auditory Research, Vol. 25. Springer, Nueva York, pp 1-5.

Faye-Lund H (1986) Projection from the inferior colliculus to the superior olivary complex in the albino rat. Anat Embryol (Berl) 175:35-52.

Feddersen WE, Sandel TT, Teas DC, Jeffress LA (1957) Localization Of High-Frequency Tones. J Acoust Soc Am 29:988-991.

Feliciano M, Saldaña E, Mugnaini E (1995) Direct projections from the rat primary auditory neocortex to nucleus sagulum, paralemniscal regions, superior olivary complex and cochlear nuclei. Auditory Neuroscience 1:287-308.

Felix RA, Fridberger A, Leijon S, Berrebi AS, Magnusson AK (2011) Sound rhythms are encoded by postinhibitory rebound spiking in the superior paraolivary nucleus. J Neurosci 31:12566-12578.

Felix RA, Kadner A, Berrebi AS (2012) Effects of ketamine on response properties of neurons in the superior paraolivary nucleus of the mouse. Neuroscience 201:307-319.

Felix RA, Vonderschen K, Berrebi AS, Magnusson AK (2013) Development of on-off spiking in superior paraolivary nucleus neurons of the mouse. J Neurophysiol 109:2691-2704.

Feng AS, Rogowski BA (1980) Effects of monaural and binaural occlusion on the morphology of neurons in the medial superior olivary nucleus of the rat. Brain Res 189:530-534.

Ferguson S, Cabrera D (2005) Vertical localization of sound from multi-way loudspeakers. J Audio Eng Soc 53:163-173.

Finlayson PG, Caspary DM (1989) Synaptic potentials of chinchilla lateral superior olivary neurons. Hear Res 38:221-228.

Finlayson PG, Caspary DM (1991) Low-frequency neurons in the lateral superior olive exhibit phase-sensitive binaural inhibition. J Neurophysiol 65:598-605.

Fleckeisen CE, Harrison RV, Mount RJ (1991) Cytoarchitecture of cochlear nucleus in the chinchilla. Acta Otolaryngol Suppl 489:12-22.

Forster CR, Illing RB (2000) Plasticity of the auditory brainstem: cochleotomy-induced changes of calbindin-D28k expression in the rat. J Comp Neurol 416:173-187.

Franken TP, Bremen P, Joris PX (2014) Coincidence detection in the medial superior olive: mechanistic implications of an analysis of input spiking patterns. Front Neural Circuits 8:42. DOI: 10.3389/fncir.2014.00042.

Fredrich M, Reisch A, Illing RB (2009) Neuronal subtype identity in the rat auditory brainstem as defined by molecular profile and axonal projection. Exp Brain Res 195:241-260.

Friauf E (1992) Tonotopic order in the adult and developing auditory system of the rat as shown by c-fos immunocytochemistry. Eur J Neurosci 4:798-812. 
Friauf E (1993) Transient appearance of calbindin-D28k-positive neurons in the superior olivary complex of developing rats. J Comp Neurol 334:59-74.

Friauf E, Ostwald J (1988) Divergent projections of physiologically characterized rat ventral cochlear nucleus neurons as shown by intra-axonal injection of horseradish peroxidase. Exp Brain Res 73:263-284.

Friauf E, Aragon C, Lohrke S, Westenfelder B, Zafra F (1999) Developmental expression of the glycine transporter GLYT2 in the auditory system of rats suggests involvement in synapse maturation. J Comp Neurol 412:17-37.

Fritzsch B. 1993. Fast axonal diffusion of 3,000 molecular weight dextran amines. J Neurosci Meth 50:95-103.

Fujino K, Koyano K, Ohmori H (1997) Lateral and medial olivocochlear neurons have distinct electrophysiological properties in the rat brain slice. J Neurophysiol 77:2788-2804.

Furst M, Aharonson V, Levine RA, Fullerton BC, Tadmor R, Pratt H, Polyakov A, Korczyn AD (2000) Sound lateralization and interaural discrimination. Effects of brainstem infarcts and multiple sclerosis lesions. Hear Res 143:29-42.

Galambos R, Schwartzkopff J, Rupert A (1959) Microelectrode study of superior olivary nuclei. Am J Physiol 197:527-536.

Garcia-Lazaro JA, Belliveau LA, Lesica NA (2013) Independent population coding of speech with sub-millisecond precision. J Neurosci 33:19362-19372.

Gardner MB (1969) Distance estimation of $0^{\circ}$ or apparent $0^{\circ}$-oriented speech signals in anechnoic space. J Acoust Soc Am 45:47-53.

Gazula VR, Strumbos JG, Mei X, Chen H, Rahner C, Kaczmarek LK (2010) Localization of Kv1.3 channels in presynaptic terminals of brainstem auditory neurons. J Comp Neurol 518:32053220.

Gelfand SA (2010) "Hearing: An Introduction to Psychological and Physiological Acoustics, $5^{a}$ edición". Informa Healthcare, Colchester, Essex.

Gleich O, Strutz J (2002) Age dependent changes in the medial nucleus of the trapezoid body in gerbils. Hear Res 164:166-178.

Glendenning KK, Hutson KA (1998) Lack of topography in the ventral nucleus of the lateral lemniscus. Microsc Res Tech 41:298-312.

Glendenning KK, Hutson KA, Nudo RJ, Masterton RB (1985) Acoustic chiasm. II: Anatomical basis of binaurality in lateral superior olive of cat. J Comp Neurol 232:261-285.

Glendenning KK, Masterton RB, Baker BN, Wenthold RJ (1991) Acoustic chiasm. III: Nature, distribution, and sources of afferents to the lateral superior olive in the cat. J Comp Neurol 310:377-400.

Glendenning KK, Baker BN, Hutson KA, Masterton RB (1992) Acoustic chiasm V: inhibition and excitation in the ipsilateral and contralateral projections of LSO. J Comp Neurol 319:100-122. 
Goldberg JM, Brown PB (1968) Functional organization of the dog superior olivary complex: an anatomical and electrophysiological study. J Neurophysiol 31:639-656.

Goldberg JM, Brown PB (1969) Response of binaural neurons of dog superior olivary complex to dichotic tonal stimuli: some physiological mechanisms of sound localization. J Neurophysiol 32:613-636.

Goldberg JM, Brownell WE (1973) Discharge characteristics of neurons in anteroventral and dorsal cochlear nuclei of cat. Brain Res 64:35-54.

Golding NL, Oertel D (2012) Synaptic integration in dendrites: exceptional need for speed. J Physiol 590:5563-5569.

Goldstein BE (2007) "Sensation and Perception". 7ª edición. Thomson, Wadsworth, Belmot, California.

Goldstein BE (2010) "Sensation and Perception". 8a edición. Wadsworth, Cengage Learning, Belmot, California.

Gómez-Nieto R, Rubio ME (2009) A bushy cell network in the rat ventral cochlear nucleus. J Comp Neurol 516:241-263.

Gómez-Nieto R, Rubio ME, López DE (2008) Cholinergic input from the ventral nucleus of the trapezoid body to cochlear root neurons in rats. J Comp Neurol 506:452-468.

Gómez-Nieto R, Sinex DG, C Horta-Júnior J de A, Castellano O, Herrero-Turrión JM, López DE (2014) A fast cholinergic modulation of the primary acoustic startle circuit in rats. Brain Struct Funct 219:1555-1573.

Gourévitch B, Brette R (2012) The impact of early reflections on binaural cues. J Acoust Soc Am 132:9-27.

Grande G, Wang LY (2011) Morphological and functional continuum underlying heterogeneity in the spiking fidelity at the calyx of Held synapse in vitro. J Neurosci 31:13386-13399.

Grandes P, Streit P (1989) Glutamate-like immunoreactivity in calyces of Held. J Neurocytol 18:685-693.

Grothe B (2000) The evolution of temporal processing in the medial superior olive, an auditory brainstem structure. Prog Neurobiol 61:581-610.

Grothe B (2003) New roles for synaptic inhibition in sound localization. Nat Rev Neurosci 4:540-550.

Grothe B, Pecka M, Mcalpine D (2010) Mechanisms of sound localization in mammals. Physiol Rev 90:983-1012.

Grothe B, Schweizer H, Pollak GD, Schuller G, Rosemann C (1994) Anatomy and projection patterns of the superior olivary complex in the Mexican free-tailed bat, Tadarida brasiliensis mexicana. J Comp Neurol 343:630-646.

Guinan JJ, Norris BE, Guinan SS (1972) Single auditory units in the superior olivary complex. II: Locations of unit categories and tonotopic organization. Int J Dev Neurosci 4:147-166. 
Guinan JJ, Jr., Li RY (1990) Signal processing in brainstem auditory neurons which receive giant endings (calyces of Held) in the medial nucleus of the trapezoid body of the cat. Hear Res 49:321-334.

Hackney CM, Pick GF (1986) The distribution of spherical cells in the anteroventral cochlear nucleus of the guinea pig. Br J Audiol 20:215-220.

Hackney CM, Osen KK, Kolston J (1990) Anatomy of the cochlear nuclear complex of guinea pig. Anat Embryol (Berl) 182:123-149.

Hafidi A, Katz JA, Sanes DH (1996) Differential expression of MAG, MBP and L1 in the developing lateral superior olive. Brain Res 736:35-43.

Hafidi A, Sanes DH, Hillman DE, Kedeshian P (1994) Structural and molecular heterogeneity of astrocytes and oligodendrocytes in the gerbil lateral superior olive. Neuroscience 60:503-519.

Hancock KE, Delgutte B (2004) A physiologically based model of interaural time difference discrimination. J Neurosci 24:7110-7117.

Harrison JM, Irving R (1966) Ascending connections of the anterior ventral cochlear nucleus in the rat. J Comp Neurol 126:51-63.

Harrison JM, Feldman ML (1970) Anatomical aspects of the cochlear nucleus and superior olivary complex. Contrib Sens Physiol 4:95-142.

Hassfurth B, Grothe B, Koch U (2010) The mammalian interaural time difference detection circuit is differentially controlled by GABAB receptors during development. J Neurosci 30:9715-9727.

Haykin S, Chen Z (2005) The cocktail party problem. Neural Comput 17:1875-1902.

Heffner HE, Heffner RS, Contos C, Ott T (1994) Audiogram of the hooded Norway rat. Hear Res 73:244-247.

Heffner RS, Heffner HE (1988) Sound localization and use of binaural cues by the gerbil (Meriones unguiculatus). Behav Neurosci 102:422-428.

Helfert RH, Schwartz IR (1986) Morphological evidence for the existence of multiple neuronal classes in the cat lateral superior olivary nucleus. J Comp Neurol 244:533-549.

Helfert RH, Schwartz IR (1987) Morphological features of five neuronal classes in the gerbil lateral superior olive. Am J Anat 179:55-69.

Helfert RH, Schwartz IR, Ryan AF (1988) Ultrastructural characterization of gerbil olivocochlear neurons based on differential uptake of $3 \mathrm{H}-\mathrm{D}$-aspartic acid and a wheatgerm agglutininhorseradish peroxidase conjugate from the cochlea. J Neurosci 8:3111-3123.

Helfert RH, Bonneau JM, Wenthold RJ, Altschuler RA (1989) GABA and glycine immunoreactivity in the guinea pig superior olivary complex. Brain Res 501:269-286.

Helfert RH, Juiz JM, Bledsoe SC, Jr., Bonneau JM, Wenthold RJ, Altschuler RA (1992) Patterns of glutamate, glycine, and GABA immunolabeling in four synaptic terminal classes in the lateral superior olive of the guinea pig. J Comp Neurol 323:305-325. 
Henkel CK (1997) Axonal morphology in fibrodendritic laminae of the dorsal nucleus of the lateral lemniscus: afferent projections from the medial superior olivary nucleus. J Comp Neurol 380:136-144.

Henkel CK, Brunso-Bechtold JK (1990) Dendritic morphology and development in the ferret medial superior olivary nucleus. J Comp Neurol 294:377-388.

Henkel CK, Brunso-Bechtold JK (1991) Dendritic morphology and development in the ferret lateral superior olivary nucleus. J Comp Neurol 313:259-272.

Henkel CK, Brunso-Bechtold JK (1993) Laterality of superior olive projections to the inferior colliculus in adult and developing ferret. J Comp Neurol 331:458-468.

Henkel CK, Brunso-Bechtold JK (1995) Development of glycinergic cells and puncta in nuclei of the superior olivary complex of the postnatal ferret. J Comp Neurol 354:470-480.

Henkel CK, Brunso-Bechtold JK (1998) Calcium-binding proteins and GABA reveal spatial segregation of cell types within the developing lateral superior olivary nucleus of the ferret. Microsc Res Tech 41:234-245.

Henkel CK, Gabriele ML (1999) Organization of the disynaptic pathway from the anteroventral cochlear nucleus to the lateral superior olivary nucleus in the ferret. Anat Embryol (Berl) 199:149-160.

Henkel CK, Spangler KM (1983) Organization of the efferent projections of the medial superior olivary nucleus in the cat as revealed by HRP and autoradiographic tracing methods. J Comp Neurol 221:416-428.

Henning GB (1974) Detectability of interaural delay in high-frequency complex waveforms. J Acoust Soc Am 55:84-90.

Hirtz JJ, Boesen M, Braun N, Deitmer JW, Kramer F, Lohr C, Muller B, Nothwang HG, Striessnig J, Lohrke S, Friauf E (2011) Cav1.3 calcium channels are required for normal development of the auditory brainstem. J Neurosci 31:8280-8294.

Hirtz JJ, Braun N, Griesemer D, Hannes C, Janz K, Lohrke S, Muller B, Friauf E (2012) Synaptic refinement of an inhibitory topographic map in the auditory brainstem requires functional Cav1.3 calcium channels. J Neurosci 32:14602-14616.

Hofman PM, Van Riswick JG, Van Opstal AJ (1998) Relearning sound localization with new ears. Nat Neurosci 1:417-421.

Horvath M, Kraus KS, Illing RB (2000) Olivocochlear neurons sending axon collaterals into the ventral cochlear nucleus of the rat. J Comp Neurol 422:95-105.

Howard DM, Angus JA (2009) “Acoustics and Psychoacoustics”, 4ª edición. Focal Press, (Elsevier), Oxford.

Illing RB, Kraus KS, Michler SA (2000) Plasticity of the superior olivary complex. Microsc Res Tech 51:364-381. 
Inbody SB, Feng AS (1981) Binaural response characteristics of single neurons in the medial superior olivary nucleus of the albino rat. Brain Res 210:361-366.

Ingård U (1953) A review of the influence of meteorological conditions on sound propagation. J Acoust Soc Am 25:405-411.

Irving R, Harrison JM (1967) The superior olivary complex and audition: a comparative study. J Comp Neurol 130:77-86.

Jalabi W, Kopp-Scheinpflug C, Allen PD, Schiavon E, Digiacomo RR, Forsythe ID, Maricich SM (2013) Sound localization ability and glycinergic innervation of the superior olivary complex persist after genetic deletion of the medial nucleus of the trapezoid body. J Neurosci 33:15044-15049.

Jeffress LA (1948) A place theory of sound localization. J Comp Physiol Psychol 41:35-39.

Jenkins SA, Simmons DD (2006) GABAergic neurons in the lateral superior olive of the hamster are distinguished by differential expression of gad isoforms during development. Brain Res 1111:12-25.

Jercog PE, Svirskis G, Kotak VC, Sanes DH, Rinzel J (2010) Asymmetric excitatory synaptic dynamics underlie interaural time difference processing in the auditory system. PLoS Biol 8:e1000406. DOI: 10.1371/journal.pbio.1000406.

Joris PX, Smith PH (2008) The volley theory and the spherical cell puzzle. Neuroscience 154:65-76.

Joris PX, Yin TC (1995) Envelope coding in the lateral superior olive. I. Sensitivity to interaural time differences. J Neurophysiol 73:1043-1062.

Joris PX, Yin TC (1998) Envelope coding in the lateral superior olive. III. Comparison with afferent pathways. J Neurophysiol 79:253-269.

Joris PX, Yin TC (2007) A matter of time: internal delays in binaural processing. Trends Neurosci 30:70-78.

Joris PX, Smith PH, Yin TC (1998) Coincidence detection in the auditory system: 50 years after Jeffress. Neuron 21:1235-1238.

Joris PX, Van De Sande B, Louage DH, Van Der Heijden M (2006) Binaural and cochlear disparities. Proc Natl Acad Sci U S A 103:12917-12922.

Jursky F, Nelson N (1995) Localization of glycine neurotransmitter transporter (GlyT2) reveals correlation with the distribution of glycine receptor. J Neurochem 64:1026-1033.

Kadner A, Berrebi AS (2008) Encoding of temporal features of auditory stimuli in the medial nucleus of the trapezoid body and superior paraolivary nucleus of the rat. Neuroscience 151:868-887.

Kadner A, Kulesza RJ, Jr., Berrebi AS (2006) Neurons in the medial nucleus of the trapezoid body and superior paraolivary nucleus of the rat may play a role in sound duration coding. J Neurophysiol 95:1499-1508. 
Kaiser A, Alexandrova O, Grothe B (2011) Urocortin-expressing olivocochlear neurons exhibit tonotopic and developmental changes in the auditory brainstem and in the innervation of the cochlea. J Comp Neurol 519:2758-2778.

Kaltenbach JA, Lazor J (1991) Tonotopic maps obtained from the surface of the dorsal cochlear nucleus of the hamster and rat. Hear Res 51:149-160.

Kandler K, Friauf E (1995) Development of electrical membrane properties and discharge characteristics of superior olivary complex neurons in fetal and postnatal rats. Eur J Neurosci 7:1773-1790.

Kandler K, Clause A, Noh J (2009) Tonotopic reorganization of developing auditory brainstem circuits. Nat Neurosci 12:711-717.

Kapfer C (2003) Aktivitätsabhängige Entwicklung der Struktur und Kinetik inhibitorischer Eingänge zu auditorischen Neuronen, Tesis doctoral, Universidad de Múnich, Alemania.

Kapfer C, Seidl AH, Schweizer H, Grothe B (2002) Experience-dependent refinement of inhibitory inputs to auditory coincidence-detector neurons. Nat Neurosci 5:247-253.

Karino S, Smith PH, Yin TC, Joris PX (2011) Axonal branching patterns as sources of delay in the mammalian auditory brainstem: a re-examination. J Neurosci 31:3016-3031.

Kelley PE, Frisina RD, Zettel ML, Walton JP (1992) Differential calbindin-like immunoreactivity in the brain stem auditory system of the chinchilla. J Comp Neurol 320:196-212.

Kelly JB, Masterton B (1977) Auditory sensitivity of the albino rat. J Comp Physiol Psychol 91:930-936.

Kelly JB, Glenn SL, Beaver CJ (1991) Sound frequency and binaural response properties of single neurons in rat inferior colliculus. Hear Res 56:273-280.

Kelly JB, Liscum A, Van Adel B, Ito M (1998) Projections from the superior olive and lateral lemniscus to tonotopic regions of the rat's inferior colliculus. Hear Res 116:43-54.

Kelly JB, Van Adel BA, Ito M (2009) Anatomical projections of the nuclei of the lateral lemniscus in the albino rat (Rattus norvegicus). J Comp Neurol 512:573-593.

Khurana S, Liu Z, Lewis AS, Rosa K, Chetkovich D, Golding NL (2012) An essential role for modulation of hyperpolarization-activated current in the development of binaural temporal precision. J Neurosci 32:2814-2823.

Kil J, Kageyama GH, Semple MN, Kitzes LM (1995) Development of ventral cochlear nucleus projections to the superior olivary complex in gerbil. J Comp Neurol 353:317-340.

Kim G, Kandler K (2003) Elimination and strengthening of glycinergic/GABAergic connections during tonotopic map formation. Nat Neurosci 6:282-290.

Kim J, Morest DK, Bohne BA (1997) Degeneration of axons in the brainstem of the chinchilla after auditory overstimulation. Hear Res 103:169-191.

Kiss A, Majorossy K (1983) Neuron morphology and synaptic architecture in the medial superior olivary nucleus. Light- and electron microscope studies in the cat. Exp Brain Res 52:315-327. 
Kitzes LM (1984) Some physiological consequences of neonatal cochlear destruction in the inferior colliculus of the gerbil, Meriones unguiculatus. Brain Res 306:171-178.

Kitzes LM, Kageyama GH, Semple MN, Kil J (1995) Development of ectopic projections from the ventral cochlear nucleus to the superior olivary complex induced by neonatal ablation of the contralateral cochlea. J Comp Neurol 353:341-363.

Klemm O (1920) Untersuchungen über die Lokalisation von Schallreizen IV.Über den Einfluss des binauralen Zeitunterschiedes auf die Lokalisation. Arch Ges Psychol 40:117-145.

Klumpp RG, Eady HR (1956) Some measurements of interaural time difference thresholds. J Acoust Soc Am 28:859-860.

Klumpp GM (2000) Sound localization in birds. En “Comparative Hearing: Birds and Reptiles”, de Dooling RJ, R. FR, N. PA (eds.). Springer-Verlag, Nueva York, pp 243-251.

Kobbert C, Apps R, Bechmann I, Lanciego JL, Mey J, Thanos S (2000) Current concepts in neuroanatomical tracing. Prog Neurobiol 62:327-351.

Koch U, Sanes DH (1998) Afferent regulation of glycine receptor distribution in the gerbil LSO. Microsc Res Tech 41:263-269.

Koka K, Read HL, Tollin DJ (2008) The acoustical cues to sound location in the rat: measurements of directional transfer functions. J Acoust Soc Am 123:4297-4309.

Konishi M (2003) Coding of auditory space. Annu Rev Neurosci 26:31-55.

Kopp-Scheinpflug C, Dehmel S, Dorrscheidt GJ, Rübsamen R (2002) Interaction of excitation and inhibition in anteroventral cochlear nucleus neurons that receive large endbulb synaptic endings. J Neurosci 22:11004-11018.

Kopp-Scheinpflug C, Tolnai S, Malmierca MS, Rübsamen R (2008) The medial nucleus of the trapezoid body: comparative physiology. Neuroscience 154:160-170.

Kopp-Scheinpflug C, Steinert JR, Forsythe ID (2011) Modulation and control of synaptic transmission across the MNTB. Hear Res 279:22-31.

Koppl C, Carr CE (2008) Maps of interaural time difference in the chicken's brainstem nucleus laminaris. Biol Cybern 98:541-559.

Korada S, Schwartz IR (1999) Development of GABA, glycine, and their receptors in the auditory brainstem of gerbil: a light and electron microscopic study. J Comp Neurol 409:664-681.

Kraus KS, Illing RB (2004) Superior olivary contributions to auditory system plasticity: medial but not lateral olivocochlear neurons are the source of cochleotomy-induced GAP-43 expression in the ventral cochlear nucleus. J Comp Neurol 475:374-390.

Kreinest M, Muller B, Winkelhoff J, FriaufE, Lohrke S (2009) Miniature EPSCs in the lateral superior olive before hearing onset: regional and cell-type-specific differences and heterogeneous neuromodulatory effects of ATP. Brain Res 1295:21-36.

Kuba H (2012) Structural tuning and plasticity of the axon initial segment in auditory neurons. J Physiol 590:5571-5579. 
Kudo M, Kitao Y, Okoyama S, Moriya M, Kawano J (1996) Crossed projection neurons are generated prior to uncrossed projection neurons in the lateral superior olive of the rat. Brain Res Dev Brain Res 95:72-78.

Kudo M, Sakurai H, Kurokawa K, Yamada H (2000) Neurogenesis in the superior olivary complex in the rat. Hear Res 139:144-152.

Kuenzel T, Borst JG, Van Der Heijden M (2011) Factors controlling the input-output relationship of spherical bushy cells in the gerbil cochlear nucleus. J Neurosci 31:4260-4273.

Kuhn GF (1977) Model for the interaural time differences in the azimuthal plane. J Acoust Soc Am 62:157-167.

Kulesza RJ, Jr. (2007) Cytoarchitecture of the human superior olivary complex: medial and lateral superior olive. Hear Res 225:80-90.

Kulesza RJ, Jr. (2014) Characterization of human auditory brainstem circuits by calcium-binding protein immunohistochemistry. Neuroscience 258:318-331.

Kulesza RJ, Jr., Berrebi AS (2000) Superior paraolivary nucleus of the rat is a GABAergic nucleus. J Assoc Res Otolaryngol 1:255-269.

Kulesza RJ, Viñuela A, Saldaña E, Berrebi AS (2002) Unbiased stereological estimates of neuron number in subcortical auditory nuclei of the rat. Hear Res 168:12-24.

Kulesza RJ, Jr., Spirou GA, Berrebi AS (2003) Physiological response properties of neurons in the superior paraolivary nucleus of the rat. J Neurophysiol 89:2299-2312.

Kulesza RJ, Jr., Kadner A, Berrebi AS (2007) Distinct roles for glycine and GABA in shaping the response properties of neurons in the superior paraolivary nucleus of the rat. J Neurophysiol 97:1610-1620.

Kumoi K, Saito N, Tanaka C (1993) Immunohistochemical localization of gamma-aminobutyric acid- and aspartate-containing neurons in the guinea pig superior olivary complex. Hear Res 68:173-179.

Kungel M, Piechotta K, Rietzel HJ, Friauf E (1997) Influence of the neuropeptide somatostatin on the development of dendritic morphology: a cysteamine-depletion study in the rat auditory brainstem. Brain Res Dev Brain Res 101:107-114.

Kuwabara N, Zook JM (1991) Classification of the principal cells of the medial nucleus of the trapezoid body. J Comp Neurol 314:707-720.

Kuwabara N, Zook JM (1992) Projections to the medial superior olive from the medial and lateral nuclei of the trapezoid body in rodents and bats. J Comp Neurol 324:522-538.

Kuwabara N, Dicaprio RA, Zook JM (1991) Afferents to the medial nucleus of the trapezoid body and their collateral projections. J Comp Neurol 314:684-706.

Kuwada S, Batra R (1999) Coding of sound envelopes by inhibitory rebound in neurons of the superior olivary complex in the unanesthetized rabbit. J Neurosci 19:2273-2287. 
Lanciego JL, Wouterlood FG (2011) A half century of experimental neuroanatomical tracing. J Chem Neuroanat 42:157-183.

Lauer AM, Connelly CJ, Graham H, Ryugo DK (2013) Morphological characterization of bushy cells and their inputs in the laboratory mouse (Mus musculus) Anteroventral Cochlear Nucleus. PLoS One 8:e73308. DOI: 10.1371/journal.pone.0073308.

Leão RN, Sun H, Svahn K, Berntson A, Youssoufian M, Paolini AG, Fyffe RE, Walmsley B (2006) Topographic organization in the auditory brainstem of juvenile mice is disrupted in congenital deafness. J Physiol 571:563-578.

Lehnert S, Ford MC, Alexandrova O, Hellmundt F, Felmy F, Grothe B, Leibold C (2014) Action potential generation in an anatomically constrained model of medial superior olive axons. J Neurosci 34:5370-5384.

Lesica NA, Lingner A, Grothe B (2010) Population coding of interaural time differences in gerbils and barn owls. J Neurosci 30:11696-11702.

Letowski TR, Letowski TS (2012) Auditory Spatial Perception: Auditory Localization. U.S. Army Research Laboratory, documento de trabajo ARL-TR-6016.

Levine RA, Gardner JC, Stufflebeam SM, Fullerton BC, Carlisle EW, Furst M, Rosen BR, Kiang NY (1993) Binaural auditory processing in multiple sclerosis subjects. Hear Res 68:59-72.

Li W, Kaczmarek LK, Perney TM (2001) Localization of two high-threshold potassium channel subunits in the rat central auditory system. J Comp Neurol 437:196-218.

Lindsey BG (1975) Fine structure and distribution of axon terminals from the cochlear nucleus on neurons in the medial superior olivary nucleus of the cat. J Comp Neurol 160:81-103.

Ling C, Hendrickson ML, Kalil RE (2012) Resolving the detailed structure of cortical and thalamic neurons in the adult rat brain with refined biotinylated dextran amine labeling. PLoS One 7:e45886. DOI: 10.1371/journal.pone.0045886.

Loftus WC, Bishop DC, Saint Marie RL, Oliver DL (2004) Organization of binaural excitatory and inhibitory inputs to the inferior colliculus from the superior olive. J Comp Neurol 472:330-344.

Lohmann C, Friauf E (1996) Distribution of the calcium-binding proteins parvalbumin and calretinin in the auditory brainstem of adult and developing rats. J Comp Neurol 367:90-109.

Lohrke S, Srinivasan G, Oberhofer M, Doncheva E, Friauf E (2005) Shift from depolarizing to hyperpolarizing glycine action occurs at different perinatal ages in superior olivary complex nuclei. Eur J Neurosci 22:2708-2722.

López DE, Saldaña E, Nodal FR, Merchán MA, Warr WB (1999) Projections of cochlear root neurons, sentinels of the rat auditory pathway. J Comp Neurol 415:160-174.

López-Poveda EA, Meddis R (1996) A physical model of sound diffraction and reflections in the human concha. J Acoust Soc Am 100:3248-3259. 
Lorente De Nó R (1933) Anatomy of the eighth nerve. The central projection of the nerve endings of the internal ear. Laryngoscope (St. Louis) 43:1-38.

Loskota W, Lomax P, Verity M (1974) "A stereotaxic atlas of the Mongolian gerbil brain (Meriones unguiculatus)”. Ann Arbor Science Publishers, Inc., Ann Arbor, Michigan.

Lu SM, Schweitzer L, Cant NB, Dawbarn D (1987) Immunoreactivity to calcitonin gene-related peptide in the superior olivary complex and cochlea of cat and rat. Hear Res 31:137-146.

Lukose R, Schmidt E, Wolski TP, Jr., Murawski NJ, Kulesza RJ, Jr. (2011) Malformation of the superior olivary complex in an animal model of autism. Brain Res 1398:102-112.

Magnusson AK, Kapfer C, Grothe B, Koch U (2005) Maturation of glycinergic inhibition in the gerbil medial superior olive after hearing onset. J Physiol 568:497-512.

Maison SF, Adams JC, Liberman MC (2003) Olivocochlear innervation in the mouse: immunocytochemical maps, crossed versus uncrossed contributions, and transmitter colocalization. J Comp Neurol 455:406-416.

Majorossy K, Kiss A (1990) Types of neurons and synaptic relations in the lateral superior olive of the cat: normal structure and experimental observations. Acta Morphol Hung 38:207-215.

Malmierca MS, Leergaard TB, Bajo VM, Bjaalie JG, Merchán MA (1998) Anatomic evidence of a three-dimensional mosaic pattern of tonotopic organization in the ventral complex of the lateral lemniscus in cat. J Neurosci 18:10603-10618.

Malmierca MS, Izquierdo MA, Cristaudo S, Hernández O, Pérez-González D, Covey E, Oliver DL (2008) A discontinuous tonotopic organization in the inferior colliculus of the rat. J Neurosci 28:4767-4776.

Mason AC, Oshinsky ML, Hoy RR (2001) Hyperacute directional hearing in a microscale auditory system. Nature 410:686-690.

Masterton RB (1992) Role of the central auditory system in hearing: the new direction. Trends Neurosci 15:280-285.

Masterton B, Diamond IT, Harrison JM, Beecher MD (1967) Medial superior olive and sound localization. Science 155:1696-1697.

Masterton B, Thompson GC, Bechtold JK, Robards MJ (1975) Neuroanatomical basis of binaural phase-difference analysis for sound localization: a comparative study. J Comp Physiol Psychol 89:379-386.

Mathews PJ, Jercog PE, Rinzel J, Scott LL, Golding NL (2010) Control of submillisecond synaptic timing in binaural coincidence detectors by K(v)1 channels. Nat Neurosci 13:601-609.

Matsubara JA (1990) Calbindin D-28K immunoreactivity in the cat's superior olivary complex. Brain Res 508:353-357.

Mcalpine D, Jiang D, Palmer AR (1996) Interaural delay sensitivity and the classification of low best-frequency binaural responses in the inferior colliculus of the guinea pig. Hear Res 97:136-152. 
Mcalpine D, Jiang D, Palmer AR (2001) A neural code for low-frequency sound localization in mammals. Nat Neurosci 4:396-401.

Mcfadden D, Pasanen EG (1976) Lateralization at high frequencies based on interaural time differences. J Acoust Soc Am 59:634-639.

McGinley MJ, Liberman MC, Bal R, Oertel D (2012) Generating synchrony from the asynchronous: compensation for cochlear traveling wave delays by the dendrites of individual brainstem neurons. J Neurosci 32:9301-9311.

Merchán MA, Saldaña E, Plaza I (1994) Dorsal nucleus of the lateral lemniscus in the rat: concentric organization and tonotopic projection to the inferior colliculus. J Comp Neurol 342:259-278.

Mershon DH, Bowers JN (1979) Absolute and relative cues for the auditory perception of egocentric distance. Perception 8:311-322.

Miles RN, Robert D, Hoy RR (1995) Mechanically coupled ears for directional hearing in the parasitoid fly O. ochracea. J. Acoust Soc Am 98:2059-3070

Mills AW (1958) On the minimum audible angle. J Acoust Soc Am 30:237-246.

Møller AR (2006) "Hearing: Anatomy, Physiology, and Disorders of the Auditory System", $2^{\text {a }}$ edición. Academic Press (Elsevier), London.

Moore DR, Russell FA, Cathcart NC (1995) Lateral superior olive projections to the inferior colliculus in normal and unilaterally deafened ferrets. J Comp Neurol 357:204-216.

Moore JK (1987) The human auditory brain stem: a comparative view. Hear Res 29:1-32.

Moore MJ, Caspary DM (1983) Strychnine blocks binaural inhibition in lateral superior olivary neurons. J Neurosci 3:237-242.

Morest DK (1968a) The growth of synaptic endings in the mammalian brain: a study of the calyces of the trapezoid body. Z Anat Entwicklungsgesch 127:201-220.

Morest DK (1968b) The collateral system of the medial nucleus of the trapezoid body of the cat, its neuronal architecture and relation to the olivo-cochlear bundle. Brain Res 9:288-311.

Morest DK, Kim J, Bohne BA (1997) Neuronal and transneuronal degeneration of auditory axons in the brainstem after cochlear lesions in the chinchilla: cochleotopic and non-cochleotopic patterns. Hear Res 103:151-168.

Moushegian G, Rupert A, Whitcomb MA (1964) Brain-stem neuronal response patterns to monaural and binaural tones. J Neurophysiol 27:1174-1191.

Mulders WH, Robertson D (2000) Evidence for direct cortical innervation of medial olivocochlear neurones in rats. Hear Res 144:65-72.

Müller M (1990) Quantitative comparison of frequency representation in the auditory brainstem nuclei of the gerbil, Pachyuromys duprasi. Exp Brain Res 81:140-149.

Müller M (1991) Developmental changes of frequency representation in the rat cochlea. Hear Res 56:1-7. 
Müller M, Von Hunerbein K, Hoidis S, Smolders JW (2005) A physiological place-frequency map of the cochlea in the CBA/J mouse. Hear Res 202:63-73.

Musicant AD, Butler RA (1984) The influence of pinnae-based spectral cues on sound localization. J Acoust Soc Am 75:1195-1200.

Mylius J, Brosch M, Scheich H, Budinger E (2013) Subcortical auditory structures in the Mongolian gerbil: I. Golgi architecture. J Comp Neurol 521:1289-1321.

Myoga MH, Lehnert S, Leibold C, Felmy F, Grothe B (2014) Glycinergic inhibition tunes coincidence detection in the auditory brainstem. Nat Commun 5:3790.

Nara T, Goto N, Hamano S, Okada A (1994) Development of the human medial superior olivary nucleus: a morphometric study. Early Hum Dev 40:13-21.

Nielsen SH (1993) Auditory distance perception in different rooms. J Am Inst Elect Eng 41:755-770.

Nordeen KW, Killackey HP, Kitzes LM (1983) Ascending auditory projections to the inferior colliculus in the adult gerbil, Meriones unguiculatus. J Comp Neurol 214:131-143.

Oertel D, Wu SH, Garb MW, Dizack C (1990) Morphology and physiology of cells in slice preparations of the posteroventral cochlear nucleus of mice. J Comp Neurol 295:136-154.

Oertel D, Wright S, Cao XJ, Ferragamo M, Bal R (2011) The multiple functions of T stellate/ multipolar/chopper cells in the ventral cochlear nucleus. Hear Res 276:61-69.

Oliver DL (2000) Ascending efferent projections of the superior olivary complex. Microsc Res Tech 51:355-363.

Oliver DL, Beckius GE, Shneiderman A (1995) Axonal projections from the lateral and medial superior olive to the inferior colliculus of the cat: a study using electron microscopic autoradiography. J Comp Neurol 360:17-32.

Oliver DL, Beckius GE, Bishop DC, Kuwada S (1997) Simultaneous anterograde labeling of axonal layers from lateral superior olive and dorsal cochlear nucleus in the inferior colliculus of cat. J Comp Neurol 382:215-229.

Oliver DL, Beckius GE, Bishop DC, Loftus WC, Batra R (2003) Topography of interaural temporal disparity coding in projections of medial superior olive to inferior colliculus. J Neurosci 23:7438-7449.

Ollo C, Schwartz IR (1979) The superior olivary complex in C57BL/6 mice. Am J Anat 155:349-373.

Osen KK (1969a) Cytoarchitecture of the cochlear nuclei in the cat. J Comp Neurol 136:453-484.

Osen KK (1969b) The intrinsic organization of the cochlear nuclei. Acta Otolaryngol 67:352-359.

Osen KK (1970) Course and termination of the primary afferents in the cochlear nuclei of the cat. An experimental anatomical study. Arch Ital Biol 108:21-51.

Osen KK, Mugnaini E, Dahl AL, Christiansen AH (1984) Histochemical localization of acetylcholinesterase in the cochlear and superior olivary nuclei. A reappraisal with emphasis on the cochlear granule cell system. Arch Ital Biol 122:169-212. 
Oshinsky ML, Hoy RR (2002) Physiology of the auditory afferents in an acoustic parasitoid fly. J Neurosci 22:7254-7263.

Ostapoff EM, Morest DK, Parham K (1999) Spatial organization of the reciprocal connections between the cat dorsal and anteroventral cochlear nuclei. Hear Res 130:75-93.

Ouda L, Druga R, Syka J (2012) Distribution of SMI-32-immunoreactive neurons in the central auditory system of the rat. Brain Struct Funct 217:19-36. Overholt EM, Rubel EW, Hyson RL (1992) A circuit for coding interaural time differences in the chick brainstem. J Neurosci 12:1698-1708.

Paolini AG, Fitzgerald JV, Burkitt AN, Clark GM (2001) Temporal processing from the auditory nerve to the medial nucleus of the trapezoid body in the rat. Hear Res 159:101-116.

Pasic TR, Moore DR, Rubel EW (1994) Effect of altered neuronal activity on cell size in the medial nucleus of the trapezoid body and ventral cochlear nucleus of the gerbil. J Comp Neurol 348:111-120.

Park TJ, Monsivais P, Pollak GD (1997) Processing of interaural intensity differences in the LSO: role of interaural threshold differences. J Neurophysiol 77:2863-2878.

Paxinos G, Watson C (2005) “The Rat Brain in Stereotaxic Coordinates”, 5a edición. Elsevier Academic Press, San Diego, California.

Pecka M, Brand A, Behrend O, Grothe B (2008) Interaural time difference processing in the mammalian medial superior olive: the role of glycinergic inhibition. J Neurosci 28:6914-6925.

Perkins RE (1973) An electron microscopic study of synaptic organization in the medial superior olive of normal and experimental chinchillas. J Comp Neurol 148:387-415.

Petersen J (1990) Estimation of loudness and apparent distance of pure tones in a free field. Acustica 70:61-65.

Popper AN, Fay RR (2005) “Sound Source Localization”. Springer Handbook of Auditory Research, Vol. 25. Springer, New York.

Portfors CV, Von Gersdorff H (2013) Macrocircuits for sound localization use leaky coincidence detectors and specialized synapses. Neuron 78:755-757.

Portfors CV, Mayko ZM, Jonson K, Cha GF, Roberts PD (2011) Spatial organization of receptive fields in the auditory midbrain of awake mouse. Neuroscience 193:429-439.

Powell TP, Cowan WM (1962) An experimental study of the projection of the cochlea. J Anat 96:269-284.

Poyatos I, Ponce J, Aragon C, Gimenez C, Zafra F (1997) The glycine transporter GlyT2 is a reliable marker for glycine-immunoreactive neurons. Brain Res Mol Brain Res 49:63-70.

Rajakumar N, Elisevich K, Flumerfelt BA (1993) Biotinylated dextran: a versatile anterograde and retrograde neuronal tracer. Brain Res 607:47-53.

Raju DV, Smith Y (2006) Anterograde axonal tract tracing. Curr Protoc Neurosci, capítulo 1, unidad 1.14. DOI: 10.1002/0471142301.ns0114s37. 
Rautenberg PL, Grothe B, Felmy F (2009) Quantification of the three-dimensional morphology of coincidence detector neurons in the medial superior olive of gerbils during late postnatal development. J Comp Neurol 517:385-396.

Redd EE, Pongstaporn T, Ryugo DK (2000) The effects of congenital deafness on auditory nerve synapses and globular bushy cells in cats. Hear Res 147:160-174.

Reiner A, Honig M (2006) Dextran amines: Versatile tools for anterograde and retrograde studies of nervous system connectivity. En "Neuroanatomical Tract-Tracing 3: Molecules, Neurons, and Systems", de Zaborsky L, Wouterlood FG, Lanciego JL (eds.). Springer, Nueva York, pp. 304-335.

Rhode WS (2008) Response patterns to sound associated with labeled globular/bushy cells in cat. Neuroscience 154:87-98.

Rhode WS, Smith PH (1986) Encoding timing and intensity in the ventral cochlear nucleus of the cat. J Neurophysiol 56:261-286.

Richards DG, Wiley RH (1980) Reverberations and amplitude fluctuations in the propagation of sound in a forest: Implications for animal communication. American Naturalist 115:381-399.

Rietzel HJ, Friauf E (1998) Neuron types in the rat lateral superior olive and developmental changes in the complexity of their dendritic arbors. J Comp Neurol 390:20-40.

Roberts MT, Seeman SC, Golding NL (2014) The relative contributions of MNTB and LNTB neurons to inhibition in the medial superior olive assessed through single and paired recordings. Front Neural Circuits 8:49. DOI: 10.3389/fncir.2014.00049

Robertson D (1996) Physiology and morphology of cells in the ventral nucleus of trapezoid body and rostral periolivary regions of the rat superior olivary complex studied in slices. Auditory Neuroscience 2:15-31.

Robertson D, Winter IM (1988) Cochlear nucleus inputs to olivocochlear neurones revealed by combined anterograde and retrograde labelling in the guinea pig. Brain Res 462:47-55.

Robertson D, Cole KS, Corbett K (1987) Quantitative estimate of bilaterally projecting medial olivocochlear neurones in the guinea pig brainstem. Hear Res 27:177-181.

Rogowski BA, Feng AS (1981) Normal postnatal development of medial superior olivary neurons in the albino rat: a Golgi and Nissl study. J Comp Neurol 196:85-97.

Roos MJ, May BJ (2012) Classification of unit types in the anteroventral cochlear nucleus of laboratory mice. Hear Res 289:13-26.

Rose JE, Galambos R, Hughes JR (1959) Microelectrode studies of the cochlear nuclei of the cat. Bull Johns Hopkins Hosp 104:211-251.

Rose JE, Gross NB, Geisler CD, Hind JE (1966) Some neural mechanisms in the inferior colliculus of the cat which may be relevant to localization of a sound source. J Neurophysiol 29:288-314. 
Rosskothen-Kuhl N, Illing RB (2014) Gap43 transcription modulation in the adult brain depends on sensory activity and synaptic cooperation. PLoS One 9:e92624. DOI: 10.1371/journal. pone.0092624.

Roth GL, Aitkin LM, Andersen RA, Merzenich MM (1978) Some features of the spatial organization of the central nucleus of the inferior colliculus of the cat. J Comp Neurol. 182:661-680.

Rouiller EM, Ryugo DK (1984) Intracellular marking of physiologically characterized cells in the ventral cochlear nucleus of the cat. J Comp Neurol 225:167-186.

Russell FA, Moore DR (1995) Afferent reorganisation within the superior olivary complex of the gerbil: development and induction by neonatal, unilateral cochlear removal. J Comp Neurol 352:607-625.

Russell FA, Moore DR (1999) Effects of unilateral cochlear removal on dendrites in the gerbil medial superior olivary nucleus. Eur J Neurosci 11:1379-1390.

Russell FA, Moore DR (2002) Ultrastructural transynaptic effects of unilateral cochlear ablation in the gerbil medial superior olive. Hear Res 173:43-61.

Russell IJ, Sellick PM (1977) Tuning properties of cochlear hair cells. Nature 267:858-860.

Ryan AF, Woolf NK, Sharp FR (1982) Tonotopic organization in the central auditory pathway of the Mongolian gerbil: a 2-deoxyglucose study. J Comp Neurol 207:369-380.

Ryugo DK, Sento S (1991) Synaptic connections of the auditory nerve in cats: relationship between endbulbs of held and spherical bushy cells. J Comp Neurol 305:35-48.

Ryugo DK, Montey KL, Wright AL, Bennett ML, Pongstaporn T (2006) Postnatal development of a large auditory nerve terminal: the endbulb of Held in cats. Hear Res 216-217:100-115.

Saint Marie RL, Baker RA (1990) Neurotransmitter-specific uptake and retrograde transport of $[3 \mathrm{H}]$ glycine from the inferior colliculus by ipsilateral projections of the superior olivary complex and nuclei of the lateral lemniscus. Brain Res 524:244-253.

Saint Marie RL, Ostapoff EM, Morest DK, Wenthold RJ (1989) Glycine-immunoreactive projection of the cat lateral superior olive: possible role in midbrain ear dominance. J Comp Neurol 279:382-396.

Saldaña E, Berrebi AS (2000) Anisotropic organization of the rat superior paraolivary nucleus. Anat Embryol (Berl) 202:265-279.

Saldaña E, Merchán MA (2005) Intrinsic and Commissural Connections of the Inferior Colliculus. En “The Inferior Colliculus”, de Winer JA, Schreiner CE (eds.). Springer, Nueva York, pp 155-181.

Saldaña E, López DL, Malmierca MS, Collia FP (1987) Morfología de las neuronas del núcleo coclear vental de la rata. Acta Microscópica 10:1-12.

Saldaña E, Feliciano M, Mugnaini E (1996) Distribution of descending projections from primary auditory neocortex to inferior colliculus mimics the topography of intracollicular projections. J Comp Neurol 371:15-40. 
Saldaña E, Aparicio MA, Fuentes-Santamaria V, Berrebi AS (2009) Connections of the superior paraolivary nucleus of the rat: projections to the inferior colliculus. Neuroscience 163:372-387.

Sánchez-González MA, Warr WB, López DE (2003) Anatomy of olivocochlear neurons in the hamster studied with FluoroGold. Hear Res 185:65-76.

Sanes DH (1990) An in vitro analysis of sound localization mechanisms in the gerbil lateral superior olive. J Neurosci 10:3494-3506.

Sanes DH, Rubel EW (1988) The ontogeny of inhibition and excitation in the gerbil lateral superior olive. J Neurosci 8:682-700.

Sanes DH, Siverls V (1991) Development and specificity of inhibitory terminal arborizations in the central nervous system. J Neurobiol 22:837-854.

Sanes DH, Wooten GF (1987) Development of glycine receptor distribution in the lateral superior olive of the gerbil. J Neurosci 7:3803-3811.

Sanes DH, Geary WA, Wooten GF, Rubel EW (1987) Quantitative distribution of the glycine receptor in the auditory brain stem of the gerbil. J Neurosci 7:3793-3802.

Sanes DH, Merickel M, Rubel EW (1989) Evidence for an alteration of the tonotopic map in the gerbil cochlea during development. J Comp Neurol 279:436-444.

Sanes DH, Goldstein NA, Ostad M, Hillman DE (1990) Dendritic morphology of central auditory neurons correlates with their tonotopic position. J Comp Neurol 294:443-454.

Sanes DH, Song J, Tyson J (1992) Refinement of dendritic arbors along the tonotopic axis of the gerbil lateral superior olive. Brain Res Dev Brain Res 67:47-55.

Sato K, Nakagawa H, Kuriyama H, Altschuler RA (1999) Differential distribution of N-methylD-aspartate receptor-2 subunit messenger RNA in the rat superior olivary complex. Neuroscience 89:839-853.

Sätzler K, Sohl LF, Bollmann JH, Borst JG, Frotscher M, Sakmann B, Lubke JH (2002) Threedimensional reconstruction of a calyx of Held and its postsynaptic principal neuron in the medial nucleus of the trapezoid body. J Neurosci 22:10567-10579.

Scheibel ME, Scheibel AB (1974) Neuropil organization in the superior olive of the cat. Exp Neurol 43:339-348.

Schmidt E, Wolski TP, Jr., Kulesza RJ, Jr. (2010) Distribution of perineuronal nets in the human superior olivary complex. Hear Res 265:15-24.

Schneggenburger R, Forsythe ID (2006) The calyx of Held. Cell Tissue Res 326:311-337.

Schnupp J, Nelken I, King A (2011) Neural basis of sound localization. En "Auditory Neuroscience: Making Sense of Sound". MIT Press, Londres, pp 177-221.

Schofield BR (1995) Projections from the cochlear nucleus to the superior paraolivary nucleus in guinea pigs. J Comp Neurol 360:135-149. 
Schofield BR (2002) Ascending and descending projections from the superior olivary complex in guinea pigs: different cells project to the cochlear nucleus and the inferior colliculus. J Comp Neurol 453:217-225.

Schofield BR, Cant NB (1991) Organization of the superior olivary complex in the guinea pig. I: Cytoarchitecture, cytochrome oxidase histochemistry, and dendritic morphology. J Comp Neurol 314:645-670.

Schofield BR, Cant NB (1999) Descending auditory pathways: projections from the inferior colliculus contact superior olivary cells that project bilaterally to the cochlear nuclei. J Comp Neurol 409:210-223.

Schroeder MR (1977) New viewpoints in binaural interactions. En "Psychophysics and Physiology of Hearing”, de Evans EF, Wilson JP (eds.). Academic Press, Nueva York, pp 455-467.

Schwartz IR (1977) Dendritic arrangements in the cat medial superior olive. Neuroscience 2:81-101.

Schwartz IR (1984) Axon organization in the cat medial superior olivary nucleus. En "Contributions to Sensory Physiology”, de Neff WD ed. Academic Press, Nueva York, pp 99-129.

Schwartz IR, Eager PR (1999) Glutamate receptor subunits in neuronal populations of the gerbil lateral superior olive. Hear Res 137:77-90.

Scott LL, Mathews PJ, Golding NL (2005) Posthearing developmental refinement of temporal processing in principal neurons of the medial superior olive. J Neurosci 25:7887-7895.

Seidl AH, Rubel EW, Harris DM (2010) Mechanisms for adjusting interaural time differences to achieve binaural coincidence detection. J Neurosci 30:70-80.

Sento S, Ryugo DK (1989) Endbulbs of held and spherical bushy cells in cats: morphological correlates with physiological properties. J Comp Neurol 280:553-562.

Shamma SA, Shen NM, Gopalaswamy P (1989) Stereausis: binaural processing without neural delays. J Acoust Soc Am 86:989-1006.

Sheeline CW (1983) An investigation of the effects of direct and reverberant signal interaction on auditory distance perception. Tesis doctoral, Stanford University, California.

Shinn-Cunningham BG, Santarelli S, Kopco N (2000) Tori of confusion: Binaural localization cues for sources within reach of a listener. J Acoust Soc Am 107:1627-1636.

Shneiderman A, Henkel CK (1985) Evidence of collateral axonal projections to the superior olivary complex. Hear Res 19:199-205.

Shneiderman A, Henkel CK (1987) Banding of lateral superior olivary nucleus afferents in the inferior colliculus: a possible substrate for sensory integration. J Comp Neurol 266:519-534.

Siveke I, Leibold C, Schiller E, Grothe B (2012) Adaptation of binaural processing in the adult brainstem induced by ambient noise. J Neurosci 32:462-473.

Skottun BC (1998) Sound localization and neurons. Nature 393:531. 
Smith AJ, Owens S, Forsythe ID (2000) Characterisation of inhibitory and excitatory postsynaptic currents of the rat medial superior olive. J Physiol 529:681-698.

Smith PH (1995) Structural and functional differences distinguish principal from nonprincipal cells in the guinea pig MSO slice. J Neurophysiol 73:1653-1667.

Smith PH, Rhode WS (1987) Characterization of HRP-labeled globular bushy cells in the cat anteroventral cochlear nucleus. J Comp Neurol 266:360-375.

Smith PH, Rhode WS (1989) Structural and functional properties distinguish two types of multipolar cells in the ventral cochlear nucleus. J Comp Neurol 282:595-616.

Smith PH, Joris PX, Carney LH, Yin TC (1991) Projections of physiologically characterized globular bushy cell axons from the cochlear nucleus of the cat. J Comp Neurol 304:387-407.

Smith PH, Joris PX, Yin TC (1993) Projections of physiologically characterized spherical bushy cell axons from the cochlear nucleus of the cat: evidence for delay lines to the medial superior olive. J Comp Neurol 331:245-260.

Smith PH, Joris PX, Yin TC (1998) Anatomy and physiology of principal cells of the medial nucleus of the trapezoid body (MNTB) of the cat. J Neurophysiol 79:3127-3142.

Sommer I, Lingenhohl K, Friauf E (1993) Principal cells of the rat medial nucleus of the trapezoid body: an intracellular in vivo study of their physiology and morphology. Exp Brain Res 95:223-239.

Sorensen SA, Rubel EW (2006) The level and integrity of synaptic input regulates dendrite structure. J Neurosci 26:1539-1550.

Spangler KM, Warr WB, Henkel CK (1985) The projections of principal cells of the medial nucleus of the trapezoid body in the cat. J Comp Neurol 238:249-262.

Spangler KM, Cant NB, Henkel CK, Farley GR, Warr WB (1987) Descending projections from the superior olivary complex to the cochlear nucleus of the cat. J Comp Neurol 259:452-465.

Spencer RF, Shaia WT, Gleason AT, Sismanis A, Shapiro SM (2002) Changes in calcium-binding protein expression in the auditory brainstem nuclei of the jaundiced Gunn rat. Hear Res 171:129-141.

Spencer MJ, Grayden DB, Bruce IC, Meffin H, Burkitt AN (2012) An investigation of dendritic delay in octopus cells of the mammalian cochlear nucleus. Front Comput Neurosci 6:83. DOI: $10.3389 /$ fncom.2012.00083.

Spirou GA, Berrebi AS (1997) Glycine immunoreactivity in the lateral nucleus of the trapezoid body of the cat. J Comp Neurol 383:473-488.

Spirou GA, Brownell WE, Zidanic M (1990) Recordings from cat trapezoid body and HRP labeling of globular bushy cell axons. J Neurophysiol 63:1169-1190.

Spirou GA, Rager J, Manis PB (2005) Convergence of auditory-nerve fiber projections onto globular bushy cells. Neuroscience 136:843-863. 
Stange A, Myoga MH, Lingner A, Ford MC, Alexandrova O, Felmy F, Pecka M, Siveke I, Grothe B (2013) Adaptation in sound localization: from GABA receptor-mediated synaptic modulation to perception. Nat Neurosci 16:1840-1847.

Sterenborg JC, Pilati N, Sheridan CJ, Uchitel OD, Forsythe ID, Barnes-Davies M (2010) Lateral olivocochlear (LOC) neurons of the mouse LSO receive excitatory and inhibitory synaptic inputs with slower kinetics than LSO principal neurons. Hear Res 270:119-126.

Stevens SS, Newman EB (1934) The localization of pure tones. Proc Natl Acad Sci USA 20:593-596.

Steward O (1981) Horseradish peroxidase and fluorescent substances and their combination with other techniques. En "Neuroanatomical Tract-Tracing Methods", de Heimer L, Robards MJ (eds.). Plenum Press, Nueva York, pp 279-310.

Stotler WA (1953) An experimental study of the cells and connections of the superior olivary complex of the cat. J Comp Neurol 98:401-431.

Strominger NL, Strominger AI (1971) Ascending brain stem projections of the anteroventral cochlear nucleus in the rhesus monkey. J Comp Neurol 143:217-242.

Strumbos JG, Polley DB, Kaczmarek LK (2010) Specific and rapid effects of acoustic stimulation on the tonotopic distribution of Kv3.1b potassium channels in the adult rat. Neuroscience 167:567-572.

Strumillo P (2011) Advances in Sound Localization. InTech Europe, Rijeka, Croacia.

Thompson AM (1998) Heterogeneous projections of the cat posteroventral cochlear nucleus. J Comp Neurol 390:439-453.

Thompson AM, Schofield BR (2000) Afferent projections of the superior olivary complex. Microsc Res Tech 51:330-354.

Thompson AM, Thompson GC (1987) Efferent projections from posteroventral cochlear nucleus to lateral superior olive in guinea pig. Brain Res 421:382-386.

Thompson AM, Thompson GC (1991) Projections from the posteroventral cochlear nucleus to the superior olivary complex in guinea pig: light and EM observations with the PHA-L method. J Comp Neurol 311:495-508.

Thompson AM, Thompson GC (1993) Relationship of descending inferior colliculus projections to olivocochlear neurons. J Comp Neurol 335:402-412. Tirko NN, Ryugo DK (2012) Synaptic plasticity in the medial superior olive of hearing, deaf, and cochlear-implanted cats. J Comp Neurol 520:2202-2217.

Tolbert LP, Morest DK, Yurgelun-Todd DA (1982) The neuronal architecture of the anteroventral cochlear nucleus of the cat in the region of the cochlear nerve root: horseradish peroxidase labelling of identified cell types. Neuroscience 7:3031-3052.

Tollin DJ (2003) The lateral superior olive: a functional role in sound source localization. Neuroscientist 9:127-143. 
Tollin DJ, Yin TC (2002) The coding of spatial location by single units in the lateral superior olive of the cat. I. Spatial receptive fields in azimuth. J Neurosci 22:1454-1467.

Tollin DJ, Yin TC (2005) Interaural phase and level difference sensitivity in low-frequency neurons in the lateral superior olive. J Neurosci 25:10648-10657.

Tollin DJ, Ruhland JL, Yin TC (2013) The role of spectral composition of sounds on the localization of sound sources by cats. J Neurophysiol 109:1658-1668.

Tolnai S, Hernandez O, Englitz B, Rübsamen R, Malmierca MS (2008) The medial nucleus of the trapezoid body in rat: spectral and temporal properties vary with anatomical location of the units. Eur J Neurosci 27:2587-2598.

Toyoshima M, Sakurai K, Shimazaki K, Takeda Y, Nakamoto M, Serizawa S, Shimoda Y, Watanabe K (2009) Preferential localization of neural cell recognition molecule NB-2 in developing glutamatergic neurons in the rat auditory brainstem. J Comp Neurol 513:349-362.

Trune DR (1982a) Influence of neonatal cochlear removal on the development of mouse cochlear nucleus: I. Number, size, and density of its neurons. J Comp Neurol 209:409-424.

Trune DR (1982b) Influence of neonatal cochlear removal on the development of mouse cochlear nucleus: II. Dendritic morphometry of its neurons. J Comp Neurol 209:425-434.

Trussell LO (2002) Modulation of transmitter release at giant synapses of the auditory system. Curr Opin Neurobiol 12:400-404.

Tsuchitani C, Boudreau JC (1966) Single unit analysis of cat superior olive S segment with tonal stimuli. J Neurophysiol 29:684-697.

Van Aelst L, Cline HT (2004) Rho GTPases and activity-dependent dendrite development. Curr Opin Neurobiol 14:297-304.

Van Der Heijden M, Trahiotis C (1999) Masking with interaurally delayed stimuli: the use of “internal" delays in binaural detection. J Acoust Soc Am 105:388-399.

Van Noort J (1969) The structure and connections of the inferior colliculus. An investigation of the lower auditory system, Tesis doctoral. Van Gorcum, Leiden, Holanda.

Vater M (1995) Ultrastructural and immunocytochemical observations on the superior olivary complex of the mustached bat. J Comp Neurol 358:155-180.

Vater M, Feng AS (1990) Functional organization of ascending and descending connections of the cochlear nucleus of horseshoe bats. J Comp Neurol 292:373-395.

Veenman CL, Reiner A, Honig MG (1992) Biotinylated dextran amine as an anterograde tracer for single- and double-labeling studies. J Neurosci Meth 41:239-254.

Vercelli A, Repici M, Garbossa D, Grimaldi A (2000) Recent techniques for tracing pathways in the central nervous system of developing and adult mammals. Brain Res Bull 51:11-28.

Vetter DE, Mugnaini E (1992) Distribution and dendritic features of three groups of rat olivocochlear neurons. A study with two retrograde cholera toxin tracers. Anat Embryol (Berl) 185:1-16. 
Vetter DE, Adams JC, Mugnaini E (1991) Chemically distinct rat olivocochlear neurons. Synapse 7:21-43.

Vetter DE, Saldaña E, Mugnaini E (1993) Input from the inferior colliculus to medial olivocochlear neurons in the rat: a double label study with PHA-L and cholera toxin. Hear Res 70:173-186.

Viñuela A, Aparicio MA, Berrebi AS, Saldaña E (2011) Connections of the superior paraolivary nucleus of the rat: II. Reciprocal connections with the tectal longitudinal column. Front Neuroanat 5:1. DOI: 10.3389/fnana.2011.00001.

Von Békésy G (1960) Experiments in Hearing. Acoustical Society of America, Woodbury, Nueva York.

Von Hehn CA, Bhattacharjee A, Kaczmarek LK (2004) Loss of Kv3.1 tonotopicity and alterations in cAMP response element-binding protein signaling in central auditory neurons of hearing impaired mice. J Neurosci 24:1936-1940.

Wang X, Robertson D (1997) Effects of bioamines and peptides on neurones in the ventral nucleus of trapezoid body and rostral periolivary regions of the rat superior olivary complex: an in vitro investigation. Hear Res 106:20-28.

Warr WB (1966) Fiber degeneration following lesions in the anterior ventral cochlear nucleus of the cat. Exp Neurol 14:453-474.

Warr WB (1972) Fiber degeneration following lesions in the multipolar and globular cell areas in the ventral cochlear nucleus of the cat. Brain Res 40:247-270.

Warr WB (1982) Parallel ascending pathways from the cochlear nucleus: Neuroanatomical evidence of functional specialization. En Contrib Sens Physiol, de Neff WD (ed.). Academic Press, Nueva York, pp 1-38.

Warr WB, Beck JE (1996) Multiple projections from the ventral nucleus of the trapezoid body in the rat. Hear Res 93:83-101.

Warr WB, Boche JB, Neely ST (1997) Efferent innervation of the inner hair cell region: origins and terminations of two lateral olivocochlear systems. Hear Res 108:89-111.

Warren RM (2008) “Auditory Perception: An Analysis and Synthesis", 3a edición. Cambridge University Press, Cambridge, Reino Unido.

Webster DB, Trune DR (1982) Cochlear nuclear complex of mice. Am J Anat 163:103-130.

Webster WR, Batini C, Buisseret-Delmas C, Compoint C, Guegan M, Thomasset M (1990) Colocalization of calbindin and GABA in medial nucleus of the trapezoid body of the rat. Neurosci Lett 111:252-257.

Wenthold RJ, Huie D, Altschuler RA, Reeks KA (1987) Glycine immunoreactivity localized in the cochlear nucleus and superior olivary complex. Neuroscience 22:897-912.

Werthat F, Alexandrova O, Grothe B, Koch U (2008) Experience-dependent refinement of the inhibitory axons projecting to the medial superior olive. Dev Neurobiol 68:1454-1462. 
Wesolek CM, Koay G, Heffner RS, Heffner HE (2010) Laboratory rats (Rattus norvegicus) do not use binaural phase differences to localize sound. Hear Res 265:54-62.

White JS, Warr WB (1983) The dual origins of the olivocochlear bundle in the albino rat. J Comp Neurol 219:203-214.

Wightman FL, Kistler DJ (1993) Sound localization. En "Human Psychophysics", de Yost WA, Popper AN, Fay RR (eds.). Springer Handbook of Auditory Research, Vol. 3. Springer, Nueva York, pp 155-192.

Winer JA, Larue DT, Pollak GD (1995) GABA and glycine in the central auditory system of the mustache bat: structural substrates for inhibitory neuronal organization. J Comp Neurol 355:317-353.

Wouterlood FG, Jorritsma-Byham B (1993) The anterograde neuroanatomical tracer biotinylated dextran-amine: comparison with the tracer Phaseolus vulgaris-leucoagglutinin in preparations for electron microscopy. J Neurosci Methods 48:75-87.

Woolf NK, Ryan AF (1985) Ventral cochlear nucleus neural discharge characteristics in the absence of outer hair cells. Brain Res 342:205-218.

Wu SH, Kelly JB (1992) Synaptic pharmacology of the superior olivary complex studied in mouse brain slice. J Neurosci 12:3084-3097.

Wu SH, Fu XW (1998) Glutamate receptors underlying excitatory synaptic transmission in the rat's lateral superior olive studied in vitro. Hear Res 122:47-59.

Yajima Y, Hayashi Y (1989) Response properties and tonotopical organization in the dorsal cochlear nucleus in rats. Exp Brain Res 75:381-389.

Yao W, Godfrey DA (1998) Immunohistochemical evaluation of cholinergic neurons in the rat superior olivary complex. Microsc Res Tech 41:270-283.

Yin TC (2002) Neural mechanisms of encoding binaural localization cues in the auditory brainstem. En "Integrative Functions in the Mammalian Auditory Pathway", de Oertel D, Fay RR, Popper AN (eds.). Springer Handbook of Auditory Research, Vol. 15. Springer, Nueva York, pp 99-159.

Yin TC, Chan JC (1990) Interaural time sensitivity in medial superior olive of cat. J Neurophysiol 64:465-488.

Yost WA (2008) Perceiving sound sources. En "Auditory Perception of Sound Sources", de Yost WA, Popper AN, Fay RR (eds.). Springer Handbook of Auditory Research, Vol. 29. Springer, New York, pp 1-12.

Yost WA, Wightman FL, Green DM (1971) Lateralization of filtered clicks. J Acoust Soc Am 50:1526-1531.

Yost WA, Popper AN, Fay RR (2008) "Auditory Perception of Sound Sources”. Springer Handbook of Auditory Research, Vol. 29. Springer, Nueva York. 
Young ED, Sachs MB (2008) Auditory nerve inputs to cochlear nucleus neurons studied with crosscorrelation. Neuroscience 154:127-138.

Zafra F, Giménez C (2008) Glycine transporters and synaptic function. IUBMB Life 60:810-817.

Zafra F, Aragón C, Olivares L, Danbolt NC, Giménez C, Storm-Mathisen J (1995) Glycine transporters are differentially expressed among CNS cells. J Neurosci 15:3952-3969.

Zahorik P, Brungart DS, Bronkhorst AW (2005) Auditory distance perception in humans: A summary of past and present research. Acustica 91:409-420.

Zeilhofer HU, Studler B, Arabadzisz D, Schweizer C, Ahmadi S, Layh B, Bosl MR, Fritschy JM (2005) Glycinergic neurons expressing enhanced green fluorescent protein in bacterial artificial chromosome transgenic mice. J Comp Neurol 482:123-141.

Zook JM, Casseday JH (1985) Projections from the cochlear nuclei in the mustache bat, Pteronotus parnellii. J Comp Neurol 237:307-324.

Zook JM, DiCaprio RA (1988) Intracellular labeling of afferents to the lateral superior olive in the bat, Eptesicus fuscus. Hear Res 34:141-147.

Zook JM, Leake PA (1989) Connections and frequency representation in the auditory brainstem of the mustache bat, Pteronotus parnellii. J Comp Neurol 290:243-261. 


\section{MATERIAL SUPLEMENTARIO}


Nota: Para visualizar los vídeos que contiene esta apartado, es necesario utilizar la aplicación informática Adobe Acrobat Reader.

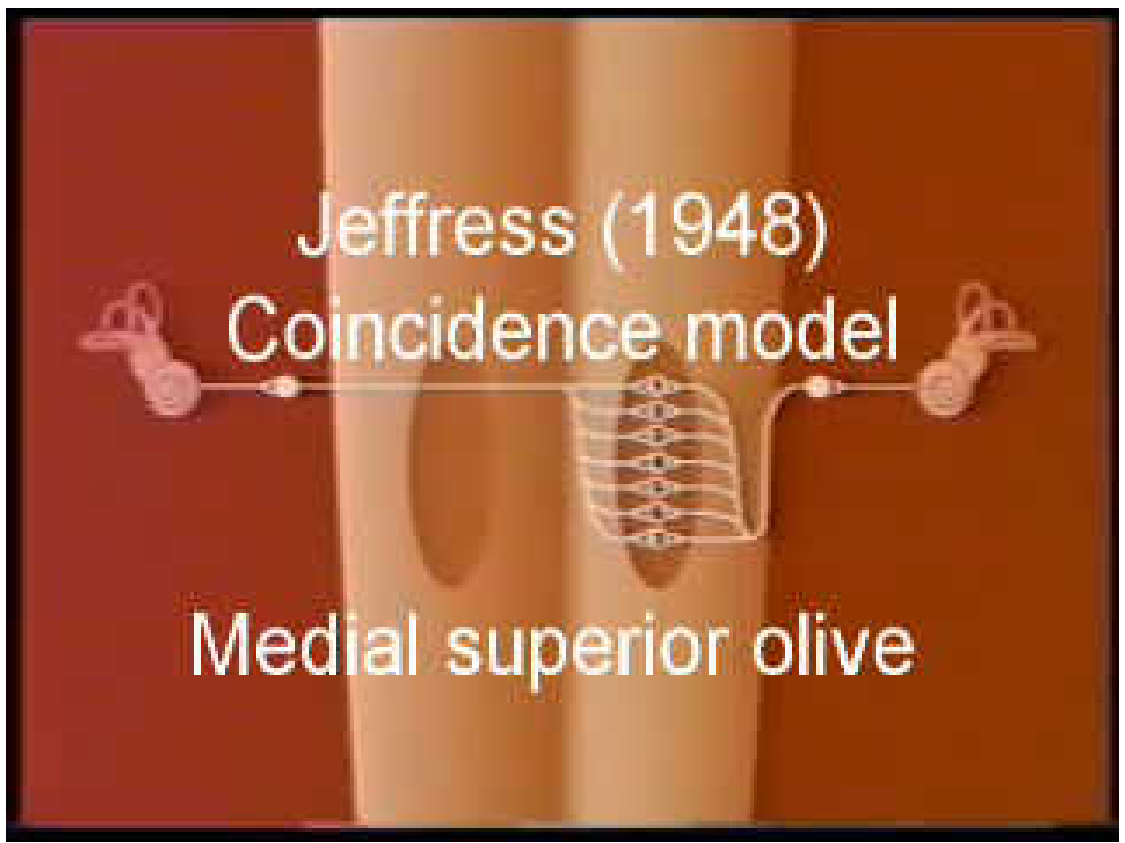

Vídeo suplementario 1. Modelo de Jeffress. Este vídeo es de la página web del laboratorio de Tom Yin de la Universidad de Wisconsin. Duración: 55 s.

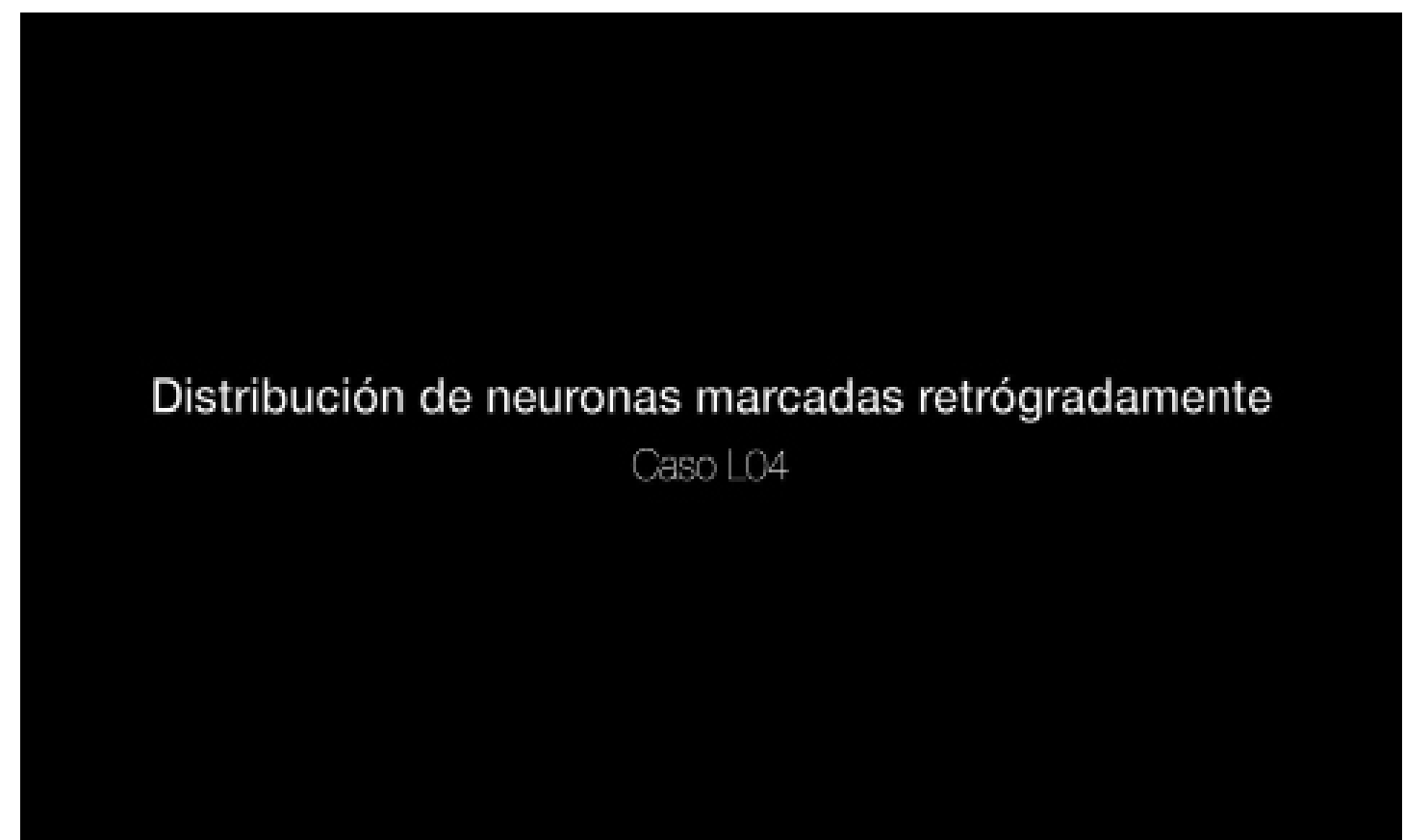

Vídeo suplementario 2. Distribución de las neuronas marcadas retrógradamente en el tronco del encéfalo. Reconstrucción tridimensional de la distribución de las neuronas marcadas retrógradamente en el caso L04, cuya zona de inyección de BDA en la OSL del lado derecho se muestra en las figuras $1 \mathrm{C}$ y $2 \mathrm{C}$. Cada punto corresponde a una neurona marcada. Se ha utilizado un mismo color para todas las neuronas marcadas en un núcleo determinado, sin distinguir entre tipos neuronales: NCoPV, en verde; NCoAV, en morado; NMCT, en rojo; y NVCT, en azul. Duración: 23 s. 


\section{Neuronas marcadas retrógradamente en el NCoV}

\section{Casos L01. L08 y L14}

Vídeo suplementario 3. Distribución de las neuronas marcadas retrógradamente en el NCoV. Reconstrucción tridimensional de la distribución de las neuronas marcadas retrógradamente en el en el NCoV de los casos L01, L08 y L14, cuya zona de inyección de BDA en la OSL del lado derecho se muestran en las figuras 1. Cada punto corresponde a una neurona marcada. Se ha utilizado el color rojo para las neuronas multipolares, el azul para las esféricas y en amarillo aquellas neuronas que no pudimos identificar. Duración: $43 \mathrm{~s}$. 